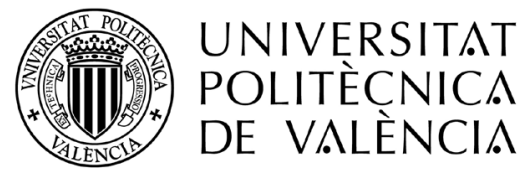

Doctoral Thesis: Tubular All

Vanadium and Vanadium/Air

Redox Flow Cells Simon Philipp
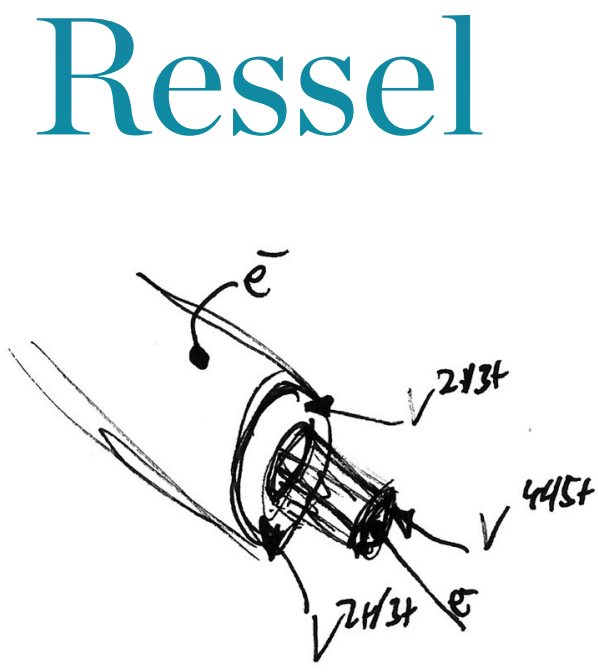

May 3, 2019

Supervisors: Dr. Antonio Chica Lara, Prof. Dr. Thorsten Struckmann 


\section{Tubular All Vanadium and Vanadium/Air Redox Flow Cells \\ DOCTORAL THESIS}

Author:

Simon Philipp ReSSEL

Evaluators:

\section{Defense Tribunal \\ President:}

Secretary:

Vocal:
Supervisors:

Dr. Antonio CHICA LARA, Prof. Dr. Thorsten STRUCKMANN

Dr. Carlos Alberto Martínez Huitle

Federal University of Rio Grande do

Norte, Brazil

Prof. Dr.-Ing. Achim Schmidt

University of Applied Sciences Hamburg, Germany

Dr. Ricardo Santamaría Ramirez Instituto Nacional del Carbón,

INCAR-CSIC, Spain

Prof. Dr. José Manuel Serra Alfaro

Instituto de Tecnología Química,

UPV-CSIC, Spain

Dr. Francisco Alcaide Moterrubio

Fundación CIDETEC, Spain

Prof. Dr.-Ing. Achim Schmidt

University of Applied Sciences Hamburg,

Germany 


\title{
Abstract
}

\section{Tubular All Vanadium and Vanadium/Air Redox Flow Cells}

\author{
by Simon Philipp RESSEL
}

An increase of the power generation from volatile renewable sources (solar, wind) requires a high flexibility in power grids. All Vanadium Redox Flow Batteries (VRFBs) have demonstrated their ability to provide flexibility by storing electrical energy on a $\mathrm{kWh}$ to $\mathrm{MWh}$ scale. High power and energy specific costs do, however prevent a wide market penetration.

In this dissertation a tubular cell design with a membrane diameter of $5.0 \mathrm{~mm}$ is developed and evaluated. Tubular VRFB cells shall lead to an enhanced power density $\left(\mathrm{kWm}^{-3}\right)$. Replacement of an electrode with a bifunctional air electrode (Vanadium/Air Redox Flow Battery) shall allow to increase the specific energy (Whkg ${ }^{-1}$ ) and reduce energy specific costs $(€ / \mathrm{kWh})$.

The developed design facilitates a fabrication of the current collectors and membrane by an extrusion process and marks an important step towards the cost-efficient extrusion of entire half cells and cells in the future.

To evaluate the cell performance and investigate loss mechanisms, polarization curve, electrochemical impedance spectroscopy and charge/discharge cycling measurements are conducted. Tubular VRFB cells with flow-by electrodes reveal a maximum discharge current and power density of $89.7 \mathrm{~mA} \mathrm{~cm}^{-2}$ and $179.2 \mathrm{~kW} / \mathrm{m}^{3}$, respectively. Low residual overpotentials at the cell's electrodes are encouraging, but the area specific cell resistance of $3.2 \Omega \mathrm{cm}^{2}$ imposes limitations on the current density.

Coulomb efficiencies of $\approx 95 \%$ are comparable to values of planar reference cells, but high ohmic losses reduce the system energy efficiency to $\approx 56 \%$.

Tubular VARFB cells with a mono-layered gas diffusion electrode and a $\mathrm{Pt} / \mathrm{IrO}$ catalyst allow for a maximum current density of $32 \mathrm{~mA} \mathrm{~cm}^{-2}\left(E_{\text {cell }}=2.1 \mathrm{~V} / 0.56 \mathrm{~V}\right.$ $C h / D c h)$. High activation overpotentials and a reduced open-circuit voltage (due to mixed potentials) lead to a comparably low power density of $15.4 \mathrm{~mW} / \mathrm{cm}^{2}$. Crossover of vanadium ions through the membrane are considered as a major drawback for tubular VARFB cells and the actual energy density of $23.2 \mathrm{~W} \mathrm{~h}^{-1}$ falls below the nominal value of $63.9 \mathrm{Wh}^{-1}$. 



\title{
Resumen
}

\author{
Celdas Tubulares de Flujo Redox de Vanadio y Vanadio/Aire \\ por Simon Philipp RESSEL
}

Un aumento de la generación de energía a partir de fuentes renovables (solar, eólica) requiere una alta flexibilidad de las redes eléctricas. En este sentido, las baterías de flujo redox de vanadio (BFRV) han demostrado una excelente capacidad para proporcionar dicha flexibilidad, mediante el almacenamiento eficiente de energía eléctrica en el rango de los $\mathrm{kWh}$ a los $\mathrm{MWh}$. Sin embargo, sus elevados costes son en la actualidad unos de los mayores inconvenientes que dificultan una amplia penetración en el mercado.

En la presente Tesis Doctoral se presenta el desarrollo y evaluación de una celda tubular especialmente diseñada con una membrana de $5.0 \mathrm{~mm}$. Las células tubulares así diseñadas deberían alcanzar una mayor densidad de potencia $\left(\mathrm{kWm}^{-3}\right)$. Del mismo modo, la sustitución de uno de los electrodos por un electrodo bifuncional de aire debería de incrementar la energía específica de dicha celda (Whkg ${ }^{-1}$ ) y reducir, por tanto, los costes energéticos asociados (€/ $\mathrm{kW} \mathrm{h})$.

El diseño de la celda desarrollado en la presente Tesis Doctoral facilita la fabricación de los colectores y membranas actuales con el empleo de procesos de extrusión y marca un paso importante hacia la fabricación rentable de semiceldas y celdas completas en el futuro.

Para evaluar el comportamiento de la nueva celda diseñada se han llevado a cabo estudios de polarización, de espectroscopia de impedancia, y medidas de ciclos de carga/descarga. Las celdas desarrolladas presentan una corriente de descarga máxima de $89.7 \mathrm{~mA} \mathrm{~cm}^{-2}$ y una densidad de potencia de $179.2 \mathrm{~kW} / \mathrm{m}^{3}$. Además, los bajos sobrepotenciales residuales obtenidos en los electrodos de la celda resultan prometedores. No obstante, la resistencia del área específica de celda de $3.2 \Omega \mathrm{cm}^{2}$ impone limitaciones significativas en la densidad de corriente.

Eficiencias Coulomb del $\approx 95 \%$ han sido obtenidas, comparables a los valores alcanzados en celdas planas de referencia. Sin embargo, las pérdidas óhmicas resultan elevadas, reduciendo la eficiencia energética del sistema al $\approx 56 \%$.

Las celdas tubulares fabricadas con un electrodo de difusión de gas de una sola capa con $\mathrm{Pt} / \mathrm{IrO}_{2}$ como catalizador permiten alcanzar densidades de corriente máximas 
de $32 \mathrm{~mA} \mathrm{~cm}^{-2}\left(E_{\text {cell }}=2.1 \mathrm{~V} / 0.56 \mathrm{~V} \mathrm{Ch} / \mathrm{Dch}\right)$. Los elevados sobrepotenciales de activación y el reducido voltaje en circuito abierto (debido a potenciales mixtos) conducen a una densidad de potencia comparativamente baja de $15.4 \mathrm{~mW} / \mathrm{cm}^{2}$. El paso de iones de vanadio a través de la membrana se considera uno de los grandes inconvenientes en este tipo de celdas tubulares, lo que lleva a que la densidad de energía real de $23.2 \mathrm{Whl}^{-1}$ caiga por debajo del valor nominal de $63.9 \mathrm{Whl}^{-1}$. 


\section{Resum}

\section{Cel·les Tubulars de Flux Redox de Vanadi i Vanadi/aire}

Simon Philipp RESSEL

Un augment de la generació d'energia a partir de fonts renovables (solar, eòlica) requereix una alta flexibilitat de les xarxes elèctriques. En aquest sentit, les bateries de flux redox de vanadi (VRFB) han demostrat una excel-lent capacitat per a proporcionar aquesta flexibilitat, mitjançant l'emmagatzematge eficient d'energia elèctrica en el rang dels $\mathrm{kWh}$ als $\mathrm{MWh}$.

En la present Tesi Doctoral es presenta el desenvolupament i avaluació d'una cel·la tubular especialment dissenyada amb una membrana de $5.0 \mathrm{~mm}$. Les cèl.lules tubulars així dissenyades haurien assolir una major densitat de potència $\left(\mathrm{kWm}^{-3}\right)$. De la mateixa manera, la substitució d'un dels elèctrodes per un elèctrode bifuncional d'aire hauria d'incrementar l'energia específica d'aquesta cel·la $\left(\mathrm{Whkg}^{-1}\right)$ i reduir, per tant, els costos energètics associats $(€ / \mathrm{kWh})$.

El disseny de la cel-la desenvolupat en la present tesi doctoral facilita la fabricació dels col-lectors i membranes actuals amb l'ocupació de processos d'extrusió i marca un pas important cap a la fabricació rendible de semiceldas i cel·les completes en el futur.

Per avaluar el comportament de la nova cel-la dissenyada s'han dut a terme estudis de polarització, d'espectroscòpia d'impedància, i mesures de cicles de càrrega/descàrrega. Les cel-les desenvolupades presenten un corrent de descàrrega màxima de $89.7 \mathrm{~mA} \mathrm{~cm}^{-2} \mathrm{i}$ una densitat de potència de $179.2 \mathrm{~kW} / \mathrm{m}^{3}$.

A més, els baixos sobrepotencials residuals obtinguts en els elèctrodes de la cel·la resulten prometedors. No obstant això, la resistència de l'àrea específica de cel·la de $3.2 \Omega \mathrm{cm}^{2}$ imposa limitacions significatives en la densitat de corrent.

Eficiències Coulomb del $\approx 95 \%$ han estat obtingudes, comparables als valors assolits en cel-les planes de referència. No obstant això, les pèrdues òhmiques resulten elevades, reduint l'eficiència energètica del sistema al $\approx 56 \%$.

Les cel-les tubulars fabricades amb un elèctrode de difusió de gas d'una sola capa amb $\mathrm{Pt} / \mathrm{IrO}_{2}$ com a catalitzador permeten assolir densitats de corrent màximes de 
viii

$32 \mathrm{~mA} \mathrm{~cm}^{-2}\left(E_{\text {cell }}=2.1 \mathrm{~V} / 0.56 \mathrm{~V} \mathrm{Ch} / \mathrm{Dch}\right)$. Els elevats sobrepotencials d'activació i el reduit voltatge en circuit obert (a causa de potencials mixtes) condueixen a una densitat de potència comparativament baixa de $15.4 \mathrm{~mW} / \mathrm{cm}^{2}$. El pas de ions de vanadi a través de la membrana es considera un dels grans inconvenients en aquest tipus de cel-les tubulars, el que porta al fet que la densitat d'energia real de $23.2 \mathrm{Wh}^{-1}$ caigui per sota del valor nominal de $63.9 \mathrm{Wh} \mathrm{h}^{-1}$. 


\title{
Zusammenfassung
}

\section{Tubuläre Vanadium- und Vanadium/Luft-Flussbatterie-Zellen}

\author{
von Simon Philipp RESSEL
}

\begin{abstract}
Die Zunahme der Stromerzeugung aus erneuerbaren Quellen (Sonne, Wind) erfordert eine gesteigerte Flexibilität der Stromnetze. Vanadium Flussbatterien (VFB) haben ihre Eignung zur Bereitstellung einer größeren Flexibilität durch die Speicherung von elektrischer Energie im Bereich von $\mathrm{kWh}$ bis MWh gezeigt. Hohe leistungsund energiespezifische Kosten verhindern bislang jedoch eine flächendeckende Nutzung.
\end{abstract}

Im Rahmen dieser Dissertation wird eine tubuläre Zellstrucktur mit einem Membrandurchmesser von $5.0 \mathrm{~mm}$ entwickelt und evaluiert. Tubuläre VFB-Zellen sollen eine Steigerung der Leistungsdichte $\left(\mathrm{kWm}^{-3}\right)$ ermöglichen. Das Ersetzen einer Elektrode durch eine bi-funktionale Luft-Elektrode (Vanadium/Luft Flussbatterie) soll zu einer erhöhten Energiedichte (Whkg ${ }^{-1}$ ) und geringeren energiespezifischen Kosten $(€ / \mathrm{kWh}$ ) führen.

Die entwickelte Zell-Strucktur ermöglicht eine Herstellung der Stromsammler und Membran mittels eines Extrusionsprozesses und stellt einen wichtigen Schritt hinsichtlich der zukünftigen Fertigung ganzer Zellen und Halbzellen durch einen kostengünstigen Extrusionsprozess dar.

Zur Bewertung der Leistungscharakteristika und Untersuchung von Verlustmechanismen werden Strom/Spannungs-Kennlinien, Impedanzspektren und Lade-/Entlade-Zyklen gemessen. Tubuläre VFB-Zellen mit flow-by Elektroden weisen eine maximale Entlade-Stromdichte von $89.7 \mathrm{~mA} \mathrm{~cm}^{-2}$ und eine maximale Leistungsdichte von $179.2 \mathrm{~kW} / \mathrm{m}^{3}$ auf. Die geringen Aktivierungs- und Konzentrations-Überspannungen an den Elektroden sind ermutigend, während der fläschenspezifische ohmsche Zellwiderstand von $3.2 \Omega \mathrm{cm}^{2}$ zu einer Begrenzung der Stromdichte führt. Der Coulomb Wirkungsgrad von $\approx 95 \%$ ist vergleichbar mit Werten planarer Zellen, aber die ohmschen Verluste verringern den energetischen Systemwirkungsgrad auf $\approx 56 \%$.

Tubuläre VLFB mit einer einlagigen Gas-Diffusions-Elektrode und einem $\mathrm{Pt} / \mathrm{IrO}_{2}-$ Katalysator ermöglichen eine maximale Stromdichte von $32 \mathrm{~mA} \mathrm{~cm}^{-2}\left(E_{\text {cell }}=2.1 \mathrm{~V} /\right.$ 
$0.56 \mathrm{~V}$ Ch/Dch). Hohe Aktivierungs-Überspannungen und eine verminderte Leerlaufspannung (verursacht durch Mischpotentiale) führen zu einer vergleichsweise geringen Leistungsdichte von $15.4 \mathrm{~mW} / \mathrm{cm}^{2}$. Der Durchtritt von Vanadium-Ionen durch die Membran stellt die größte Herausforderung für die Entwicklung von tubulären VLFB-Zellen dar und die tatsächliche Energiedichte von $23.2 \mathrm{Whl}^{-1}$ liegt unterhalb des nominalen Werts $\left(63.9 \mathrm{Wh} \mathrm{h}^{-1}\right)$. 


\section{Acknowledgements}

This work is not only the result of my efforts, but aggregates the thoughts, input, support and contribution of many. It is my pleasure to express my thanks to some of them.

First, I want to acknowledge the support of my supervisors Dr. Antonio Chica Lara and Prof. Dr. Thorsten Struckmann, who always dedicated their time to my research related questions and concerns. Their expertise in research and science was always of great help for me and the guidance they provided allowed me to continue and finalize this thesis. I would also like to thank my tutor Prof. Dr. Javier Orozco-Messana and highlight the pioneering work of Prof. Dr. Wolfgang Winkler on tubular systems at the HAW Hamburg and the role he played to ignite my enthusiasm for tubular Redox Flow Batteries. Dr.-Ing. Thomas Flower appeared when support of my research activities at the University was needed. The continuity of electrochemical research activities was crucial for the project and my thesis. Thank you for that!

Financial support of my research activities was provided by the $B M B F$ through the common research project tubulAir \pm . I would like to express my thanks to the research consortium members for their contributions: Dipl.-Biol. Simon Fischer (Uniwell Rohrsysteme), Dr.-Ing. Bernd Bauer and Dr.-Ing. Michael Jeske (Fumatech BWT), Dr. Claudia Weidlich and Dr. Klaus-Michael Mangold (DECHEMA), Prof. Dr. Julien Bachmann (FAU Erlangen), Prof. Dr. Peter Burger (Hamburg University), Prof. Dr.-Ing. Matthias Wessling (RWTH Aachen).

Furthermore, I am grateful for the support of Marcel Quittkat, Dr. Bernd Hildenbrand and the Leonardis-Stiftung.

During the past years I was privileged to get known to many individuals, who worked together with me in our working group at the HAW and the ITQ. Their efforts, time, thoughts and willingness to go through uncountable discussions with me always was and still is invaluable for me. I, therefore, want to express my special thanks to Cristina Cerdá Moreno of ITQ and my colleagues at the HAW: Alexander von Stryk, Alireza Riazi, Valentin Roscher, Margaryta Paramonova, Leon Gosh, Sebastian Gerhard, Masud Bascharyar, Armin Laube, Maike Enders, Morten Peix, Simon Mayer, Lucas Holtz, Niklas Janshen, Max Nix, Florian Bill, Peter Kuhn, Fabian Brandes.

I appreciate the willingness of Tobias Theilacker and Bastian Jakob to spend their leisure time for the proofreading of my thesis drafts and am grateful for the guidance, ideas and templates Nina Janßen provided for me when fancy layouts and appearances were of great importance. 
Within the period of my PhD thesis and throughout my entire life I was lucky to be surrounded by close friends and family members, who supported me when support was needed and made me what I am today. It is far beyond the scope of this section to include all of you, but I want to express my heartfelt gratefulness to my parents, my partner Lena and my brother and sister.

I would also like to mention some of those, who cheered me up when failures in the lab didn't seem to come to an end and those of you, who gave their best to get me away from work: Christof Schneider, Jan Röder, Tobias Theilacker, Mario Farber, Ali "Mokhtar" Ghafoori, Kevin Kpwe Cham, Anke Fischer, Thorsten Ernst, ...

- Erik Akira Esser - 


\section{Contents}

Abstract

Acknowledgements $\quad$ xi

1 Introduction 1

1.1 State of the Art . . . . . . . . . . . . . . . . 2

1.1.1 Redox Flow Batteries . . . . . . . . . . . . . . . . . 2

1.1.2 All Vanadium Redox Flow Batteries (VRFB) . . . . . . . . . . 6

1.1.3 Vanadium/Air Redox Flow Batteries (VARFB) . . . . . . . . . . 9

1.1 .4 Cell Designs . . . . . . . . . . . . . . . . . . . 13

1.2 Aim of the Thesis . . . . . . . . . . . . . . . . . 18

1.3 Thesis Outline . . . . . . . . . . . . . . . . . . . . 19

2 Fundamentals 23

2.1 Figures of Merit . . . . . . . . . . . . . . . . . 23

2.1.1 Current and Charge .................. 24

2.1 .2 Cell Potential . . . . . . . . . . . . . . . . 28

2.1 .3 Power and Energy . . . . . . . . . . . . . . . . 36

2.1 .4 State of Charge . . . . . . . . . . . . . . . 37

2.1 .5 Efficiencies . . . . . . . . . . . . . . . 39

2.2 Methods ......................... . . 41

2.2.1 Current Interrupt . . . . . . . . . . . . . . . . . . 42

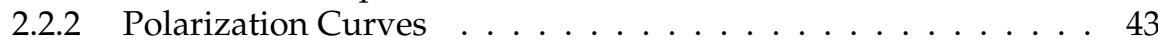

2.2.3 Half Cell Potential Measurement . . . . . . . . . . . . . . . . . . 46

2.2.4 Electrochemical Impedance Spectroscopy . . . . . . . . . . . . . . . . 51

2.3 Design Principles for Tubular Cells . . . . . . . . . . . . . . . . . 55

2.3.1 Design Requirements . . . . . . . . . . . . . . . 55

2.3.2 Electrical Cell Resistance . . . . . . . . . . . . . . . . . 62

2.3.3 Pressure Drop . . . . . . . . . . . . . . . . . 66

2.3.4 Tubular Cell Concepts . . . . . . . . . . . . . . . 70 
3 Tubular All Vanadium Redox Flow Cells $\quad 75$

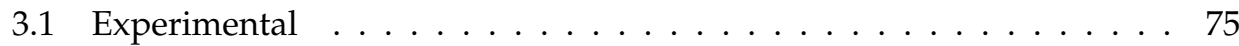

3.1 .1 Test Cells . . . . . . . . . . . . . . . . 76

3.1.2 Fabrication and Material Preparation . . . . . . . . . . . . . 82

3.1.3 All Vanadium Redox Flow Battery Test Rig . . . . . . . . . . . . . . 86

3.1 .4 Test Routines . . . . . . . . . . . . . . . . . . . . . . . . . . . . . . 99

3.2 Results and Discussion . . . . . . . . . . . . . . . . 93

3.2.1 Liquid Permeability and Pressure Drop . . . . . . . . . . . . . . 93

3.2.2 Planar Reference Cell Characterization . . . . . . . . . . . . . 99

3.2.3 Tubular VRFB Cell Performance . . . . . . . . . . . . . . . . . . . 104

3.2.4 Half Cell Overpotentials . . . . . . . . . . . . . . . . . . 120

3.2.5 Charge/Discharge Cycling . . . . . . . . . . . . 122

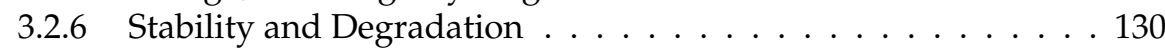

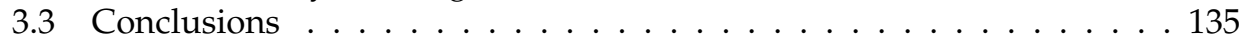

3.3.1 Tubular flow-through VRFB cells $(F T-V R F B) \ldots \ldots 136$

3.3.2 Tubular flow-by VRFB cells $(F B-V R F B) \ldots \ldots . \ldots 137$

3.3.3 Degradation . . . . . . . . . . . . . . . . 140

3.3.4 Measurement Setup and Methods . . . . . . . . . . . . . . . 140

4 Tubular Vanadium/Air Redox Flow Cells 143

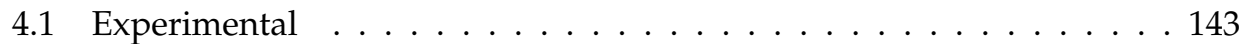

4.1.1 Tubular Vanadium/Air Redox Flow Cell . . . . . . . . . . . . . 144

4.1.2 MEA Fabrication and Material Preparation . . . . . . . . . . . . . 146

4.1.3 Vanadium/Air Redox Flow Battery Test Rig . . . . . . . . . . . . 150

4.1 .4 Test Routines . . . . . . . . . . . . . . . . . . . . . . 152

4.2 Results and Discussion . . . . . . . . . . . . . . . . 156

4.2.1 Cell Performance . . . . . . . . . . . . . . . . . . . . . . . . . . . . . . . . . . . . . . . . .

4.2.2 Cross-Over and OCV drop . . . . . . . . . . . . . . 172

4.2.3 Electrode Overpotentials . . . . . . . . . . . . . . . 178

4.3 Conclusions . . . . . . . . . . . . . . . . . 180

4.3.1 Performance Characteristics and Limitations . . . . . . . . . . . . . 180

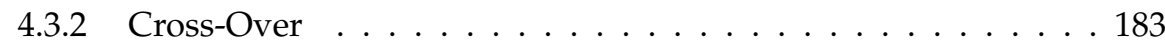

4.3 .3 Voltage Losses . . . . . . . . . . . . . . . . . . . . . . . . . . . . . . . . . . . . . . . . . .

4.3.4 Tubular MEA Design . . . . . . . . . . . . . . . 186

5 Conclusions and Outlook 189

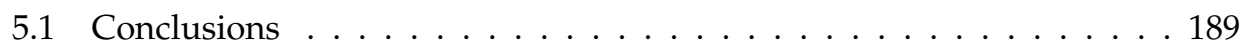

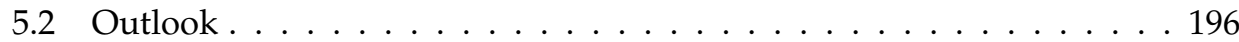

$\begin{array}{ll}\text { Bibliography } & 199\end{array}$ 


\section{List of Abbreviations}

AC

ASR

BET

CCC

CE

CPE

DHE

DoD

EE

$\mathrm{EE}_{\text {sys }}$

EESS

FB

FB-VRFB

FKM

FT

FT-VRFB

GDE

GFE

$\mathrm{HgE}$

LSV

MEA

OCV

OER

ORR

PEM-FC

PFSA

PTFE

PVDF

RFB

SCE

SHE

SoC alternating current

Area specific cell resistance

Brunauer Emmett Teller (-model)

Composite Current Collector

Coulombic efficiency

constant phase element

Dynamic hydrogen electrode

depth of discharge

energy efficiency

system energy efficiency

Electrical Energy Storage System

Flow-By (electrode configuration)

Flow-By All Vanadium Redox Flow Cell

Fluorocarbon rubber

Flow-Through (electrode configuration)

Flow-Through All Vanadium Redox Flow Cell

gas-diffusion electrode

Graphite felt reference electrode

Mercury/mercurous sulfate electrode

linear sweep voltammetry

membrane eelectrode assembly

Open-circuit voltage

Oxygen evolution reaction

Oxygen reduction reaction

Polymer Electrolyte Membrane-Fuel Cell

Perfluorsulfonic acid

Polytetrafluoroethylene

Polyvinylidene fluoride

Redox Flow Battery

Saturated calomel electrode

Standard hydrogen electrode

State of charge 
xvi
VARFB Vanadium/Air Redox Flow Battery
VE voltage efficiency
VOFC Vanadium/ Oxygen Fuel Cell
V-PEMWE Vanadium-Polymer Electrolyte Membrane water electrolysis
VRFB All Vanadium Redox Flow Battery
$\mathbf{W}_{Z} \quad$ Warburg element 
xvii

\section{Physical Constants}

elementary charge

Avogadro constant

Faraday constant

universal gas constant

$$
\begin{aligned}
e & =1.60217662 \times 10^{-19} \mathrm{C} \\
N_{A} & =6.02214086 \times 10^{23} \mathrm{~mol}^{-1} \\
F & =96485.33289 \mathrm{Cmol}^{-1} \\
R & =8.314472 \mathrm{~J} \mathrm{~K}^{-1} \mathrm{~mol}^{-1}
\end{aligned}
$$





\section{List of Symbols}

$a_{j} \quad$ activity

a volume specific surface area

$\mathrm{moll}^{-1}$

A geometric surface area

$\mathrm{m}^{-1}$

$A_{\text {mem }}$

active membrane surface area

$\mathrm{m}^{2}$

$A_{\text {proj }} \quad$ projected electrode area

$\mathrm{cm}^{2}$

$A S R \quad$ (membrane) area specific cell resistance

$\mathrm{cm}^{2}$

$b$

Tafel slope

$\Omega \mathrm{cm}^{2}$

$\mathrm{V}$

c concentration

$\mathrm{moll}^{-1}$

$c_{R e, e} \quad$ concentration of $R e$ in bulk electrolyte

$\mathrm{moll}^{-1}$

$c_{R e, s}$

concentration of $R e$ at electrode surface

$\mathrm{moll}^{-1}$

$c_{K C} \quad$ Kozeny-Carman constant

$c_{V, t o t}$

total vanadium concentration

$d_{f} \quad$ fiber diameter

$\mathrm{moll}^{-1}$

$D_{H} \quad$ hydraulic diameter

$\mu \mathrm{m}$

$E^{00} \quad$ standard electrode potential

$E^{00^{\prime}}$ formal standard electrode potential

$E_{\text {cell }} \quad$ cell potential

standard cell potential

$\mathrm{m}$

V

$\mathrm{V}$

$\mathrm{V}$

$E_{c e l l}^{00}$

$E_{\text {cell }}^{0^{\prime}}$

formal cell potential

$\mathrm{V}$

energy

$E_{\text {neg }}^{0}$

Nernst-Potential at negative electrode

$E_{\text {pos }}^{0}$

Nernst-Potential at positive electrode

$E_{\text {pump }}$ pumping energy

$i_{0} \quad$ exchange current density per membrane area

$i_{\text {lim }} \quad$ limiting current density

$j_{0} \quad$ exchange current density per electrode surface

$K \quad$ permeability

$\mathrm{V}$

Wh

$\mathrm{V}$

$\mathrm{V}$

Wh

$\mathrm{mA} / \mathrm{cm}^{2}$

$\mathrm{mA} / \mathrm{cm}^{2}$

$\mathrm{mA} / \mathrm{cm}^{2}$

$\mathrm{mA} / \mathrm{cm}^{2}$

$\mathrm{m}^{2}$

$L \quad$ length

$\mathrm{m}$

$n$ amount of substance

mol 
OCV open-circuit voltage $\quad \mathrm{V}$

$p \quad$ pressure $\mathrm{hPa}$

$P$ power $\mathrm{W}$

$P_{\text {cell }} \quad$ cell power $\quad \mathrm{W}$

$P_{\text {Pump }}$ pumping power $\mathrm{W}$

$p_{\text {cell }}^{A} \quad$ membrane area specific power density $\quad \mathrm{mW} / \mathrm{cm}^{2}$

$p_{\text {cell }}^{\ell}$ cell volume specific power density $\mathrm{kW} / \mathrm{m}^{3}$

$Q \quad$ charge

$Q_{\max }$ maximum charge of a substance

$\dot{Q} \quad$ volumetric flow rate

$\mathrm{RH} \quad$ relative humidity

$\mathrm{SoC}$ state of charge

$T$ temperature

$u \quad$ velocity

$U_{\text {elyt }} \quad$ electrolyte utilization

$\mathrm{mAh}(\mathrm{C})$

$\mathrm{mAh}(\mathrm{C})$

$\mathrm{ml} \min ^{-1}\left(\mathrm{~m}^{3} / \mathrm{s}\right)$

$\%$

$\%$

${ }^{\circ} \mathrm{K}$

$\mathrm{ms}^{-1}$

$\%$

$\mathrm{ml}\left(\mathrm{m}^{3}\right)$

$V_{i} \quad$ Volume of $\mathrm{i}$

$z \quad$ number (in moles) of transferred electrons per reaction

Z impedance

$\Omega \mathrm{cm}^{2}$

$\alpha \quad$ charge transfer coefficient

$\epsilon \quad$ porosity

$\epsilon \quad$ permittivity

$\varphi \quad$ potential

$\varphi_{j}^{0} \quad$ standard potential of species $j$

$\phi \quad$ phase shift

$\eta \quad$ overpotential

$\eta_{\text {act }}$ activation overpotential

$\eta_{\text {conc }} \quad$ concentration overpotential

$\eta_{\text {neg }} \quad$ residual overpotential at negative electrode

$\eta_{\text {ohm }} \quad$ ohmic overpotential

$\eta_{\text {pos }}$ residual overpotential at positive electrode

$\eta_{\text {res }} \quad$ residual overpotential

$\vartheta_{i} \quad$ stoichiometric coefficient of component $i$

$\mu \quad$ dynamic viscosity

$v \quad$ kinematic viscosity

$\rho$ density

$\rho_{\text {res }} \quad$ electric resistivity

$\chi \quad$ electrode compression ratio

$\omega \quad$ angular frequency

-

$-$

$\mathrm{F} \mathrm{m}^{-1}$

$\mathrm{V}$

$\mathrm{V}$

$\circ$

$\mathrm{mV}$

$\mathrm{mV}$

$\mathrm{mV}$

$\mathrm{mV}$

$\mathrm{mV}$

$\mathrm{mV}$

$\mathrm{mV}$

mol

Pas

$\mathrm{m}^{2} \mathrm{~s}$

$\mathrm{g} \mathrm{ml}^{-1}$

$\Omega \mathrm{m}$

$\%$

$\mathrm{rad}$ 
Dedicated to Lena Christian and my parents 



\section{Chapter 1}

\section{Introduction}

Today's (2016) world electric energy generation is mainly (65.3\%) done by thermal combustion of carbon emitting resources (coal, natural gas, oil) [7]. From 2005 to 2016 the worldwide electricity production from wind and solar photovoltaic sources increased by a factor of 12 while the total electricity generation increased by $37 \%$ [7]. Several national and trans national agreements aim on the transition of today's electric energy production towards a power generation from renewable sources. As the power generation from wind and solar sources (renewable) depends on weather conditions, the volatile power generation needs to be matched with the fluctuating power demand.

In $201618 \%$ of Germany's total net electricity production (Spain: 20.7\%) was done from wind and solar photovoltaic sources [7]. The German power demand and generation over the course of 8 days in October 2018 is displayed in figure 1.1. Pumped hydro, gas and coal power plants are controlled to mitigate the gap between consumer demands and the volatile generation from wind and solar photovoltaic.

With an increasing share of the power generation from volatile renewable sources (wind, solar photovoltaic) a higher level of flexibility services for grid operators is required. A higher flexibility can be achieved by transmission and distribution grids, demand-side management and electrical energy storage systems (EESS).

EESS can be used for multiple grid-connected applications such as frequency regulation, voltage support, grid stabilization, peak shaving, energy management, backup power and black start. EESS are also used in off-grid applications to ensure a reliable electricity supply of households, communities or technical utilities in remote areas. Another field of application is the combination of domestic photovoltaic systems with an EESS. By storing the excess energy during peak power generation periods (daytime) self consumption can be increased and electricity bills can be reduced.

The variety of applications implies different requirements for EESSs and storage technologies are unequally suited to meet the specific requirements. While flywheels, capacitors and super capacitors are typically installed in storage applications with a 


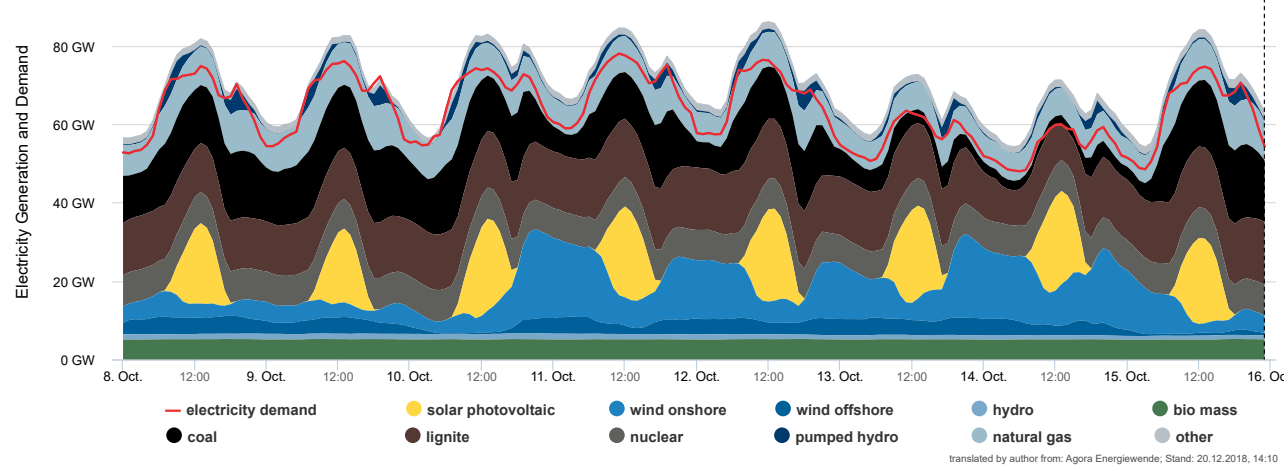

FIGURE 1.1: Net power demand and power generation (by source) in Germany over the course of one week in October 2018 [8].

short response time, a high power output and a short ( $\mathrm{ms}$ to min) discharge time, pumped hydro, compressed air energy storage (CAES) and batteries are used in applications with a lower power to discharge period ratio.

While the development of pumped hydro and CAES is limited by geographic and geological requirements (slopes, caverns), batteries have attained considerable attraction. Although the technological status of several batteries may be considered as mature, financial, reliability, cycle life, safety and energy density concerns do still constrain a wide utilization of batteries in stationary storage applications.

Redox Flow Batteries offer an interesting potential in terms of their scalability, high cycle life, safety, environmental amenity, recyclability and performance characteristics.

\subsection{State of the Art}

\subsubsection{Redox Flow Batteries}

The possibility of storing electrical energy in solutions was first contemplated in 1941 by M. Vollmer and W. Kangro [59]. In 1949 a patent covering the basic process and function of a Redox Flow Battery (RFB) was granted to Walther Kangro from the Technische Hochschule Braunschweig in Germany [60].

The development of Redox Flow Battery systems with a design comparable with modern RFBs was initiated in Japan in 1971 [133] and preliminary feasibility studies and laboratory experimentation on RFBs were done at $N A S A$ in 1973 [93]. In subsequent decades further investigation and development efforts were done by NASA and in 
Japan and led to several pilot scale Redox Flow Battery systems [133, 152].

\section{Basic Principle}

The setup of a Redox Flow Battery is illustrated in figure 1.2. It is composed of a conversion unit, which is connected to two tanks with a piping system. Pumps are used to pass liquid electrolyte solutions from the storage tanks through the conversion unit.

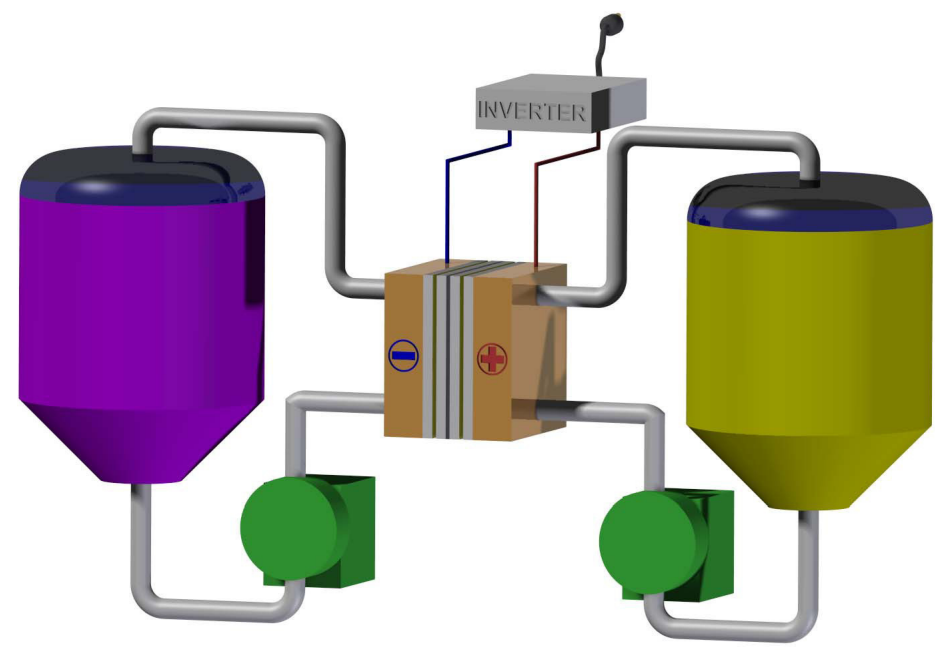

FIGURE 1.2: Illustration of a Redox Flow Battery.

In the simplest case, the conversion unit is made up of a single electrochemical cell with a positive and a negative compartment (half cell). Each half cell is equipped with an electrode (cathode and anode) and an ion conducting membrane is typically used to separate both compartments. During operation a negative and positive electrolyte solution is passed through the respective electrode.

In contrast to conventional lead-acid or lithium ion batteries the electro-active substance (redox species) is not bound to the electrodes but is dissolved in the electrolyte solutions. As two different redox species with a specific electrochemical potential $\left(E_{i}^{0}\right.$ in $\mathrm{V}$ ) are utilized in the positive and negative electrolyte, a potential difference arises in-between the positive and negative electrodes (cell potential $E_{c e l l}^{0}$ ).

During charging and discharging of the battery electron transfer reactions take place 
at the inert electrodes and the redox species are converted into their reduced and oxidized state, respectively.

The power supply of the conversion unit during charging and application of an electrical load during discharging is done via an interconnected inverter unit as grid connected applications are typically operated with alternating current $(a c)$.

Due to the fact that the electron transfer reactions take place at the inert electrode surface and the electro-active species are dissolved in the electrolyte solutions the power (in $\mathrm{W}$ ) of a $R F B$ is mainly defined by the conversion unit, while the battery's capacity (in A h) is determined by the electrolyte solutions. This gives Redox Flow Batteries the unique ability to rate the power independent from the capacity.

Furthermore, RFBs can be discharged to a low state of charge ( $S o C \geq 0 \%)$ as the inert electrodes do not undergo physio-chemical changes [152].

In contrast to conventional batteries the cycle life of RFBs is not dependent on the number of cycles and the depth of discharge $(D o D)$ and comparably high cycle lifes ( $>10,000$ cycles) [133] can be realized.

End of life costs and recyclability of Redox Flow Batteries are another potential advantage over conventional batteries as electrolyte solutions can be withdrawn easily and might be reprocessed.

The high energy efficiency (up to $85 \%$ ) [133], the short response time (ms) [133, 161] and the high degree of system layout flexibility make RFBS an interesting candidate for a variety of stationary EESS applications. However, high costs do still prevent a broad application of Redox Flow Batteries [133, 161].

\section{Costs}

Tolerable costs for EESSs heavily depend on the specific storage application (e.g.: power quality, peak shaving, utility scale, demand-side, off-grid), infrastructure, as well as governmental and legislative framework. The costs of Redox Flow Batteries can be separated in capital system costs, capital cycle-life system costs, operational and maintenance costs, as well as end of life related costs.

Capital cycle-life system costs are obtained by relating the capital system costs of a battery to it's cycle-life. The system costs can be expressed relative to the capacity (in $€ / \mathrm{Ah}$ ) or output power (in $€ / \mathrm{kW}$ ). By considering the redox species' electrochemical potentials of the positive and negative electrolyte $\left(E_{c e l l}^{0}\right)$ the capacity can be converted into energy (in $\mathrm{Wh}$ ) and energy specific system costs (in $€ / \mathrm{kWh}$ ) might be stated.

Energy specific costs of Redox Flow Batteries are mainly driven by the costs of the electrolyte substances, the number of transferred electrons per reaction turnover and the 
redox potential. Power specific costs $(€ / \mathrm{kW})$ are related to cell material costs, manufacturing costs of conversion units and performance characteristics of the conversion unit (cell, stack), as well as reaction kinetics.

To improve the power output per cell volume $\left(\mathrm{kW} \mathrm{m}^{-3}\right)$ and reduce pressure drop losses, cell and stack designs, as well as electrode configurations need to be optimized [101, 133, 152, 161]. Resulting gains in a Redox Flow Battery's system energy efficiency will lead to decreased power related capital system costs.

\section{Redox Couples}

Since the initial works of Kangro a wide range of redox couples has been screened and investigated regarding their electrochemical reversibility, reaction kinetics, stability and electrochemical potentials [59, 98, 101, 133, 152, 157]. In the negative and positive electrolytes metal based redox couples with different and identical elements were mostly used and dissolved in acidic solutions. While Kangro and Pieper proposed $\mathrm{Ti}^{3+} / \mathrm{Ti}^{4+}$ for the negative and $\mathrm{Fe}^{2+} / \mathrm{Fe}^{3+}$ for the positive electrolyte as a suitable system [59], a screening of possible redox couples done by NASA concluded that a $\mathrm{Cr}^{2+} / \mathrm{Cr}^{3+} / / \mathrm{Fe}^{2+} / \mathrm{Fe}^{3+}$ system is favorable for the development of a $\mathrm{RFB}$ [98, 133]. Low electrolyte costs and the comparably high $E_{c e l l}^{0}$ of $1.19 \mathrm{~V}$ were decisive factors for the subsequent development of a $1 \mathrm{~kW}$ prototype Fe/Cr Redox Flow Battery system $[98,133]$. In the $1980 \mathrm{~s}$ an iron/chromium $R F B$ with a power of $10 \mathrm{~kW}$ and an energy efficiency of $80 \%$ was developed by Kansai Electrical Power Co. in Japan [133]. The commercialization of the iron/chromium system was, however, not realized as electrolyte cross-mixing through the membrane and membrane fouling represented a major drawback for the development of Fe/Cr RFBs [133]. Since 2004 the commercialization of the $\mathrm{Fe} / \mathrm{Cr} \mathrm{RFB}$ was, however revisited by the U.S. based companies Deeya Energy [35] (later on Imergy Power Systems) and EnerVault (from 2008) [39].

In recent years novel electrolytes with fully organic and partially organic redox couples were reported and tested in Redox Flow Cells [27, 28, 54, 98, 157, 160]. Thereby, redox active substances can be made up from molecules [160] or polymers [44, 55] and electrolytes might be both, aqueous or nonaqueous. These novel organic electrolytes offer an interesting potential for low cost and environmentally friendly Redox Flow Batteries in the future. A comprehensive overview of organic redox flow batteries is not given here but can be obtained from several review papers $[26,75,98,154$, 157].

However, a single metal based redox system has to date shown the greatest potential for an application in Redox Flow Batteries and tremendous research and development efforts have made it the most mature RFB technology. Vanadium ions with four different oxidation states are used in the positive and negative electrolyte and have, therefore, led to the term All Vanadium Redox Flow Battery. 


\subsubsection{All Vanadium Redox Flow Batteries (VRFB)}

To circumvent the observed cross-mixing of electrolytes in the $\mathrm{Fe} / \mathrm{Cr} \mathrm{RFB}$ Maria Skyllas-Kazacos and co-workers proposed a system, which is solely based on vanadium [133]. From 1984 development works on the All Vanadium Redox Flow Battery (VRFB) were carried out at the University of New South Wales in Australia [133].

\section{Basic Principle}

A schematic illustration of a $V R F B$ with the reduction and oxidation reactions is presented in figure 1.3. In order to insulate the positive and negative half cell and prevent electrolyte cross-mixing an ion-exchange membrane is inserted between both compartments. Cations $\left(\mathrm{H}^{+}\right)$are passed through the membrane during charging and discharging to maintain conservation of charge. Porous graphite materials are typically used as electrodes in both half cells. A porous structure is chosen to increase the electrode surface area. The reduction and oxidation reactions during charging and discharging proceed at the electrode surface and electrons are transferred across the electrode-electrolyte interface. The electron conduction to/from the positive and negative terminals is done through the graphite electrode material and connected current collectors.

$\mathrm{V}^{2+} / \mathrm{V}^{3+}$ and $\mathrm{V}^{4+} / \mathrm{V}^{5+}\left(\mathrm{VO}^{2+} / \mathrm{VO}_{2}^{+}\right)$redox couples are used in the negative and positive electrolyte, respectively. The redox active substances are dissolved in aqueous solutions and sulfuric acid is used as a supporting electrolyte for an enhanced ionic conductivity. As the cell is charged $(c h) V^{3+}$ is reduced to $V^{2+}$ in the negative half cell and $\mathrm{VO}^{2+}$ is oxidized to $\mathrm{VO}_{2}^{+}$at the positive electrode. During discharging $(d c h)$ redox reactions proceed in reverse direction.

Positive half cell:

$$
\mathrm{VO}_{2}^{+}+2 \mathrm{H}^{+}+e^{-} \rightleftharpoons_{c h}^{d c h} \mathrm{VO}^{2+}+\mathrm{H}_{2} \mathrm{O}
$$

Negative half cell:

$$
V^{2+}-e^{-} \underset{c h}{d c h} V^{3+}
$$

The standard potential of $V^{2+} / V^{3+}\left(E_{n e g}^{0}=-0.26 \mathrm{~V}\right.$ vs. SHE) combines with the standard potential of $\mathrm{VO}^{2+} / \mathrm{VO}_{2}^{+}(1.00 \mathrm{~V}$ vs. SHE) and results in a standard cell potential of $E_{\text {cell }}^{0}=1.26 \mathrm{~V}$. 


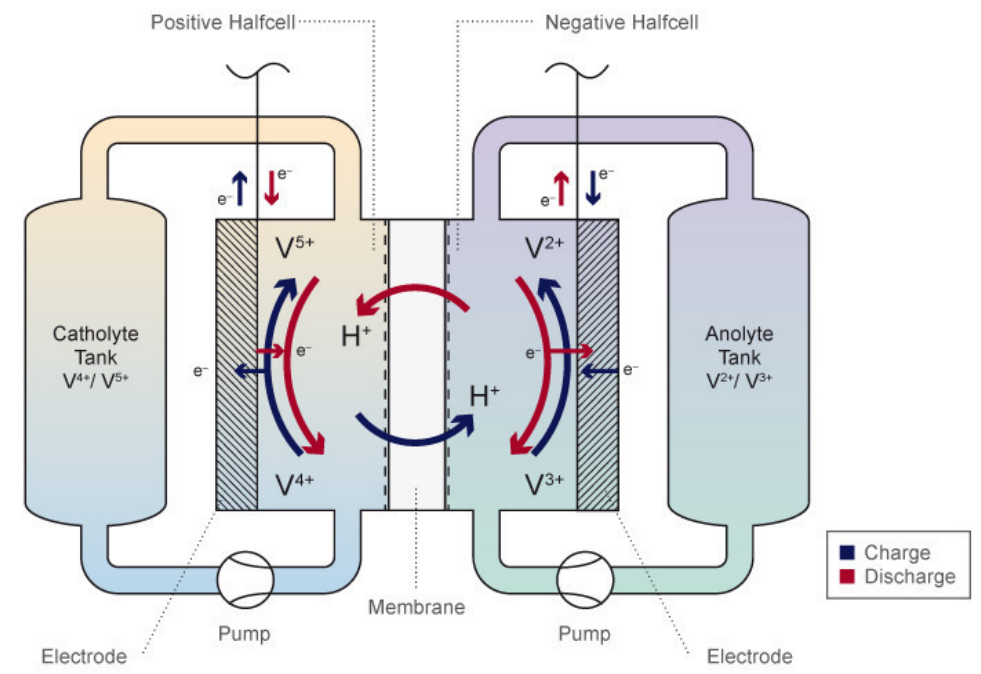

FIGURE 1.3: Schematic illustration of an All Vanadium Redox Flow Battery.

\section{Technology Potentials and Limitations}

In several pilot scale, demonstration and commercial projects $V R F B$ storage systems exhibited system energy efficiencies from $70 \%$ to $90 \%$ [133]. VRFBs are mostly utilized in load shifting storage applications with small power to discharge period ratios. The short response times $(<50 \mathrm{~ms})$ of $V R F B s$ do, however also permit an operation in power quality (short discharge period) or dual applications [158].

As the electrolytes employed in VRFBs are aqueous solutions, they are nonflammable and can be considered as safe. A parasitic cross-over of vanadium ions across the membrane does not lead to an electrolyte degradation as solely vanadium is utilized in both electrolyte solutions. Cross-over can be corrected by adequate rebalancing methods [29] and electrolytes can theoretically be used infinitely [133] and might be fully recycled at the end of life.

As the redox reactions take place at functional surface groups (hydroxyl $-\mathrm{OH}$, carbonyl $\mathrm{C}=\mathrm{O}$, carboxyl $-\mathrm{COOH}$ ) or the graphitic carbon surface of the electrodes [41], no noble catalyst materials (e.g. $I r, P t$ ) are required for $V R F B s$.

A drawback of $V R F B s$ is the limited amount of energy (in $\mathrm{Wh}$ ) which can be stored per volume (in l) or mass (in $\mathrm{kg}$ ) of electrolyte solution (specific energy density in $\mathrm{Wh} \mathrm{H}^{-1}$ or $\mathrm{Wh} \mathrm{kg}^{-1}$ ). All Vanadium Redox Flow Batteries are, therefore, not suited for 
storage applications where space and weight is limited (e.g. mobile applications in cars). An increase of the energy density is restricted by the thermal precipitation of $V^{5+}$ in $2 M$ sulfuric acid solution at temperatures above $40^{\circ} \mathrm{C}$ [106]. In a study of Rahman and Skyllas-Kazacos [106] it was concluded that a maximum concentration of $3 M V^{5+}$ in $6 M$ sulfate/bisulfate solutions might be used in VRFBs up to a temperature of $40^{\circ} \mathrm{C}$ [106]. This translates into a maximum specific energy of $37.5 \mathrm{~W} \mathrm{~h} \mathrm{~kg}^{-1}$ [106] and is, thus below typical values of lithium-ion ( $70 \mathrm{~W} \mathrm{~h} \mathrm{~kg}^{-1}$ to $180 \mathrm{~W} \mathrm{~h} \mathrm{~kg}^{-1}$ ) and lead-acid ( $25 \mathrm{~W} \mathrm{~h} \mathrm{~kg}^{-1}$ to $40 \mathrm{Wh} \mathrm{kg}^{-1}$ ) batteries [157, 161].

In recent years several research efforts have been made to increase the stability of $V^{5+}$ at elevated temperatures [29] and to improve vanadium concentrations for higher energy densities. Vanadium electrolytes with a mixed sulfuric/chlorine acid system have shown to permit higher specific energy densities than the conventional sulfuric acid based electrolytes [107]. Furthermore, mixed acid electrolytes exhibit a higher stability at temperatures above $40^{\circ} \mathrm{C}$, which broadens the operation temperature window and might allow to run $V R F B$ storage systems without heat exchangers $[65,146]$.

Despite the improvements of the electrolyte stability and associated performance gains, energy specific capital costs are still above targeted costs of $\$ 150 \mathrm{kWh}^{-1}$ to $\$ 250 \mathrm{kWh}^{-1}[133,152,161]$. The high costs for vanadium are considered as the dominant factor for the energy specific capital costs $[147,161]$.

\section{Demonstration Projects and Commercialization}

Since the initial development works at the University of New South Wales (UNSW) several pilot scale systems, demonstration projects and commercial VRFB systems have been installed and tested [133]. From 1993 field trials with VRFB systems where conducted in Australia, Thailand and Japan [133, 152]. A VRFB system developed at the UNSW with an energy capacity of $12 \mathrm{kWh}$ was installed and operated in a solar demonstration house in Thailand [133].

In 1997 a grid-connected $V R F B$ load leveling system with a nominal power of $200 \mathrm{~kW}$ and energy capacity of $800 \mathrm{kWh}$ was installed at Kashima-Kita Electric Power station in Japan. The system was subjected to long term cycling and exhibited an energy efficiency of almost $80 \%$ [133].

Within the period from 1996 to 2017 Sumitomo Electric Industries (SEI) has installed 29 VRFB systems for a variety of applications (load leveling, peak shaving, uninterrupted power supply, emergency power supply, wind and solar connected, micro grid, behind the meter). The total nominal power of all projects sum up to $28 \mathrm{MW}$ and the total capacity amounts to $104 \mathrm{MWh}$. Rated system powers cover a range from $2 \mathrm{~kW}$ to $15000 \mathrm{~kW}$ [129].

In a project funded by Japan's New Energy and Industrial Development Organization 
(NEDO) SEI installed a $4 \mathrm{MW} / 6 \mathrm{MWh}$ VRFB system at the Tomomae wind farm [57, 129]. The system exhibited an energy efficiency of $80 \%$ and was reported to have undergone more than 270, 000 cycles within 3 years of operation [133].

From the early 2000s H. Zhang and co-workers developed VRFB stacks and systems at the Dalian Institute of Chemical Physics in China [133]. Developed systems are manufactured and distributed by Dalian Rongke Power [79]. Until 2017 Dalian Rongke Power has reported on a total of 20 VRFB projects with an energy capacity of $30 \mathrm{MWh}$ across China, the U.S. and Germany [79].

$P u$ Neng is another China based company, which was founded in 2006. By 2017 it had completed more than 20 VRFB storage projects in the $\mathrm{kW}$ and $\mathrm{MW}$ range in $\mathrm{Eu}$ rope, Asia, the U.S. and Africa [52].

The Europe based company Enerox (formerly GILDEMEISTER energy storage, Austria) has developed a shipping container sized $V R F B$ storage system (cellcube) with a nominal power from $10 \mathrm{~kW}$ to $250 \mathrm{~kW}$ and rated capacities from $40 \mathrm{kWh}$ to $2000 \mathrm{~kW} \mathrm{~h}$ [90]. According to the company more than 130 cellcubes storage systems have been installed worldwide and were operated for more than 10 years. Ongoing life-cycle testing at the utility has reached over 10,000 cycles [24].

Further European manufacturers of VRFB systems are RedT Energy (UK), Schmid Group (Germany), Voltstorage (Germany) and Volterion (Germany). While RedT Energy focuses on shipping container integrated storage systems for grid connected and micro-grid applications [84], Voltstorage and Volterion provide small sized (2 $\mathrm{kW}$ to $10 \mathrm{~kW} / 6 \mathrm{kWh}$ to $30 \mathrm{kWh}$ ) VRFB storage systems for domestic "behind the meter" applications.

In 2012 the U.S. based company UniEnergy Technologies (UET) was founded. UET has developed, manufactured and installed various VRFB storage systems in the $500 \mathrm{~kW}$ to $2000 \mathrm{~kW}$ range ( $2 \mathrm{MWh}$ to $8 \mathrm{MWh}$ ) for grid-connected power and energy storage applications across the U.S. and Europe [76]. UET uses the mixed-acid electrolyte in their system, which was developed at the Pacific Northwest National Laboratory.

\subsubsection{Vanadium/Air Redox Flow Batteries (VARFB)}

In 1992 Kaneko et al. patented a Redox Flow Battery, which employs a $V^{2+/ 3+}$ redox couple in the negative half cell and an oxidizing substance in a gas in the positive half cell [58]. Oxygen or air was mentioned as the preferred oxidizing substance. With the replacement of the $V^{4+/ 5+}$ redox couple Kaneko et al. aimed to reduce energy specific costs and to increase the energy density of $V R F B s$. 


\section{Basic Principle}

As the RFB proposed by Kaneko et al. [58] only permits discharging, it is denoted as a Vanadium/Oxygen Fuel Cell (VOFC) in subsequent sections. In contrast to the VOFC, the electrochemical cell of a Vanadium/Air Redox Flow Battery (VARFB) enables to charge and discharge the battery. A schematic illustration of a VARFB with a $V^{2+/ 3+}$ redox couple in the negative half cell and a positive air/water electrode is shown in figure 1.4.

The negative half cell setup of a VARFB is analog to the negative half cell setup

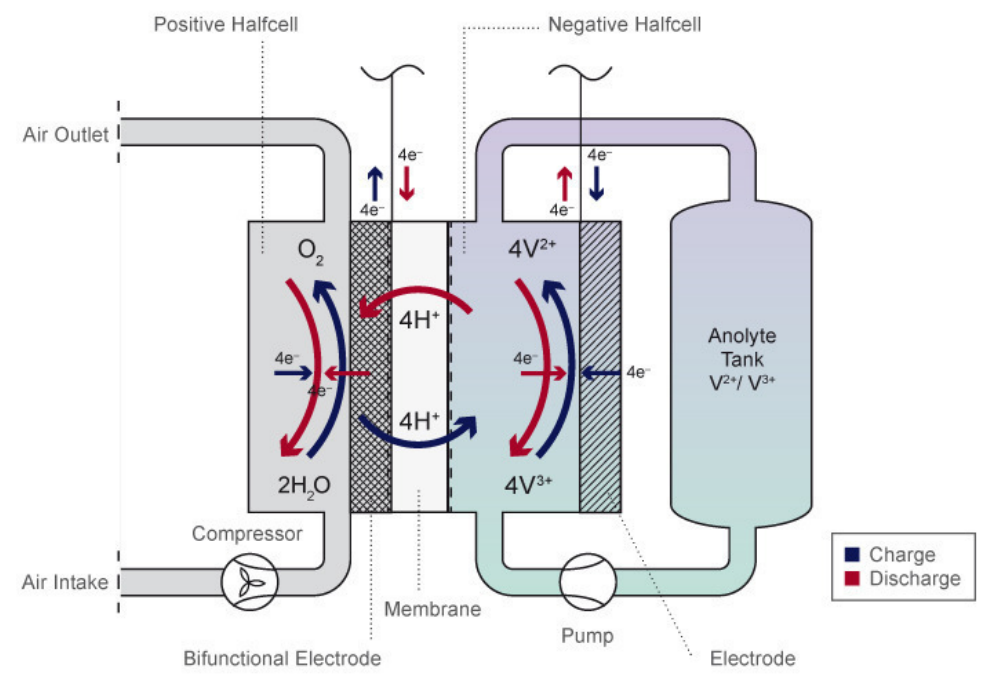

FIGURE 1.4: Schematic of a Vanadium/Air Redox Flow Battery.

used in VRFBs. The electrolyte solution with a $V^{2+/ 3+}$ redox couple is stored in a storage tank and passed through the negative electrode. In the positive half cell a bifunctional air/water electrode with a porous structure is employed. The oxygen/air required during discharging is fed to the positive half cell with a connected compressor. Withdrawing air from the environment allows to operate the battery without a second storage tank. By humidifying the intake air with water, the positive electrode can be supplied with water during charging.

This Vanadium/Air Redox Flow Battery potentially doubles the energy density of the well-established $V R F B$ as air and water, required for the oxygen reduction reaction $(O R R)$ and oxygen evolution reaction $(O E R)$, is withdrawn from the environment. During charging $V^{3+}$ is reduced at the negative electrode while water is oxidized 
$(O E R)$ at the positive electrode. During discharging the oxygen reduction reaction occurs at the positive electrode and $V^{2+}$ is oxidized at the negative electrode. The redox reactions then read:

Positive half cell:

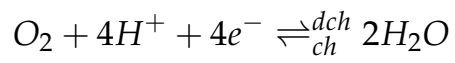

Negative half cell:

$$
4 V^{2+}-4 e^{-} \underset{c h}{d c h} 4 V^{3+}
$$

Due to the standard electrode potential of the positive electrode $(1.229 \mathrm{~V}$ vs. SHE [56]) the standard cell potential (1.49V) of VARFBs is higher than $E_{c e l l}^{0}$ of VRFBs.

By eliminating the $\mathrm{VO}^{2+} / \mathrm{VO}_{2}^{+}$redox couple, thermal precipitation of $V^{5+}$ does not impose limitations on a further concentration increase and might allow to achieve higher energy densities. The elevated cell potential is also beneficial for higher energy and power densities. Due to the strongly oxidizing nature of the $V^{5+}$ material stability requirements are high in $V R F B$ cells. As no electrolyte solutions with $V^{5+}$ are present in a $V A R F B$ material requirements are expected to be less restrictive.

For the OER and ORR bifunctional catalysts are needed. Pt and $\mathrm{IrO}_{2}$ are still among the most widely used catalyst materials for bifunctional air electrodes and will impose limitations on power specific costs. However, energy storage applications (long discharge durations) are more sensitive to energy specific costs than to power specific costs and electrolyte costs in VARFBs can be expected to be substantially below the electrolyte costs of VRFBs.

In the dissertation of $S$. Hosseiny a planar VARFB with a unitized cell was proposed [50]. For the positive gas diffusion electrode (GDE) a porous Ti non-woven or mesh was used. In [51] Hosseiny et al. reported on the influence of the porous GDE structure on the mass transport of water and associated cross-over of dissolved oxygen into the negative half cell. Although a unitized cell design for charging and discharging was initially proposed [50], different GDEs were used during charge and discharge cycles [51]. Achieved cell currents $\left(i_{\text {cell }}\right)$ and powers did, however remain low $\left(i_{\text {cell }}=2.4 \mathrm{~mA} / \mathrm{cm}^{2}\right)$ and energy efficiencies did not exceed $45.7 \%$.

From 2012 to 2016 research efforts on planar VARFBs were also done by grosse Austing et al. at the EWE Research Centre for Energy Technology in Oldenburg, Germany [13-16]. In contrast to Hosseiny et al. a double-layered electrode was used in the positive half cell. Both layers were made from porous graphite substrates. While one layer was coated with a $\mathrm{Pt}$ catalyst for the $\mathrm{ORR}, \mathrm{IrO}_{2}$ catalyst material was loaded on the second layer. During charging the positive electrode was fed with $2 \mathrm{M} \mathrm{H}_{2} \mathrm{SO}_{4}$ solution. To discharge the cell $2 \mathrm{M} \mathrm{H}_{2} \mathrm{SO}_{4}$ supply was stopped and an air flow was applied along the $P t$ layer $[15,16]$. Corrosion of the graphite substrates and crossover of vanadium ions and oxygen across the membrane were identified as limiting 
factors for the long-term stability and energy efficiency, respectively $[15,16]$. However, substantially increased current densities $\left(40 \mathrm{~mA} / \mathrm{cm}^{2}\right)$ and an average energy efficiency of $41.7 \%$ (at $\left.i_{\text {cell }}=20 \mathrm{~mA} / \mathrm{cm}^{2}\right)$ were achieved during charge/discharge cycling experiments [16].

Recent (2016) research efforts of grosse Austing et al. focused on the investigation of cross-over processes in the VARFB [13] and the modification of a membrane material to reduce the parasitic cross-over of vanadium ions and oxygen [14].

Five years after Kaneko et al. first patented the Vanadium/Oxygen Fuel Cell (VOFC) Menictas and Skyllas-Kazacos initiated research and development efforts on VOFCs at the UNSW [85]. In 2011 results of a Vanadium/Oxygen Fuel Cell stack with 5 serially connected cells were published [85]. Different cathode and membrane combinations were used to fabricate membrane electrode assemblies (MEAs) by a heat bonding process. Varying amounts of $P t$ catalyst were coated on a porous graphite gas diffusion layer (E-Tek, ELAT) and heat bonded to two types of cation exchange membranes (Nafion 112, Nafion 117). During discharging at different temperatures and relative oxygen humidity, a delamination of the membrane and cross-over of vanadium ions was observed. Deterioration of the $M E A$ could, however be minimized and allowed for a stable operation of the VOFC over $100 \mathrm{~h}$ [85]. Furthermore, a maximum discharge current density of $40.5 \mathrm{~mA} / \mathrm{cm}^{2}$ was reported. In $2016 \mathrm{C}$. Menictas announced the resumption of research activities on VOFCs at the UNSW [86]. First results achieved by a co-operation of the UNSW and the Fraunhofer-Institute for Chemical Technology in Germany on VOFCs with increased $V^{2+/ 3+}$ concentrations were presented in 2018 [87].

At the Fraunhofer-Institute for Chemical Technology experimental work on Vanadium/ Oxygen Fuel Cells was first reported in 2010 [95]. In subsequent years the working group developed and characterized a VOFC with an active area of $280 \mathrm{~cm}^{2}$ [95], investigated the long-term stability of the cell [97] and established a coupled-physics model of the Vanadium/Oxygen Fuel Cell [150].

The VOFC of Noack et al. features an additional membrane cavity in-between the positive and negative half cell to eliminate $V^{2+}$ cross-over from the negative half cell into the cathode $[95,96]$. The catalyst layer of the oxygen electrode was directly coated on the cathode side of the membrane (catalyst coated membrane CCM). The cathode design of Noack et al. is, thus in contrast to the VOFC design of Menictas and Skyllas-Kazacos as well as the air electrode design of the VARFBs of Hosseiny and grosse Austing et al.

Discharging of the $280 \mathrm{~cm}^{2}$ VOFC over a period of $4 \mathrm{~h}$ at a constant current density of $40 \mathrm{~mA} / \mathrm{cm}^{2}$ allowed to convert $18.2 \%$ of the theoretically available energy [95]. The comparably high level of losses was mainly attributed to parasitic cross-over, kinetic losses of the $O R R$ and losses introduced by the complex cell setup (ohmic losses) 
[95]. Further investigations of Noack et al. on the long term operation (676 h discontinuous operation) of a Vanadium/Oxygen Fuel Cell indicated a volatile characteristic of the cathode, which was assumed to stem from the complex physio-chemical conditions and processes at the membrane electrode interface [97].

\subsubsection{Cell Designs}

The power of Redox Flow Batteries is mainly specified by the conversion unit and the surface area of the electrodes. By electrically connecting several cells the electrode surface can be enlarged and the conversion unit's power is increased. While a serial connection of cells leads to an enhanced potential, a parallel connection of cells yields a higher current. In RFBS cells are typically connected in series and are then termed as stacks.

The cell design has a strong influence on possible stack configurations and implicates specific requirements on stack component layouts and manufacturing efforts. A reduction of power specific costs can be achieved by an enhanced stack performance and/or a reduction of the cell and stack costs.

\section{Planar Cell Designs}

Cells and stacks commonly employed in All Vanadium Redox Flow Batteries and Redox Flow Batteries in general feature a planar cell design $[2,65,101,133,152,161]$. The standard planar cell setup is illustrated in figure 1.5. It consists of an ion-selective membrane sheet, which separates the positive from the negative half cell. Each half cell is equipped with a planar sheet electrode. Electrical contacting of the electrodes is realized by cathode and anode plates fabricated from expanded graphite or electrically conductive carbon-polymer composite material. Flow frames featuring manifolds are used to supply negative and positive electrolyte solutions to the electrodes. By stacking planar cells in a bipolar manner, the cells are electrically connected in series and the overall stack potential is increased. Anode and cathode plates are then referred to as bipolar plates.

Sealing of planar cells and stacks is an issue of paramount importance as leak tightness is a basic requirement for a safe and reliable long term operation and it is closely linked to high material and manufacturing efforts and costs [98, 133]. In planar cells the circumferential length of the sheet electrodes needs to be sealed to prevent leakage of electrolyte solutions into the environment or adjacent half cell. Efforts in the development of easy and low cost manufacturing and sealing techniques need to be done as conventional gaskets or O-Ring sealings limit the cell size of planar designs and lead to laborious and cost intensive stack assembling. The comparatively high number of different components of planar cells leads to elaborate stack assembling 


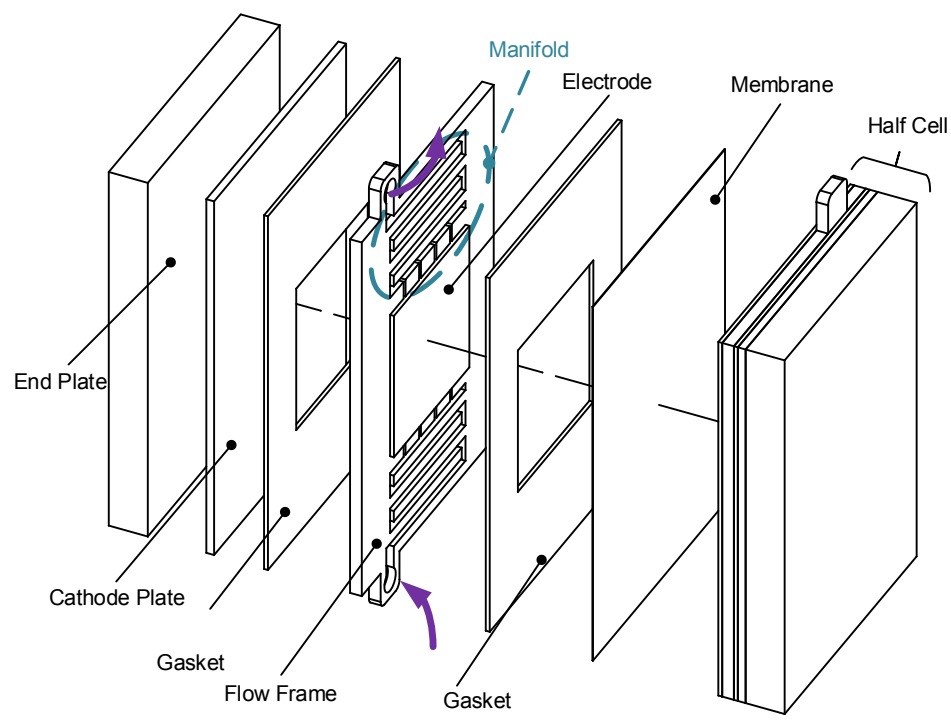

FigURE 1.5: Planar Redox Flow Cell setup.

routines, which place high demands and costs on stack assembling automation.

Efforts to assemble and seal cells and stacks by welding of cell components have been reported in [133] and Volterion has developed and tested a fully welded stack [124]. Another attempt to reduce stack components and ease planar stack assembling was patented by Eisenhuth GmbH and Clausthal University of Technology [38]. The invention allows to reduce the number of cell components by use of a flow frame with integrated sealings and manifolds which is directly attached to the bipolar plate by injection molding.

Another issue which needs to be addressed for a reduction of system costs is the reduction of shunt current losses [101, 133, 152, 161], which arise in the manifolds and tubings of Redox Flow Cells as they are electrically connected in series. Manifold designs are adopted [68, 140,141] and integrated in the flow frames (see fig. 1.5) or bipolar plates to lower stack internal shunt currents. The often complex manifold design [11] in return causes additional pressure drop losses and increased manufacturing efforts and costs for planar plates and flow frames.

\section{Electrode Configurations}

The electrodes of Redox Flow Batteries can be operated in two different configurations. In the flow-through configuration (see fig. 1.6 right) the electrolyte solution is passed 
through the porous structure of the electrode. The flow distribution across the electrode is dependent on the pore size distribution and the actual pore length. The pressure drop along the electrode is defined by the liquid permeability of the porous electrode material. In this flow-through configuration mass flow rates are limited by the pressure drop arising along the flow direction which results in increased mass transfer losses and reduced system energy efficiencies.

On the left of figure 1.6 a flow-by electrode configuration is illustrated. The elec-

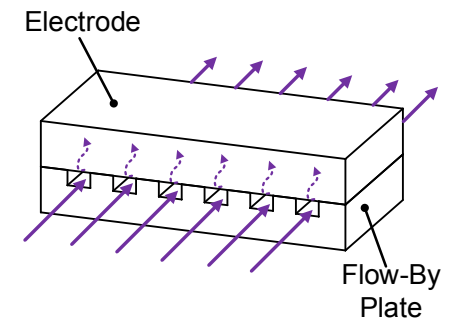

diffusion $\nearrow$ convective flow

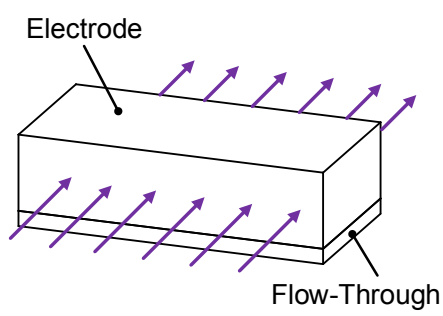

Plate

FIGURE 1.6: Electrode configurations; left: flow-by, right: flowthrough.

trolyte solution is passed through flow channels, which are integrated in the surface of a bipolar plate. A porous graphite electrode is placed adjacent to the flow-field. Therefore the electrolyte solution flows along the electrode surface and modeling results suggest that mass transfer into the porous electrode bulk is manly done by diffusion [61]. Due to the higher permeability of the flow channels pressure drops are lower than the pressure drop in a flow-through configuration. The integration of flow-fields in the bipolar plate does however add to manufacturing costs and a post processing of the plates by milling or polishing is often required. The porous electrode layer used in flow-by configurations is comparably thin $(<1.0 \mathrm{~mm})$ and flow-by configurations are sometimes also denoted as zero-gap setup.

In the review of Weber et al. [152] flow-through electrode configurations are considered as best suited for liquid electrolytes with comparably low concentrations of active substance and low diffusivity. Flow-by configurations are favorably used for gaseous reactants as protons required for the reaction are not present in the reactant stream and the reaction has to take place in the vicinity of the electrolyte (membrane, 3-phase layer). Furthermore, the enhanced diffusivity of gaseous substances is beneficial for a fast mass transfer into the porous electrode layer.

The flow-through electrode configuration is mostly used for Redox Flow Batteries with a liquid electrolyte. In 2012 Aaron et el. reported a flow-by VRFB single cell with 
maximum power density of $0.56 \mathrm{~W} \mathrm{~cm}^{-2}$ (per active membrane area $A$ ) at a current density of $700 \mathrm{~m} \mathrm{~A} \mathrm{~cm}^{-2}$ utilizing an adapted laboratory scale $\left(A=5 \mathrm{~cm}^{2}\right)$ fuel cell [2]. The enhanced performance was attributed to the flow-by electrode configuration with a serpentine flow field, high flow rate of $20 \mathrm{ml} \mathrm{min}^{-1}$, thin carbon electrodes (GDL 10AA, SGL Carbon) and a comparatively low area specific cell resistance (ASR) of $0.5 \Omega \mathrm{cm}^{2}$.

At the Pacific Northwest National Laboratory (PNNL) the performance of planar stacks composed of flow-through configuration cells $\left(A=780 \mathrm{~cm}^{2}\right)$ was improved by use of bipolar plates with integrated flow fields and low porosity $(\epsilon=80 \%)$ woven carbon electrode $(E L A T-H)$ operating in an interdigitated configuration [107]. Thereby the stack energy efficiency could be increased to $74.2 \%$ while the current density was doubled to $320 \mathrm{~mA} \mathrm{~cm}^{-2}$ and the pressure drop (at $i=160 \mathrm{~mA} \mathrm{~cm}^{-2}$ ) was cut in half. To avoid deployment of cost intensive bipolar plates with integrated flow fields, PNNL proposed a low cost electrode configuration with flow fields being cut or laser scribed into the graphite felt electrodes. However, overpotentials caused by electrode polarization appeared to be higher than values measured with flow field bipolar plates, but lowest pressure drops of all designs were detected.

\section{Tubular Cell Designs}

Despite the improvement of the cell and stack performance and the progress in terms of cell designs and production technologies, manufacturing costs remain high. Furthermore, planar cells can only be stacked by serial connection and stack designs with parallel connected cells are hardly feasible. A tubular cell design might permit to overcome these limitations, reduces sealing lengths and might allow to be manufactured with a cost efficient extrusion process. Such a tubular cell design is displayed in figure 1.7.

The ion-exchange membrane features a tubular shape and separates the inner half cell from the outer half cell. To enhance electrical conductivity along the cell, a current collector is employed in the inner half cell, which is surrounded by a porous electrode. The electrode of the outer half cell is housed in a tubular current collector. Half cells are fed with anolyte and catholyte solutions in parallel flow at one end face of the tubular cell.

Sealing of tubular cells must only be done at the end faces of the cell, which leads to significantly reduced sealing lengths compared to planar cell designs. Sealing techniques must be employed to seal the inner and outer current collector, as well as the tubular membrane.

By considering a tubular cell design a potential reduction of cell manufacturing costs 


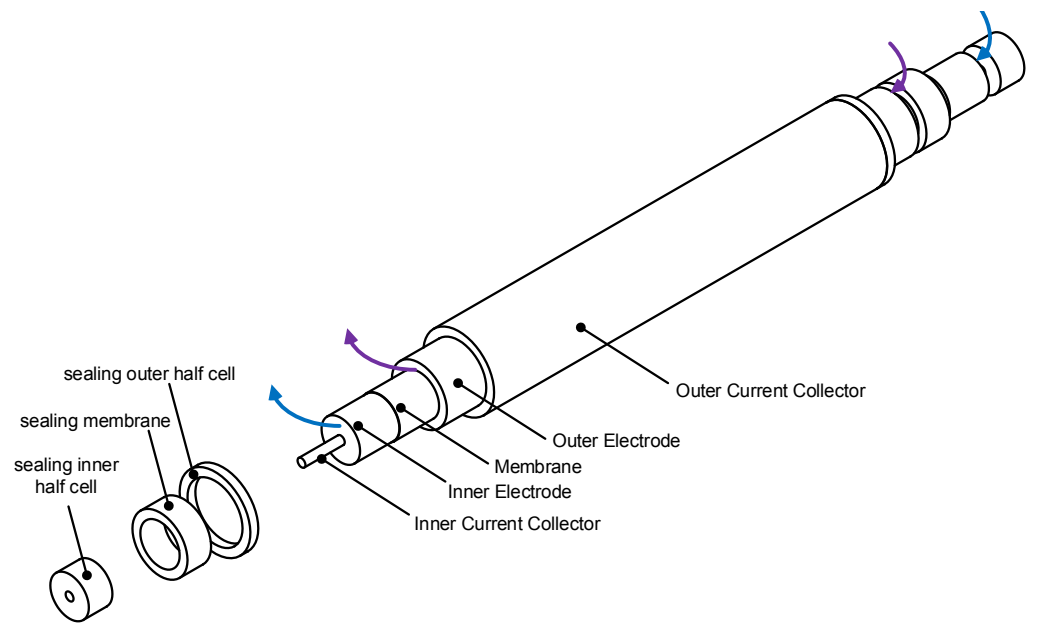

FIGURE 1.7: Tubular cell setup with sealings.

can be realized as half cells or entire cells can be fabricated in a single step. Implementing a co-extrusion based fabrication technology permits continuous industrial cell production.

Due to the circular layout of the cell cross section a higher power density per cell volume is expected for tubular cells, which might lead to a reduction in material costs per $\mathrm{kW}$.

By use of multiple tubular single cells upscaling from single cell level to W...kWsized modules can be realized. Modules or cell bundles could be designed with a parallel connection (electrical) of 2 to 100 cells. In case of a VRFB system serial connection of 40 modules could then be added up to a $48 \mathrm{~V}$ d.c. base line system. Similar power systems consisting of several hundred to one thousand single cells are reported in the field of tubular [37, 63] and micro-tubular Solide Oxide Fuel Cells $[9,74]$ respectively.

A further advantage of the proposed tubular design is the increased flexibility in system design. Cell bundles or modules without internal shunt current losses could be realized by electrically connecting cells in parallel. Accordingly, cell manifold designs do not need to feature shunt current reducing measures and allow lower pressure drops. As cells are connected in parallel, undesired cell overpotentials, which might occur in serially connected cells due to contact resistances or cell and component failure, can be avoided and system resilience is improved. Shunt current losses occurring in serially connected planar stacks $[68,141]$ are expected to occur in serially connected tubular cell bundles or modules as well, but can be mitigated in a 
comparably easy way as preventing measures can be integrated in the external piping environment.

While the use of tubular cell designs is common in the field of Solide Oxide Fuel Cells $[9,37,74]$ and partly in the field of Direct Methanol Fuel Cells [128, 151, 162] and PEM Fuel Cells [40, 48, 49, 91, 92], only recently published work on tubular Redox Flow Batteries of the Schubert group [134, 135] and a patent describing a tubular Redox Flow Cell design [108] is known to the author.

\subsection{Aim of the Thesis}

Within this dissertation a tubular cell design will be developed, which permits fabrication of tubular half cells or entire cells in an extrusion coating process in the future and does, thus, lead to a reduction of production costs.

To demonstrate the feasibility of a tubular cell design for Redox Flow Batteries a tubular Vanadium Redox Flow Battery will first be developed.

By replacing the positive half cell of a $V R F B$ with a bifunctional air electrode a tubular VARFB cell will be developed in a second step, which potentially doubles the specific energy density of $V R F B s$ and leads to a reduction of energy specific costs.

Tubular VRFB and VARFB test cells will be designed, developed and fabricated in order to validate the manufacturability, determine performance limitations and facilitate experimental testing of electrical contacting and sealing mechanisms.

In order to conduct experimental testing of tubular VRFB/VARFB test cells, a test rig will be developed, which enables to operate the batteries under defined conditions and measure relevant process parameters.

By combining experimental results with model-based results detailed knowledge of the multi physical phenomena will be gained and optimization of process parameters will be realized.

Tubular VRFB cell designs will be developed with flow-through and flow-by electrode configurations and their influences and dependences on the manufacturability, achievable performance (current density, power density and efficiency) and operating parameters will be evaluated. 
Special emphasis in the development process of tubular VARFB test cells is placed on the fabrication, characterization and optimization of the membrane electrode assembly $(M E A)$. The bond between the catalyst loaded porous gas diffusion electrode $(G D E)$ and the membrane is of paramount importance for the mass transfer of protons between the membrane and electrochemically active sites in the 3-phase layer. A lab-scale fabrication method for tubular MEAs will be developed, tested and used to characterize tubular MEAs in VARFB test cells.

\subsection{Thesis Outline}

\section{Fundamentals}

The development of tubular All Vanadium and Vanadium/Air Redox Flow Cells requires a detailed knowledge of the fundamental processes, their dependencies and interactions. In order to identify and quantify characteristic performance parameters of $V R F B$ and VARFB cells fundamental processes and quantities are first analyzed. Possible sources of losses are identified and figures of merit are defined and used for a comparison of the developed cells with literature values.

Subsequently, relevant measurement parameters required for the characterization and evaluation of test cells are deduced from the process analysis.

\section{Methods}

The electrochemical characterization methods and techniques required to determine the figures of merit are introduced and specified. Electrochemical methods and techniques used for the experimental characterization of test cells include:

- Charge/discharge cycling

- Open-circuit voltage $(O C V)$ measurements

- Current Interrupt (CI) measurements

- Polarization $\left(E_{\text {cell }} / i\right)$ curve measurements

- Electrochemical Impedance Spectroscopy (EIS)

The evaluation of the measurement data is done by use of two types of models:

1. Equivalent circuit models of test cells are fitted to measured impedance spectra

2. Empirical cell models are fitted to the $E_{\text {cell }} / i$-characteristics 
Fitting parameters of the models allow to quantify ohmic cell resistances, charge transfer resistances, exchange current densities and limiting current densities.

Emphasis is placed on a potential measurement armature, which is designed and developed within the scope of this work for the in situ measurement of Nernst potentials and overpotentials. As this setup differs from commonly used reference electrode configurations, a planar VRFB reference cell is used to validate the developed potential measurement setup with literature values of planar VRFB electrode overpotentials.

\section{Design Principles for Tubular Cell}

At the beginning of the development process requirements are specified and required research and development efforts are outlined. Subsequently, a conceptual cell design study of tubular cells for an extrusion based fabrication is done. Several concepts of tubular VRFB and VARFB cells with different electrode configurations, sealing mechanisms and electrical contacting methods are established.

Design concepts of tubular $V R F B$ cells with a flow-through and a flow-by electrode configuration are further detailed and considered for the fabrication and experimental characterization.

Three concepts of tubular VARFB cell designs with different half cell configurations and GDE substrates are established. Out of these concepts one cell design is further investigated.

\section{Tubular All Vanadium Redox Flow Cells}

To study the performance of the developed tubular VRFB cell designs, test cells are integrated in a specially designed test rig and subjected to the experimental methods specified above.

Measurements of a planar $V R F B$ reference cell are used to compare the results of the tubular $V R F B$ cells. The performance characteristics and sources of losses of the developed designs are evaluated and compared with the figures of merit of state of the art cells.

\section{Tubular Vanadium/Air Redox Flow Cells}

A lab-scale fabrication technique for tubular membrane electrode assemblies ( $M E A s)$ is developed and used to produce tubular $M E A$ s from tubular membranes and gas diffusion electrodes with bifunctional $\mathrm{Pt} / \mathrm{IrO} \mathrm{O}_{2}$ catalysts. Subsequently, the performance of the developed tubular VARFB cells is characterized and limitations are 
identified and analyzed. Results are compared with published results of planar VARFB cells and Vanadium/Oxygen Fuel Cells.

\section{Conclusions and Outlook}

Conclusions on the feasibility of tubular cell designs for All Vanadium and Vanadium/Air Redox Flow Batteries are drawn and an outlook on required future research and development efforts is given. 



\section{Chapter 2}

\section{Fundamentals}

The development of tubular All Vanadium and Vanadium/Air Redox Flow Cells requires a detailed knowledge of the fundamental processes, their dependencies and interactions. In the subsequent section fundamental processes are introduced and figures of merit are defined.

The experimental analysis of the performance characteristic of tubular cells is done with several methods. Specifically developed experimental setups and routines, as well as established electrochemical methods are used to quantify the cells' figures of merit. An overview of the methods used in this work is given in section 2.2.

In the final section of this chapter design principles for tubular cells are specified. A list of requirements for the development of tubular All Vanadium and Vanadium/Air Redox Flow Cells is specified and dependencies of the cell design on the performance are detailed. Required research and development efforts are outlined and tubular $V R F B$ and VARFB cell concepts are introduced.

\subsection{Figures of Merit}

Figures of merit need to be defined in order to characterize the performance of the developed cells and facilitate their comparison with other Redox Flow Cells.

Characteristic quantities of batteries typically include the current, potential, capacity, energy, power and efficiency. The tubular cell's current and power are related to the electrode geometry and cell volume to facilitate a better comparability with planar cell designs.

In the second half of this section loss mechanisms and related overpotentials are introduced and efficiencies are defined to evaluate the performance. 


\subsubsection{Current and Charge}

In figure 2.1 an electrochemical cell with a $d c$ power source and an ampere meter is displayed. The electrochemical cell consists of a positive (anode) and a negative (cathode) electrode, which are immersed in an electrolyte solution. In the electrolyte solution positive charged ions (e.g. $\mathrm{Cu}^{2+}$ ) and negative charged ions (e.g. $\mathrm{Cl}^{-}$) are dissolved.

As an electric current $I$ is applied positive charged ions (cations) move to the cath-

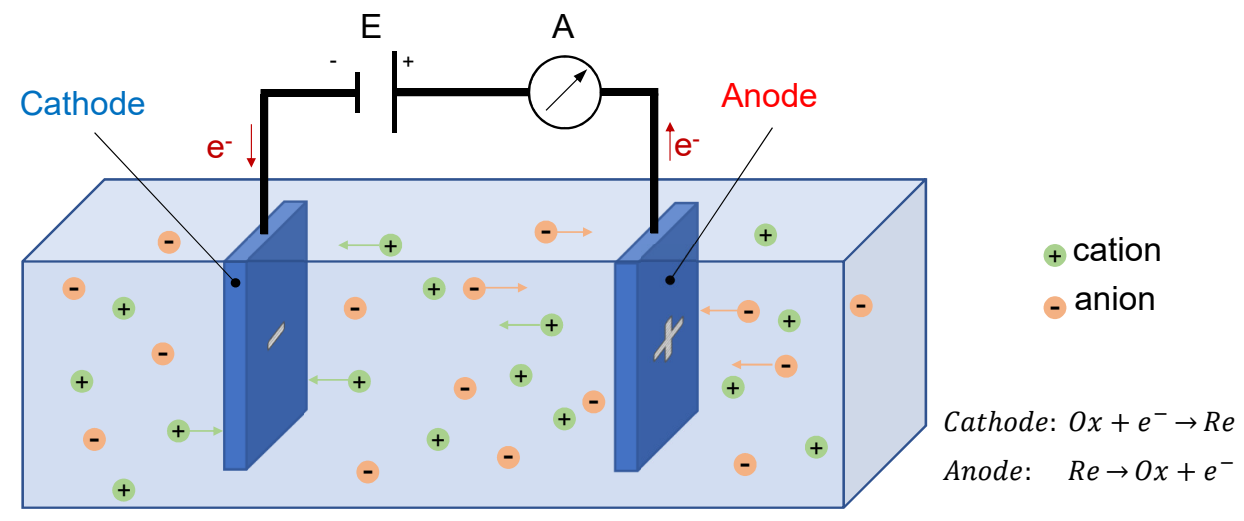

FIGURE 2.1: Schematic of electrochemical cell with connected $d c$ power source (E) and ampere meter (A).

ode, while the negative charged ions (anions) move to the anode. Electrons $\left(e^{-}\right)$are transferred through the conductive external wiring and cathode material (e.g. Pt) where the cations $(O x)$ are reduced in an reduction reaction. At the anode anions (Red) are oxidized and electrons are transferred into the electrode material. cathode:

$$
\begin{gathered}
\vartheta_{O x} \cdot \mathrm{Ox}+z \cdot e^{-} \rightarrow \vartheta_{\text {Red }} \cdot \text { Red } \\
C u^{2+}+2 e^{-} \rightarrow C u^{0}
\end{gathered}
$$

anode:

$$
\begin{gathered}
\vartheta_{\text {Red }} \cdot \operatorname{Red} \rightarrow \vartheta_{O x} \cdot \mathrm{Ox}+z \cdot e^{-} \\
2 \mathrm{Cl}^{-} \rightarrow \mathrm{Cl}_{2}+2 \cdot e^{-}
\end{gathered}
$$




\section{Charge and Capacity}

As the transferred charge of electrons in the external circuit equals the transferred charge of the anion and cation flux, the amount of substance $n$ turnover at the electrodes has to be proportional. This correlation is described by Faraday's Law [120].

$$
\frac{d Q(t)}{d t}=\frac{d n(t)}{d t} \cdot z \cdot F=I(t)
$$

The proportional constant $F$ is the product of the elementary charge $e$ and the Avogadro constant $N_{A}\left(F=e \cdot N_{A}\right)$ and was named after Michael Faraday. By considering the number of transferred electrons per reaction $z$ (valence number in mol) the charge $\Delta Q$ (in C) required to turnover the amount of a substance $A\left(\Delta n_{A}\right)$ in an electrochemical cell can be estimated with equation 2.3:

$$
\Delta Q=z \cdot F \cdot \Delta n_{A}
$$

In All Vanadium Redox Flow Batteries the reactive substance $\left(V^{2+/ 3+}\right.$ and $\left.V^{4+/ 5+}\right)$ is dissolved in the electrolyte solutions and is quantified as amount of substance of solute $n$ per unit volume of solution $V$ (or molar concentration $c$ ):

$$
c=\frac{n}{V}
$$

The total amount of transferable charge, which is present in the electrolyte volume $V_{\text {elyt }}$ of the battery, is denoted as the battery's maximum capacity $Q_{\max }$ and can be calculated with equation 2.4 and 2.5:

$$
Q_{\max }=c_{V, t o t} \cdot V_{\text {elyt }} \cdot z \cdot F
$$

Note that the capacity of $R F B s$ is solely dependent on the electrolyte volume, molar concentration of the active species $\left(c_{V, \text { tot }}\right)$ and the transferred number of electrons per reaction turnover $(z)$ and can be rated independently from the power.

However, the actual capacity $Q_{a c t}$ of a VRFB or VARFB differs from $Q_{\max }$ as not the entire electrolyte capacity is utilized and parasitic side reactions, electrolyte oxidation (self-discharge) with ambient air, as well as vanadium cross-over through the membrane might occur during operation.

The portion of the maximum capacity, which is actually utilized within a charge or discharge sequence can be related to the maximum capacity and is then denoted as electrolyte utilization $\left(U_{\text {elyt }}\right)$ :

$$
U_{\text {elyt }}=\frac{\Delta Q_{c h, d c h}}{Q_{\max }}
$$




\section{Current and Current Density}

Within this thesis a sign convention analog to fuel cells is used for the electrical current flux between the electrodes of a cell $I_{\text {cell }}$. Accordingly, $I_{\text {cell }}$ is negative during charging and positive during discharging:

charging: $I_{\text {cell }}<0$

discharging: $I_{\text {cell }}>0$

In order to evaluate and compare cells, the current $I_{\text {cell }}$ is related to the electrode surface and denoted as current density $i_{\text {cell }}$. In the field of fuel cells the projected electrode area $A_{\text {proj }}$ (fig. 2.2) is commonly used as electrodes typically feature a thin electrode layer thickness. Although thicker three-dimensional porous electrodes are employed in RFBs, current densities are related to $A_{\text {proj}}$. In planar cell designs the projected electrode area equals the active membrane surface area $A_{\text {mem }}$. The current density $i_{\text {cell }}$ of tubular and planar RFB cells is, thus, related to $A_{\text {mem }}$.

$$
i_{\text {cell }}=\frac{I_{\text {cell }}}{A_{\text {mem }}}
$$

However, actual electrode surface area $\left(A_{\text {elec }}\right)$ related current densities $(j)$ are required to evaluate cell designs with different electrode material thicknesses $(t$ in fig. 2.2) and to quantify the reaction kinetics of electrode materials.

$$
j=\frac{I}{A_{\text {elec }}}
$$

\section{Electrode Surface Area}

In figure 2.2 a schematic and Scanning electron microscopy (SEM) images of a typical porous electrode material for RFB applications are displayed. The porous electrodes are made from non-woven graphite fibers with uniform fiber diameters $\left(d_{f}\right)$. In case of fibrous electrode material or other 3-dimensional electrode structures the electrode surface area is often related to the electrode volume $\left(V_{\text {elec }}=h \cdot t \cdot w\right)$ and a volume specific surface area $a_{\text {elec }}=A_{\text {elec }} / V_{\text {elec }}$ is used. By assuming a smooth fiber surface morphology and a single fiber composition of the porous electrode material, the fiber volume $\left(V_{f}\right)$ specific surface area $\left(a_{f}\right)$ can be approximated by:

$$
a_{f}=\frac{A_{f}}{V_{f}}=\frac{d_{f} \cdot \pi \cdot l_{f}}{\frac{\pi}{4} d_{f}^{2} \cdot l_{f}}=\frac{4}{d_{f}}
$$

The porosity $\epsilon_{\text {elec }}$ of porous electrode material is defined by the volume or density quantities of the porous bulk material $\left(V_{\text {elec }}, \rho_{\text {elec }}\right)$, void pore-space $\left(V_{v}, \rho_{v}\right)$ and solid 


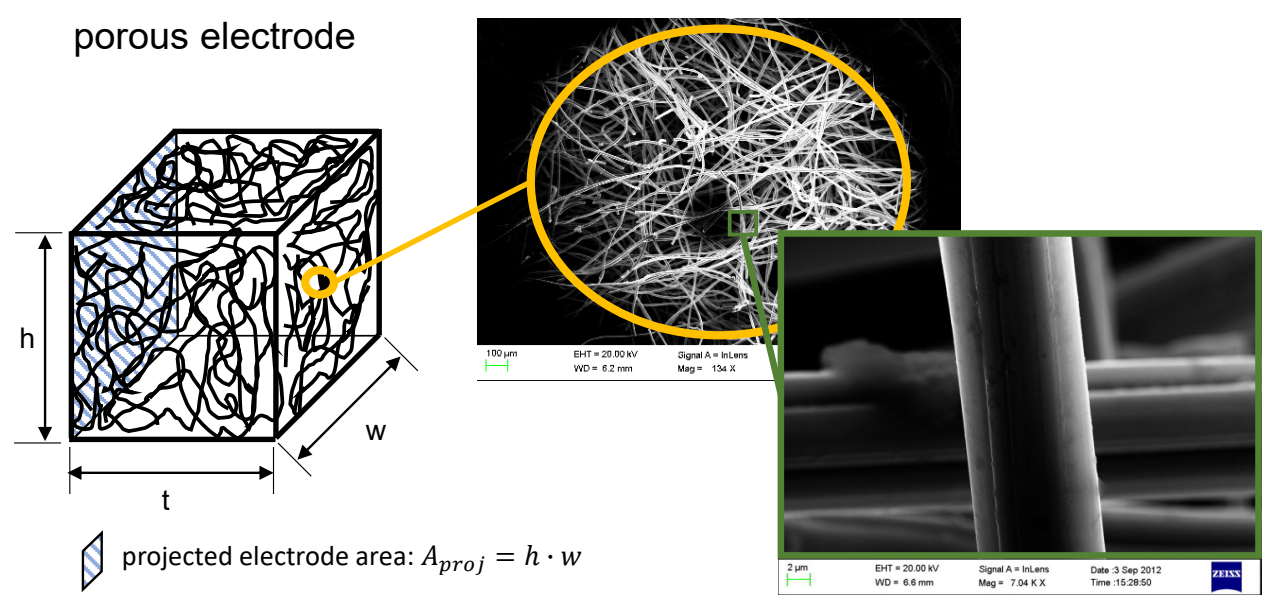

FIGURE 2.2: Schematic of porous electrode and SEM images of fibrous electrode material.

portion of the material $\left(V_{f}, \rho_{f}\right)$ :

$$
\epsilon_{\text {elec }}=\frac{V_{v}}{V_{\text {elec }}}=\frac{V_{v}}{V_{f}+V_{v}}=\frac{\rho_{f}-\rho_{\text {elec }}}{\rho_{f}-\rho_{v}}
$$

In case of the void pore-space being filled with air, equation 2.9 further simplifies to:

$$
\epsilon_{\text {elec }}=1-\frac{\rho_{\text {elec }}}{\rho_{f}}
$$

Combination of equation 2.8 and 2.9 now allows to estimate the geometric electrode surface area [23].

$$
A_{\text {elec }} \approx A_{f}=\frac{4 \cdot V_{\text {elec }}}{d_{f}}(1-\epsilon\}
$$

The actual surface area of porous electrodes will, however be higher than the estimated $A_{\text {elec }}$ as the surface morpohology might differ significantly from the assumed perfectly smooth fiber surface morphology (see table 3.3). To account for the surface morphology caused increase of the surface area, $B E T$-surface area measurements can be employed to estimate the volume specific surface area $a_{B E T}$. 


\subsubsection{Cell Potential}

Up to this point the electrode potentials were neglected and the current flux was simply attributed to a $d c$ power source. However, an electromotive force actually drives the current flux. It arises in an electrochemical cell (fig. 2.1) as a result of the charge separation and the chemical potential difference between the electrodes.

In the first part of this section electrode potentials are examined without any net current flux and cell potentials are introduced at open-circuit conditions.

In the second part the current dependent cell potential is introduced and current dependent loss mechanisms are detailed.

\section{Standard cell potential}

The standard electrode potential $\left(E^{00}\right)$ of a reversible redox, metal/metal ion or gas electrode specifies the electrode's potential at standard conditions $\left(c=1 \mathrm{moll}^{-1}\right.$, $p=101.3 \mathrm{kPa}, T=298.15 \mathrm{~K}$ ). The standard potential of an electrode can not be measured directly but can be calculated from the electrode reaction's maximum obtainable work [53], which is denoted as Gibbs free energy $\left(\Delta G^{0}\right)$ [46]:

$$
E^{00}=-\frac{\Delta G^{0}}{z \cdot F}
$$

As the standard potentials can not be measured individually, potential values are listed relative to the standard hydrogen electrode (SHE) potential, which is defined to be $0.00 \mathrm{~V}$. In figure 2.3 several $E^{00}$ values of the electrochemical potential series are given.

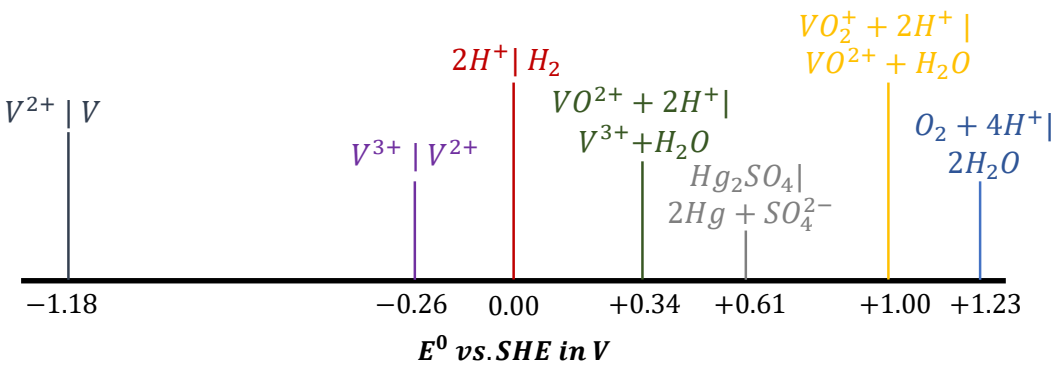

FIGURE 2.3: List of selected standard electrode potentials vs. the standard hydrogen electrode SHE. 
The standard potential of a cell $\left(E_{\text {cell }}^{00}\right)$ can now be obtained by calculation of the potential difference of the positive and negative standard electrode potentials $\left(E_{\text {pos }}^{00}\right.$ and $\left.E_{n e g}^{00}\right)$.

$$
E_{\text {cell }}^{00}=E_{\text {pos }}^{00}-E_{\text {neg }}^{00}
$$

As the concentration, pressure and temperature of a redox electrode diverges from standard conditions a shift of the electrode potential is observed. The Nernst equation describes the concentration dependent variation of the electrode potential (Nernst Potential) at equilibrium.

$$
E_{n e g, p o s}^{0}=E_{n e g, p o s}^{00}+\frac{R T}{z F} \ln \frac{a_{O x}^{\vartheta_{O x}}}{a_{\text {Red }}^{\vartheta_{R e d}}}
$$

The activities of the respective species in oxidized and reduced state $\left(a_{O x}\right.$ and $\left.a_{R e d}\right)$ describe the actual reactivity of the substance $(O x, R e d)$ in an electrolyte. $O x$ and Red ions are surrounded by other ions, which are present in the electrolyte and, thereby reduce the reactivity. Activation coefficients $\left(f_{i} \leq 1\right)$ are employed to account for this ionic strength dependent reactivity decrease [46].

$$
a_{i}=f_{i} \cdot c_{i}
$$

Activities are no measurable quantities and their application for the estimation of the Nernst potential is hardly feasible. However, for diluted solutions the ionic strength is low and activation coefficients are often defined to be 1 [120]. Another commonly used approach implies the assumption of constant activity constants. The activity dependent potential variation can then be included in the standard electrode potential $\left(E_{\text {neg,pos }}^{00}\right)$, which is then referred to as formal standard electrode potential $\left(E_{n e g, p o s}^{00^{\prime}}\right)[53]$. The Nernst potential can now be estimated with concentration values.

$$
E_{\text {neg, pos }}^{0}=E_{\text {neg, pos }}^{00^{\prime}}+\frac{R T}{z F} \ln \frac{c_{O x}^{\vartheta_{O x}}}{c_{\text {Red }}^{\vartheta_{\text {Red }}}}
$$

The Nernst potential of a cell is calculated with the Nernst potentials of the positive and negative electrode and is commonly denoted as open-circuit voltage $(O C V)$ :

$$
O C V=E_{c e l l}^{00^{\prime}}+\frac{R T}{z F} \ln \frac{\Pi c_{O x}^{\vartheta_{O x}}}{\Pi c_{R e d}^{\theta_{R e d}}}
$$

By exchanging the concentration values with the partial pressure equation 2.17 can also be used to estimate the Nernst potential of gas electrodes. 
The positive and negative electrodes of Redox Flow Battery cells are separated by a membrane, which introduces another potential to the OCV. It is known as Donnan Potential and can be included in equation 2.17. Applied to All Vanadium Redox Flow Batteries the OCV is then obtained by [67]):

$$
O C V=E_{\text {cell }}^{00^{\prime}}+\frac{R T}{n F} \ln \left(\frac{c_{V_{2}^{+}} \cdot c_{V^{2+}} \cdot\left(c_{H^{+}}^{+}\right)^{2} \cdot c_{H^{+}}^{+}}{c_{V O^{2+}} \cdot c_{V^{3+}} \cdot c_{H^{+}}^{-}}\right)
$$

Positive and negative superscripts are used in equation 2.18 to denote the positive and negative half cell. In figure 2.4 the calculated (with eq. 2.18) OCV of a VRFB cell with a total vanadium concentration of $1.6 \mathrm{moll}^{-1}$ and $2 \mathrm{M} \mathrm{H}_{2} \mathrm{SO}_{4}$ (used in this work $)$ is displayed. For equal vanadium ion concentrations $\left(x=0.8 \mathrm{moll}^{-1}=c_{v 2+}=\right.$ $\left.c_{v 3+}=c_{v 4+}=c_{v 5+}\right)$ an $O C V$ of $1.38 \mathrm{~V}$ is estimated.

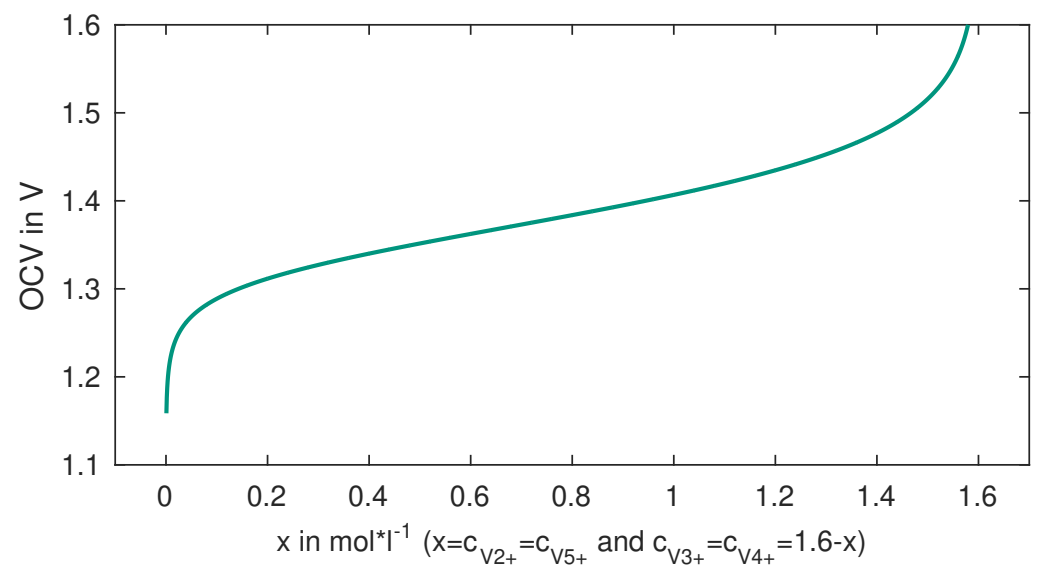

FIGURE 2.4: Estimated (equation 2.18) open-circuit voltage (OCV) of a $V R F B$ cell with a total vanadium concentration of $c_{V}=1.6 \mathrm{moll}^{-1}$ and electrolyte composition as used in this work.

\section{Current dependent cell voltage}

Up to this point, electrode potentials are only considered without any net current flux. As an electric current flows through the electrodes, the cell and its external wiring, additional potentials arise, which are also referred to as overpotentials $\left(\eta_{i}(i)\right)$. As a cell is charged the current dependent cell potential $E_{\text {cell }}(i)$ increases from the open-circuit voltage by the overpotentials, while during discharging a reduction of 
the $O C V$ by $\eta_{i}(i)$ can be observed.

$$
E_{\text {cell }}(i)=O C V \pm\left|\eta_{i}(i)\right|
$$

Overpotentials are composed of ohmic overpotentials $\left(\eta_{\text {ohm }}(i)\right)$, activation overpotentials $\left(\eta_{\text {act }}(i)\right)$ and mass transfer or concentration overpotentials $\left(\eta_{\text {conc }}(i)\right)$. Ohmic overpotentials originate from the electron conduction through the electrode material, external wiring and contact interfaces, as well as the conduction of ions in the liquid and solid (membrane) electrolyte.

Activation overpotentials $\left(\eta_{\text {act }}(i)\right)$ arise at the electrode-electrolyte interface due to the charge transfer of electrons.

The buildup of concentration profiles across the bulk electrolyte at the electrode interface can be caused by insufficient mass transfer of reactive species to the electrode surface (or from the electrode surface) and induce further overpotentials $\left(\eta_{\text {conc }}(i)\right)$.

$$
E_{\text {cell }}(i)=O C V \pm\left(\left|\eta_{\text {ohm }}(i)\right|+\left|\eta_{\text {act }}(i)\right|+\left|\eta_{\text {conc }}(i)\right|\right)
$$

\section{Ohmic overpotential}

As current flows through the electron conducting materials and ion conducting electrolytes of a cell, an electric resistance opposes the flow of charge and leads to an overpotential. Ohm's Law can be applied to describe the proportional variation of the ohmic overpotential $\left(\eta_{\text {ohm }}(i)\right)$ with the current $\left(I_{\text {cell }}\right)$.

$$
\eta_{\text {ohm }}(i)=I_{\text {cell }} \cdot R_{\text {cell }}=i_{\text {cell }} \cdot R_{\text {cell }} \cdot A_{\text {mem }}=i_{\text {cell }} \cdot A S R
$$

The electric cell resistance ( $R_{\text {cell }}$ or area specific cell resistance $\left.A S R\right)$ is the proportional factor, which is specific to the material properties, component geometry and cell design. The resistance of a conductor is defined by the cross-sectional area of the conductor $\left(A_{\perp}\right)$ perpendicular to the charge flow, it's length $(l)$ and the intrinsic electrical resistivity $\left(\rho_{\text {res }}\right)$ of the conductor.

$$
R=\rho_{\text {res }} \cdot \frac{l}{A_{\perp}}
$$

The electric conductivity of a conductor $(\sigma)$ might also be used to quantify the conductors ability to transfer electric charge. As $\sigma$ is the reciprocal of the resistivity $\left(\rho_{\text {res }}=1 / \sigma\right)$, the resistance of a conductor can also be expressed as:

$$
R=\frac{1}{\sigma} \cdot \frac{l}{A_{\perp}}
$$


The electric resistance of a cell is composed of the sum of the resistances of the electrically conductive components (membrane, electrolytes, electrodes, current collectors, bipolar plates) and the contact resistances in-between two conductive components (e.g. electrode/current collector).

$$
R_{\text {cell }}=R_{\text {mem }}+R_{\text {elyt }}+R_{\text {elec }}+R_{C C}+R_{\text {contact }}
$$

\section{Activation overpotential}

In a Redox Flow Cell redox reactions of the active species take place in the electrolyte double-layer at the electrode-electrolyte interface. If a fast mass transfer of the reactant from the bulk electrolyte to the double-layer (and transfer of product from the double-layer to the bulk electrolyte) is assumed, the speed of the reaction only depends on the reaction kinetics. The rate at which the reactions proceed are defined by the reaction rate $(r)$, which is proportional to the concentration of the reactant (educt).

$$
r=k \cdot c_{\text {educt }}^{\vartheta}
$$

The rate constant $(k)$ quantifies the reaction kinetic of the reactive substance at a specific electrode material for a given temperature. By use of Faraday's Law (eq. 2.3) the transferred amount of substance can be related to the equivalent current.

$$
j_{o x}=z \cdot F \cdot k_{o x} \cdot c_{r e d}^{\vartheta}
$$

For the introduction of the activation overpotential a single oxidation reaction (eq: 2.2) at equilibrium conditions is considered. The reaction occurs in both directions (oxidation and reduction) simultaneously and the current density for reduction reactions is defined to be negative $\left(j_{\text {red }}<0\right)$. The current density for the reduction reaction then reads:

$$
j_{\text {red }}=-z \cdot F \cdot k_{\text {red }} \cdot c_{o x}^{\vartheta}
$$

For a mono-valent reaction the total exchange current density at the electrode is obtained by

$$
j=j_{o x}+j_{r e d}=z \cdot F \cdot k_{o x} \cdot c_{r e d}-z \cdot F \cdot k_{r e d} \cdot c_{o x}
$$

At standard potential no net current flow exists (see fig. 2.5) and the total current density is:

$$
j_{0}=j_{o x}+j_{\text {red }}=0
$$

As the potential at the electrode deviates from it's standard potential, current densities $\left(j_{o x}\right.$ and $\left.j_{r e d}\right)$ are found to change with the potential. Accordingly, reaction rate constants need to be a function of the electrode potential and equation 2.26 and 2.27 


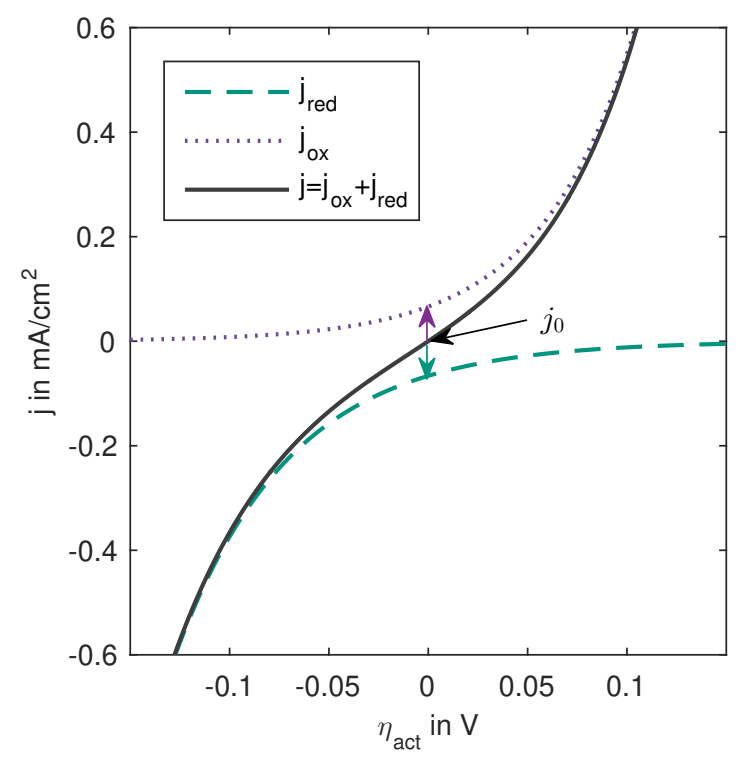

FIGURE 2.5: Plot of transfer-current-potential relationship j( $\left.\eta_{a c t}\right)$ (equation 2.36 with $\alpha=0.55$ ) and reduction and oxidation current densities $\left(j_{\text {red }}\right.$ and $\left.j_{o x}\right)$.

can be modified to:

$$
\begin{gathered}
j_{o x}=z \cdot F \cdot k_{o x}^{0} \cdot c_{r e d} \cdot e^{\frac{\alpha \cdot z \cdot F}{R \cdot T} E} \\
j_{\text {red }}=-z \cdot F \cdot k_{r e d}^{0} \cdot c_{o x} \cdot e^{\frac{(1-\alpha) \cdot z \cdot F}{R \cdot T} E}
\end{gathered}
$$

The charge transfer coefficient $\alpha$ describes the change of the activation energy with the free enthalpy of reaction and has to be between 1 and $0(0<\alpha<1)$ for monovalent reactions. The symmetry factor of the reduction reaction can, thus be defined to be $1-\alpha$.

The activation overpotential $\left(\eta_{a c t}\right)$ corresponds to the change of the electrode potential from its potential at standard potential conditions.

$$
\eta_{a c t}(j)=E(j)-E^{00}
$$

For oxidation reactions $j_{o x}$ exceeds $j_{\text {red }}$ and the current density $(j)$ becomes positive (eq. 2.28, fig. 2.5), while a negative exchange current density is obtained for reduction reactions. By application of equation 2.32 exchange current densities for the 
oxidation and reduction $\left(j_{o x}\right.$ and $\left.j_{r e d}\right)$ can be separated in a standard potential part and an overpotential part:

$$
\begin{gathered}
j_{o x}=z \cdot F \cdot k_{o x}^{0} \cdot c_{r e d} \cdot\left(e^{\frac{\alpha \cdot z \cdot F}{R \cdot T} E^{00}}+e^{\frac{\alpha \cdot z \cdot F}{R \cdot T} \eta_{a c t}(j)}\right) \\
j_{r e d}=-z \cdot F \cdot k_{r e d}^{0} \cdot c_{o x} \cdot\left(e^{-\frac{(1-\alpha) \cdot z \cdot F}{R \cdot T} E^{00}}-e^{-\frac{(1-\alpha) \cdot z \cdot F}{R \cdot T} \eta_{a c t}(j)}\right)
\end{gathered}
$$

Under standard conditions equation 2.29 applies and the exchange current density $\left(j_{0}\right)$ can be calculated from eq. 2.33 and $2.34\left(\eta_{a c t}(j)=0\right)$ :

$$
j_{0}=z \cdot F \cdot k_{o x}^{0} \cdot c_{r e d} \cdot e^{\frac{\alpha \cdot z \cdot F}{R \cdot T} E^{00}}=-z \cdot F \cdot k_{r e d}^{0} \cdot c_{o x} \cdot\left(e^{-\frac{(1-\alpha) \cdot z \cdot F}{R \cdot T} E^{00}}\right)
$$

The transfer-current-potential relationship at an electrode can now be estimated by superposition of the oxidation and reduction current densities (eq. 2.33 and 2.34) and can be expressed with the standard exchange current density (eq. 2.35) (ButlerVolmer Equation):

$$
j=j_{0} \cdot\left[e^{\left(\frac{\alpha \cdot z \cdot F}{R \cdot T} \cdot \eta_{a c t}(j)\right)}-e^{\left(-\frac{(1-\alpha) \cdot z \cdot F}{R \cdot T} \cdot \eta_{a c t}(j)\right)}\right]
$$

In figure 2.5 the Butler-Volmer-Equation for an electrode is displayed and the overpotential dependent reduction and oxidation current densities are shown.

The overall activation overpotential of a cell can be calculated by applying eq. 2.36 to both electrodes and adding their respective $\eta_{\text {act }}$ according to eq. 2.13.

\section{Concentration overpotential}

For the derivation of the activation overpotential a fast mass transfer of the reactant from the bulk electrolyte to the double-layer (and transfer of the product from the double-layer into the bulk electrolyte) was assumed. Accordingly, the concentration of the reactant and product at the electrode surface $\left(c_{r e d, s}\right.$ and $\left.c_{o x, s}\right)$ is equal to the respective concentrations in the bulk electrolyte $\left(c_{r e d, e}\right.$ and $\left.c_{o x, e}\right)$ :

$$
\begin{gathered}
c_{o x}=c_{o x, e}=c_{o x, s} \\
c_{r e d}=c_{r e d, e}=c_{r e d, s}
\end{gathered}
$$

As the reactions proceed at the double-layer reactants are consumed and products are produced and need to be transferred from/to the bulk electrolyte. This mass transfer might occur by diffusion, migration and convective processes and is therefore limited. As a result a layer with a concentration gradient forms in front of the 
double-layer $\left(c_{o x, e} \neq c_{o x, s}\right.$ and $\left.c_{r e d, e} \neq c_{r e d, s}\right)$ and a concentration overpotential ( $\left.\eta_{c o n c}\right)$ has to be added to the activation overpotential:

$$
\eta_{\text {res }}=\eta_{a c t}+\eta_{c o n c}
$$

As the formation of a substantial concentration gradient layer typically involves high current densities $\left(j\left(\eta_{a c t}\right)\right)$, the share of the reverse reaction's current density is much lower than the current density of the actual reaction (fig. 2.5).

Oxidation: $j_{o x}>>\left|j_{\text {red }}\right| \Longrightarrow j\left(\eta_{\text {act }}\right) \approx j_{o x}$

Reduction: $\left|j_{\text {red }}\right|>>j_{o x} \Longrightarrow j\left(\eta_{\text {act }}\right) \approx j_{\text {red }}$

For an anodic reaction (oxidation) the current density can then be cacluclated with the concentration at the electrode surface $\left(c_{r e d, s}\right)$ and equation 2.33 .

$$
j_{o x} \approx j(\eta)=z \cdot F \cdot k_{o x}^{0} \cdot c_{r e d, s} \cdot\left(e^{\frac{\alpha \cdot z \cdot F}{R \cdot T} E^{00}}+e^{\frac{\alpha \cdot z \cdot F}{R \cdot T} \eta(j)}\right)
$$

Application of the exchange current density $\left(j_{0}\right)$ (eq. 2.35) to equation 2.40 with $c_{r e d}=$ $c_{\text {red }, e}$ then yields [46]:

$$
j(\eta)=j_{0} \cdot \frac{c_{r e d, s}}{c_{r e d, e}} \cdot e^{\left(\frac{\alpha \cdot z \cdot F}{R \cdot T} \cdot \eta\right)}
$$

Solving equation 2.41 for $\eta$ results in:

$$
\eta=\frac{R \cdot T}{\alpha \cdot z \cdot F} \cdot\left(\ln \left(\frac{j(\eta)}{j_{0}}\right)+\ln \left(\frac{c_{r e d, e}}{c_{r e d, s}}\right)\right)
$$

By comparing equation 2.42 with the activation overpotential of an anodic reaction (eq. 2.33)

$$
\eta_{a c t}=\frac{R \cdot T}{\alpha \cdot z \cdot F} \cdot \ln \left(\frac{j}{j_{0}}\right)
$$

the concentration overpotential becomes apparent:

$$
\eta_{\text {conc }}=\frac{R \cdot T}{\alpha \cdot z \cdot F} \cdot \ln \left(\frac{c_{r e d, e}}{c_{r e d, s}}\right)
$$

For the cathodic reaction the concentration overpotential then reads.

$$
\eta_{\text {conc }}=\frac{R \cdot T}{(1-\alpha) \cdot z \cdot F} \cdot \ln \left(\frac{c_{o x, e}}{c_{o x, s}}\right)
$$




\subsubsection{Power and Energy}

The power output and input, as well as the amount of energy, which can be stored in a battery are key parameters of a battery and determine it's suitability for a specific energy storage application. In mobile applications (e.g. electric vehicles and portable devices) a high power output and amount of energy needs to be provided by a small and light-weight storage device, while a significantly bigger and heavier storage device can still fulfill the requirements of stationary storage applications. In the subsequent section the amount of energy, which can be stored in a RFB is specified and volume and weight related quantities are defined.

\section{Energy}

To determine the theoretical amount of energy $\left(E_{\text {theo }}\right)$, which can be stored in a Redox Flow Battery, the maximum capacity (equation 2.6) is multiplied with the open-circuit cell voltage (eq. 2.17) at $c_{O x}=c_{\text {Red }}$

$$
E_{\text {theo }}=Q_{\text {max }} \cdot \mathrm{OCV}
$$

As already mentioned in section 2.1.1 the actual capacity will be below $Q_{\max }$ and lead to a reduced amount of energy. In addition, the cell potential will be reduced by the overpotentials during discharging. The actual amount of energy $\left(E_{a c t}\right)$ incorporates these losses and is obtained by:

$$
E_{\text {act }}=\Delta Q \cdot E_{\text {cell }}(i)
$$

The transferred charge $(\Delta Q)$ and cell potential do, however strongly depend on the operating parameters. In order to compare the actual amount of energy operating parameters need to be standardized as it is done for conventional batteries or Lithium-Ion batteries [46].

To evaluate energy storage systems, the energy density $\left(e_{v o l}\right)$ is calculated by relating the amount of energy to the volume of the active species (electrolyte $V_{\text {elyt }}$ ) or container $\left(\operatorname{tank} V_{\text {tank }}\right)$.

$$
e_{v o l}=\frac{E_{\text {theo }}}{V_{\text {elyt }}}, e_{\text {vol,a }}=\frac{E_{a c t}}{V_{\text {tank }}}
$$

The specific energy $\left(e_{m}\right)$ is obtained by relating the amount of energy to the mass $(M)$ of the active species or container.

$$
e_{m}=\frac{E_{\text {theo }}}{M_{\text {elyt }}}, e_{m, a}=\frac{E_{a c t}}{M_{\text {tank }}}
$$




\section{Cell Power}

The cell power $P_{\text {cell }}$ is the product of the cell current density $I_{\text {cell }}$ and the cell potential.

$$
P_{\text {cell }}(I)=I_{\text {cell }} \cdot E_{\text {cell }}(I)
$$

In the field of fuel cells, the cell power is often referred to the projected electrode area or membrane area $p_{A}(i)=P_{\text {cell }}(I) / A_{\text {mem }}$. For the comparison of different energy storage and conversion technologies, the power is related to the volume of the conversion unit. In this work the cell power is related to the cell volume and denoted as volumetric power density $p_{\text {vol }}(I)=P_{\text {cell }}(I) / V_{\text {cell }}$.

\section{Pumping Power}

In chapter 1 the system design of VRFBS and VARFBS are introduced. Pumps are employed to circulate the electrolyte solutions from the tank through the cell. Accordingly, the actual output/input power of a RFB storage system $\left(P_{s y s}\right)$ will be reduced/increased by the pumping power $P_{\text {pump }}$ :

$$
P_{\text {pump }}=\Delta p \cdot \dot{Q}
$$

The pressure drop $(\Delta p)$ arises as the electrolyte solution passes through the cell and is dependent on the electrolyte properties, as well as the electrode and cell design. A detailed description of the half cell specific pressure drop estimation is given in section 2.3.3. The volumetric flow rate of the electrolyte $(\dot{Q})$ has to be low in order to reduce the pumping power but needs to be sufficiently high for minimized mass transfer related overpotentials.

\subsubsection{State of Charge}

The state of charge $\left(S_{O} C\right)$ of a battery is defined by the transferred charge $(\Delta Q)$ divided by the battery's maximum capacity $\left(Q_{\max }\right.$, eq. 2.6$)$.

$$
S o C=\frac{\Delta Q}{Q_{\max }}=\frac{\int_{t 0}^{t 1}-I(t) d t}{Q_{\max }}
$$

In fully charged state a battery's SoC is 1 (or $100 \%$ ), while a state of charge of 0 $(0 \%)$ equals a fully discharged state. The estimation of the SoC can be done by an integration of the current in time, which is often denoted as Coulomb Counting. For the SoC determination by Coulomb Counting the entire charge/discharge history has 
to be recorded or the initial state of charge $\left(S_{o} C_{0}\right)$ of the battery has to be known.

$$
\operatorname{SoC}(\Delta Q)=\frac{\Delta Q}{Q_{\max }}+S_{0} C_{0}=m \cdot \Delta Q+S_{0} C_{0}, m=\frac{1}{Q_{\max }}
$$

The determination of the state of charge by Coulomb Counting does, however, lead to a long-term drift and does not account for parasitic side reactions.

In section 2.1.2 the concentration dependent open-circuit voltage $(O C V)$ of a $R F B$ cell was introduced. As the concentrations of the active species changes proportionally with the $S o C$, the open-circuit voltage can be employed to estimate the state of charge. Concentrations of the VRFB electrolytes can be related to the SoC [19].

$$
\begin{gathered}
c_{V O_{2}^{+}}=c_{V^{2}+}=c_{V, t o t} \cdot S o C \\
c_{V O^{2+}}=c_{V^{3}+}=c_{V, t o t} \cdot(1-S o C)
\end{gathered}
$$

In order to determine the $S o C$ based on the $O C V$ under current flow conditions (charging/discharging) an additional OCV cell needs to be implemented in the battery's electrolyte cycles [142].

Another method to determine the $S o C$ by in situ measurements of the Nernst potential in the negative half cell $\left(E_{\text {neg, }}^{0}\right.$ eq. 2.16) in combination with Coulomb Counting $(\operatorname{SoC}(\Delta Q)$, eq. 2.53) was published by the author and other working group members [115].

The method involves a one-step calibration of the parameters $E_{\text {neg }}^{0^{\prime}}, m=1 / Q_{\max }$ and $S_{o} C_{0}$ by fitting of the equation:

$$
E_{n e g}^{0}(\Delta Q)=E_{n e g}^{0^{\prime}}+\frac{R T_{n e g}}{F} \ln \left(\frac{1-m \cdot \Delta Q-S O C_{0}}{m \cdot \Delta Q+S O C_{0}}\right)
$$

to the measured Nernst potential $E_{n e g}^{0}(\Delta Q)$. The fitting parameter $E_{\text {neg }}^{0^{\prime}}$ can then be employed to determine the state of charge $\operatorname{SoC}\left(E_{n e g}^{0}\right)$ from in situ Nernst potential measurements of the negative half cell.

$$
\operatorname{SOC}\left(E_{n e g}^{0}\right)=\left(1+e^{\frac{\left(E_{n e g}^{0}-E_{n e g}^{0^{\prime}}\right) F}{R T_{n e g}}}\right)^{-1}
$$

The variation of the electrolyte composition with the state of charge does not only 
induce potential shifts, but also causes other electrolyte properties, such as the viscosity, $\mathrm{pH}$ value, density, conductivity and absorbance to change. Works of the author and co-workers have demonstrated the variation of the electrolyte density and $\mathrm{pH}$ value with the state of charge [109, 115, 136, 156]. Further publications report on a $S o C$ determination with the electrolyte conductivity [31, 132], viscosity [77] and absorbance $[132,142,168]$.

\subsubsection{Efficiencies}

Efficiencies of Redox Flow Batteries are calculated from the cell current and potential during charge/discharge cycles. One cycle consists of a charging step with a subsequent discharging step. Each step can be performed in a constant current (galvanostatic), constant potential (potentiostatic) or constant power mode. In storage applications a combination of the different operation modes might be employed to match power input and output demands.

In this work charge/discharge cycles are performed in galvanostatic mode and different efficiencies are calculated from the cell current and cell potential values during charge and discharge periods $\left(\Delta t_{c h}\right.$ and $\left.\Delta t_{d c h}\right)$, respectively.

\section{Coulombic Efficiency}

The Coulombic Efficiency $(C E)$ relates the transferred charge during discharging $\left(\Delta Q_{d c h}\right)$ to the transferred charge during charging $\left(\Delta Q_{c h}\right)$.

$$
C E=\frac{\Delta Q_{d c h}}{\left|\Delta Q_{c h}\right|}=\frac{\int_{t_{0}}^{t_{d c h}} I_{\text {cell }}(t) d t}{\left|\int_{t_{0}}^{t_{c h}} I_{\text {cell }}(t) d t\right|}
$$

Since charge and discharge steps are done in galvanostatic mode, the current is held constant during charging and discharging and the Coulombic Efficiency can be calculated by:

$$
C E=\frac{\Delta Q_{d c h}}{\left|\Delta Q_{c h}\right|}=\frac{I_{c e l l, d c h} \cdot \Delta t_{d c h}}{\left|I_{c e l l, c h}\right| \cdot \Delta t_{c h}}
$$

The Coulombic Efficiency is an indicator for parasitic side reactions (e.g. hydrogen or oxygen gas formation), self discharge due to an oxidation of active species with ambient oxygen, capacity losses due to leaks in the half cell cycles and enables to evaluate the membrane performance. Ideal membranes should feature a high selectivity to prevent active substance ions from passing through the membrane into the adjacent half cell. In reality, cross-over of vanadium ions, water and sulfate ions through the membrane might occur and result in capacity losses and diminished $C E$ 
values.

It has to be noted that the charge/discharge potential limits and current values of the charge/discharge cycling directly influence the estimated Coulombic Efficiency. While high cell potential cut-off limits might lead to gas evolution at the electrodes, high constant current values lead to reduced charging and discharging periods and result in a diminished cross-over of vanadium ions through the membrane (diffusive cross-over process is time dependent).

\section{Voltage Efficiency}

The Voltage Efficiency $(V E)$ is obtained by relating the cell potential during discharging to the cell potential during charging.

$$
V E=\frac{\int_{t_{0}}^{t_{d c h}} E_{c e l l, d c h}(t) d t}{\int_{t_{0}}^{t_{c h}} E_{c e l l, c h}(t) d t}
$$

Voltage Efficiency values always fall below $100 \%$ as activation overpotentials arise during the charge transfer process at the electrode (eq. 2.36) and increase or decrease the open-circuit voltage during charging and discharging, respectively. Voltage Efficiencies are, thus dependent on the reaction kinetics, active electrode surface and cell current. Ohmic and concentration overpotentials (eq. 2.20) further add to the cell potential and cause a $V E$ decrease. In order to increase the voltage efficiencies the ohmic losses caused by the electrode material, electrical contacting, membrane resistivity and electrolyte resistance need to be minimized. The onset of concentration overpotentials also reduces the Voltage Efficiency and might be reduced by an optimization of the mass transfer at the electrode.

\section{Energy Efficiency}

The actual amount of energy converted during charging and discharging was introduced in eq. 2.47. The Energy Efficiency (EE) relates the battery's useful amount of energy output during discharging to the required amount of energy during charging:

$$
E E=\frac{E_{a c t, d c h}}{\left|E_{a c t, c h}\right|}=\frac{\int_{t_{0}}^{t_{d c h}} P_{c e l l, d c h}(t) d t}{\left|\int_{t_{0}}^{t_{c h}} P_{c e l l, c h}(t) d t\right|}=\frac{\int_{t_{0}}^{t_{d c h}} E_{c e l l}(t) \cdot I_{c e l l}(t) d t}{\left|\int_{t_{0}}^{t_{c h}} E_{c e l l}(t) \cdot I_{c e l l}(t) d t\right|}
$$


If the charge/discharge cycles are conducted at constant current (galvanostatically), the Energy Efficiency can be calculated by multiplication of $V E$ and $C E$ :

$$
E E=V E \cdot C E
$$

The energy efficiency incorporates all losses associated with the charging and discharging of the battery cell but does not account for the power losses introduced by auxiliary components of a RFB storage system. In order to estimate the energy efficiency of the whole battery system, the power required to operate $a c / d c$ converters, system control units and pumps need to be included. Since $a c / d c$ converters and system control units are not incorporated in the test setup and the implementation of the developed tubular cells in storage systems is beyond the scope of this work, the System Energy Efficiency ( $\left.E E_{s y s}\right)$ only considers the pumping losses.

$$
E E_{\text {sys }}=\frac{\int_{t_{0}}^{t_{\text {dch }}} P_{\text {cell,dch }}(t) d t-\int_{t_{0}}^{t_{\text {dch }}} P_{\text {pump }}(t) d t}{\left|\int_{t_{0}}^{t_{c h}} P_{\text {cell,ch }}(t) d t\right|+\int_{t_{0}}^{t_{c h}} P_{\text {pump }}(t) d t}
$$

For the estimation of $E E_{s y s}$ the required pumping power is calculated with equation 2.51 and a pumping efficiency of $60 \%$ [147] is assumed.

\subsection{Methods}

In the previous section an overview of the fundamental processes of All Vanadium and Vanadium/Air Redox Flow Batteries is given and the sources of cell performance losses are introduced. Figures of merit are defined to quantify the performance of tubular VRFB and VARFB cells and to permit an elaborate evaluation and comparison with published results.

In this section the electrochemical characterization methods and techniques required to determine the figures of merit are introduced and specified.

Emphasis is placed on a potential measurement armature, which is also designed and developed within the scope of this work for the in situ measurement of Nernst potentials and overpotentials. As this setup differs from commonly used reference electrode configurations, a validation and comparison with published results is done in this section. 


\subsubsection{Current Interrupt}

In section 2.1.2 the current dependent cell potential is introduced and a classification of the overpotentials is given. The ohmic overpotential $\eta_{\text {ohm }}=i_{\text {cell }} \cdot$ ASR comprises the overpotentials, which arise due to the conduction of electrons and ions through the current collectors, electrodes, electrolytes and the membrane. A technique denoted as current interrupt $C I$ can be employed to determine the area specific cell resistance $(A S R)$. It is commonly used in electrochemical experiments with three electrode setups (e.g. cyclovoltammetry) to identify and compensate the ohmic potential drop of the measurement setup [1, 83]. In the field of fuel cell, electrolysis cell and battery research $C I$ measurements are often performed to determine the ohmic resistance of an entire cell (ASR) [30].

The method involves the application of a defined current $I$ for several tenths of a millisecond or seconds with an abrupt interruption of the current perturbation (see figure 2.6). The potential of the test cell or experimental setup is measured during

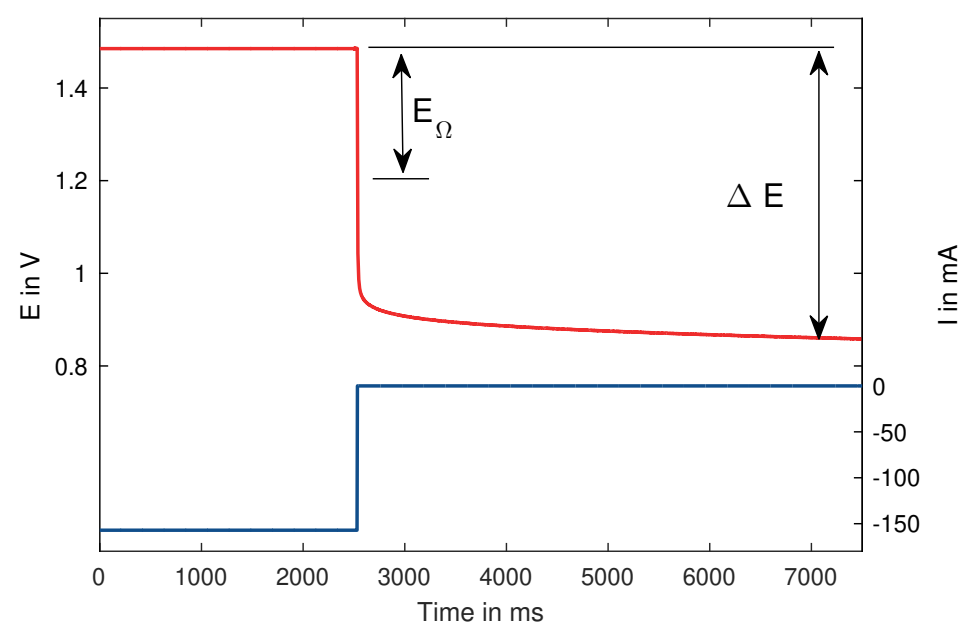

FIGURE 2.6: Potential drop and current perturbation signal of a current interrupt measurement.

the duration of the perturbation and the potential drop $\Delta E$ at the current interruption event is recorded with microsecond sample rates (see figure 2.6). The vertical portion of the potential drop $\Delta E_{\Omega}$ at the instant of time of the current interrupt can be attributed to the ohmic potential drop and the ohmic resistance $R_{u}$ is obtained with Ohm's law $\left(R_{u}=\Delta E_{\Omega} / I\right)$. Analog to the utilization of the current interrupt step 
(falling edge), the current application step (rising edge) can be employed to determine the ohmic potential drop.

Within this work current interrupt measurements are performed with the potentiostat $S P-240 / 4 A / 14 V$ of BioLogic and area specific cell resistances $\left(A S R_{C I}\right)$ are determined with the software EC-Lab of BioLogic.

CI measurements require comparably low measurement equipment and analysis efforts. However, it has to be noted that this technique involves perturbations with substantial potential magnitudes, which might lead to a non-uniform potential distribution across porous electrodes. These mixed potentials can create current fluxes within the porous electrode structure and result in an additional potential drop and distorted resistance values [30]. Electrochemical impedance spectroscopy (EIS) and high frequency resistance (HFR) measurements involve smaller potential perturbation magnitudes and frequency-domain analysis of the response signal. Their application for an $A S R$ determination is described in more detail in section 2.2.4.

\subsubsection{Polarization Curves}

Polarization curve measurements are used to evaluate the cell performance at specific operating parameters $\left(\dot{Q}, S_{o} C, T, \ldots\right)$ and enable to identify and quantify overpotentials from the cell's $E / i$-characteristic $[4,71,72,94]$. A polarization curve can be divided into three characteristic sections (see figure 2.7):

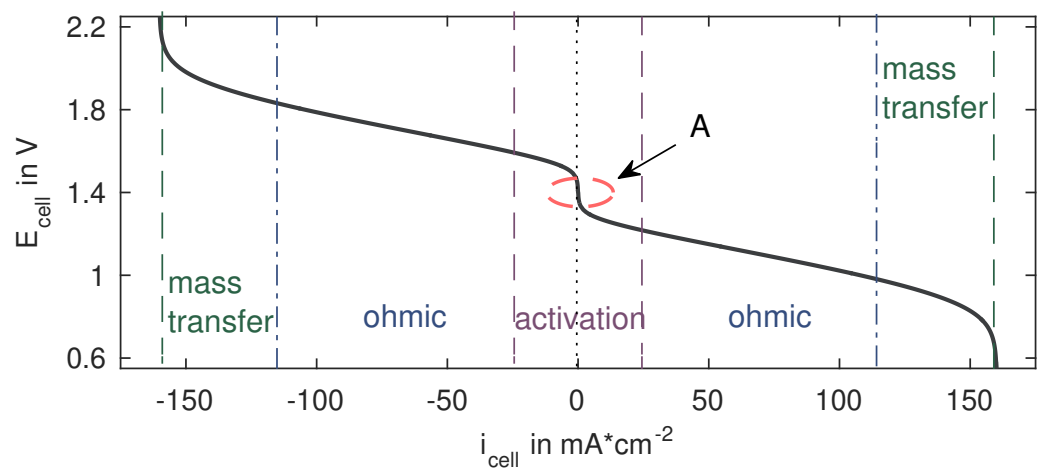

FIGURE 2.7: Polarization curve with the three characteristic sections: activation polarization, ohmic (operating range) and mass transfer controlled. 
Activation polarization: At low current densities the cell potential is dominated by the charge transfer at the electrode-electrolyte interface. The reaction kinetics, electrode surface and temperature characterize the quasi-exponential potential progression, which is also denoted as activation overpotential $\eta_{\text {act }}$ (section 2.1.2).

The actual operating range at increased current densities shows a linear progression, which is mainly governed by the specific ohmic cell resistance and resulting ohmic overpotential $\left(\eta_{\text {ohm }}\right)$ (section 2.1.2).

The mass transfer controlled section of a polarization curve typically onsets at high current densities as convective and diffusive mass transport of active species ions from the electrolyte bulk to the electrode surface limit the speed at which the charge transfer occurs (concentration overpotential $\eta_{\text {conc }}$ ). A maximum current density also denoted as limiting current density $i_{\text {lim }}$ is reached as solely the mass transfer rate controls the current density.

Evaluation of polarization curves can be done by fitting empirical models to the measurement data as it is done in the field of PEM fuel cells [42, 64, 70]. By considering the three characteristic sections mentioned above the current dependent cell potential $\left(E_{\text {cell }}\left(i_{\text {cell }}\right)\right)$ can be described by equation 2.20 ( + charging, - discharging):

$$
E_{\text {cell }}\left(i_{\text {cell }}\right)=O C V \pm\left\{\left|\eta_{\text {ohm }}\left(i_{\text {cell }}\right)\right|+\left|\eta_{\text {act }}\left(i_{\text {cell }}\right)\right|+\left|\eta_{\text {conc }}\left(i_{\text {cell }}\right)\right|\right\}
$$

In section 2.1.2 the activation overpotential at an electrode was introduced (eq. 2.36). In figure 2.5 the activation overpotential of the oxidation reaction (anodic) and reduction reaction (cathodic), which compose the electrode's $\eta_{\text {act }}$ are shown.

For high overpotentials $\left(\left|\eta_{\text {act }}\right|>>\frac{R \cdot T}{z \cdot F}[46],|\eta|>100 \mathrm{mV}\right.$ in this work) the reverse reaction can be neglected and $\eta_{\text {act }}$ of an electrode simplifies $(j \rightarrow i)$ for

cathodic reactions:

$$
\ln \left(\frac{i_{\text {cell }}}{i_{0}}\right)=-\frac{(1-\alpha) \cdot z \cdot F}{R \cdot T} \cdot \eta_{\text {act }}, \eta_{\text {act }}=-\frac{R \cdot T}{(1-\alpha) \cdot z \cdot F} \cdot \ln \left(\frac{i_{\text {cell }}}{i_{0}}\right)
$$

anodic reactions:

$$
\ln \left(\frac{i_{c e l l}}{i_{0}}\right)=\frac{\alpha \cdot z \cdot F}{R \cdot T} \cdot \eta_{a c t}, \eta_{a c t}=\frac{R \cdot T}{\alpha \cdot z \cdot F} \cdot \ln \left(\frac{i_{c e l l}}{i_{0}}\right)
$$

Equation 2.64 and 2.65 are also referred to as Tafel Equation and their area of application is denoted as Tafel Region. By introducing the Tafel slope (b) the Tafel Equation $(2.64,2.65)$ can also be written as:

$$
\eta_{a c t}=b \cdot \ln \left(\frac{i_{c e l l}}{i_{0}}\right), b=-\frac{R \cdot T}{(1-\alpha) \cdot z \cdot F}
$$


To estimate the overall activation overpotential of the cell the $\eta_{\text {act }}$ of the cathode and anode need to be calculated individually and are added.

$$
\eta_{\text {act }}=\eta_{\text {act }, \text { cathode }}-\eta_{\text {act, anode }}
$$

The limiting current density $\left(i_{\text {lim }}\right)$ in the mass transfer controlled section can be employed to model the concentration overpotential $\eta_{\text {conc }}[45]$ :

$$
\eta_{\text {conc }}=\frac{R \cdot T}{z \cdot F} \ln \left(\frac{i_{\text {lim }}}{i_{\text {lim }}-i_{\text {cell }}}\right)
$$

For overpotentials $\eta>100 \mathrm{mV}$ the cell potential can be estimated by combining equation 2.66 and 2.68 with equation 2.20:

$$
E_{\text {cell }}\left(i_{\text {cell }}\right)=O C V \pm\left\{\left|b \cdot \ln \left(\frac{i_{\text {cell }}}{i_{0}}\right)\right|+\left|\frac{R \cdot T}{z \cdot F} \ln \left(\frac{i_{\text {lim }}}{i_{\text {lim }}-i_{\text {cell }}}\right)\right|+i_{\text {cell }} \cdot A S R\right\}
$$

In the vicinity $(\eta<25 \mathrm{mV})$ of $E_{\text {cell }}^{0}$ the $E_{\text {cell }}\left(i_{\text {cell }}\right) / i_{\text {cell-correlation exhibits a linear }}$ progression (see detail A in figure 2.7). For these small overpotentials the ButlerVolmer Equation (eq.: 2.36) can be linearized $\left(e^{x}=1+x\right)[46,120]$ and $\eta_{\text {act }}$ is estimated by:

$$
\eta_{\text {act }}=\frac{i_{\text {cell }}}{i_{0}} \cdot \frac{R \cdot T}{z \cdot F}
$$

To estimate the cell potential only activation and ohmic overpotentials need to be included in equation 2.20 as the concentration overpotentials at these low current densities can be neglected.

$$
E_{\text {cell }}\left(i_{\text {cell }}\right)=\operatorname{OCV} \pm\left\{\left|\frac{i_{\text {cell }}}{i_{0}} \cdot \frac{R \cdot T}{z \cdot F}\right|+i_{\text {cell }} \cdot A S R\right\}
$$

In this work nonlinear regression is performed to fit equation 2.69 and 2.71 to the measured polarization curve. Measurement routines are specified in section 3.1.4 and 4.1.4. By use of the Matlab function nlin fit fitting parameters are estimated with an iterative least square method. Fitting parameters are the specific cell resistance $\left(A S R_{E / i}\right)$, open-circuit voltage $(O C V)$, Tafel slope $(b)$, exchange current density $\left(i_{0}\right)$ and limiting current density $\left(i_{l i m}\right)$. 


\subsubsection{Half Cell Potential Measurement}

In the field of fuel cell research reference electrodes are integrated in test cells to serve as a reference for half cell polarization and impedance measurements [47, 166]. In doing so, the contribution of the negative and positive electrode overpotential to the overall cell potential can be identified. Among the most widely used reference electrodes in PEM FCS is the dynamic hydrogen electrode (DHE) [166]. By contacting two platinum wires with an electrolyte (e.g. PEM) and connecting it to a power source, hydrogen can be produced at the $\mathrm{Pt}$ wire and a stable electrode potential is established. DHE can be integrated in the test cells in an edge-type or sandwich-type configuration. By attaching the Pt-wires to the membrane in the vicinity of the electrodes, an edge-type configuration is realized, which utilizes the hydrated membrane for the contact with the electrode. Sandwich-type DHEs are obtained by placing the Pt-wires in-between two membranes, which separate the two electrodes of the test cell. Accordingly, the test cell design and setup has to be adapted to the sandwichtype DHE and the electric test cell resistance is increased.

A sandwich-type DHE was used by Aaron et al. to conduct in situ studies on the reaction kinetics of the negative and positive electrode of a planar VRFB test cell [3]. Sun et al. used an identical reference electrode setup for the determination of the impedance spectra of the positive and negative electrode of a planar VRFB $[138,139]$. In [139] a further edge-type $\mathrm{Hg} / \mathrm{Hg}_{2} \mathrm{SO}_{4}$ reference electrode $(\mathrm{HgE})$ was integrated at the perimeter of the test cell by placing the tip of the $\mathrm{HgE}$ on the membrane and contacting it by wetting with $0.5 \mathrm{M} \mathrm{H}_{2} \mathrm{SO}_{4}$. An analog edge-type $\mathrm{HgE}$ was used by Nibel et al. [94] (junction reference electrode: $2 \mathrm{M} \mathrm{H}_{2} \mathrm{SO}_{4}$ ) to evaluate the performance, stability and degradation of different graphite electrodes in a VRFB cell.

To study and identify the contribution of the cathode and anode overpotential of a planar VARFB cell, grosse Austing et al. implemented a edge-type DHE on the cathode layer of the membrane [16]. The potential of the DHE showed to be stable and exhibited a potential of $0 \mathrm{~V}$ vs. SHE as it was validated against a $\mathrm{Ag} / \mathrm{AgCl} / \mathrm{KCl}_{\text {sat }}$ electrode. In 2014 Noack et al. presented studies on the performance of a planar VOFC with a DHE on the cathode side of the MEA [95]. The reference electrode could be used for impedance spectra measurements, but was later on reported to be unstable during long term measurements [97].

Another reference electrode setup of Noack et al. was used to evaluate the performance and SoC of a Vanadium-PEM Water Electrolysis Cell (V - PEMW) and VOFC $[95,97,99]$. The Nernst potential of the electrolyte solution was measured between a glassy carbon rod and a $\mathrm{Hg} / \mathrm{Hg}_{2} \mathrm{SO}_{4}$ reference electrode $(\mathrm{HgE})$, which were placed in the electrolyte tank. The cell's electrode potential was measured by connecting $\mathrm{HgE}$ with the respective electrode of the cell.

In [71, 72] Langner et al. presented a potential measurement setup for VRFB cells 
by use of a $\mathrm{Ag} / \mathrm{AgCl} / 3 \mathrm{MKCl}$ reference electrode. The reference electrode was introduced in the inlet and outlet pipe of each half cell. The potential of the positive and negative electrode during polarization was measured by connecting the reference electrodes to the cells electrode terminals.

In order to conduct in-situ electrolyte potential measurements and determine the contribution of the negative and positive electrode overpotentials to the total cell potential of tubular VRFB test cells, two potential flow armatures are designed and integrated in the $V R F B$ test rig. In ideal three-electrode setups, reference electrodes should be positioned in front of the respective electrode within the current flow field of the working and counter electrode. As the design and dimensions of the tubular test cell do not permit to implement the reference electrode in front of the respective electrodes and the tubular membranes are difficult to access for an installation of edge-type DHEs, a different setup is required. Figure 2.8 illustrates the potential measurement setup, which was developed within this work. Each armature is equipped with a mercury-mercurous sulfate reference electrode with $2 \mathrm{MH}_{2} \mathrm{SO}_{4}(\mathrm{HgE})$ and a second graphite felt reference electrode (GFE). $\mathrm{HgE}$ reference electrodes are chosen to ensure that only sulfate ions are present in the the VRFB and VARFB cycles. The design and geometry of the GFE is identical with the inner flow-by electrode of a tubular VRFB (section 3.1.1). Hence, the pressure drop across the GFE is minimized and imposes only an insignificant addition to the half cell $\Delta p$ measurement (section 3.1.4). The graphite felt material used is the same as for the tubular VRFB flow-by electrodes (SIGRACET GDL\#2614 Pyron, SGL Carbon) and is subjected to an analog heat treatment (section 3.1.2).

The $\mathrm{Hg} / \mathrm{Hg}_{2} \mathrm{SO}_{4}$ reference electrode $(\mathrm{HgE})$ with $2 \mathrm{MH}_{2} \mathrm{SO}_{4}$ of Sensortechnik Meinsberg is installed close to the inlet of the potential armature. In regular three-electrode setups Luggin capillaries are attached to the tip of the reference electrode. The electrolyte flow path (test cell manifold, tubing, flow armature inlet) of this setup can be considered as Luggin capillary. The relatively long distance $(\approx 5 \mathrm{~cm})$ between the $\mathrm{HgE}$ tip and the test cell electrode is not critical as no current flow exists between the reference electrode and the electrode of the test cell. In order to prevent overpressure induced influx of electrolyte solution through the diaphragm of the $\mathrm{HgE}$, a pressure equalizing tube is implemented between the $2 \mathrm{MH}_{2} \mathrm{SO}_{4}$ refill socket and electrolyte flow channel. A $\mathrm{HgE}$ electrode potential of $656 \mathrm{mV}$ vs. standard hydrogen electrode $(S H E)$ is determined by measuring the $H g E$ against a calibrated $\left(E_{S C E}^{0}=(243 \pm 1) m V\right.$ vs. $\left.S H E\right)$ saturated calomel electrode (SCE) of Sensortechnik Meinsberg. Potential shifts of the $\mathrm{HgEs}$ are determined by calibration measurements before and after every measurement and are corrected accordingly. 


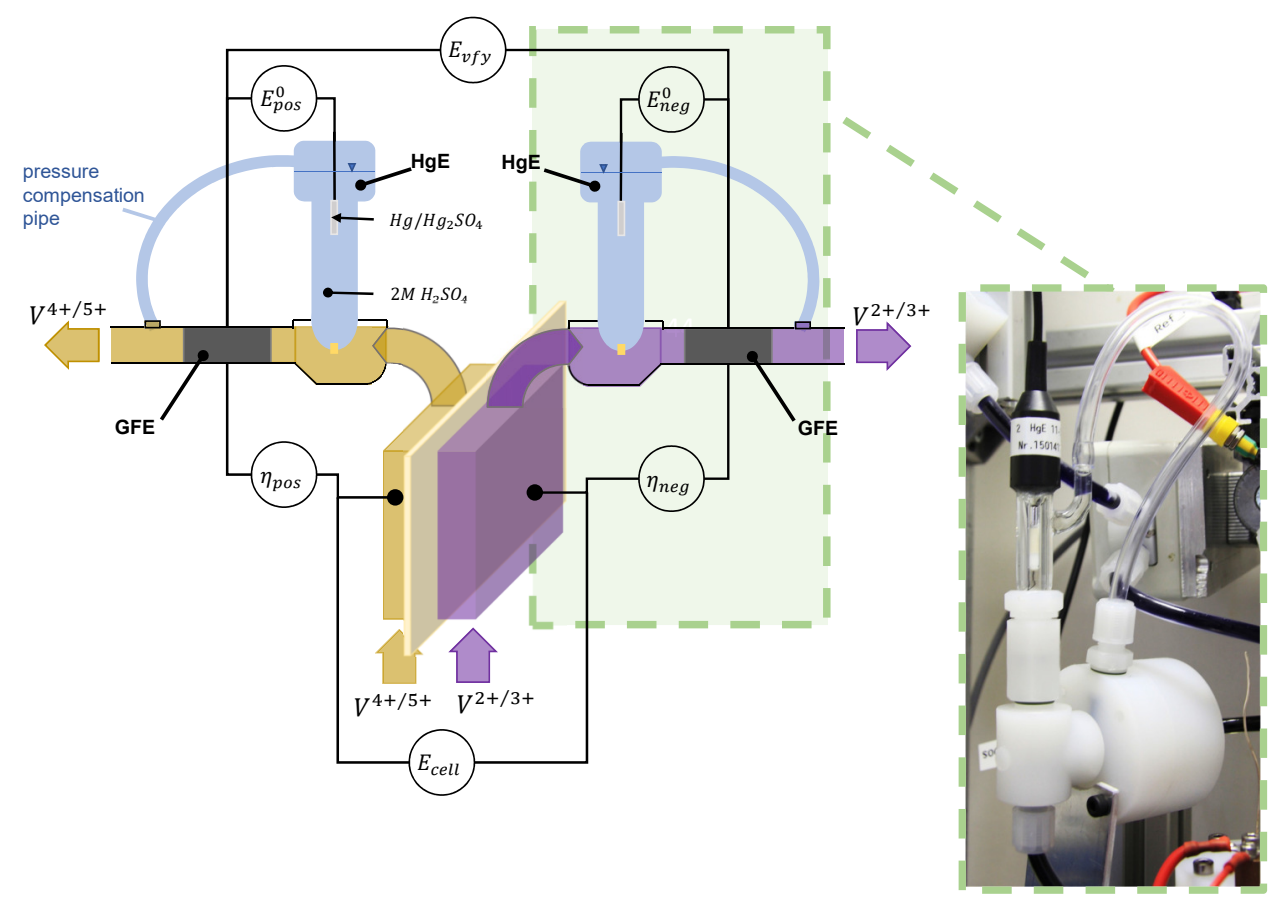

FIGURE 2.8: Left: Schematic of half cell potential measurement setup. Right corner: Picture of potential flow armature.

By measuring the potential between $H g E$ and GFE the Nernst potentials of the negative and positive half cell $\left(E_{n e g}^{0}\right.$ and $\left.E_{p o s}^{0}\right)$ are obtained. The residual overpotentials $\eta_{n e g}$ and $\eta_{\text {pos }}$ are determined by measuring the potential between the GFE and the negative and positive test cell electrode, respectively. A further potential measurement between the GFE in the positive and negative flow armatures $\left(E_{v f y}=\right.$ $\left.G F E_{p o s}-G F E_{n e g}\right)$ yields the open-circuit potential (OCV) under no current flux conditions and $O C V \pm \eta_{\text {ohm }}$ (Kirchhoff's circuit law) at current flow $\left(i_{\text {cell }}\right)$. As the $E_{\text {vfy }}$ signal comprises the entire potential measurement setup (including test cell), it is used to verify the residual overpotential measurement setup. All potential measurements are performed with digital multimeters (34405A, Agilent). Flow armature housings are made of $P V D F$ material and were machined by Werkzeug-Formen-MaschinenbauService (WFM-S).

By employing the potential measurement setup during polarization curve measurements, the overpotentials of the negative and positive half cell ( $\eta_{n e g}$ and $\left.\eta_{p o s}\right)$ can be 
separated from the cell's total residual overpotential $\left(\eta_{\text {res }}\right)$.

To verify the potential measurement setup, the measured $E_{c e l l} / i$-characteristic of a planar $V R F B$ cell (section 3.1.1) is plotted against the constructed cell potential $E_{c e l l}=O C V+\eta_{\text {ohm }}+\eta_{\text {pos }}-\eta_{\text {neg }}$ (fig. 2.9). Note that there is a slight mismatch between the measured and constructed cell potential .

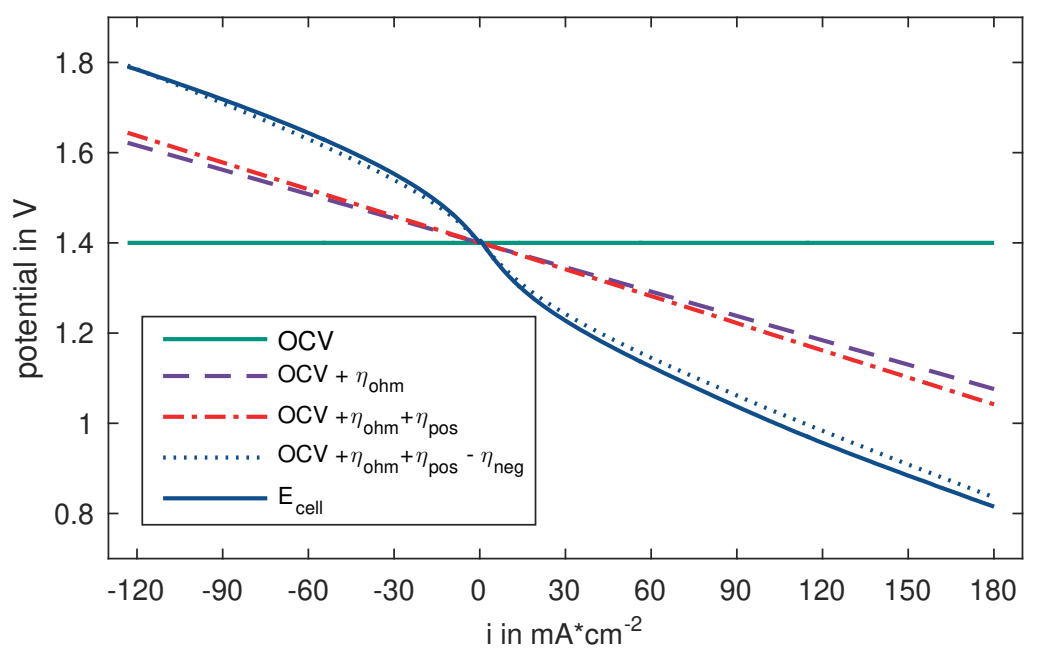

FIGURE 2.9: Polarization curves of planar VRFB cell at a flow rate of $12.8 \mathrm{ml} \mathrm{min}{ }^{-1}$ with measured $\eta_{\text {pos }}, \eta_{\text {neg }}, \eta_{\text {ohm }}, O C V$ and constructed cell potential (dotted).

In the study of Sun et al. [138] on the losses in a VRFB only the constructed cell potential is shown and no mismatch between the constructed and measured cell potential is reported. The work of Nibel et al. [94] also employs a DHE for the identification of overpotentials in a VRFB and does not explicitly differentiate between measured and constructed cell potentials. A comparison between the mismatch of potential measurement with DHE setups and the potential measurement used in this work can, thus not be made.

L. Langner et al. report a similar offset in their measurement setup, which they refer to ohmic overpotentials within the potential measurement setup [71]. However, a closer look at the discrepancy reveals a non-linear progression of the mismatch (see figure 2.10). Accordingly, the current flux in the measurement setup would have to alter independently from the cell current density $\left(i_{\text {cell }}\right)$. By an additional measurement of the potential between the negative GFE and positive GFE a verification 
potential $\left(E_{v f y}\right)$ is obtained, which covers all effects in-between the positive reference electrode armature, test cell and negative reference electrode armature. By subtracting the $O C V$ and adding the ohmic overpotential to $E_{v f y}$, an identical mismatch $\left(\Delta \eta_{i}\right)$ is determined and shown in figure 2.10. Note that both signals were recorded with separate potential metrology (potentiostat and mulitimeters). The periodic peaks in the $E_{v f y}$ signal can be attributed to pressure pulses introduced by the pumps.

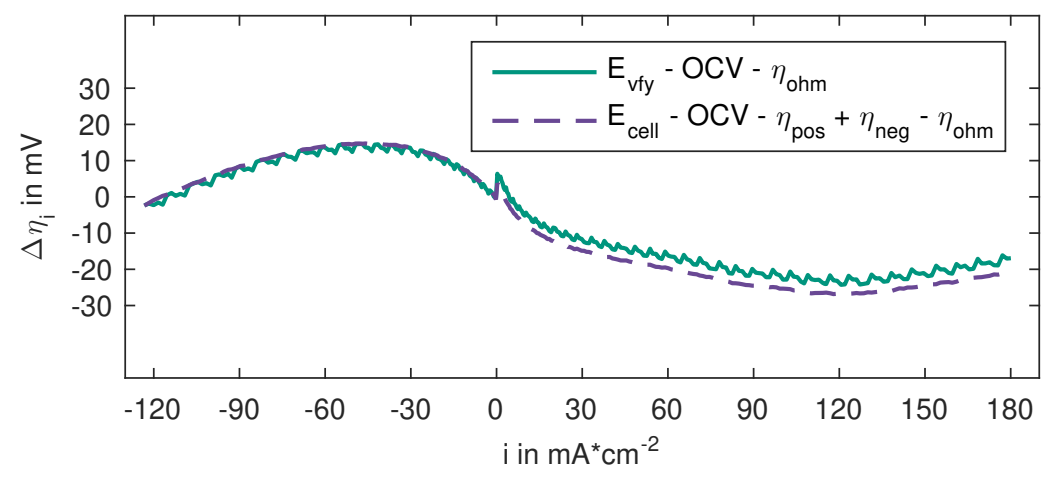

FIGURE 2.10: Potential mismatch $\left(\Delta \eta_{i}\right)$ of the constructed and measured cell potential (dashed) and potential mismatch $\left(\Delta \eta_{i}\right)$ of the verification potential with subtracted $O C V$ and $\eta_{o h m}$ portions $\left(\Delta \eta_{i}=\right.$

$$
\left.E_{v f y}-O C V-\eta_{o h m}\right) \text {. }
$$

An elaborate study of edge effects on different DHE setups in PEM-FCs was published by He and van Nguyen." It was found that the reference sensing point is greatly affected by the relative geometry and alignment of the two electrodes on the main membrane and electrode assembly (MEA) and the nature of electrode kinetics" [47]. Although the measurement setup employed in this work does not utilize the membrane as contact (salt bridge) between the $\mathrm{HgE}$ and electrode, comparable edge effects at the test cell electrodes are assumed to occur and lead to highly non-linear deviations of the measured potential. The mismatch of the potential is dependent on the test cell electrode geometry, reaction kinetics and current density at the same time and can, thus, not be compensated easily. Therefore, the measurement setup deployed within this work is rather used for a qualitative analysis than quantitative evaluation of overpotentials. 


\subsubsection{Electrochemical Impedance Spectroscopy}

Electrochemical Impedance Spectroscopy (EIS) is a well established method, which is applied in fuel cell [10, 30, 69, 148, 165], electrolysis cell [88, 117, 131], battery [20, 143], material and corrosion [81] research. In recent years EIS has also been employed in the field of Redox Flow Batteries for the characterization of cell components [139] and entire cells [95, 97, 138], studies on the reaction mechanisms at the electrodes [41, 43] and for the investigation of electrode degradation [36].

The basic principle of EIS involves the application of an electrical stimulus (defined current or potential) to an electrochemical cell and observation of its potential or current response (see figure 2.11). The sinusoidal stimulus is modulated in the generator unit of the EIS metrology and consists of mono-frequency current or potential signals. The resulting real $\operatorname{Re}(Z)$ and imaginary $\operatorname{Im}(Z)$ parts or phase shift $(\phi)$ and amplitude of the response signal are measured and analyzed by equivalent circuit fitting or fast Fourier transformation in the analyzer unit. Applied frequencies typically range from $1 \mathrm{mHz}$ to $1 \mathrm{MHz}$ [17] and feature comparably low amplitudes from $2 \mathrm{mV}$ to $10 \mathrm{mV}$ [82].
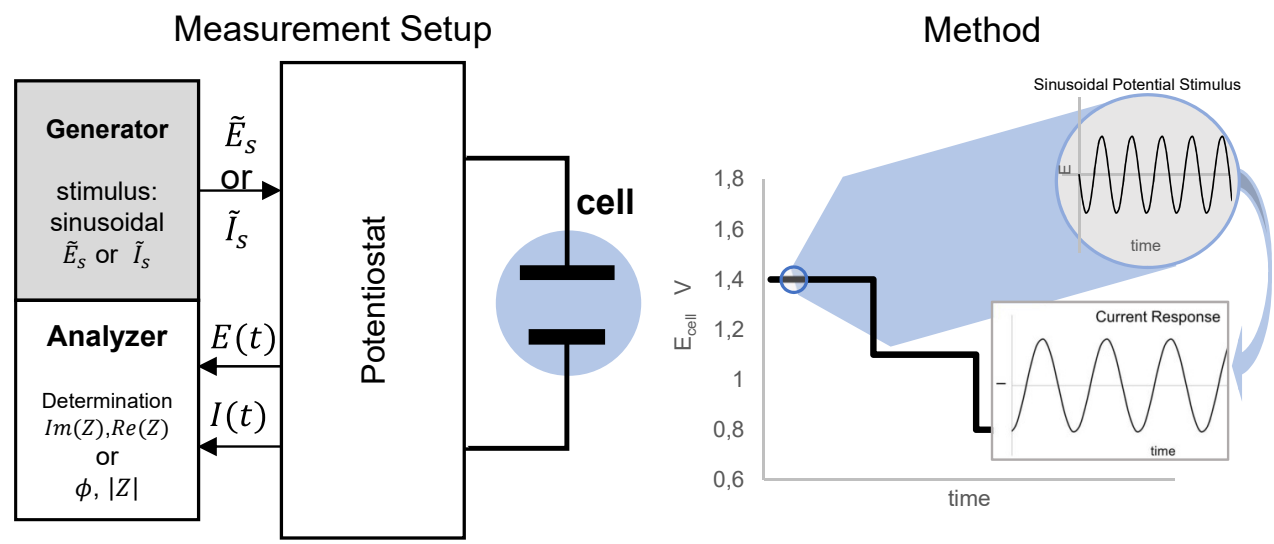

FIGURE 2.11: Schematic of EIS measurement setup and method.

The sinusoidal stimulus signal can be applied to the cell at open-circuit voltage $\left(E_{c e l l}=O C V\right)$ or superimposed onto a $d c$ voltage $\Delta E_{d c}$ stimulus signal $\left(\Delta E_{d c}=\right.$ $\left.E_{\text {cell }}-O C V\right)$. To investigate the frequency dependent impedance of a cell within a range of frequencies, multiple frequencies of interest are applied in a consecutive 
manner.

Electrical stimulation induces a variety of processes throughout the cell including electron transfer through conductors, ion transport in electrolyte solutions and polymer electrolytes (membranes), charge transfer at the electrode-electrolyte interface and mass transfer of charged species in-between the charge transfer layer and bulk electrolyte. These macroscopic processes might occur simultaneously, can be interrelated and cumulate in the measured impedance.

Equivalent circuit models are fitted to the determined complex impedance spectra to interpret the fundamental processes arising in the test cell. While simultaneous processes are described by parallel connection of the respective impedance element, consecutive processes are considered by serial connection of the respective element. A common equivalent circuit model to describe the kinetically controlled conversion of a substance at an electrode-electrolyte interface consists of a Faraday impedance in parallel with a double-layer capacitance $\left(C_{d l}\right)[17,82,148]$ (A in fig. 2.12). In the simplest case the Faraday impedance is described by a resistor $\left(R_{c t}\right)$. This charge transfer resistance represents the kinetic process of the charge transfer through the electrochemical double-layer. For small overpotentials $\left(E_{c e l l} \approx O C V\right)$ the exchange current density $i_{0}$ can be estimated from $R_{c t}$ (deduced from equation 2.70):

$$
R_{c t}=\frac{R \cdot T}{z \cdot F \cdot i_{0}}
$$

When the the capacitance of the double-layer $\left(C_{d l}\right)$ is considered as a plate capacitor it can be calculated with the permittivity $(\epsilon)$, double-layer distance $\left(D_{d l}\right)$ and electrode surface $\left(A_{\text {elec }}\right)$ :

$$
C_{d l}=\frac{\epsilon \cdot A_{\text {elec }}}{D_{d l}}
$$

The impedance response of the capacitance $\left(Z_{C d l}\right)$ can also be expressed as a complex number with the imaginary number $(j)$ and angular frequency $(\omega)$ :

$$
Z_{C d l}=\frac{-j}{\omega \cdot C_{d l}}
$$

As an electrode cannot be measured without an additional resistance induced by the electrical connection of the electrode and a resistance caused by the ion conduction in the electrolyte solution, a resistor $\left(R_{u}\right)$ is connected in series with the electrode element (A in figure 2.12). This equivalent circuit is often denoted as simplified Randles circuit and is displayed in figure 2.13 in Nyquist (left) and Bode (right) representation.

In full cell EIS measurements ohmic resistances arise from the electrical connection of 

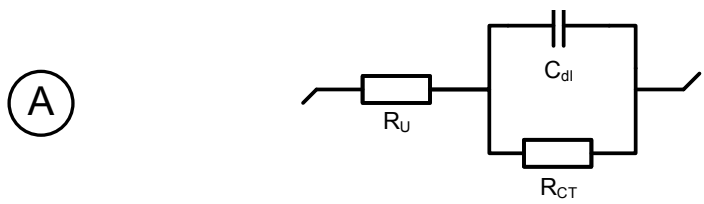

(B)
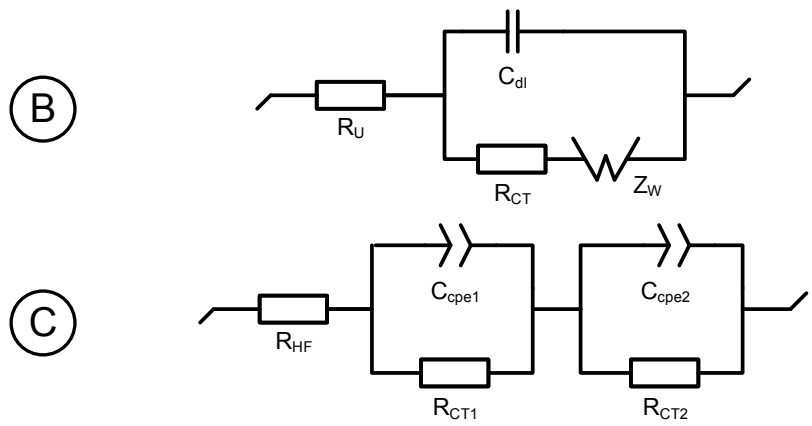

FIGURE 2.12: A: Simplified Randles equivalent circuit B: Randles equivalent circuit with diffusive mass transfer C: simplified full cell equivalent circuit.

the metrology's wires with the electrode terminals, conduction of electrons through the conductive cell components (electrode, current collectors), as well as ionic conduction in the liquid electrolytes and membrane. These resistances are represented by a single resistor $\left(R_{H F}\right)$, which is connected in series with the impedance elements of the two electrodes (C in figure 2.12).

The ohmic resistance $\left(R_{u}\right.$ or $\left.R_{H F}\right)$ does not feature an imaginary part $(I M(Z)=0)$ and appears as zero-crossing at $\operatorname{Re}(Z)=R_{H F}$ in a Nyquist representation, accordingly (fig. 2.13). The area specific cell resistance $\left(A S R_{H F}=R_{H F} \cdot A_{m e m}\right)$ can, thus, be determined by a simple read out of $\operatorname{Re}(Z)$ at the zero-crossing frequency. This method is denoted as High Frequency Resistance (HFR) measurement.

The Randles equivalent circuit and simplified full cell equivalent circuit introduced above do not consider impedances introduced by mass transfer related processes. To include frequency dependent diffusion in the equivalent circuit models, a Warburg impedance $\left(Z_{W}\right)$ is connected in series with the charge transfer resistance $\left(R_{c t}\right)$ (B in figure 2.12). As the diffusion path is short at high frequencies, the Warburg impedance is small. At lower frequencies the Warburg impedance increases and appears as a line with a slope of $45^{\circ}$ in a Nyquist representation (fig. 2.14 left). For infinite diffusion layers the impedance is denoted as infinite Warburg impedance and is 

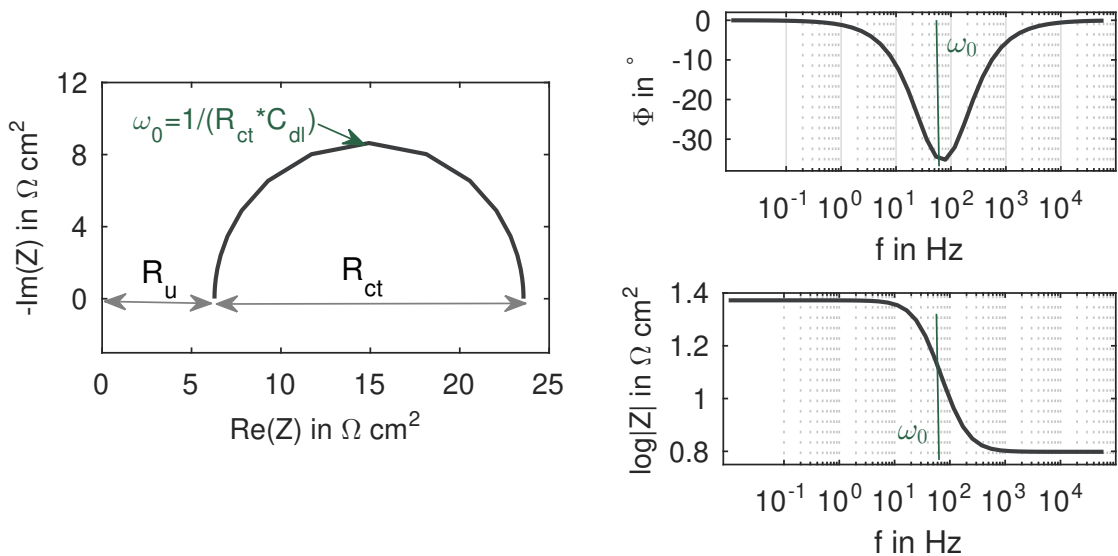

FIGURE 2.13: Left: Nyquist plot of simplified Randles circuit (A in fig 2.12). Right: Bode Plots of simplified Randles circuit.

defined as:

$$
Z_{W}=\frac{\sigma_{W}}{\sqrt{\omega}} \cdot(1-j)
$$

with the Warburg coefficient $\sigma_{W}$

$$
\sigma_{W}=\frac{R \cdot T}{z^{2} F^{2} A_{\text {elec }} \sqrt{2}}\left(\frac{1}{c_{o x} \sqrt{D_{o x}}}+\frac{1}{c_{\text {red }} \sqrt{D_{\text {red }}}}\right)
$$

$c_{o x}$ and $c_{r e d}$ are the oxidant and reductant concentrations in the bulk electrolyte and $D_{o x}$ and $D_{\text {red }}$ denote the diffusion coefficients of the respective species.

For a diffusion layer with a thickness $\delta$ (Nernst-diffusion-layer thickness) the finite Warburg impedance is used (fig. 2.14 right) and equation 2.74 is not valid anymore. The finite Warburg impedance is then defined as:

$$
Z_{W}=\frac{\sigma_{W}}{\sqrt{\omega}} \cdot(1-j) \cdot \tanh \left(\delta \cdot \sqrt{\frac{j \cdot \omega}{D}}\right)
$$

In the Randles equivalent circuit the capacitance $\left(C_{d l}\right)$ is described analog to an ideal capacitor. In a real cell the electrodes feature material impurities, surface heterogeneities and a rough surface area and irreversible redox processes might occur. To account for these effects, the capacitor is replaced by a constant phase element (CPE) 

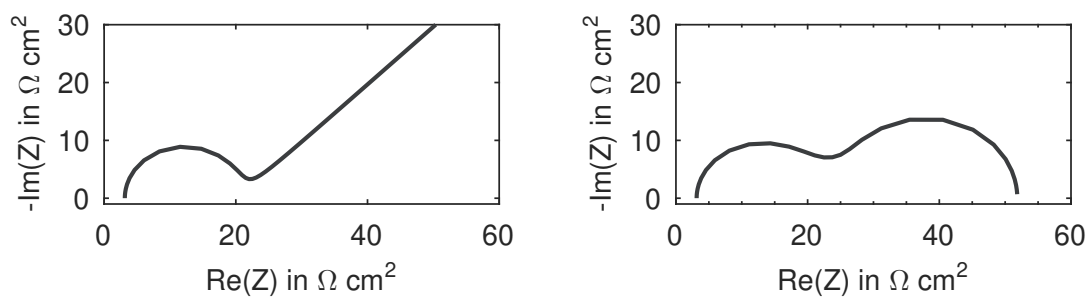

FIGURE 2.14: Nyquist plot of Randles circuit (B in fig 2.12) with infinite Warburg element (left) and finite Warburg element (right).

( $\mathrm{C}$ in figure 2.12). The impedance response of the $C P E$ is defined as:

$$
Z_{C P E}=\frac{1}{(j \cdot \omega)^{a} C_{c p e}}
$$

For an exponent $a=1 Z_{C P E}$ equals $Z_{C d l}$. To account for the irregularities in a real full cell (C in figure 2.12) the exponent $a$ can be set to values between 0 and 1 .

\subsection{Design Principles for Tubular Cells}

In this section a list of requirements for the development of tubular VRFB and VARFB cells is first specified and required development efforts are outlined. Simplified estimations of the electrical resistance and pressure drop in flow-by and flow-through electrode configurations are then conducted and considered for the assessment of potential half cell configurations. Developed cell concepts are presented at the end of this section.

\subsubsection{Design Requirements}

In this section a list of requirements for the development of tubular VRFB and VARFB cell designs is specified. Implications of the operating conditions on the cell designs, components and materials are emphasized and required research and development efforts are outlined. 


\section{All Vanadium Redox Flow Cells}

Operating Conditions: In VRFBs $V^{2+} / V^{3+}$ and $V^{4+} / V^{5+}\left(V O^{2+} / V O_{2}^{+}\right)$redox couples are used in the negative and positive electrolyte, respectively. The redox active substances are dissolved in aqueous solutions and sulfuric acid or a mixture of sulfuric and chlorine acid [107] is used as a supporting electrolyte. Electrolyte solutions with sulfuric acid concentrations above $2 \mathrm{~mol}$ are sometimes employed in electrolytes with a high vanadium concentration ( $>2 \mathrm{~mol}$ ) [106]. Within this work a commercial electrolyte with $0.8 \mathrm{MVOSO}_{4}, 0.4 \mathrm{MV}_{2}\left(\mathrm{SO}_{4}\right)_{3}, 0.05 \mathrm{MH}_{3} \mathrm{PO}_{4}$ and $2 \mathrm{MH}_{2} \mathrm{SO}_{4}$ is used. The developed cells shall, however, be suited for a future application in mixed acid electrolytes and electrolytes with $\mathrm{H}_{2} \mathrm{SO}_{4}$ concentrations above $2 \mathrm{~mol}$.

The operating temperature of the $V R F B$ cells is limited by thermal precipitation of $V^{5+}$ in $2 M$ sulfuric acid solution at temperatures above $40^{\circ} \mathrm{C}$ [106]. The developed $V R F B$ cells shall, thus, permit an operation within a temperature range from $18^{\circ} \mathrm{C}$ to $40^{\circ} \mathrm{C}$. As the developed tubular $V R F B$ half cells shall also be utilized as negative half cell of $V A R F B$ cells, operating temperatures up to $80^{\circ} \mathrm{C}$ must be facilitated.

In order to prevent a parasitic oxidation of $V^{2+}$ with ambient air (oxygen), the developed cells must be operated under inert conditions and air penetration into the cell has to be avoided.

As an aqueous electrolyte is used in VRFBs, the operating cell potential window is limited by the decomposition of water. During charging significant $\mathrm{H}_{2}$ evolution can occur at the graphite electrodes for potentials below $-0.456 \mathrm{~V}$ (vs. $S H E$ ) [153]. Charge/discharge cycling of VRFB cells is, therefore, done within cell potentials from $0.8 \mathrm{~V}$ to $1.7 \mathrm{~V}$.

Electrolyte flow rates must be sufficiently high to prevent electrolyte starvation and mass transfer limitations. To reduce pumping losses (eq. 2.51) low flow rates are, however, favorable. A trade-off between minimum pumping losses and minimum mass transfer losses has to be made. Typical electrolyte excess ratios $\left(\lambda_{\text {elyt }}=I_{\text {stoi }} / I_{\text {cell }}\right.$, $I_{\text {stoi }}=\dot{Q} \cdot c_{\text {soc } 50} \cdot F \cdot z$ ) range from 5.2 to 15.5 [107].

Current Collectors: As an electrical current flows through VRFB cells, potential drops occur in the current conducting parts of a cell. These potential drops are due to the ohmic resistances of the electron (and ion conducting) cell parts, as well as their interfaces and result in power losses and reduced efficiencies of the cell. In planar cell designs bipolar plates and current collector plates are typically used to enable electrical current conduction between the outer circuit and the porous graphite felt electrodes where the redox reactions occur.

Materials for bipolar plates and current collector plates must not only feature high electric conductivities, but must also resist the harsh operating environment (highly oxidizing electrolyte, acid, elevated temperatures and high potentials during overcharging). Furthermore, bipolar and current collector plates must feature a sufficient 
mechanical stability and have to be impermeable for the liquid electrolyte. For planar cell designs impregnated graphite materials and conductive polymers are mostly used as bipolar plate materials [101]. Conductive plastics are made from thermoplastic polymers and conductive graphite or carbon fillers. The conductive filler might be composed of particles or fibers or a mixture of both. Other materials include a thermoplastic polymer, an elastomeric polymer and conductive filler materials [169].

As no tubular current collectors are commercially available novel tubular current collectors have to be developed. The tubular current collectors need to be easy and cheap in fabrication and exhibit a good electrical conductivity. Furthermore, the developed tubular current collectors have to fulfill stability (chemical, electrochemical, mechanical) and impermeability requirements analog to planar bipolar plate requirements.

Electrode Materials and Configurations: Suitable electrode materials for VRFBs have to be stable in the electrolyte, feature a sufficient electrical conductivity, exhibit high hydrogen and oxygen evolution overpotentials and must feature a good electrochemical activity. Porous graphite felt materials made from Rayon or polyacrylonitrile (PAN) fiber precursors have shown to be suitable for $V R F B$ applications and are activated by thermal or chemical treatments for an enhanced electrochemical activity [101].

For planar flow-through electrode configurations (fig. 1.6) comparably thick ( $3 \mathrm{~mm}$ to $6 \mathrm{~mm}$ ) graphite felt sheet materials with a fiber diameter of $8 \mu \mathrm{m}$ to $11 \mu \mathrm{m}$ and porosity $>90 \%$ are typically used. For planar flow-by electrode configurations thinner $(<1.0 \mathrm{~mm})$ porous graphite materials with porosities $>85 \%$ are used. Flowby electrode substrates can be made from nonwoven graphite felt, woven graphite fibers or carbon paper [2, 107].

Within this work tubular VRFB cells with a membrane diameter of $5.0 \mathrm{~mm}$ shall be developed. The inner flow-through electrode of the tubular VRFB cells can not be obtained by wrapping of commercially available felt material as the bending radius is to small. A process to fabricate tubular flow-through electrodes for the inner half cell from graphite sheet material has, thus, to be developed.

For tubular VRFB cells with a flow-by electrode configuration carbon paper materials can not be used as their bending stiffness is to high and does not permit electrode wrapping. Suitable graphite felt and non-woven graphite fiber materials need to be selected and preparation techniques have to be developed. Different tubular current collector designs have to be designed to fabricate and analyze tubular VRFB cells with flow-by and flow-through electrode configurations. Furthermore, the developed electrode and current collector designs and materials must permit an in-line fabrication of entire cells by extrusion in the future. 
Pressure Drop: As already mentioned above, pressure drops across the half cells need to be minimized for reduced pumping losses. The pressure drop arises as the electrolyte flows through the porous electrode (flow-through) or the flow channels (flow-by).

For a maximum permeability (low pressure drop) of the flow-through electrodes, the porous electrode structure should not be compressed as the liquid permeability is reduced with increasing compression. On the other hand, the porous felt material has to be compressed to achieve low contact resistances between the electrode and the current collector interface. A trade-off between the electrical contact resistance and the pressure drop has to be made. The compression dependent liquid permeability and contact resistance of the flow-through electrode materials needs to be known and shall be considered for the development of the tubular cells.

Due to the different geometry of the inner and the outer half cell of tubular cells, a pressure difference might arise between the half cells. To reduce the mechanical stress on the membrane the pressure difference between the half cells has to be minimized and/or supporting structures for the membrane need to be employed. The inner and outer half cells (flow-by and flow-through) should be designed with identical hydraulic resistances (liquid permeabilities).

Membrane: Ion exchange membranes rank among the most widely used membranes in planar $V R F B$ cells. Anion as well as cation exchange membranes can be used in $V R F B$ cells and allow for coulomb efficiencies from $93 \%$ to $99 \%$. As planar cell designs require membrane sheet material, commercially available membrane materials are mostly supplied as sheet material. For the tubular cell design a lab-scale process and/or tool has to be developed to fabricate tubular membranes from membrane sheet material. Within the research project tubulAir \pm (Funding no. 03FS0436A, German Federal Ministry of Education and Research) extruded membranes are developed by FUMATECH BWT and Uniwell Rohrsysteme, which might also be used for this work.

Sealing: The outer and inner current collector of the tubular cell have to be sealed at the end faces (see fig. 1.7) to prevent leakage of electrolyte solution. In addition to the leak of electrolyte solution from the cell into the environment permeation of ambient air into the cell has to be avoided. Sealing techniques are required, which are gas-tight, chemically and mechanically resistant and durable.

Leakage of electrolyte solution between the positive and negative half cell would lead to a loss of capacity and a physical contact of the negative and positive electrolyte might induce shunt currents. The tubular membrane separates both half cells 
and has to be sealed at the end faces.

Suitable membrane and current collector sealing mechanisms need to be identified, tested, adapted to the tubular cell design and integrated in the test cell housing.

Fabrication: The tubular cell developed within this work shall be fabricated by a co-extrusion process in the future. Developed cell component designs and used materials must permit to be produced by extrusion or allow for an endwise feed into the in-line process. The number of cell components shall be preferably low to reduce the fabrication complexity and process steps. In order to demonstrate the feasibility of extruded tubular VRFB cells, test cells have to be assembled from extruded cell components and shall be subjected to an elaborate experimental analysis. The lab scale assembly procedure shall be done manually.

\section{Vanadium/Air Redox Flow Cells}

By replacing the positive half cell of a $V R F B$ with a bifunctional air/water electrode a VARFB cell is created. The VARFB's negative half cell is identical with the negative half cell of an All Vanadium Redox Flow Cell. In this section requirements for the development of a tubular VARFB cell are only defined for the positive half cell of a $V A R F B$, accordingly.

Operating Conditions: Due to the elimination of $V^{5+}$ (positive half cell) the limitation of the operating temperature $\left(40^{\circ} \mathrm{C}\right)$ is circumvented and can be set within a range from $25^{\circ} \mathrm{C}$ to $80^{\circ} \mathrm{C}$. Increased operation temperatures are beneficial for the reaction kinetic of the oxygen reduction reaction $(O R R)$ and oxygen evolution reaction $(O E R)$. The tubular VARFB cell shall be operated within this temperature range and used cell materials and components must withstand the thermal load and permit thermal cycling.

Within this work negative electrolytes with a total $V^{2+/ 3+}$ concentration of $1.6 \mathrm{~mol}$ and $2 \mathrm{M} \mathrm{H}_{2} \mathrm{SO}_{4}$ shall be used. The developed tubular VARFB cell components shall, however, permit an operation with increased sulfuric acid and vanadium concentrations in the future.

The supply of water to the positive half cell during charging is done with humidified air or oxygen. To realize a maximum water supply while maintaining low gas flow rates a gas supply with a relative humidity above $70 \%$ shall be set during charging. Gas inlet temperatures might exceed $80^{\circ} \mathrm{C}$ to prevent condensation. The operating pressure in the air/water half cell shall only be increased slightly relative to ambient pressure during charging to increase the mass fraction of water. During discharging 
elevated gas pressures and reduced relative humidities might be applied for an enhanced mass transfer. Operation at elevated temperatures might only be feasible by direct heating or insulation of the tubular cell. Suitable thermal management concepts must be considered for the cell design and operation.

The maximum cell potential during charging is limited by hydrogen evolution in the negative half cell $\left(E_{n e g} \leq-0.456 \mathrm{~V}\right.$ vs. SHE). Permissible cell potential limits during charging might exceed the maximum potential of VRFBs (1.8V) and cell potentials above $2.0 \mathrm{~V}$ can be obtained if the negative electrode potential is maintained above $-0.456 \mathrm{~V}$ (vs. SHE). Discharge cell potential limits shall be preferably high to achieve a substantial cell power.

Membrane Electrode Assembly: The membrane electrode assembly (MEA) is composed of a bifunctional air/water electrode and an ion exchange membrane. For the direct four-electron reduction of oxygen $(O R R)$ a noble metal catalyst such as platinum is required, while $\mathrm{IrO}_{2}$ catalysts show a rather good performance for the evolution reaction (OER) [56]. In this work bifunctional electrodes with a $\mathrm{Pt} / \mathrm{IrO} \mathrm{O}_{2}$ catalyst shall be used.

In the $M E A$ the proton conducting membrane is contacted with the bifunctional catalyst by a liquid ion-conducting film. The catalyst can be deposited directly on the membrane $(C C M)$ or a porous gas diffusion electrode $(G D E)$ substrate (see figure 2.15), which is electrically conductive and does, thus, permit a transfer of electrons to the reactive sites. This boundary layer is referred to as 3-phase layer. As the ORR and $O E R$ occurs, oxygen (gas) or vaporized water (during charging) is supplied to the catalyst surface (solid) while liquid product water is discharged.

To achieve high current densities and low concentration overpotentials, a tubular bifunctional GDE has to be developed, which features a well-defined porous structure enabling mass transfer of gaseous oxygen and liquid water in reverse directions while maintaining a moisture-sensitive 3-phase layer. A PFSA/PTFE copolymer dispersion can be applied on the GDE to extend the reaction zone and enhance proton migration in the 3-phase layer.

The porous GDE structure and catalyst material must withstand the highly oxidizing conditions during charging and reducing conditions during discharging. Due to the presence of oxygen in a highly reactive form during charging carbon materials are severely attacked [56] and can not be used for GDE structures. A suitable porous titanium material shall, therefore, be identified and utilized for the tubular GDE.

For the development of a tubular $M E A$ a brushing, dip-coating or impregnation procedure for the coating of PFSA/PTFE copolymer dispersions on the GDE must be established. In order to obtain a stable bond between the GDE and the tubular membrane, a lab-scale bonding tool and routine shall be developed. 


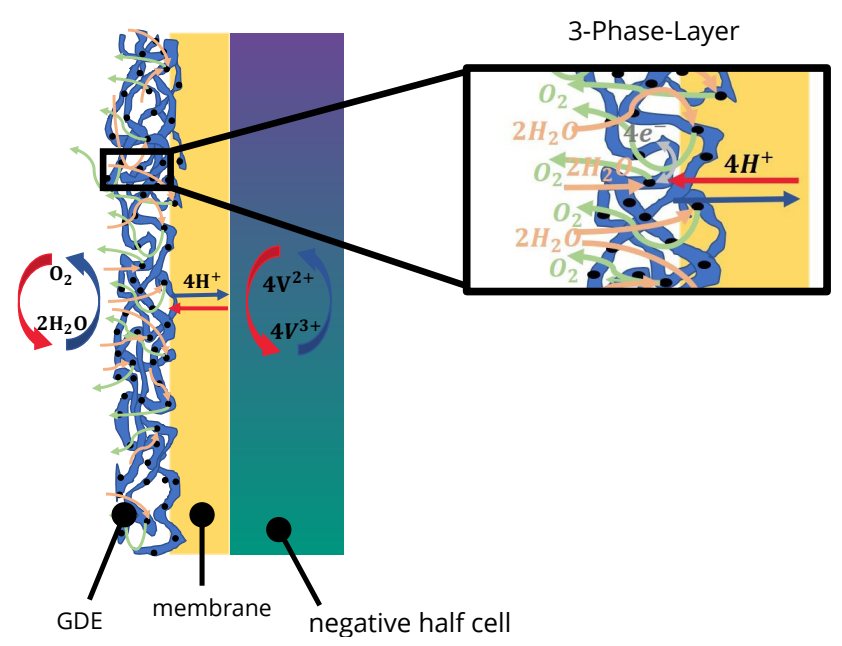

FIGURE 2.15: Illustration of membrane electrode assembly. Detail right: 3-phase-layer with charge and mass transfer.

Pressure Drop: Diverging pressure drops are expected along the positive and negative half cell as different fluids (gas mixture and liquid vanadium electrolyte solution) and electrode permeabilities are used in the positive and negative half cell. This difference in the half cell pressure introduces mechanical stress on the membrane. To avoid membrane failure suitable membrane support structures might be required and have to be considered for the tubular cell design.

Electrical Contacting: While the negative electrode of the tubular VARFB cell shall be contacted with a tubular current collector (see above), contacting of the GDE might be realized by a direct contact of the titanium GDE substrate at the end face. A suitable contacting method of the GDE substrate shall be developed, which is reproducible, durable and features a low electrical contact resistance $(\leq 5 \mathrm{~m} \Omega)$.

Sealing: To avoid gas leakage from the positive half cell into the environment or the negative half cell, tubular membrane sealing methods shall be developed. Tubular VARFB cell designs with an outer air electrode will also require a leak tight housing. As the sealings and the housing will be exposed to hot humid gas and reactive intermediates of the electrochemical reaction, materials with a high chemical and 
thermal degradation resistance shall be used.

Fabrication: The tubular cell developed within this work shall be fabricated by a co-extrusion process in the future. Developed cell component designs and used materials must permit to be produced by extrusion or allow for an endwise feed into the in-line process. The number of cell components shall be preferably low to reduce the fabrication complexity and process steps. Within this work tubular membrane electrode assemblies shall be fabricated with a specifically designed lab-scale bonding tool from welded or extruded membranes and GDE substrates. However, the suitability of GDE materials and designs for a future extrusion based in-line production of $M E A s$ shall be taken into consideration. In order to demonstrate the feasibility of extruded tubular VARFB cells, test cells have to be assembled from extruded cell components and the developed tubular $M E A$. The lab scale assembly procedure shall be done manually.

\subsubsection{Electrical Cell Resistance}

In equation 2.24 the electrical cell resistance $\left(R_{\text {cell }}\right)$ is defined. It is composed of the electric resistances of all electron conducting (electrode, current collector) and ion conducting (electrolyte and membrane) cell components. Electrical resistances are defined by the geometry of the conductor and its material specific resistivity constant (see equation 2.22). At the contact surfaces of the electron conducting components additional contact resistances $\left(R_{\text {contact }}\right)$ arise. Considering the contact surface to be free of parasitic layers, such as corrosive layers or impurities, the contact resistance is due to the constriction resistance.

Due to the microscopic surface roughness of the contact surfaces, the actual contact occurs at micro-contact points. As current conduction is restricted to these contact points, the current density increases locally leading to the constriction resistance. The constriction resistance, thus, depends on the surface roughness of the contact surfaces, the specific resistivity of the conductive materials and the actual contact points, which depend on the material strength and the applied normal force.

By compressing porous graphite felt electrode materials against a conductive surface (e.g. of a current collector), a normal force is applied to the graphite fibers at the contact surface and the contact resistance is reduced.

In figure 2.16 the compression ratio dependent specific resistivity $\left(\rho_{G F A}\right)$ and specific contact resistance $\left(\rho_{\text {cont }}\right)$ of GFA EA graphite felt electrode material of SGL Carbon is shown. Measurements were done with a plain copper made contact surfaces $\left(A_{\text {cont }}=615.8 \mathrm{~mm}^{2}\right)$ and the felt compression ratio of $0 \%$ was defined to be 
at 7 mbar. Although the contact resistance depends on the actual contact surface (contact points), specific contact resistances are related to the macroscopic contact surface $A_{\text {cont }}$.

While a quasi-exponential decrease of the specific contact resistance can be observed
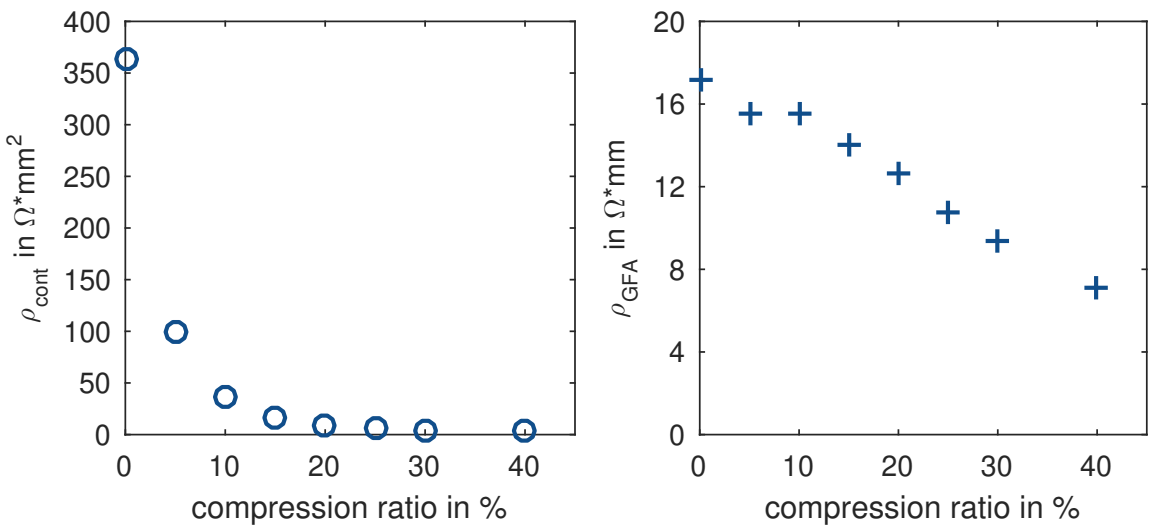

FIGURE 2.16: Left: Compression ratio dependent specific contact resistance of GFA EA electrode; right: specific resistivity of GFA EA electrode.

with an increasing compression ratio, the specific resistance decreases linearly from $\rho_{G F A}=17 \Omega \mathrm{mm}$ at $0 \%$ compression (published $\rho_{G F A}$ of SGL Carbon: $<12 \Omega \mathrm{mm}$ [126]). In order to yield low contact resistances in a cell compression ratios should be set to values below $20 \%$, accordingly.

The ohmic resistance of a cell is typically related to the membrane surface area and is then denoted as area specific cell resistance ( $A S R$, see equation 2.21). To date, the lowest $A S R$ value $\left(0.5 \Omega \mathrm{cm}^{2}\right)$ for a lab-scale $V R F B$ cell with flow by electrodes is reported by Aaron et al. [2]. ASR values of planar cells with a standard flow-through electrode configuration do, however, turn out to be higher and are in a range from $1.3 \Omega \mathrm{cm}^{2}$ to $2.0 \Omega \mathrm{cm}^{2}$ [72]. For the tubular cell designs developed within this work an $A S R \leq 3 \Omega \mathrm{cm}^{2}$ shall be achieved.

A simplified analytical model of several cell designs is used to estimate the ASR. Specific resistivities of current collector materials and electrodes, as well as the specific contact resistance displayed in figure 2.16 are then used to calculate and evaluate cell design concepts. For the sake of brevity, only two flow-through cell design concepts are exemplified. In table 2.1 specific electric resistivity values of potential electrode 
and current collector materials are listed. Due to the comparably high specific resistivity and preferably high cell lengths $\left(l_{\text {cell }} \geq 100 \mathrm{~mm}\right)$ graphite felt electrodes cannot be contacted at the end face. As the GDE of the tubular VARFB is made of titanium substrates, electrical contacting at the end face is possible in the positive VARFB half cell.

By inserting a longitudinally oriented current collector into the center of an inner

TABLE 2.1: Specific electric restivities of potential electrode and current collector materials.

\begin{tabular}{cccccc}
\hline & copper & titanium & extruded graphite & graphite/polymer & GFA EA electrode \\
\hline$\rho[\Omega \mathrm{m}]$ & $1.68 \cdot 10^{-8}$ & $4.2 \cdot 10^{-7}$ & $1.0 \cdot 10^{-5}[125]$ & $1.3 \cdot 10^{-3}[101]$ & $1.2 \cdot 10^{-2}[126]$ \\
\hline
\end{tabular}

tubular graphite felt electrode (see figure 2.17) an enhanced electrical conductivity along the cell can be achieved. In the outer half cell a tubular current collector, which houses the outer felt electrode, can be utilized to increase the longitudinally conductivity. The calculated area specific resistance of the inner and outer half cell with
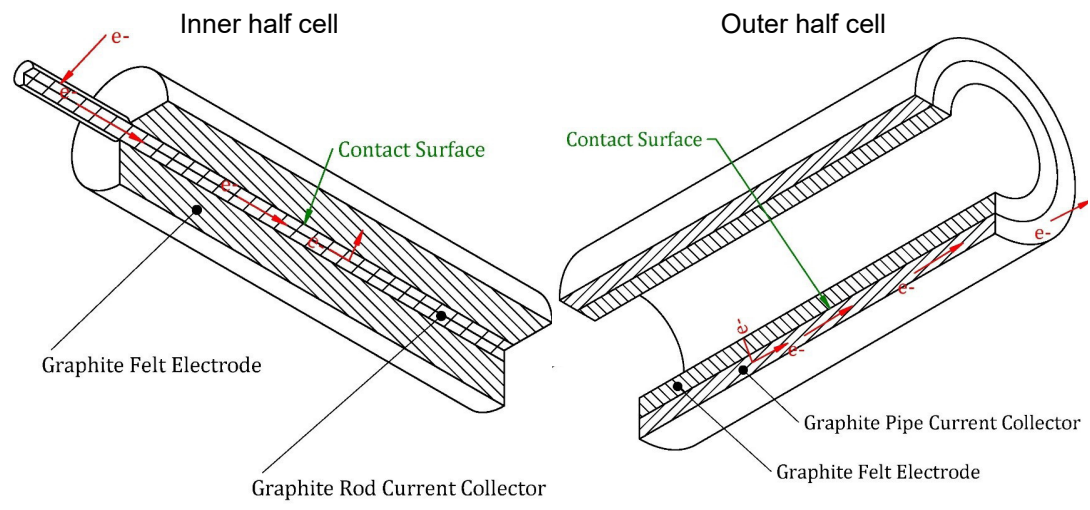

FIGURE 2.17: Illustration of tubular flow-through half cells with graphite current collectors.

graphite made current collectors is displayed in figure 2.18. As the membrane diameter of the cell is defined to be $5.0 \mathrm{~mm}$ the tolerable cross-sectional area of the inner current collector is strongly limited. To allow for a sufficient electrode volume the inner current collector diameter should not exceed $1.0 \mathrm{~mm}$. The specific electric resistivity and comparably small cross-sectional area of the inner current collector lead 
to an $A S R=14.5 \Omega \mathrm{cm}^{2}$ at a cell length of $100 \mathrm{~mm}$. In the outer half cell substantially lower $A S R$ values could be achieved as higher cross-sectional areas of the outer current collector can be realized.

To overcome this restriction metal current collector materials (e.g. copper) must
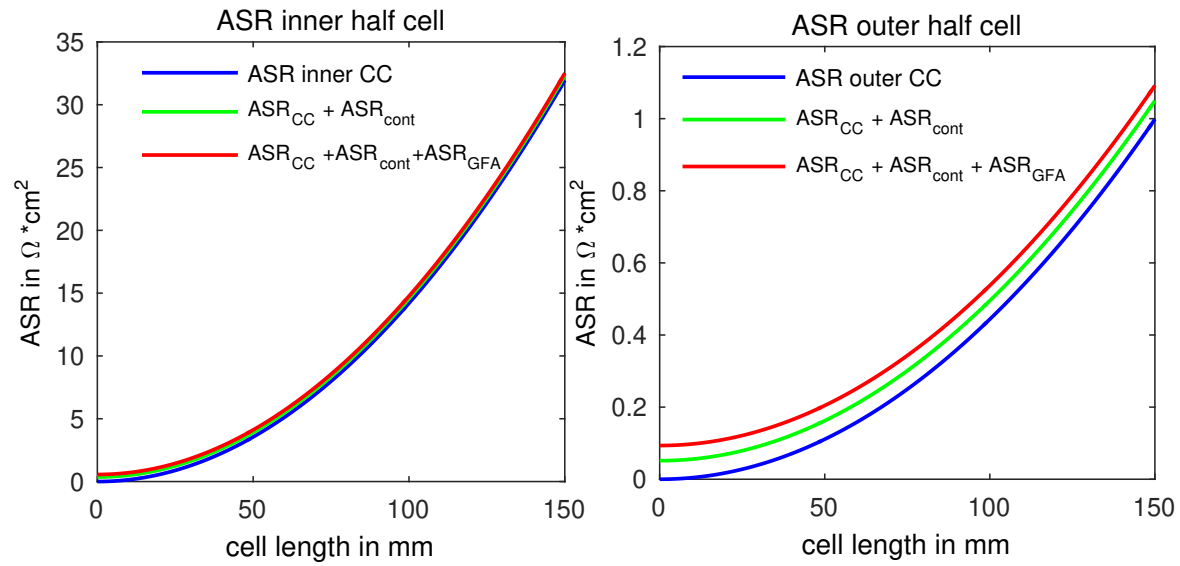

FIGURE 2.18: Estimated ASR of flow-through half cells with graphite current collector. Left: inner half cell, right: outer half cell.

be used. The highly corrosive environment in the half cell does, however, prohibit the use of metals and a protective layer with a good electric conductivity must be applied (see figure 2.19). Conductive polymers made from graphite/polymer compounds exhibit a good electrical conductivity and are chemically stable [101]. The area specific resistance of an inner and outer flow-through electrode configuration with composite current collectors is displayed in figure 2.20. The inner half cell still exhibits a higher resistance than the outer half cell but area specific resistances are sufficiently low to achieve an overall $A S R \leq 3 \Omega \mathrm{cm}^{2}$.

The major contribution to the inner half cell resistance is introduced by the contact resistance at the interface of the graphite felt and the current collector. The comparably small contact surface area of the inner current collector is the bottle neck in terms of the achievable cell resistance of tubular flow-through cells, accordingly. The composite current collector reduces the electric conductivity in longitudinal direction and allows for cell lengths $>100 \mathrm{~mm}$ and membrane diameters of $5.0 \mathrm{~mm}$. 

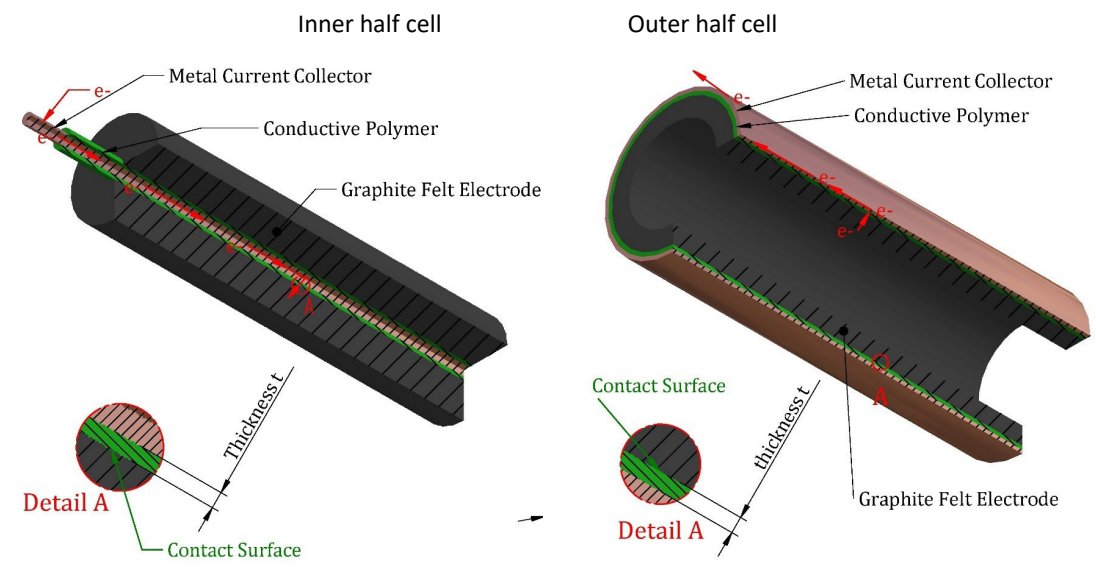

FIGURE 2.19: Illustration of tubular flow-through half cells with composite current collectors.

\subsubsection{Pressure Drop}

During the operation of Redox Flow Batteries electrolyte solutions are pumped through the cell. Hydraulic resistances of the half cells result in pressure drops, which need to be compensated by an applied pumping power (see equation 2.51). The pumping power has to be minimized to yield high system energy efficiencies (see equation 2.63).

Accordingly, pressure drops across the tubular half cells need to be taken into account when tubular cell concepts are developed.

In section 1.1.4 two electrode configurations are introduced. In flow-through electrode configuration electrolyte solutions flow through the porous structure of the electrode, while electrolyte solutions are passed through flow channels along the electrode in flow-by electrode configurations. In subsequent sections an empirical method for the calculation of pressure drops in porous media is described and a simplified approach for the estimation of pressure drops along flow channels is presented. The introduced estimations are then used for the development of design concepts and the analysis of tubular cells.

\section{Flow through porous media}

The Reynolds number $(R e)$ is a dimensionless quantity, which describes the ratio of internal to viscous forces within a fluid and permits to predict flow patterns in different fluid flow conditions. Under consideration of the superficial flow velocity $u$, 

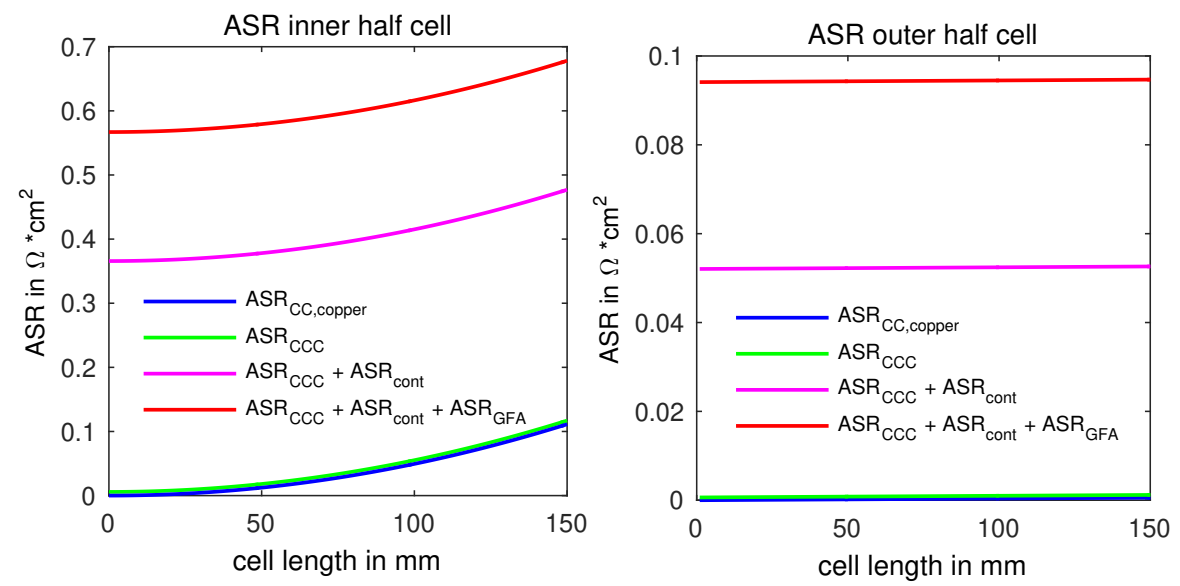

FIGURE 2.20: Estimated ASR of flow-through half cells with composite current collector (CCC). Left: inner half cell, right: outer half cell.

characteristic lengths $d_{h}$, dynamic viscosity $\mu$ and the porosity $\epsilon$ the Reynolds number can be calculated for fluid flow in porous media:

$$
\operatorname{Re}=\frac{\rho \cdot u \cdot d_{h}}{\mu \cdot \epsilon}
$$

By assuming flow through pipes with non-circular cross-section the characteristic length can be replaced by the hydraulic diameter $D_{H}\left(d_{h}=4 \cdot D_{H}\right)$ [18]. The hydraulic diameter $D_{H}$ for porous media is defined by the relation of the pore volume $V_{\text {por }}$ (fluid volume) to the surface area, which encloses the fluid (graphite felt surface area $A_{\text {elec }}$ eq.: 2.11) [22]:

$$
D_{H}=\frac{\epsilon}{a_{\text {elec }}}=\frac{\epsilon \cdot d_{f}}{4 \cdot(1-\epsilon)}
$$

The Reynolds number for porous graphite felt then reads:

$$
R e=\frac{\dot{Q} \cdot \rho \cdot d_{f}}{\mu(1-\epsilon) A_{\perp}}
$$

For Reynolds numbers above 100 a turbulent flow regime is present in the porous 
media. Laminar flow conditions occur for Re from about 1 ...10 up to 100. Plug flow conditions can be observed for $\operatorname{Re}<1$.

Darcy's Law can be applied for plug flow and a low laminar flow regime and permits to estimate the superficial flow velocity $u$ of a fluid flux through porous media:

$$
u=K \cdot \frac{\Delta p}{\mu \cdot L}
$$

With the permeability $K$, dynamic viscosity $\mu$ and pressure drop $\Delta p$ across a porous sample with the length $L$. Kozeny and Carman developed a correlation to estimate the permeability for porous media of different composition and porosity $\epsilon$ by using the hydraulic diameter $D_{H}$ of the porous substrate and a constant $c_{K C}$ often denoted as Kozeny-Carman Constant.

$$
K=\frac{D_{H}^{2} \cdot \epsilon}{c_{K C}}
$$

Combination of equation 2.77 and 2.80 then yields:

$$
K=\frac{\epsilon^{3} \cdot d_{f}^{2}}{(1-\epsilon)^{2} \cdot 16 \cdot c_{K C}}
$$

Application of Kozeny-Carman's permeability estimate K to Darcy's Law (eq.: 2.79) allows to calculate the pressure drop across porous felt material $\Delta p_{K C}$ :

$$
\Delta p_{K C}=\frac{\dot{Q} \cdot \mu \cdot L \cdot(1-\epsilon)^{2} \cdot 16 \cdot c_{K C}}{A_{\perp} \cdot \epsilon^{3} \cdot d_{f}^{2}}
$$

The $c_{K C}$ constant is an empirically determined parameter, which is specific to the structure of the porous media. In [80] Ma et al. developed a three-dimensional model for the negative half cell of a $V R F B$. In the model the permeability of the electrodes was estimated with equation $2.81\left(d_{f}=17.6 \mu \mathrm{m}, \epsilon=92.9 \%\right)$ and a $c_{K C}=4.28$ was obtained by fitting. In a model of Wei et al. [155] the pressure drop across a flowthrough electrode of a VRFB was also modeled by applying Darcy's Law and KozenyCarman's permeability estimate. However, the permeability was defined to be $K=$ $\left(d_{f}^{2} \cdot \epsilon^{3}\right) /\left(c_{K C}(1-\epsilon)^{2}\right)$ and an electrode porosity $\epsilon=68 \%$ and $d_{f}=3 \times 10^{-9} \mu \mathrm{m}$ was used for the simulation. A two-dimensional model framework for VRFBs was proposed by Shah et al. [127]. In the model an analog definition for the permeability than in [155] is used to estimate the pressure drop in flow-through electrodes with a fiber diameter of $10 \mu \mathrm{m}$ and porosity of $68 \%$. A default value of 5.55 was used for 
the Kozeny-Carman Constant in the model.

Although Darcy's Law and Kozeny-Carman's permeability estimate are used in several VRFB flow-through electrode models [80, 127, 155], inconsistent definitions of the permeability $(K)$, Kozeny-Carman Constant $\left(c_{K C}\right)$ and porous graphite electrode properties are found in the literature. A calculation of the pressure drop in tubular flow-through electrodes based on published data can not be done, accordingly. Measurements of the pressure drop in potential electrode materials need to be conducted and Kozeny-Carman Constant have to be determined. In section 3.2.1 pressure drop measurements across porous GFA EA graphite felt electrodes are conducted and $c_{K C}$ values are estimated.

\section{Flow through channels}

In flow-by electrode configurations electrolyte solution is passed through flow channels. Calculation of the Reynolds number can then be done with the general definition.

$$
R e=\frac{\rho \cdot u \cdot d_{h}}{\mu}
$$

For $R e<2300$ a laminar flow regime can be observed as a fluid flows through a tube. If an incompressible flow of a Newtonian fluid flows through a long tube with a fully developed velocity profile (parabolic), the Hagen-Poiseuille equation can be applied [18]. As the flow channel's cross-section can be regarded as circular-like, features a relatively long channel length compared to the cross-sectional diameter and a laminar flow is maintained, the Hagen-Poiseuille equation is employed to describe the pressure drop $(\triangle p H P)$ in flow-by electrode configurations.

$$
\Delta p H P=\frac{\dot{Q} \cdot 8 \cdot \mu \cdot l}{\pi \cdot r^{4}}
$$

The length of the channel is specified by $l$ and the radius of the channel is denoted as $r$. The required pumping power ( $P_{\text {pump }}$, eq. 2.51) for a tubular $V R F B$ cell with flowby electrode configuration is displayed in figure 2.21. For the estimation a half cell design with 8 flow channels with a diameter of $0.5 \mathrm{~mm}$ is hypothesized. By relating the pumping power to the cell power $\left(P_{\text {cell }}\right.$, eq. 2.50$)$ the share of the pressure drop induced losses becomes apparent. The cell power is calculated for a cell with an $A S R=3 \Omega \mathrm{cm}^{2}$, current density of $100 \mathrm{~mA} \mathrm{~cm}^{-2}$ and residual overpotentials analog to the published value $\left(\eta_{\text {res }}=318 \mathrm{mV}\right)$ of Aaron et al. [2]. Furthermore, an $S o C$ of $50 \%$, total vanadium concentration of $1.6 \mathrm{moll}^{-1}$ and pump efficiency of $60 \%$ [147] is assumed. Even if a cell with a length of $10 \mathrm{~cm}$ is operated with an electrolyte excess ratios $\left(\lambda_{\text {elyt }}\right)$ of 15 the required pumping power does not exceed $1.0 \%$ of the cell power. 


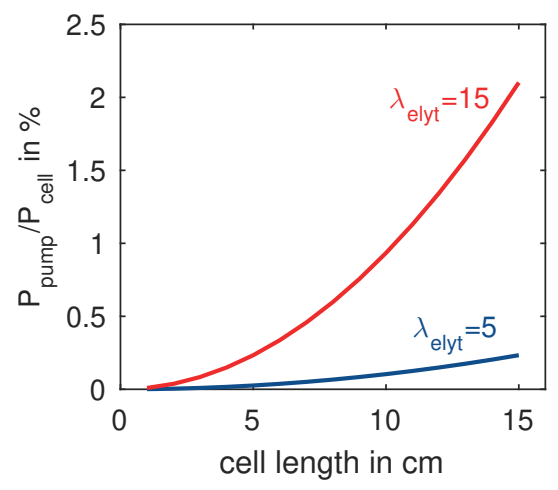

FIGURE 2.21: Estimated share of required pumping power $\left(P_{\text {pump }} / P_{\text {cell }}\right)$ for tubular VRFB cell with flow-by electrodes.

\subsubsection{Tubular Cell Concepts}

The development, evaluation and selection of potential tubular VRFB and VARFB cell designs is done in consideration of the methods described in the VDI standard VDI2221 "Systematic approach to the development and design of technical systems and products" [144].

First, sub-functions of cell components are analyzed and alternative solutions for the sealing of components, electrical contacting of electrodes and cell setups are developed. Suitable electrode and current collector materials are selected. Cell concepts are then generated by a systematic combination of partial solutions. An assessment of the cell concept's fulfillment of the requirement specifications (section 2.3.1) and manufacturability is done. Most promising cell concepts are selected, further detailed and considered for the lab-scale fabrication and experimental characterization. For the sake of brevity, only the selected cell concepts are introduced in this section.

\section{Tubular VRFB Cells}

Analysis of the electrical resistance of tubular $V R F B$ cells revealed the necessity of metal current collectors for an enhanced conductivity in longitudinal cell direction. In order to prevent corrosion of the metal a protective layer with a high conductivity needs to be applied. A graphite/polyolefin compound material, which can be processed by extrusion, shall be used to produce composite current collectors (CCC). In flow-through design the cross-sectional area of the inner CCC is limited by the required electrode volume and membrane diameter $(5.0 \mathrm{~mm})$. Contact resistances at the inner CCC/electrode interface are expected to be comparable high as only a 
limited surface area is available. The electrical resistance of the inner half cell is, therefore, considered to be the bottle neck.

In flow-by electrode configuration thinner electrodes are typically used $[2,107]$ than in flow-through configuration. The inner flow-by CCC can, hence, be designed with a higher cross-sectional area and contact surface.

Estimation of the pressure drop indicates that tubular flow-by current collectors can be designed, which only require $1 \%$ of the cell power to overcome the pressure drop. The pressure drop along porous flow-through electrodes is assumed to outreach the pressure drop in flow-by configuration and would lead to reduced system energy efficiencies.

Although lower electric resistances and pumping losses might be realized in tubular $V R F B$ cells with flow-by electrode configuration, the suitability of flow-by electrodes in a liquid electrolyte system is questionable. In the review of Weber et al. [152] flowthrough electrodes with a porous 3D electrode (e.g. graphite felt) and convection forced mass transfer are considered to be better suited for liquid-phase electrolytes as mass transfer in flow by electrodes is mainly due to diffusion and the diffusivity of liquid-phase species is low. It is further stated that "flow-by electrodes, due to their limited surface area and long ion-transport distances, would almost never be preferred over $3 D$ electrodes occupying the same volume"' [152]. Experimental investigations of a planar flow-by $V R F B$ cell have, however, shown that current densities above $500 \mathrm{~mA} \mathrm{~cm}^{-2}$ can be achieved [2].

Within this work two tubular VRFB cell concepts with flow-through and flow-by electrode configuration will, therefore, be developed and evaluated.

For the tubular flow-by VRFB cell graphite felt electrodes with a thickness of $700 \mu \mathrm{m}$ will be used for the inner and outer half cell. In the inner half cell of the tubular flow-through VRFB cell cylindrical porous GFA EA graphite felt electrodes will be used, which need to be fabricated from commercially available sheet material.

Tubular membranes will either be made from welded cation exchange sheet material or will be manufactured by extrusion.

When flow-by electrodes with an identical volume are utilized in the inner and outer half cell shorter diffusion path lengths can be realized in the outer half cell. Accordingly, the electrolyte solution containing the species with the lowest diffusivity should be employed in the outer half cell. In Vanadium Redox Flow Batteries the $V^{2+/ 3+}$ redox couple features lower diffusion coefficients than $V^{4+/ 5+}$ and should, thus, be utilized in the outer half cell. In addition, wider flow channels can be realized in the outer half cell and the electrode surface area adjacent to the flow channel is higher in the outer than inner half cell.

In flow-through electrode configurations a homogenous electrolyte flow distribution (velocity) is assumed and mass transfer mainly occurs due to forced convection [152]. Accordingly, diffusion path lengths are less critical in flow-through cells and 
species with lower diffusivity can also be employed in the inner half cell. However, under non ideal conditions (pore size distribution, inhomogeneous felt) channeling effects might occur in the porous electrodes and the share of the diffusive mass transfer might be higher than expected. Tubular flow-through VRFB cells will, hence, also be designed with an negative outer half cell.

\section{Tubular Vanadium/Air RFB Cells}

As a matter of principle, tubular VARFB cells might be designed with the bifunctional air/water electrode in the inner or outer half cell. The half cell configuration extensively influences the manufacturability and cell performance. In the left and center of figure 2.22 tubular VARFB cell concepts with an inner air/water half cell are illustrated. A VARFB cell concept with an outer air/water half cell is displayed on the right in figure 2.22.

In previous sections the electrical resistance of half cells with flow-by and flow-
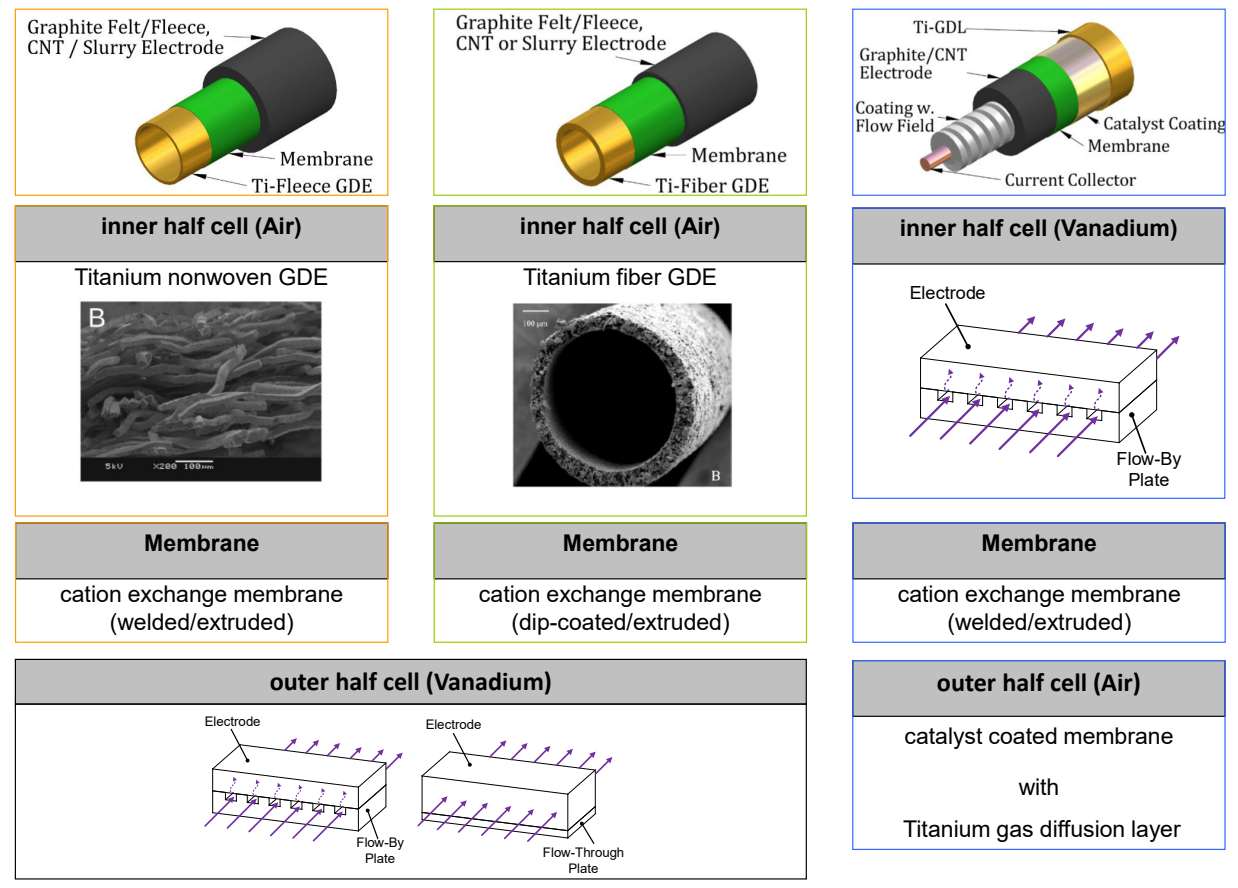

FIGURE 2.22: Tubular VARFB cell concepts.

through graphite felt electrodes was analyzed and the inner half cell was identified 
as the bottle neck. The bifunctional air/water electrode can either be made of a GDE with a titanium substrate or a catalyst coated membrane with a porous titanium gas diffusion layer. In any of the two setups a titanium substrate is utilized, which exhibits a sufficiently high electric conductivity in longitudinal cell direction. Tubular $V A R F B$ cells with an inner GDE might, therefore, lead to lower area specific cell resistances and are considered as the preferential configuration. Furthermore, tubular $V A R F B$ cells with an inner air/water electrode do not place restrictions on the reduction of the cell diameter as GDEs are typically designed with small layer thicknesses and electrical contacting can be done at the end face.

The GDE of all three cell concepts shall be operated in flow-by mode as the diffusivity of gas-phase species is comparably high. Within this work two flow channel designs shall be evaluated. One flow channel design is denoted as single flow channel design, as the gas is simply passed along the electrode. For the second flow channel design an additional component with helix flow channels shall be used. The helix flow channel design might enhance the mass transfer, while the single flow channel design would reduce the number of components.

In this work a mono-layered GDE design is chosen to be the preferential design (left and center in figure 2.22). The use of a single GDE layer reduces the number of components and process steps, which is beneficial for a cost efficient fabrication [56]. Bifunctional $\mathrm{Pt} / \mathrm{IrO} \mathrm{O}_{2}$ catalysts and PSFA ionomers are directly coated on the porous titanium structure. The GDE structure will first be made from a sintered titanium non-woven material (left in figure 2.22). For the future inline extrusion of the entire tubular membrane electrode assembly, the sintered non-woven GDE substrate might be replaced by a sintered titanium hollow fiber (center in figure 2.22). The titanium hollow fiber could be fabricated with a dry-wet spinning process with a subsequent sintering process as it is described in the paper of David et al. [34].

The third cell concept (right in figure 2.22) is regarded as a fall-back option. The bifunctional air/water electrode is composed of a catalyst coated membrane with a porous titanium gas diffusion layer. As the catalyst coating of the inner membrane surface in an extrusion process would lead to an elaborate [92] and cost intensive fabrication, the bifunctional air/water electrode is located in the outer half cell. This cell concept might only be further detailed and investigated if the reactive zone in the porous GDE of the preferential cell concept (left in figure 2.22) would turn out to be too small. 



\section{Chapter 3}

\section{Tubular All Vanadium Redox Flow Cells}

In chapter 2 implications of tubular cell designs on the cell performance and fabrication are outlined and possible half cell and electrode configurations are introduced. Based on these considerations tubular VRFB cells with flow-by and flow-through electrode configurations are designed and fabricated. An experimental characterization and evaluation of the developed VRFB test cells is presented in this chapter. The performance characteristic of a planar reference cell and liquid permeability data of tubular flow-by and flow-through electrodes are employed for the evaluation of the developed tubular $V R F B$ cells.

Part of the results on a tubular VRFB cell with an electrode compression ratio of $25 \%$ were published by the author in The Journal of Power Sources in 2017 [114]. Further results on tubular VRFB cells were presented at The International Flow Battery Forum 2017 within a poster session [113]. Oral presentations covering parts of the results were given at the GDCh Scientific Forum Chemistry 2017 [110] and the 10th World Congress of Chemical Engineering [112].

\subsection{Experimental}

Characterization and evaluation of the tubular cell's performance characteristics are done with the methods described in section 2.2. In this section the test cell designs are introduced before the established fabrication techniques and employed cell components are specified. The applied measurement routines and parameters used to characterize the test cells are detailed at the end of this section. 


\subsubsection{Test Cells}

For the evaluation of the pressure drop in tubular flow-by and flow-through half cells reference data are required. To generate this reference data pressure drop measurements are done with permeability test cells. A specification of the permeability test cells is given at the beginning of this section, accordingly.

Next, the planar reference cell design is described and employed cell components are listed. A description of the flow-through VRFB cell's (FT-VRFB) design and geometry is given before the flow-by VRFB cells $(F B-V R F B)$ are described. All tubular test cells are integrated in the same test cell housing.

\section{Liquid Permeability Test Cell}

The measurement of the pressure drop along flow-by and flow-through electrodes is done with specially designed permeability test cells. In figure $3.1 \mathrm{~A}$ a cross-sectional view of the inner electrode test cell is displayed. The PVDF made housing features
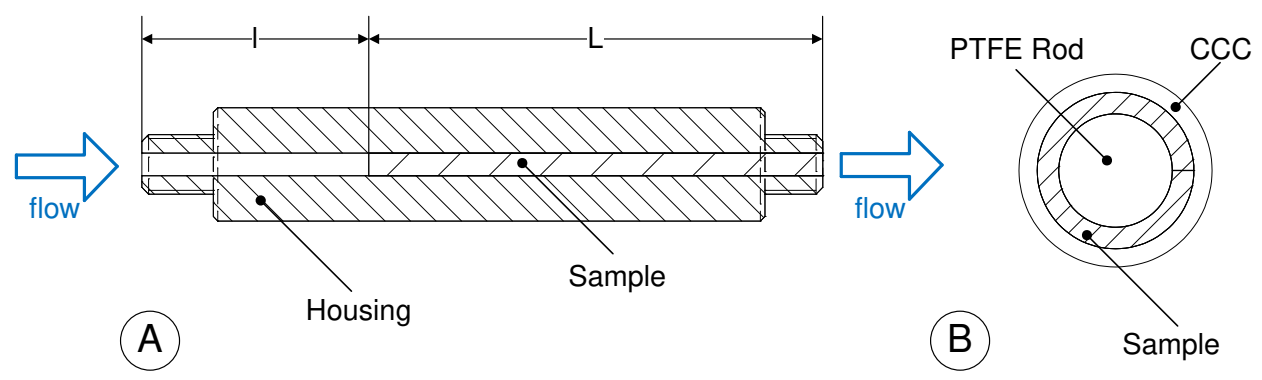

FIGURE 3.1: A: Cross-sectional view of permeability test cell for inner electrode samples. B: Top view of permeability test cell for outer electrode samples (not true to scale).

a cylindrical cavity, which contains the tubular flow-through and flow-by samples. Socket end fittings are screwed to the fluid inlet and outlets and a void section at the inlet with an entrance length $(l)$ is maintained to assure complete flow profile dispersion.

Outer flow-by and flow-through electrode samples are measured with a second permeability test cell $(B)$. It is composed of an outer composite flow-by (fig. 3.2) or flow-through $(B)$ current collector (sec. 3.1.2) with the respective electrode material (sample in fig. $3.1 \mathrm{~B}$ ) and a PTFE rod in the center. Connection of the test cell with 


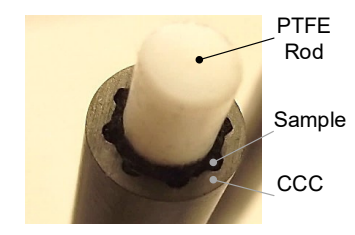

FIGURE 3.2: Outer flow-by permeability cell. the inlet and outlet piping is done by integrating the test cell into the test cell housing (see below).

For the determination of the Kozeny-Carman constant $\left(C_{C K}\right)$ several samples of different sample length $(L)$, porosities $(\epsilon)$ and compression ratios $(\chi)$ are prepared and listed in table 3.1. Specifications of the flow-by electrode samples can also be found in table 3.1.

TABLE 3.1: Liquid permeability measurement samples (flowthrough (FT): Sigracell GFA6 EA, flow-by (FB): GDL \#2614 Pyron of SGL Carbon, Germany) with properties and settings.

\begin{tabular}{lcccccc}
\hline $\begin{array}{l}\text { sample } \\
\text { no. }\end{array}$ & $\begin{array}{c}L \\
\mathrm{~mm}\end{array}$ & $\begin{array}{c}\epsilon \\
\%\end{array}$ & $\begin{array}{c}\chi \\
\%\end{array}$ & hc & heat treatm. & config. \\
\hline 1 & 100 & 92.9 & 25 & inner & no & FT \\
2 & 65 & 92.9 & 25 & inner & no & FT \\
3 & 35 & 92.9 & 25 & inner & no & FT \\
4 & 100 & 93.7 & 10 & inner & no & FT \\
5 & 100 & 94.3 & 0 & inner & no & FT \\
6 & 100 & 93.1 & 20 & outer & no & FT \\
7 & 100 & 92.9 & 25 & inner & yes & FT \\
8 & 100 & 83.3 & 25 & inner & no & FB \\
9 & 100 & 83.3 & 25 & outer & no & FB \\
\hline
\end{tabular}

\section{Planar Reference VRFB Cell}

In this work the planar Micro Flow Cell of ElectroCell, Denmark is employed as a reference $V R F B$ cell. It features an active membrane area $\left(A_{\text {mem }}\right)$ of $10 \mathrm{~cm}^{2}$ and a flow-through electrode configuration. A fumapem ${ }^{\circledR} F 10100$ cation exchange membrane of FUMATECH BWT GmbH with a thickness of $100 \mu \mathrm{m}$ separates the positive from the negative electrode. KFD 4.6EA alt. heat treat graphite felt electrodes of SGL Carbon with a projected electrode area of $(33 \times 30) \mathrm{mm}^{2}$ and a thickness of $4.6 \mathrm{~mm}$ are employed in both half cells. Electrode materials did not undergo a heat treatment as they were already tempered by SGL Carbon. Electrical contacting of the electrodes is realized by compression of the graphite felt material against a SIGRACELL Bipolar plate, TF6 of SGL Carbon. The bipolar plate material is made 
of a graphite/fluoropolymer composite material and features an area specific resistance $<0.05 \Omega \mathrm{cm}^{2}$ (through plate) and thickness of $0.6 \mathrm{~mm}$. Copper current collector sheets with a thickness of $0.35 \mathrm{~mm}$ are compressed to the back sides of the bipolar plates to permit a sufficiently high conductivity along the bipolar plate. Connection of the electrodes with power and sense wires is achieved by cable sockets, which are screwed to the copper sheet.

In figure 3.3 the test cell housing with gaskets and cell components is shown in an exploded view. The membrane $(A)$ is sandwiched between two FKM gaskets (1) and two flow-frames (2) with integrated electrolyte manifolds. The electrodes $(B)$ are placed into the flow-frames. A second pair of $F K M$ gaskets (3) is inserted between the flow-frames and bipolar plates with current collectors $(C)$. The planar cell is then placed between two more PTFE gaskets (4), two PTFE plates with socket end fittings (5) and two stainless steel end plates (6).

To assure sufficient sealing and electrical contacting of the electrodes, 6 bolts (7) are uniformly torqued with $2 \mathrm{~N} \mathrm{~m}$. Compression of the gaskets leads to a compression of

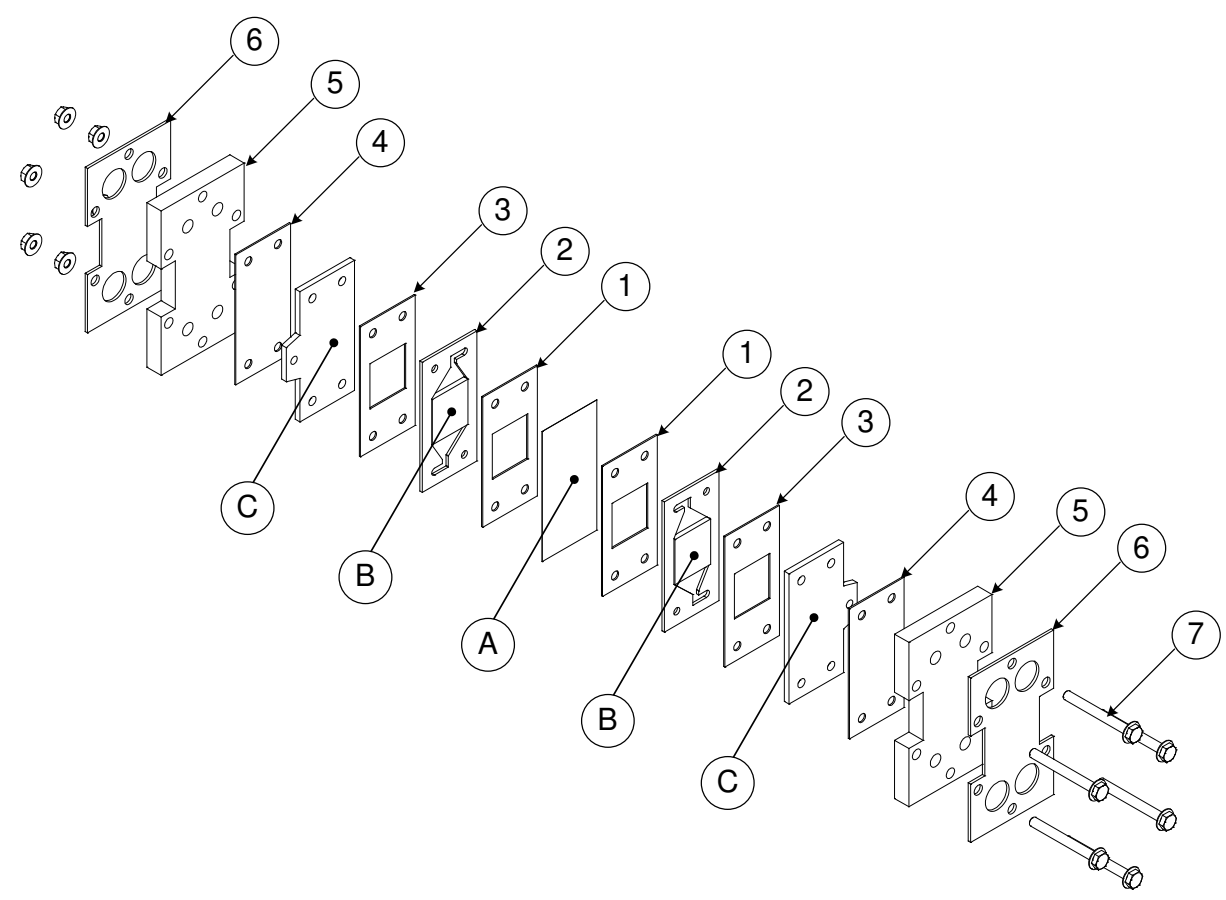

FIGURE 3.3: Exploded view of the planar VRFB reference cell (Micro Flow Cell of ElectroCell, Denmark). 
the electrode thickness and results in an electrode compression ratio $(\chi)$ of $24 \%$. The electrode compression ratio $\chi=\left(1-V_{\text {elec }} / V_{\text {elec }}^{0}\right) \cdot 100 \%$ is calculated from the ratio of the compressed electrode volume $V_{\text {elec }}$ to the uncompressed electrode volume $V_{\text {elec }}^{0}$.

\section{Tubular Flow-Through VRFB Cells}

In figure 3.4 a tubular $V R F B$ cell with flow-through electrode configuration (FT$V R F B)$ and an active cell length $\left(l_{\text {cell }}\right)$ of $84.5 \mathrm{~mm}$ is depicted. The tubular test cell is composed of an inner half cell (pos. 4 and 5) and an outer half cell (pos. 1 and 2 ), which are separated by a tubular membrane (pos. 3) with a membrane diameter $\left(D_{\text {mem }}\right.$ ) of $5.0 \mathrm{~mm}$ (active membrane area $A_{\text {mem }} \approx 13.3 \mathrm{~cm}^{2}$ ).

The inner half cell features a composite current collector CCC (pos. 5) with an outer diameter of $1.2 \mathrm{~mm}$ and is surrounded by an electrode (pos. 4). During operation the electrolyte solution enters the inner electrode at an end face, flows through the porous bulk of the electrode and leaves the electrode at the opposite end face.

A CCC tube (pos. 1) with an inner diameter of $6.9 \mathrm{~mm}$ containing the outer electrode (pos. 2) forms the outer half cell. As the tubular FT-VRFB is operated in parallel flow, electrolyte solution of the outer half cell enters the outer flow-through electrode at the same end face as the inner electrode and flows through the porous bulk volume of the outer electrode. To obtain an identical active electrode surface area, hydraulic
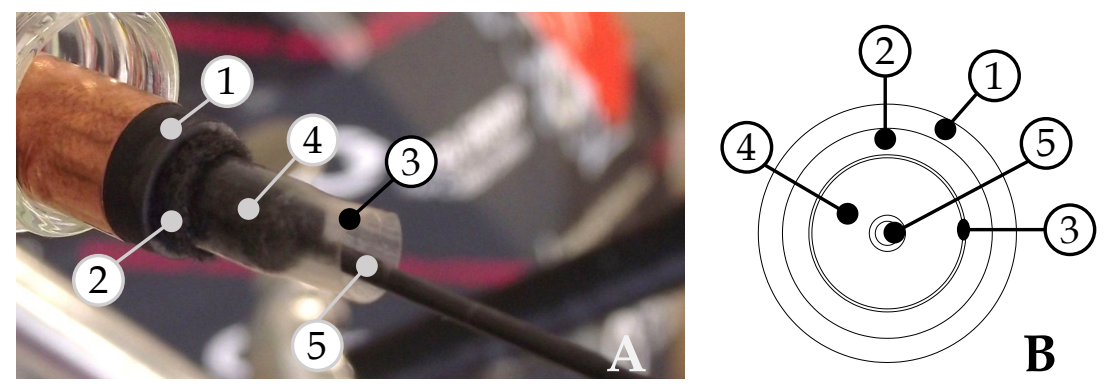

FIGURE 3.4: A: Picture of tubular VRFB test cell with flow-through electrode configuration (FT-VRFB); B: Schematic of cell cross section; 1 outer composite current collector; 2 outer electrode; 3 membrane; 4 inner electrode; 5 inner composite current collector.

diameter and pressure drop along the cell, the inner and outer half cell geometry was designed to result in equal electrode bulk volumes. An electrode compression ratio $(\chi)$ of $25 \%$ was estimated for the tubular flow-through test cell FT-25-VRFB. In section 3.1.2 the fabrication of electrodes is described and the tubular membrane employed in FT-25-VRFB is specified. 


\section{Tubular Flow-By VRFB Cells}

In figure 3.5 a tubular $V R F B$ cell with flow-by electrode configuration (FB-VRFB) and an active cell length $\left(l_{\text {cell }}\right)$ of $100 \mathrm{~mm}$ is depicted. Analog to the FT-VRFB the test cell is composed of an inner half cell (pos. 4 and 5) and an outer half cell (pos. 1 and 2 ), which are separated by a tubular membrane (pos. 3) with a membrane diameter $\left(D_{\text {mem }}\right)$ of $5.0 \mathrm{~mm}$ (active membrane area $A_{\text {mem }} \approx 15.7 \mathrm{~cm}^{2}$ ).

The inner half cell features a composite current collector CCC (pos. 5) surrounded by an electrode (pos. 4). Eight longitudinally oriented straight flow channels are integrated into the surface of the CCC. During operation the electrolyte solution enters the channels at the end face of the inner $C C C$, flows along the electrode through the channels and leaves the inner half cell at the opposite end face.

A CCC tube (pos. 1) containing the outer electrode (pos. 2) forms the outer half cell. Analog to the inner CCC 8 straight flow channels are incorporated into the inner tubular surface of the outer CCC. As tubular $F B-V R F B s$ are operated in parallel flow, electrolyte solution of the outer half cell enters the flow channels at the same end face as the inner half cell electrolyte and flows along the outer electrode through the flow channels. CCCs were designed with an identical sectional channel area
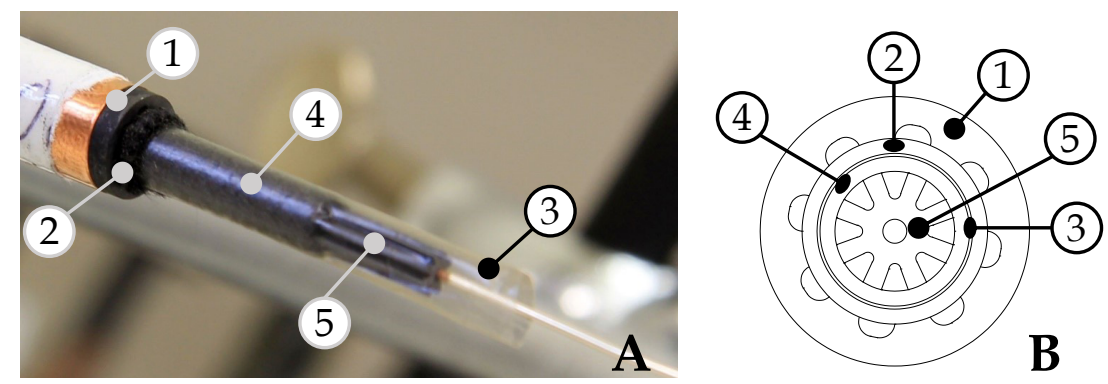

FIGURE 3.5: A: Picture of tubular VRFB test cell with flow-by electrode configuration (FB-VRFB); B: Schematic of cell cross section; 1 outer composite current collector; 2 outer electrode; 3 membrane; 4 inner electrode; 5 inner composite current collector.

$A_{\perp} \approx 0.625 \mathrm{~mm}^{2}$ in both half cells to maintain equal electrolyte flow velocities. By this way comparable pressure drops along the inner and outer half cells are expected and pressure gradients across the membrane (inner to outer half cell) are minimized. The outer diameter of the inner CCC is $4.0 \mathrm{~mm}$ while the inner diameter of the outer CCC tube is $6.2 \mathrm{~mm}$. Accordingly, an annular gap with a thickness of $1.1 \mathrm{~mm}$ houses the outer electrode (2), membrane (3) and inner electrode (4). Different electrode 
compression ratios can be obtained by either varying the electrode thickness or membrane thickness. Within this thesis $F B-V R F B$ cells with an electrode compression ratio of $25 \%$ FB-25-VRFB and $45 \%$ FB- $45-V R F B$ were obtained by employing tubular membranes of different thickness (see table 3.4).

\section{Tubular Test Cell Housing}

For the experimental characterization and operation test cells are mounted in a custom made test cell housing (fig. 3.6) [73], which was machined by Alfa Feinwerktechnik and Werkzeug- Formen- Maschinenbau-Service (WFM-S). The test cell housing features 1A PVDF fittings of EM-Technik to connect the positive and negative half cells to

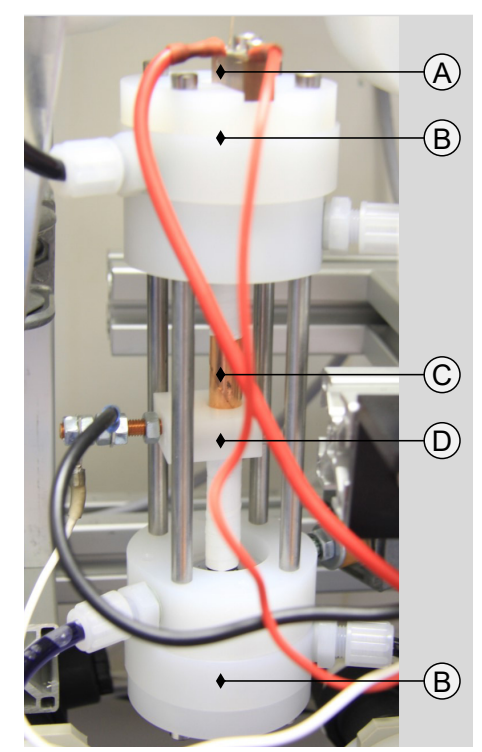

FIGURE 3.6: Test cell housing (B) with assembled VRFB cell $(C)$ and electrode terminals (A, D). the positive and negative electrolyte cycle of the test rig (see fig. 3.10). The electrodes and flow channels of the test cells are fed with the positive and negative electrolytes through manifolds which are integrated in the PVDF made end plates $(B)$ of the test cell housing. The end plates feature several seals to prevent leakage of electrolyte between the half cells and into the environment. The outer CCC of the test cell $(C)$ is clamped between the end plates and sealed with FKM gaskets at the end faces.

The positive and negative terminal of the test cell housing enable to connect the positive and negative electrodes of the test cells to a potentiostat. The terminal of the inner electrode $(A)$ is made of a copper bar with two lug terminals (for the power and sense wires), which is clamped to the copper wire of the inner CCC. The terminal of the outer electrode $(D)$ consists of a copper pin with a concave contacting surface which is compressed against the outer surface of the outer CCC by use of a spring (spring load 6.3 N). Analog to the inner electrode terminal two lug terminals are mounted to the copper pin. A contact resistance of $4 \mathrm{~m} \Omega$ of the outer electrode terminal was measured and the standard deviation was determined to be within $10 \%$. 


\subsubsection{Fabrication and Material Preparation}

The electrodes, composite current collectors (CCCs) and membranes of the tubular $F B-V R F B$ and FT-VRFB test cells are fabricated from several materials. As the components are not commercially available with the required tubular cell geometry, new routines and processes for the fabrication, modification and preparation were developed and applied to obtain tubular cell components. An overview of the employed components and fabrication techniques is given in table 3.2.

In this section the processes and techniques to fabricate the inner half cells of $F B$ -

TABLE 3.2: Overview of cell components and fabrication techniques of tubular FB-VRFB and FT-VRFB test cells.

\begin{tabular}{|c|c|c|c|}
\hline Component & FT-25-VRFB & FB-25-VRFB & FB-45-VRFB \\
\hline inner electrode & GFA 6 EA (drilled) & GDL \#2614 Pyron (cut) & GDL \#2614 Pyron (cut) \\
\hline outer electrode & GFA 6 EA (milled) & GDL \#2614 Pyron (cut) & GDL \#2614 Pyron (cut) \\
\hline \multirow[t]{2}{*}{ membrane } & fumasep ${ }^{\circledR} F F T$ & fumapem $^{\circledR}$ F950 & fumasep ${ }^{\circledR} F F T$ \\
\hline & (extruded) & (welded) & (extruded) \\
\hline composite current & flow-through CCC & flow-by CCC & flow-by CCC \\
\hline collector (CCC) & (extruded) & (extruded) & (extruded) \\
\hline
\end{tabular}

$V R F B$ and FT-VRFB test cells are described and the fabrication of the outer half cells is specified. The fabrication of tubular membranes and specification of membrane material is shown at the end of the section.

\section{Inner Half Cell}

Inner Composite Current Collectors: The inner composite current collector (CCC) for the flow-through and flow-by electrode configuration is made of a graphite/polyolefin compound-encased copper wire (Conrad Electronic SE). The copper wire has a diameter of $0.8 \mathrm{~mm}$, is silver coated and provides longitudinal electric conductivity. The polymer compound has a specific electric conductivity of approximately $1000 \mathrm{~S} \mathrm{~m}^{-1}$, is impermeable for the electrolyte and was manufactured by Uniwell Rohrsysteme $G m b H$ \& Co. KG. To ensure a low contact resistance at the polymer compound-copper wire interface the electrically conductive adhesive V58 A of SGL Carbon was used to bond the copper wire into the center of the polymer compound component.

Inner Flow-Through Electrodes: Inner flow-through electrodes were made from GFA6 EA graphite felt sheet material of SGL Carbon with a thickness of $6.0 \mathrm{~mm}$ (see 
Tab. 3.3). GFA6 EA electrode material was chosen as it was the only material available with the required thickness.

TABLE 3.3: Specification of used Sigracell graphite felt materials (SGL Carbon) [126]. ${ }^{1)}$ BET surface area before heat treatment. ${ }^{2)}$ determined by scanning electron microscopy (SEM). ${ }^{3)}$ calculated with equation 2.11. ${ }^{4)}$ calculated with equation 2.10 .

\begin{tabular}{llll}
\hline Property & GFA 6 EA & KFD 4.6 EA & GDL \#2614 Pyron \\
\hline fiber precursor & Rayon & PAN & PAN \\
porosity $\epsilon$ & $4) 94 \%$ & $93 \%$ & $88 \%$ \\
bulk density & $0.08 \mathrm{~g} \mathrm{~cm}^{-3}$ & $0.1 \mathrm{~g} \mathrm{~cm}^{-3}$ & $0.17 \mathrm{~g} \mathrm{~cm}^{-3}$ \\
fiber diameter & $2) 11 \mu \mathrm{m}$ & $9 \mu \mathrm{m}$ & $8.5 \mu \mathrm{m}$ \\
fiber density & $1.4 \mathrm{~g} \mathrm{~cm}^{-3}$ & $1.4 \mathrm{~g} \mathrm{~cm}^{-3}$ & $1.4 \mathrm{~g} \mathrm{~cm}^{-3}$ \\
1) $a_{B E T}$ per mass & $0.8 \mathrm{~m}^{2} / \mathrm{g}$ & $0.6 \mathrm{~g}^{2} / \mathrm{g}$ & - \\
1) $a_{B E T}$ per vol. & $640 \mathrm{~cm}^{-1}$ & $600 \mathrm{~cm}^{-1}$ & - \\
3) $a_{\text {geo }}$ per vol. & $222 \mathrm{~cm}^{-1}$ & $311 \mathrm{~cm}^{-1}$ & $576 \mathrm{~cm}^{-1}$ \\
\hline
\end{tabular}

To fabricate electrodes with a cylindrical shape from the highly elastic graphite felt material and realize diameters of $5.9 \mathrm{~mm}$ with sub-mm precision a special process and tooling (fig. 3.7) was developed. The required high cutting depth for electrode lengths $>100 \mathrm{~mm}$ precludes the application of water jet or laser cutting technologies (water jet divergence).

Fabrication of cylindrical electrodes from graphite felt sheet material is thus done
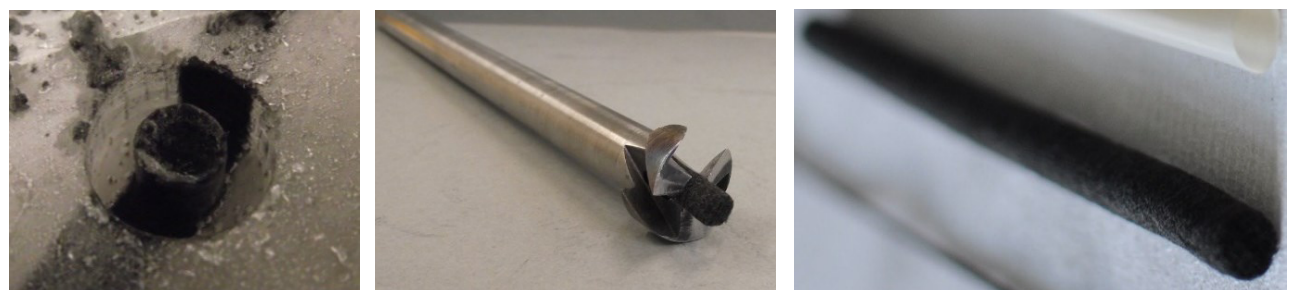

FIGURE 3.7: Left: frozen graphite sheet material. Middle: developed drilling tool with cylindrical electrode in the center. Right: cylindrical graphite felt electrode after fabrication.

by stabilization of the porous felt in a freezing process with subsequent core drilling. First, the felt material is fully immersed in double distilled water and placed in an specially designed bracket. Next, it is frozen for $12 \mathrm{~h}$. The ice block containing the felt sheet (left in fig. 3.7) is then mounted to a vertical drill press. A core drill with 
three cutting edges (fig. 3.7) and an inner diameter of $5.9 \mathrm{~mm}$ was designed, machined by WFM-S and used to drill out the cylindrical electrode (right in fig. 3.7) from the ice block.

Inner Flow-By Electrodes: Inner flow-by electrodes were made of a $700 \mu \mathrm{m}$ thick and $14 \mathrm{~mm}$ wide graphite felt. The felt material features a fiber diameter $d_{f}$ of $8 \mu \mathrm{m}$ to $9 \mu \mathrm{m}$, area specific mass of $120 \mathrm{~g} \mathrm{~m}^{-2}$ and through plane electric resistance of $22 \mathrm{~m} \Omega \mathrm{cm}^{2}$ at an electrode compression ratio $\chi \approx 44 \%$.

Inner Half Cell Assembley: The inner flow-through half cell is assembled by piercing the inner CCC through the axis of the cylindrical electrode. Inner flow-by half cells are obtained by wrapping the flow-by electrode around the inner FB CCC. The electrode is secured in position by use of electrically conductive adhesive.

\section{Outer Half Cell}

Outer Composite Current Collectors: For the outer flow-by and flow-through composite current collectors (CCCs) the same graphite/polyolefin compound material as for the inner CCC is used. Extrusion of the polymer compound was done by Uniwell Rohrsysteme $\mathrm{GmbH} \&$ Co. KG. A copper foil with a thickness of $50 \mu \mathrm{m}$ is wrapped around the shell to enhance longitudinal electric conductivity. To ensure a low contact resistance at the polymer compound-copper foil interface the electrically conductive adhesive V58 A of SGL Carbon was used to bond both components.

Outer Flow-Through Electrode: Analog to the inner half cell SIGRACELL GFA 6 $E A$ graphite felt sheet material of SGL Carbon with a thickness of $6.0 \mathrm{~mm}$ is used for the outer flow-through electrode. The required electrode width of $19 \mathrm{~mm}$ and thickness of $1.2 \mathrm{~mm}$ was achieved by cutting and milling, respectively.

Outer Flow-By Electrode: Outer flow-by electrodes were made of a $700 \mu \mathrm{m}$ thick and $17.4 \mathrm{~mm}$ wide SIGRACET GDL \# 2614 Pyron graphite felt material of SGL Carbon. Outer flow-by and flow-through half cells are obtained by inserting the outer electrodes into the outer CCCs. 
Electrode Heat Treatment: To introduce oxygen functional groups to the flow-by and flow-through electrode surface thermal treatment of the graphite felt sheet material is done prior to cutting, milling and drilling. The thermal treatment was done at DECHEMA-Forschungsinstitut by tempering the felt material in a furnace at $400{ }^{\circ} \mathrm{C}$ for $5 \mathrm{~h}$ in ambient air.

\section{Tubular Membranes}

Tubular membranes employed in this thesis were extruded from membrane material granules or welded of membrane sheet material.

A custom-made thermal contact welding tool (fig. $3.8 \mathrm{~A}$ ) was designed and utilized to fabricate the tubular membrane of fumapem ${ }^{\circledR}$ F950 cation exchange membrane sheet material (FUMATECH BWT GmbH, Germany) (fig. $3.8 \mathrm{C}$ ). The welding tool is
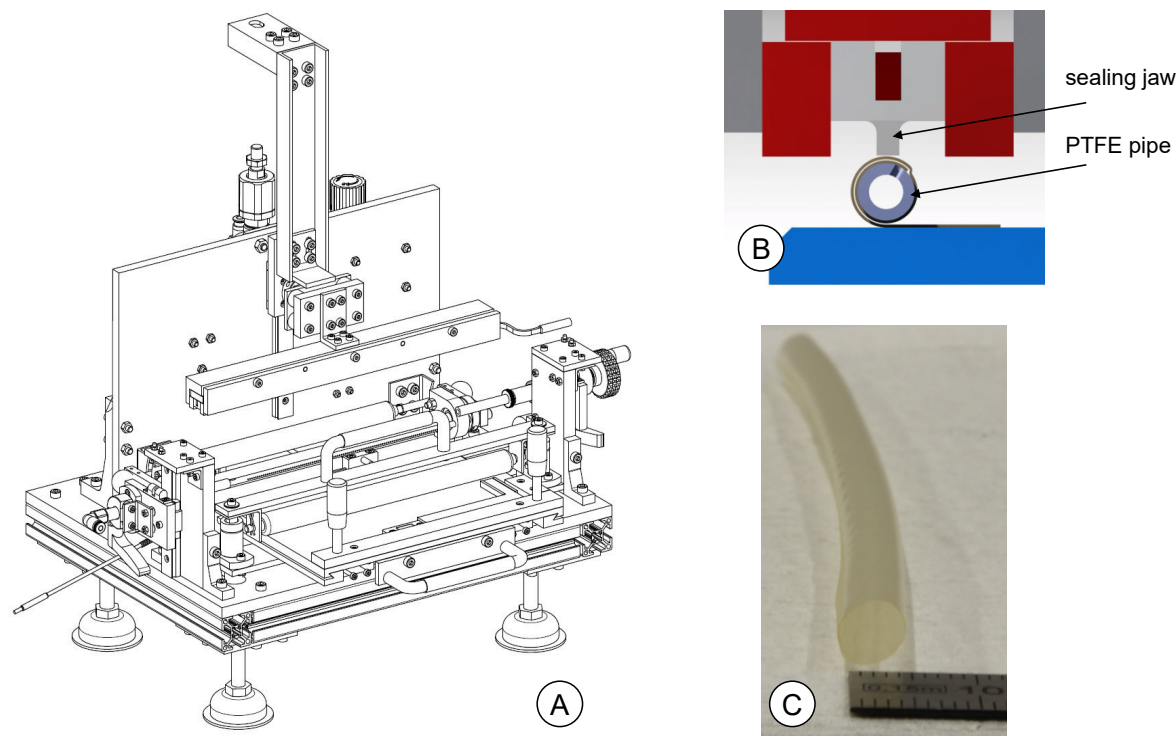

FIGURE 3.8: A: Welding tool B: Welding setup C: Welded fumapem ${ }^{\circledR}$ F950 membrane.

equipped with a perforated PTFE supporting pipe with an outer diameter of $5.0 \mathrm{~mm}$ (fig. $3.8 \mathrm{~B}$ ). A connected pump evacuates the pipe while the membrane sheet is being wrapped around the pipe. Vacuum in the pipe assures a tight membrane enclosure and achievement of the required dimension. The welding seam is located at the lap joint of the sheet material. A pneumatic cylinder is used to apply a sealing jaw to 
the intended welding location with a defined pressure and time. The sealing jaw features a concave contact surface and was heated up to $T=300{ }^{\circ} \mathrm{C}$ during contact welding in order to produce a longitudinal welding seam with a thickness $\leq 1.5 \mathrm{~mm}$. Prior to cell assembling, leak tightness testing was performed by applying air (pressure $p_{g} \leq 1000 \mathrm{hPa}$ ) to the interior of the tubular membrane and submerging it in double distilled water.

Extruded tubular membranes (fig. 3.9) were fabricated by Uniwell Rohrsysteme GmbH $\mathcal{E}$ Co. KG from the perflouronated sulfonic acid /PTFE copolymer granulate material VM-fumasep ${ }^{\circledR}$ FFT of FUMATECH BWT GmbH. Extruded membranes feature an

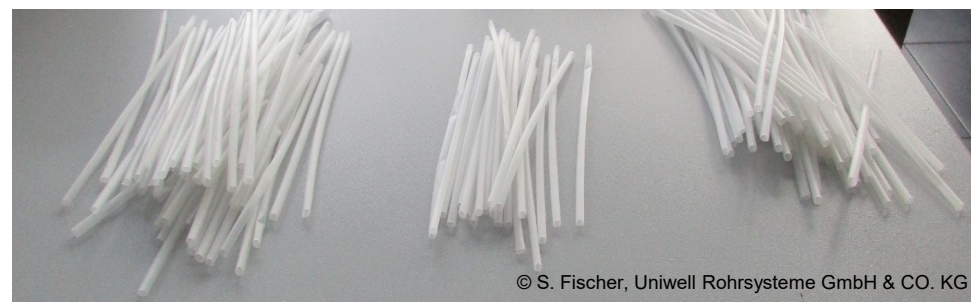

FIGURE 3.9: Picture of extruded VM-fumasep ${ }^{\circledR}$ FFT membranes.

inner diameter of approximately $5 \mathrm{~mm}$ and thicknesses from $50 \mu \mathrm{m}$ to $150 \mu \mathrm{m}$. Activation and hydrolysis of the extruded cation exchange membranes was done by $F U$ MATECH BWT GmbH and resulted in specific proton conductivities from $95 \mathrm{mScm}^{-1}$ to $98 \mathrm{mScm}^{-1}$. An overview over the tubular VRFB cells and membranes studied within this work is shown in table 3.4.

TABLE 3.4: List of tubular VRFB cells with membrane properties.

\begin{tabular}{|c|c|c|c|}
\hline Property & FB-25-VRFB & FB-45-VRFB & FT-25-VRFB \\
\hline $\begin{array}{l}\text { membrane material } \\
\text { fabrication } \\
\text { thickness } \\
\text { membrane area }\end{array}$ & $\begin{array}{l}\text { fumapem }^{\circledR} \text { F950 } \\
\text { welded } \\
50 \mu \mathrm{m} \\
15.7 \mathrm{~cm}^{2}\end{array}$ & $\begin{array}{l}\text { VM-fumasep }{ }^{\circledR} F F T \\
\text { extruded } \\
80 \mu \mathrm{m} \\
15.7 \mathrm{~cm}^{2}\end{array}$ & $\begin{array}{l}\text { VM-fumasep }{ }^{\circledR} F F T \\
\text { extruded } \\
100 \mu \mathrm{m} \\
13.3 \mathrm{~cm}^{2}\end{array}$ \\
\hline
\end{tabular}

\subsubsection{All Vanadium Redox Flow Battery Test Rig}

Within the scope of this work a VRFB test rig is designed, assembled and implemented, which allows to operate test cells in a defined environment and enables in situ measurements of several operational parameters. 
In figure 3.10 the schematic of the test rig is displayed. It is composed of a positive and negative electrolyte cycle, 4 custom made glass tanks and an Argon (Ar) gas cycle. Photo level sensors mounted to the lower tanks are used to control back drainage valves, which are located between each upper and lower tank, respectively. VRFBS can, thus, be operated in a batch like (4-tank) mode or - in case of the valves being set to 'constantly open' - in regular two tank mode.

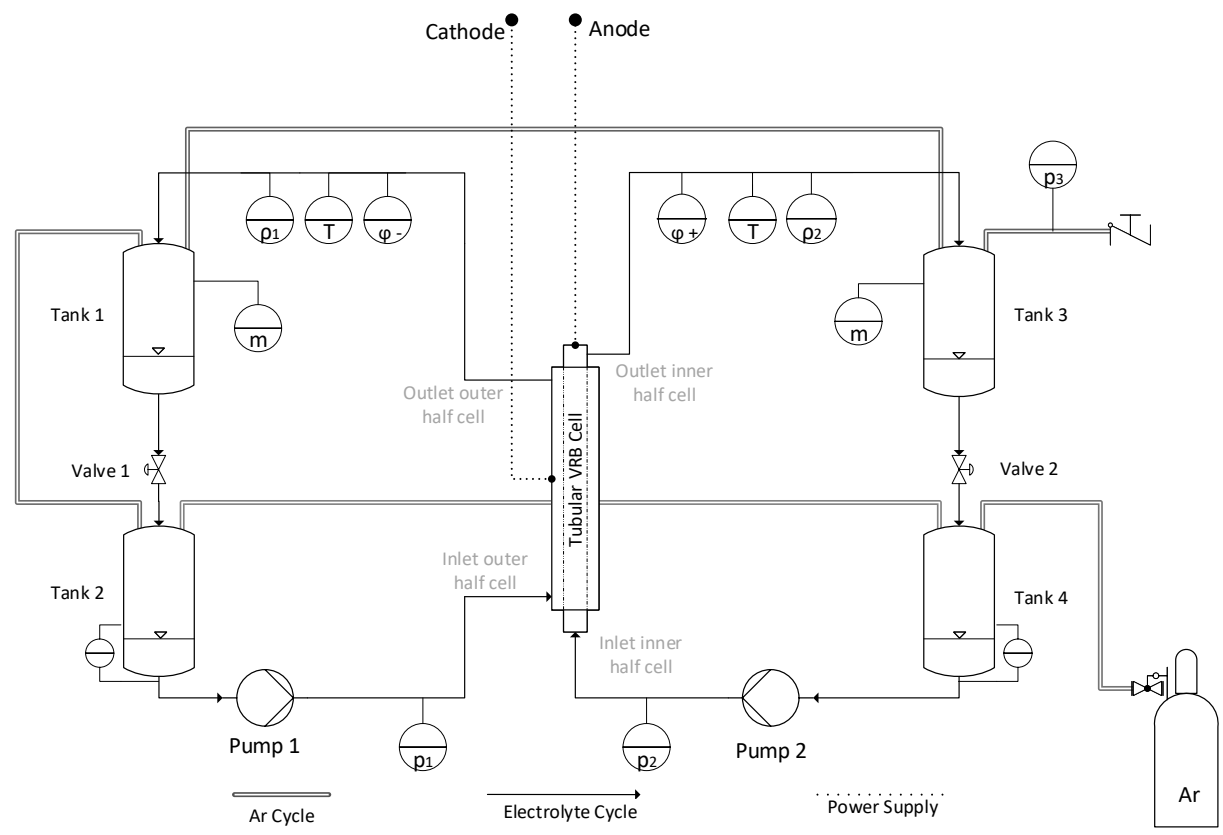

FIGURE 3.10: Schematic of VRFB test rig.

The Ar cycle interconnects all 4 tanks with an Ar gas bottle with fitted pressure reducer ( $p_{\text {out }}=0.0 \ldots 500$ mbar, Doppelregulus of Tescom Europe $G m b H$ ) and features a remote seal pressure sensor $p_{3}$ (EM Technik) located right in front of the outlet valve. The Ar cycle is used to purge the electrolyte cycle prior to experiments and allows to operate test cells under static Ar atmosphere (to prevent electrolyte oxidation) at elevated system pressure $p_{\text {sys }}$.

Two solenoidal membrane dosing pumps (accuracy $\leq \pm 5 \%$, Delta optodrive, ProMinent) are used to pump the electrolyte solutions through the half cells and tubing to the upper tanks. The electrolyte mass in the upper tanks is measured continuously with connected scales (52-37, Kern und Sohn GmbH).

By implementing remote seal pressure sensors $p_{1}$ and $p_{2}$ in front of the half cell inlets 
the pressure drop across the half cell $\Delta p=p_{1}-p_{3}$ and $\Delta p=p_{2}-p_{3}$ is measured during operation.

As the electrolyte leaves the half cells it passes through two custom made potential flow armatures $\phi_{+}$and $\phi_{-}$and density measurement modules $\rho_{+}$and $\rho_{-}$(DMA 35n, Anton Paar). Potential measurements are described in more detail in section 2.2.3. Electrolyte densities are determined by use of the oscillating U-tube principle within a range of $0<\rho \leq 2 \mathrm{mg} \mathrm{ml}^{-1}$ with a systematic error of $\pm 0.0005 \mathrm{mg} \mathrm{ml}^{-1}$. The density module features an integrated temperature sensor, which is used for electrolyte temperature measurement $T_{1}$ and $T_{2}$.

Electrochemical experiments are conducted by connecting the SP-240/4A/14V potentiostat of BioLogic to the positive and negative electrode connections of the test cells. System control and data acquisition is realized by a LabVIEW based Virtual Instrument VI (National Instruments) with a connected Programmable Logic Controller PLC of (Phoenix Contact).

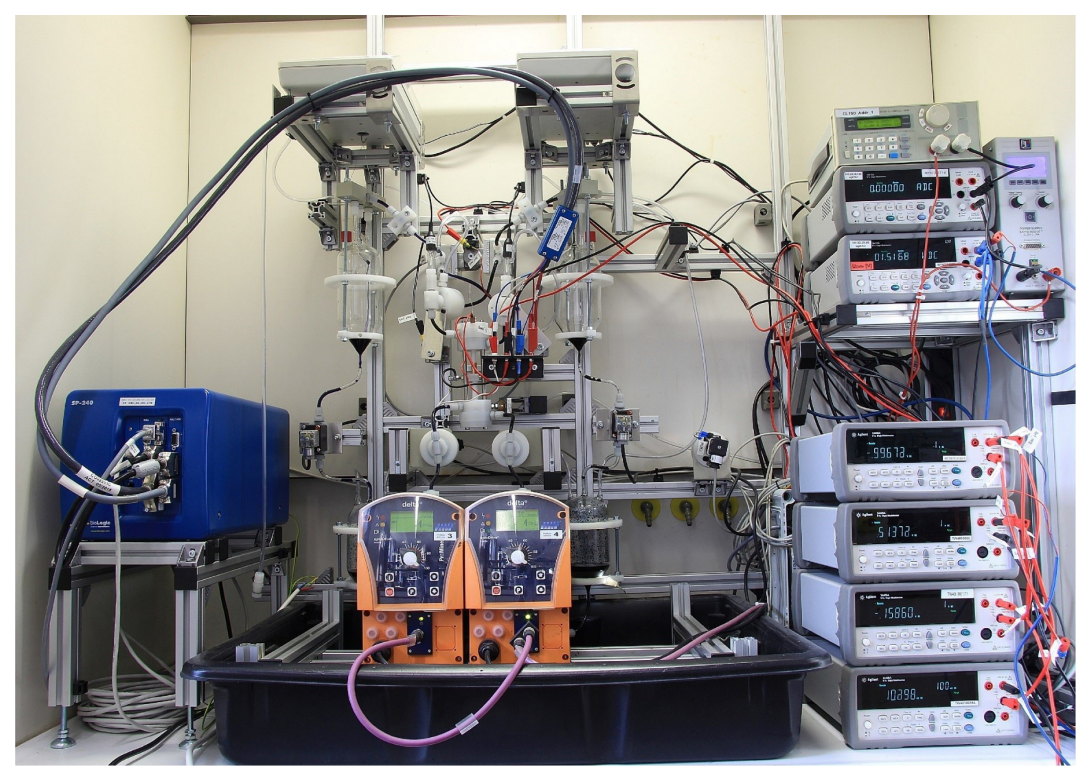

FIGURE 3.11: Picture of VRFB test rig with integrated VRFB cell. 


\subsubsection{Test Routines}

For the evaluation of pressure drops along the tubular $V R F B$ half cells reference data of flow-by and flow-through electrodes are required. Performed routines for the generation of the reference data are listed at the beginning of this section.

For the characterization of the VRFB cells a test routine was established, which is composed of several subsequent techniques. The test routine enables to analyze the cell performance, charge/discharge cycling efficiencies, cell stability and degradation effects and comprises the following steps:

1. Electrolyte formation with subsequent charging to $S o C \approx 50 \%$

2. Polarization curve measurements

3. EIS measurements

4. Charge/discharge cycling

5. Long term $O C V$ measurement

6. Polarization curve measurements

7. EIS measurements

Employed methods are introduced in section 2.2. A detailed specification of the deployed measurement settings is given within this section.

\section{Pressure Drop Measurement}

Pressure drop measurements of flow-through and flow-by electrodes are performed with the VRFB test rig described in section 3.1.3. Permeability test cells (fig. 3.1) are integrated in one electrolyte cycle and an additional pressure sensor $p_{3}$ was connected to the test cell outlet to determine the pressure drop $\Delta p=p_{1}-p_{3}$.

Measurement runs are performed with bi-distilled water and $V^{3.5+}$ electrolyte solution of GfE (Gesellschaft für Elektrometallurgie $\mathrm{mbH}$ ) at ambient temperature.

Pressure drop measurements of every sample are done at different flow rates $(\dot{Q})$ within $0<R e \leq 15$ (plug and laminar flow conditions). $\dot{Q}$ is increased in 15 steps from low to high flow rates. Set flow rates are increased as follows:

- $1.6 \mathrm{ml} \mathrm{min}^{-1}$ to $12.8 \mathrm{ml} \mathrm{min}^{-1}$ with $\Delta \dot{Q}=1.6 \mathrm{ml} \mathrm{min}^{-1}$ steps

- $12.8 \mathrm{ml} \mathrm{min}^{-1}$ to $19.2 \mathrm{ml} \mathrm{min}^{-1}$ with $\Delta \dot{Q}=3.2 \mathrm{ml} \mathrm{min}^{-1}$ steps 
- $24.0 \mathrm{ml} \mathrm{min}^{-1}$ to $56.0 \mathrm{ml} \mathrm{min}^{-1}$ with $\Delta \dot{Q}=8.0 \mathrm{ml} \mathrm{min}^{-1}$ steps

- $80.0 \mathrm{ml} \mathrm{min}^{-1}$ to $112.0 \mathrm{ml} \mathrm{min}^{-1}$ with $\Delta \dot{Q}=15.9 \mathrm{ml} \mathrm{min}^{-1}$ steps

Prior to the actual measurement runs the fluid is pumped through the test cell with increasing flow rates $\left(1.6 \mathrm{ml} \mathrm{min}^{-1}\right.$ to $\left.112.0 \mathrm{ml} \mathrm{min}^{-1}\right)$ in order to remove entrapped gas from the test setup and sample, respectively. To separate the test setup induced pressure drop from the actual $\Delta p$ of the electrode samples, a measurement run without any sample was conducted and showed to exhibit no pressure drops within the measurement accuracy. The static pressure is measured prior to every test run and is used to correct the measured $\Delta p$ values.

\section{Electrolyte Formation}

Formation (sometimes denoted as pre-charging) of the commercially available $V^{3.5+}$ electrolyte solution of GfE (Gesellschaft für Elektrometallurgie $\mathrm{mbH}$ ) is performed in the test rig described in section 3.1.3.

To prevent oxidation of the vanadium electrolyte $\left(V^{2+}\right)$ the entire test rig piping, tank and cell volume is purged with Argon gas before formation is done. Pristine $V^{3.5+}$ electrolyte is pumped through the test cell at a constant flow rate for approximately one hour to remove entrapped gas bubbles and hydrate the membrane. Subsequently, the gas cycle of the test rig is purged again with Ar gas and a static overpressure $\Delta p=50 \mathrm{hPa}$ is applied on the system before the actual formation is started. The $V^{3.5+}$ electrolyte is composed of $0.8 \mathrm{MVOSO}_{4}, 0.4 \mathrm{MV}_{2}\left(\mathrm{SO}_{4}\right)_{3}, 0.05 \mathrm{MH}_{3} \mathrm{PO}_{4}$ and $2 \mathrm{MH}_{2} \mathrm{SO}_{4}$. In order to obtain solely $V^{3+}$ in the negative and $\mathrm{VO}^{2+}\left(\mathrm{V}^{4+}\right)$ in the positive half cell (corresponding to $\mathrm{SoC}_{\mathrm{O}}=0 \%$ ), $\mathrm{VOSO}_{4}$ needs to be reduced to $\mathrm{V}^{3+}$ in the negative half cell while $V_{2}\left(S_{4}\right)_{3}$ has to be oxidized in the positive half cell $[29,67,137]$. This is done by formation of $V^{3.5+}$ electrolyte in the planar or tubular $V R F B$ cell. Therefor two equal volumes $(V=100 \mathrm{ml})$ of $V^{3.5+}$ electrolyte are poured into the tanks of the positive and negative cycles, respectively. Pre-charging with planar VRFB cells is carried out galvanostatically at a constant current density $(i)$ of $35 \mathrm{~mA} \mathrm{~cm}^{-2}$ until an open-circuit potential (OCV) of $1.4 \mathrm{~V}$ is obtained. For the developed tubular VRFB cells the $E / i$-characteristic is unknown at the time of formation. Formation is, thus, done potentiostatically at $E_{\text {cell }}=1.3 \mathrm{~V}$ and $E_{\text {cell }}=1.7 \mathrm{~V}$ until a charge $\Delta Q \propto S o C \approx 50 \%$ is transferred (determined by Coulomb counting).

\section{Polarization Curve Measurement}

To reveal the performance characteristics of VRFB cells for their intended application, polarization curve measurements are done at operating parameters which 
resemble the conditions during charge/discharge cycling. However, polarization curves of $V R F B$ cells at a high $S o C$, high electrolyte excess and low discharging potential limits are often found in literature $[2,78,123,172]$, which rather aim on the detection of maximum current and power densities than on charge/discharge cycling cell characteristics.

In this work polarization curves are done within a cell potential range from $0.8 \mathrm{~V}$ to $1.8 \mathrm{~V}$ using the test rig described in section 3.1.3. To maintain a constant $\mathrm{SoC}$ of approximately $50 \%$ throughout the measurement, the potential curve sequence is done in 4-tank mode within one tank volume turnover.

A potential scan is first done from $O C V$ to $E_{\max }=1.8 \mathrm{~V}$ ( $B$ in fig. 3.12). After a relaxation period $t_{d}\left(C\right.$ in fig. 3.12) a subsequent scan from $O C V$ to $E_{\min }=0.8 \mathrm{~V}$ ( $D$ in fig. 3.12) is performed. Potential scans are done in two ways: (1) stepwise $(50 \mathrm{mV}$ or $100 \mathrm{mV}$ ) increase and decrease of the potential (left in fig. 3.12) or (2) a linear potential scan (LPS) at $50 \mathrm{mV} \mathrm{min}^{-1}$ or $100 \mathrm{mV} \mathrm{min}^{-1}$ (right in fig. 3.12). Linear scans are done for a better ability to fit models to $E / i$ measurement data.
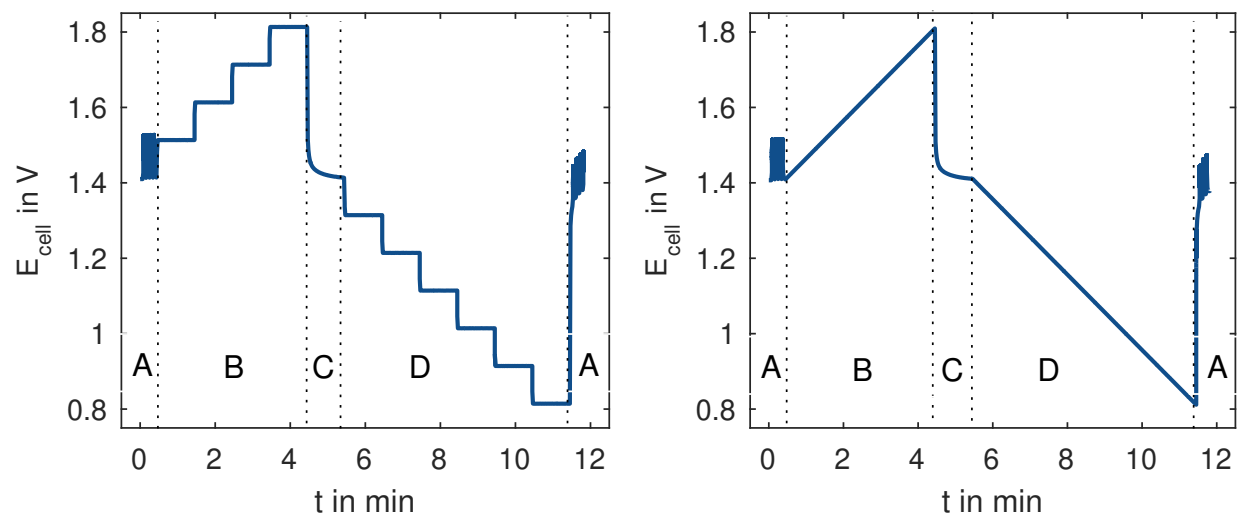

FIGURE 3.12: Polarization curve measurement sequence with a stepwise potential scan (left) and linear potential scan (right).

To obtain stationary conditions during stepwise scans, the potential is held constant over a period $t_{d}$ sufficiently long to turnover the half cell volume $V_{h c}$ twice $\left(t_{d}=\left(2 \cdot V_{h c}\right) / \dot{Q}\right) . E / i$ data at the end of every step are utilized to establish the polarization curve. 
At the beginning and end of every measurement run Current Interrupt $(C I)$ measurements are conducted ( $A$ in fig. 3.12) to determine the $A S R$ of the test cell. $C I$ measurements consist of a series of 4 excitations of $0.5 \mathrm{~s}$ with $I=100 \mathrm{~mA}$. Cell voltage drop is recorded with $\Delta t=0.4 \mathrm{~ms}$ and ohmic cell resistance is calculated by use of the software EC-Lab of BioLogic.

Polarization curve measurements are done at different electrolyte flow rates from $\dot{Q}=1.6 \mathrm{ml} \mathrm{min}^{-1}$ to $12.8 \mathrm{ml} \mathrm{min}^{-1}$.

\section{Electrochemical Impedance Spectroscopy}

In this work the $S P-240 / 4 A / 14 V$ device of BioLogic is employed to perform EIS measurements. Solely full cell impedance analysis of $V R F B$ test cells is conducted as cells are connected in two-electrode mode. VRFB cells are characterized by applying sinusoidal potential signals with an amplitude of $5 \mathrm{mV}$ and frequencies from $60 \mathrm{kHz}$ to $10 \mathrm{mHz}$. Frequencies are scanned with 6 points per decade (log spacing) from high to low values and three measurements are conducted for every frequency value. Impedance measurements are conducted at $O C V$ and at 4 equally spaced cell potentials $\left(\Delta E_{\text {cell }}=150 \mathrm{mV}\right)$ between $O C V$ and $E_{\text {cell }}=0.8 \mathrm{~V}$. For the EIS measurements with applied $d c$ potentials sinusoidal perturbation is initiated after a stabilization period of $5 \mathrm{~s}$. The flow rate is held constant at $\dot{Q}=6.4 \mathrm{ml} \mathrm{min}^{-1}$ throughout the EIS measurement sequence.

To determine the fitting parameters $\left(\alpha, R_{c t}, C_{d l}, C_{c p e}, R_{H F}\right)$ of the equivalent circuit model elements that result in a consistent description of the measured impedance data, a non-linear least square fitting algorithm (Levenberg-Marquardt) is employed. In this work equivalent circuit model fitting is done by use of the tool $Z$ Fit which is part of the software EC-Lab of BioLogic.

\section{Charge/Discharge Cycling and OCV Measurement}

Charge/discharge cycling is done to evaluate the cell performance under long term operation and to analyze battery and system efficiencies. Furthermore, membrane related phenomena, such as crossover and selectivity as well as cell and electrolyte stability and degradation can be investigated by cycling experiments.

Galvanostatic charge/discharge cycles are done within a cell potential range from $E_{\text {cell }}=0.8 \mathrm{~V}$ to $1.7 \mathrm{~V}$ at a constant electrolyte flow rate $\dot{Q}$ of $6.4 \mathrm{ml} \mathrm{min}^{-1}$. As a sequence of polarization and EIS measurements is done after electrolyte formation at a SoC of $50 \%$, cycling is initiated with a charge step followed by a discharge step. Subsequently, 5 charge/discharge cycles are conducted, which are considered for the evaluation. A final charge step with subsequent long term $O C V$ measurement 
$(t>13 \mathrm{~h})$ terminates the cycling routine. In-between every charge and discharge sequence $O C V$ measurements $(t=15 \mathrm{~min})$ and $4 \mathrm{CI}$ Measurements are done.

The formation and charge/discharge cycling is done with a electrolyte volume of $100 \mathrm{ml}$ in each tank corresponding to a maximum capacity of $Q_{\max }=4288 \mathrm{~mA} \mathrm{~h}$.

\subsection{Results and Discussion}

Within this section results on the developed tubular VRFB cells are presented and discussed.

First, an evaluation of the pressure drop characteristics along flow-through and flowby electrode configurations is done. Kozeny-Carman constants ( $c_{K C}$; eq. 2.82) for flowthrough electrodes are determined and used to evaluate the pressure drop along the $F T-25-V R F B$ cell. An analog approach is then done to evaluate the pressure drops along the $F B-25-V R F B$ and $F B-45-V R F B$ cells.

A polarization curve analysis of the planar reference cell is conducted next. Results are used to compare the performance characteristics of tubular cells in subsequent sections.

The performance of the developed tubular flow-by and flow-through cells is then determined by polarization curve and EIS measurements. As two different methods are employed to obtain the performance characteristics, measurement errors are assessed and presented at the end of section 3.2.3.

A detailed evaluation of the half cell's overpotential contribution to the cell's overall overpotentials is done in section 3.2.4, while the efficiencies and operating parameters during charge/discharge cycling of the tubular cells are analyzed in section 3.2.5.

Studies on the stability and degradation of the developed tubular VRFB cells conclude this section.

\subsubsection{Liquid Permeability and Pressure Drop}

Implementation of pressure sensors at the half cell inlet and outlet allow to measure the pressure drop across the half cells and provides valuable information on the electrolyte flow through the electrodes. In order to utilize the pressure drop data for the analysis of the tubular flow-through and flow-by electrodes, liquid permeability properties of the porous electrode material is required and the pressure drop along the flow channel has to be known.

In this section Kozeny-Carman constants for graphite felt electrodes are first determined with permeability test cells, before they are used to evaluate the pressure drop across the half cells of the FT-25-VRFB cell. 
An analog approach is done to evaluate the pressure drop across the half cells of the tubular flow-by cells. Reference data of the inner and outer flow-by electrode is generated and used to compare the actual flow through the FB-25-VRFB and FB-45$V R F B$ half cells.

\section{Liquid Permeability of Flow-Through Electrodes}

To estimate the pressure drop $\Delta p$ of a fluid flux as it flows through porous electrode material, an equation (eq. 2.82) based on Darcy's Law (eq. 2.79) and a Kozeny-Carman correlation for the permeability $K$ (eq. 2.81) is introduced in section 2.3.3.

$$
\Delta p_{K C}=\frac{\dot{Q} \cdot \mu \cdot L \cdot(1-\epsilon)^{2} \cdot 16 \cdot c_{K C}}{A_{\perp} \cdot \epsilon^{3} \cdot d_{f}^{2}}
$$

For the determination of the Kozeny-Carman constant $c_{K C}$ of porous graphite felt (GFA $6 E A)$ flow-through electrodes, multiple pressure drop measurements $\left(\Delta p_{\text {meas }, i}\right)$ with varying sample length $L$, porosities $\epsilon$, cross-sectional areas $A_{\perp}$ and fluids $\left(H_{2} \mathrm{O}\right.$, $V^{3.5+}$ electrolyte) were conducted at various flow rates $\dot{Q}$. Furthermore, $\Delta p_{\text {meas }}$ of flow-through electrodes were measured in an inner and outer half cell configuration (fig. 3.1), as well as with heat treated and untreated electrodes.

Kozeny-Carman constants were obtained by using equation 2.82 and the mean values of the measured pressure values $\left(\Delta p_{\text {meas }, i}\right)$.

Deployed model parameters include the electrode properties listed in table 3.1, the set flow rates $\dot{Q}$, dynamic viscosity values $(\mu)$ of water [145] and $V^{3.5+}$ electrolyte [159] $\left(\rho_{V 3.5+}=1350 \mathrm{~kg} \mathrm{~m}^{-3}\right)$ and a fiber diameter $d_{f}=11 \mu \mathrm{m}$.

The measured pressure drops show to be in accordance with predicted $\Delta p_{K C, i}$ values for untreated electrode materials with investigated lengths $L$, porosities, crosssectional areas $A_{\perp}$ and half cell configurations and permit to estimate a universally valid $c_{K C}$ for water.

In figure 3.13 the measured and predicted pressure drops of flow-through electrodes with different lengths and a compression ratio of $25 \%$ are displayed. The increase of $\Delta p_{\text {meas }}$ with rising Reynolds numbers (Re; equation 2.76) occurs with two different slopes. For $0<R e \leq 1.5\left(0 \mathrm{ml} \mathrm{min}^{-1}<\dot{Q}<11.6 \mathrm{ml} \mathrm{min}^{-1}\right)$ a reduced slope of $\Delta p_{\text {meas }}(R e)$ can be observed compared to the increase of $\Delta p_{\text {meas }}$ with $R e$ for $1.5<$

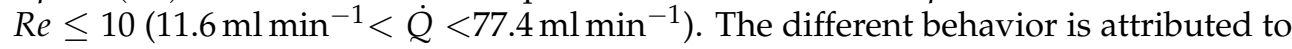
the change of the flow regime in the porous electrodes. For $0<R e \leq 1.5$ the fluid flows with a plug flow profile, while at $1.5<R e \leq 10$ a laminar flow profile develops. By definition Darcy's Law is only valid for plug flow conditions. However, the progression of the pressure drops in figure 3.13 shows that equation 2.82 can also be 
employed to predict $\Delta p_{K C}$ under laminar flow conditions, as a specific $c_{K C}$ is used.

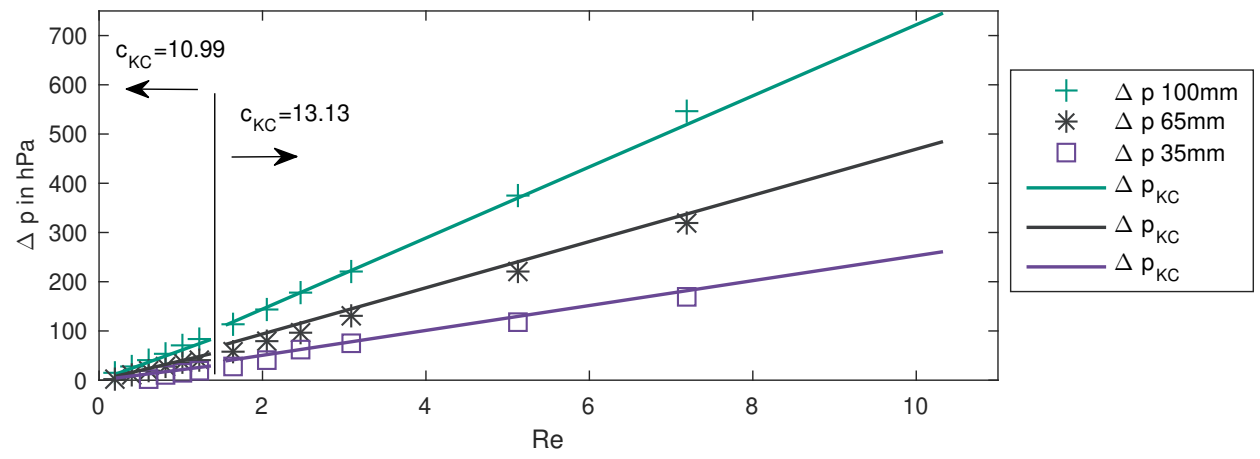

FIGURE 3.13: Measured pressure drop along flow-through electrodes with different lengths and a compression ratio of $25 \%$ (fluid: $\mathrm{H}_{2} \mathrm{O}$ ). Calculated pressure drops $\Delta p_{K C}$ with determined $c_{K C}$ constants.

An analog behavior is observed (not shown) for treated and untreated electrodes and $V^{3.5+}$ electrolyte fluid. However, studies on the influence of the electrode treatment on the pressure drop revealed a deviant slope of the pressure drops with Re for heat treated and untreated materials. Accordingly, individual Kozeny-Carman constants are determined for the respective electrodes. This difference is assigned to the change in the electrode's wetting characteristics, which is linked to the treatment process. While untreated electrodes are hydrophobic, heat treated electrodes exhibit a hydrophilic surface behavior. This change in the wettability creates a different distribution of the fluid flux within the electrode and alters the permeability.

Comparison of the results for different fluids $\left(\mathrm{H}_{2} \mathrm{O}, V^{3.5+}\right.$ electrolyte) shows, that the pressure drop model underestimates the increase of $\Delta p_{\text {meas }}$ for electrolyte solution, which should by definition be directly proportional to the change of the dynamic viscosity. This discrepancy is resolved by specific $c_{K C}$ values for $\mathrm{H}_{2} \mathrm{O}$ and $V^{3.5+}$ electrolyte. An overview of all Kozeny-Carman constants with their specific validity is given in table 3.5 .

The Kozeny-Carman constants can now be used to estimate the pressure drop along porous graphite felt electrodes of different geometries and are employed to evaluate the pressure drops in FT-VRFB cells. 
TABLE 3.5: Kozeny-Carman constants $c_{K C}$ for porous flow-through graphite felt electrodes.

\begin{tabular}{|c|c|c|c|c|}
\hline \multicolumn{3}{|c|}{ scope of validity } & \multirow[b]{2}{*}{$c_{K C}$} & \multirow[b]{2}{*}{$R^{2}$} \\
\hline fluid & heat treatment & $\operatorname{Re}$ & & \\
\hline \multirow{2}{*}{$\mathrm{H}_{2} \mathrm{O}$} & no & $0<\operatorname{Re} \leq 1.5$ & 10.99 & 0.960 \\
\hline & no & $1.5 \leq \operatorname{Re}<10$ & 13.13 & 0.987 \\
\hline \multirow{2}{*}{$V^{3.5+}$} & yes & $0<\operatorname{Re} \leq 1.5$ & 14.54 & 0.992 \\
\hline & no & $0<\operatorname{Re} \leq 1.5$ & 15.99 & 0.992 \\
\hline
\end{tabular}

\section{Pressure Drop along Tubular Flow-By Electrodes}

In figure 3.14 the measured pressure drops of the flow-by electrodes in the inner and outer permeability test cell are shown. Flow channels of the inner and outer half cell were designed with equal cross-sectional areas $A_{\perp}$ to obtain equal flow velocities in both half cells. Furthermore, flow channel geometries were adapted to requirements of the extrusion head design and process to enable fabrication of robust current collectors. The different channel designs lead to unequal flow resistances and the pressure drop along the outer flow-by electrode $\left(\Delta p_{\text {outer }}\right)$ exceeds the $\Delta p_{\text {inner }}$ significantly.

Pressure drops of all measurements rise linearly with the flow rate and confirm

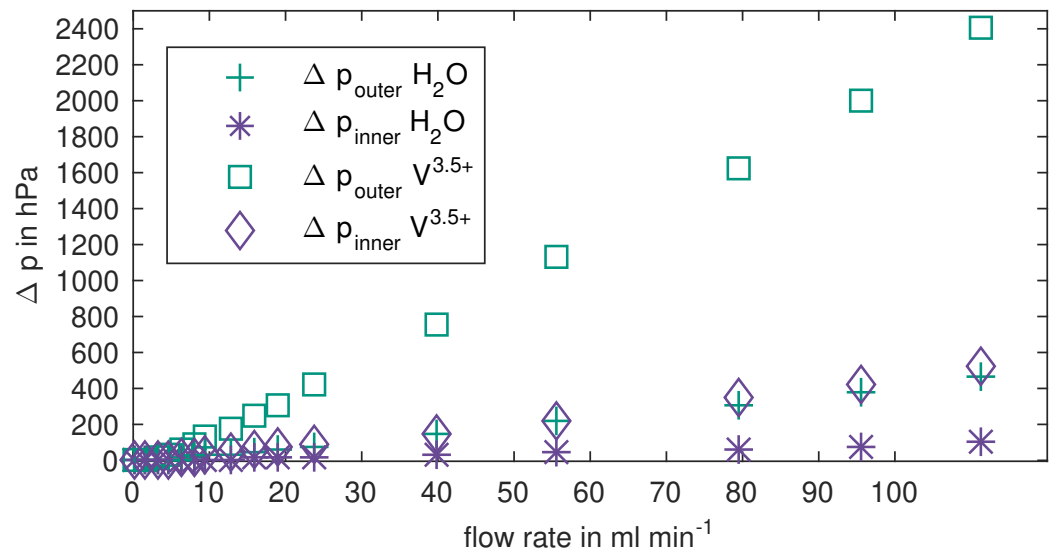

FIGURE 3.14: Pressure drop across inner and outer flow-by electrode with $\mathrm{H}_{2} \mathrm{O}$ and $V^{3.5+}$ Vanadium electrolyte.

the assumption of laminar flow conditions. As identical flow by sample geometries 
and lengths are employed for the measurements with water and $V^{3.5+}$ electrolyte, $\Delta p V^{3.5+}$ values are expected to outnumber $\Delta p \mathrm{H}_{2} \mathrm{O}$ values by the increased dynamic viscosity of the $V^{3.5+}$ electrolyte. Comparison of the pressure drop measurements with water and $V^{3.5+}$ electrolyte reveal fivefold increased $\Delta p V^{3.5+}$ values at identical flow rates and are in good agreement with the estimated increase of $\mu_{V 3.5+} / \mu_{H 20}=5.2$.

Presented results indicate that the Law of Hagen-Poiseuielle (eq. 2.84) can be employed for a simplified estimation of the pressure drop of the flow-by electrodes and fitted $\Delta p \mathrm{H}_{2} \mathrm{O}$ values can be used as reference data for the evaluation of the pressure drops across the tubular $F B$-VRFB half cells in the subsequent section.

\section{Pressure Drop in FT-VRFB and $F B-V R F B$ Half Cells}

FT-25-VRFB: By use of the experimentally determined Kozeny-Carman constant for tempered graphite felt electrode material $\left(c_{K C}=14.54\right), 1.6 \mathrm{M}$ Vanadium $3.5^{+}$electrolyte solution and plug flow conditions (tab. 3.5), the pressure drops across the positive and negative half cell $\left(\Delta p_{p o s} K C, \Delta p_{n e g} K C\right)$ of the FT-25-VRFB cell can be estimated. Dynamic viscosity $(\mu)$ data required to calculate $\Delta p K C$ is obtained by multiplying published kinetic viscosity values $(v)$ for vanadium electrolyte solutions [159] with the measured electrolyte densities $(\rho)$ :

$$
\begin{gathered}
\mu_{\text {pos }}=v_{\text {pos }} \cdot \rho_{\text {pos }}=3 \cdot 10^{-6} \mathrm{~m}^{2} \cdot \mathrm{s}^{-1} \cdot 1338.4 \mathrm{~kg} \cdot \mathrm{m}^{3}=4015.2 \cdot 10^{-6} \mathrm{~kg} \cdot \mathrm{m}^{-1} \cdot \mathrm{s}^{-1} \\
\mu_{\text {neg }}=v_{\text {neg }} \cdot \rho_{\text {neg }}=3.56 \cdot 10^{-6} \mathrm{~m}^{2} \cdot \mathrm{s}^{-1} \cdot 1353.7 \mathrm{~kg} \cdot \mathrm{m}^{3}=4819.2 \cdot 10^{-6} \mathrm{~kg} \cdot \mathrm{m}^{-1} \cdot \mathrm{s}^{-1}
\end{gathered}
$$

Measurements of the pressure drop across the positive half cell $\left(\Delta p_{\text {pos }}\right.$; inner half cell) and negative half cell ( $\Delta p_{\text {neg; }}$; outer half cell) of the tubular FT-25-VRFB cell were done with the test setup described in section 3.1 .3 at flow rates of $0.8 \mathrm{ml} \mathrm{min}^{-1}$, $3.2 \mathrm{ml} \mathrm{min}^{-1}$ and $6.4 \mathrm{ml} \mathrm{min}^{-1}$, electrolyte temperatures $\left(T_{\text {elyt }}\right)$ of $25.9^{\circ} \mathrm{C}$ and a $\mathrm{SoC}$ of $\approx 50 \%$. In figure 3.15 measured and estimated pressure drops of the tubular FT25-VRFB half cells are plotted.

The measured pressure drops across the negative (outer) half cell are in good accordance with the estimated pressure drop $\left(\Delta p_{n e g} K C\right)$ values. Along the positive (inner) half cell the measured pressure drops $\left(\Delta p_{p o s}\right)$ fall below the estimated pressure $\left(\Delta p_{p o s} K C\right)$ and amount to roughly half of the corresponding outer half cell values $\left(\Delta p_{p o s}\right)$. The reduced pressure drop in the inner half cell might be caused by the insertion technique of the inner current collector during fabrication of the tubular FT-25-VRFB cell. As the inner current collector is pierced through the centerline of the porous electrode material, an annular clearance between the current collector and electrode is created. A major portion of the electrolyte flow rate might rather 


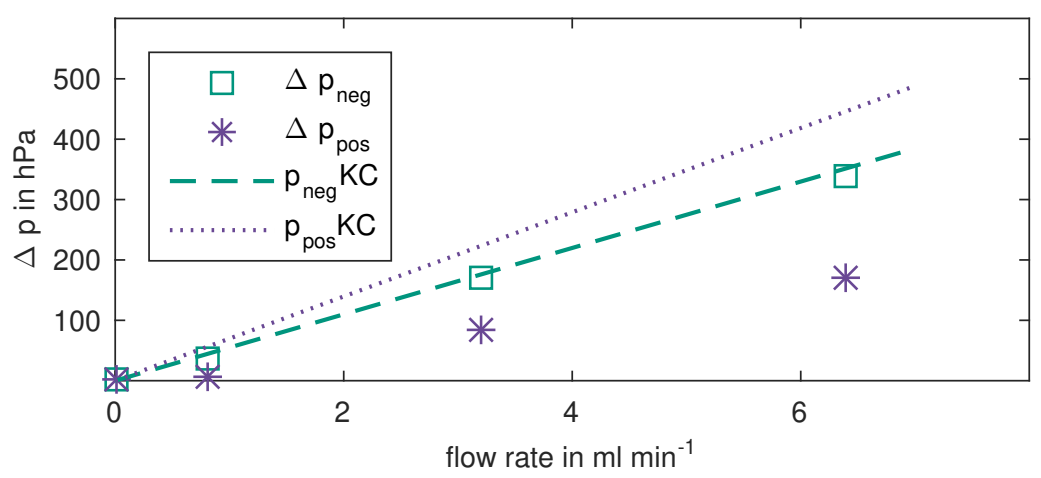

FIGURE 3.15: Pressure drop across positive and negative half cell of $F T-25-V R F B$ cell at different flow rates and $S o C \approx 50 \%$.

flow through this annular clearance than uniformly through the porous bulk electrode material and lead to a reduced pressure drop.

FB-VRFB: Analog to the experimental determination of the pressure drop along flow-through electrodes, pressure drop measurements of tubular half cells with flowby electrode configurations were performed and described above. Pressure drops were recorded for the inner and outer half cells with flow-field geometries identical to those employed in the tubular $F B-25-V R F B$ and $F B-45-V R F B$ cells. In dependence on the Law of Hagen-Poiseuielle (eq. 2.84), a linear slope is fitted $\left(R^{2}=0.99\right)$ to the the $\Delta p \mathrm{H}_{2} \mathrm{O}$ reference data (fig. 3.14) and adapted to the respective electrolyte viscosities at a State of Charge of $50 \%$. These calculated pressure drops for the positive $\left(\Delta p_{\text {pos }} H P\right.$; inner $)$ and negative $\left(\Delta p_{\text {neg }} H P\right.$; outer) half cell are plotted in figure 3.16. While the measured pressure drops across the positive (inner) half cell of $F B$-25$V R F B\left(\Delta p_{p o s} F B-25\right)$ are in good agreement with those of the $F B-45-V R F B$ cell $\left(\Delta p_{p o s}\right.$ $F B-45)$ and correlate with the estimated pressure drop $\Delta p_{\text {pos }} H P$, diverging values arise in the negative (outer) half cell. The pressure drops of the tubular $F B-45-V R F B$ cell $\left(\triangle p_{\text {neg }} F B-45\right)$ exceed the values of the $F B-25-V R F B\left(\Delta p_{\text {neg }} F B-25\right)$, as well as the estimated pressure drops $\left(\triangle p_{\text {neg }} H P\right)$. Although the $F B-45-V R F B$ cell features an higher electrode compression ratio, the cross-sectional area of the flow channels is not expected to be reduced significantly and the increased pressure drops can not be attributed to the increased electrode compression ratio. However, a blockage of the 


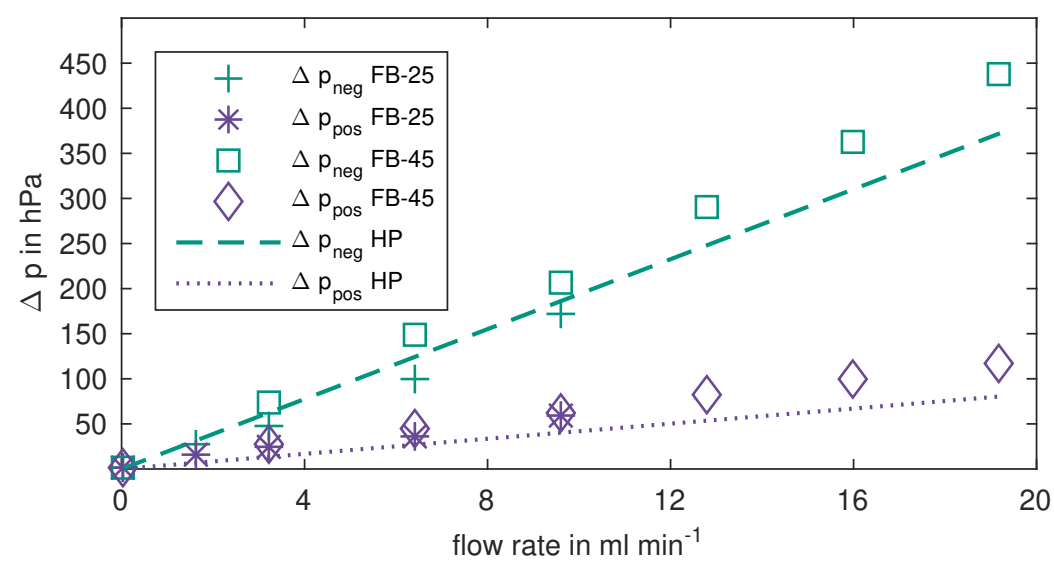

FIGURE 3.16: Pressure drop across positive and negative half cell of $F B-25 / 45-V R F B$ cells at different flow rates and $S o C \approx 50 \%$.

flow channels at the outlet of the outer half cell due to irregularities in the assembling procedure was detected after experimental characterization and cell disassembly. Accordingly, the blocked flow channels led to the increased pressure drop. Note that the $\Delta p_{n e g} F B-25$ at a flow rate of $\dot{Q}=9.6 \mathrm{ml} \mathrm{min}^{-1}$ was measured at a slightly lower $S o C$ as the other data and does therefore exhibit a higher magnitude (due to increased viscosity).

\subsubsection{Planar Reference Cell Characterization}

The $E_{\text {cell }} / i$-correlation of cells is a crucial characteristic for the evaluation of cell performance parameters and limitations, such as power and current densities. The source and share of ohmic, kinetic or mass transfer related losses can be identified and quantified by polarization curve (sec. 2.2.2) measurements.

In this section polarization curves of the planar $V R F B$ cell at different flow rates are displayed and half cell overpotentials are evaluated. Presented results are first compared with the literature in order to validate the planar reference cell and the developed $V R F B$ test rig. Planar $V R F B$ cell results are then employed as a reference for the results of the developed tubular cells in subsequent sections. 


\section{Planar VRFB Cell Performance}

In figure 3.17 polarization curves of the planar $V R F B$ cell introduced in section 3.1.1 are displayed. Polarization curve measurements were done with the linear potential scan (LPS) routine described in section 3.1.4. The $E / i$-curves were done at flow rates from $6.4 \mathrm{ml} \mathrm{min}^{-1}$ to $12.8 \mathrm{ml} \mathrm{min}^{-1}$ at an open-circuit voltage $(O C V)$ of $1.401 \mathrm{~V}$ $(S o C \approx 60 \%)$. The $O C V$ is measured prior to the polarization sequence and remains constant during the measurement as a 4-tank setup is used for the experiment. The measured $O C V$ of $1.401 \mathrm{~V}$ compares quite well with the calculated (including $\mathrm{H}^{+}$ concentrations effects and the Donnan potential; equation 2.18) $O C V$ value of $1.40 \mathrm{~V}$ (fig. 2.4) and measured open-circuit voltages between $1.35 \mathrm{~V}$ to $1.45 \mathrm{~V}[67,102]$.

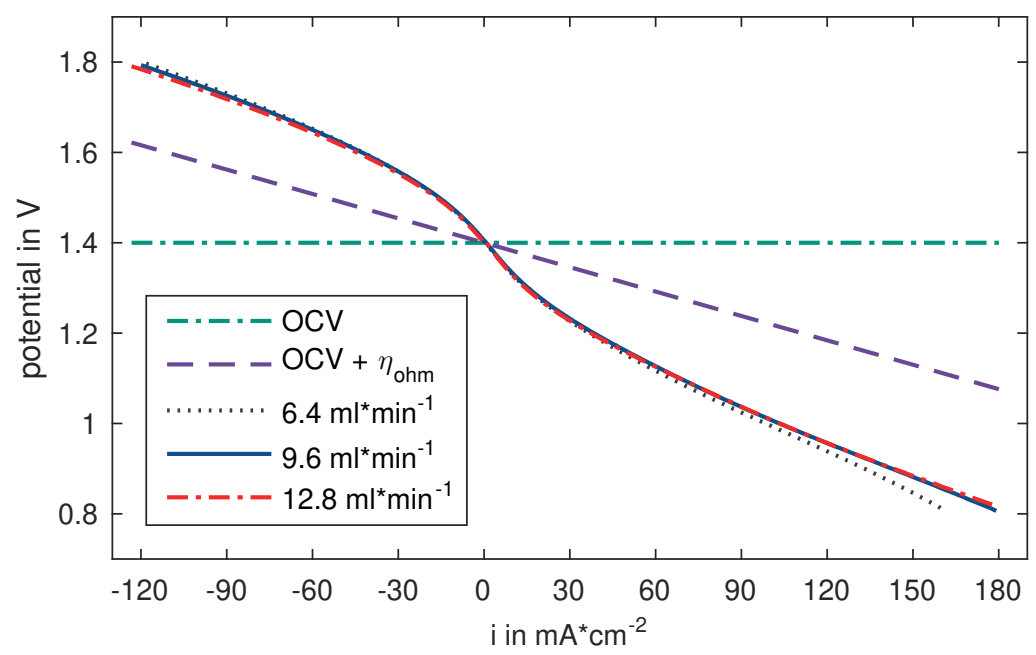

FIgURE 3.17: Polarization curves of planar $V R F B$ cell at a $S o C \approx 50 \%$ and flow rates of $6.4 \mathrm{ml} \mathrm{min}^{-1}, 9.6 \mathrm{ml} \mathrm{min}^{-1}$ and $12.8 \mathrm{ml} \mathrm{min}^{-1}$.

Maximum Power and Current Densities: While the cell potential exhibits mass transfer related overpotentials $\left(\eta_{\text {conc }}\right)$ for current densities above $60 \mathrm{~mA} \cdot \mathrm{cm}^{-2}$ at a flow rate of $6.4 \mathrm{ml} \mathrm{min}^{-1}$, the cell potentials at $9.6 \mathrm{ml} \mathrm{min}^{-1}$ coincide with $E_{\text {cell }}$ at $12.8 \mathrm{ml} \mathrm{min}^{-1}$. Accordingly, the polarization curves above flow rates of $9.6 \mathrm{ml} \mathrm{min}{ }^{-1}$ do not feature mass transfer related overpotentials.

At a flow rate of $12.8 \mathrm{ml} \mathrm{min}^{-1}$ and cell potential $\left(E_{\text {cell }}\right)$ of $0.8 \mathrm{~V}$ a maximum discharge current density $\left(i_{\max }\right)$ of $180.1 \mathrm{~mA} \mathrm{~cm}^{-2}$ and corresponding area specific cell power 
$\left(p_{A}\right)$ of $146.8 \mathrm{~mW} \mathrm{~cm}^{-2}$ is achieved. The cell volume specific power density $\left(p_{v o l}\right)$ is calculated with the active cell volume (electrodes, membrane, current collectors) and results in $163.24 \mathrm{~kW} \mathrm{~m}^{-3}$.

In the dissertation of J. Langner [72] an identical planar Micro Flow Cell of ElectroCell, Denmark is used. In the cell PAN based electrode material of Freudenberg New Technologies, Germany with a compression ratio of $20 \%$ [72] is employed without any additional heat treatment (this work: PAN based KFD4.6 EA, SGL Carbon without additional heat treatment). Furthermore, a cation exchange membrane (Nafion 117, $\mathrm{Du}$ Pont) and analog electrolyte solution is used to perform polarization curve measurements at an $\mathrm{SoC}$ of $60 \%$.

The maximum power and current densities of the cell of J. Langner [72] and the planar reference cell of this work are compared in table 3.6. The $E / i$ characteristics of both cells show a good correlation and maximum current and power densities compare quite well. Note, that the reduced volume specific power density of J. Langner stems from thicker current collector plates.

In table 3.6 results of D. Aaron et al.[2] on a planar VRFB cell with flow-by elec-

TABLE 3.6: Comparison of maximum power and current densities of planar VRFB and published results. ${ }^{1)}$ at $S o C=60 \%$.

\begin{tabular}{lcccccc}
\hline Cell & $\begin{array}{c}E_{\text {cell }}\left(i_{\text {max }}\right) \\
{[\mathrm{V}]}\end{array}$ & $\begin{array}{c}\text { SoC } \\
{[\%]}\end{array}$ & $\begin{array}{c}\dot{Q} \\
{\left[\mathrm{ml} \mathrm{min}^{-1}\right]}\end{array}$ & $\begin{array}{c}i_{\max } \\
{\left[\mathrm{mA} \mathrm{cm}^{-2}\right]}\end{array}$ & $\begin{array}{c}p_{A, \max } \\
{\left[\mathrm{mW} / \mathrm{cm}^{2}\right]}\end{array}$ & $\begin{array}{c}p_{\text {vol,max }} \\
{\left[\mathrm{kW} / \mathrm{m}^{3}\right]}\end{array}$ \\
\hline planar VRFB & 0.80 & 60 & 12.8 & 180.1 & 146.8 & 163.4 \\
J. Langner [72] & 0.95 & 60 & - & 150.0 & 141.9 & 124.7 \\
D. Aaron et al. [2] & 0.20 & 100 & 20 & 920 & $1) 557$ & - \\
\hline
\end{tabular}

trodes and an active membrane area of $5 \mathrm{~cm}^{2}$ are listed. Although the cell designs can not be compared directly and polarization measurement settings deviate from the settings used in this work and the dissertation of J. Langner, it has to be noted that substantially higher power and current densities are reported.

Performance Limitations: As described in section 2.1.2 the current dependent cell voltage $\left(E_{\text {cell }}(i)\right)$ is the summation of the $O C V$ and total overpotentials $\left(\eta_{i}(i)\right)$. To analyze the polarization curves the total overpotential is split into ohmic and residual overpotentials $\eta_{i}(i)=\eta_{\text {ohm }}(i)+\eta_{\text {res }}(i)$. Accordingly, residual overpotentials include activation and mass transfer (concentration) related overpotentials. The ohmic overpotential is estimated by multiplying the measured $A S R_{C I}$ of $1.80 \Omega \mathrm{cm}^{2}$ with the current density $\left(\eta_{\text {ohm }}=A S R \cdot i\right)$.

At a current density of $25 \mathrm{~mA} \mathrm{~cm}^{-2}$ overpotentials $\left(\eta_{i}(i)\right)$ of $152 \mathrm{mV}$ are estimated 
for the polarization curve at $12.8 \mathrm{ml} \mathrm{min}^{-1}$. The $\eta_{\text {ohm }}$-free residual overpotentials make up $107 \mathrm{mV}$ and are, thus more than twice as high as the ohmic overpotentials $\left(\eta_{\text {ohm }}=45 \mathrm{mV}\right.$. For current densities $\left(\left|i_{\text {cell }}\right|\right)$ above $120 \mathrm{~mA} \mathrm{~cm}^{-2} \eta_{\text {ohm }}$ becomes the major source of overpotentials. In order to achieve higher current densities lower $A S R$ values are required, accordingly.

In table 3.7 the overpotentials of the planar reference cell are compared with literature values. The residual overpotentials at a current density of $25 \mathrm{~mA} \mathrm{~cm}^{-2}$ are almost $25 \%$ higher than $\eta_{\text {res }}$ of the planar cell of J. Langner [72] and almost twice as high as the residual overpotentials of the planar flow-by cell of D. Aaron et al. [2]. The deviation of the residual overpotentials of the planar reference cell and the

TABLE 3.7: Comparison of overpotentials of planar VRFB cell and published results.

\begin{tabular}{lcccc}
\hline Cell & $\begin{array}{c}i_{\text {cell }} \\
{\left[\mathrm{mA} \mathrm{cm}^{-2}\right]}\end{array}$ & $\begin{array}{c}\eta_{\text {ohm }} \\
{[\mathrm{mV}]}\end{array}$ & $\begin{array}{c}\eta_{\text {res }} \\
{[\mathrm{mV}]}\end{array}$ & $\begin{array}{c}\eta_{i} \\
{[\mathrm{mV}]}\end{array}$ \\
\hline planar VRFB & 25 & 45 & 107 & 152 \\
J. Langner [72] & 25 & 34 & 82 & 116 \\
D. Aaron et al. [2] & 20 & 10 & 60 & 70 \\
\hline
\end{tabular}

cell of J. Langner might be attributed to the different electrode materials, while the significantly lower $\eta_{\text {res }}$ of Aaron et al. is assumed to arise from the flow-by electrode configuration, the different electrode material and the heat treatment of the electrodes.

While the ASR of the planar cell and the cell of Langner are of similar magnitude, a comparably low ASR of $0.5 \Omega \mathrm{cm}^{2}$ was reported by Aaron et al.[2].

\section{Half Cell Overpotentials}

To further analyze the contribution of the negative and positive half cell overpotential to the total cell overpotential, the polarization curve at $\dot{Q}=12.8 \mathrm{ml} \mathrm{min}^{-1}$ is chosen as it does not feature mass transport related overpotentials.

The measurement of the half cell overpotentials is done with the potential measurement setup described in section 2.2.3. The positive and negative half cell overpotentials of the polarization curve are displayed in figure 3.18. In the dissertation of J. Langner [72] the same planar test cell (see section 3.1.1) is used as in this work and a similar reference electrode setup was used to measure the negative and positive overpotential contribution (sec. 2.2.3). Therefore, comparable positive and negative residual overpotentials are expected to occur in both experiments. In table $3.8 \eta_{\text {neg }}$ and $\eta_{p o s}$ are compared. The data reveal a consistent progression and similar values 
of the overpotentials.

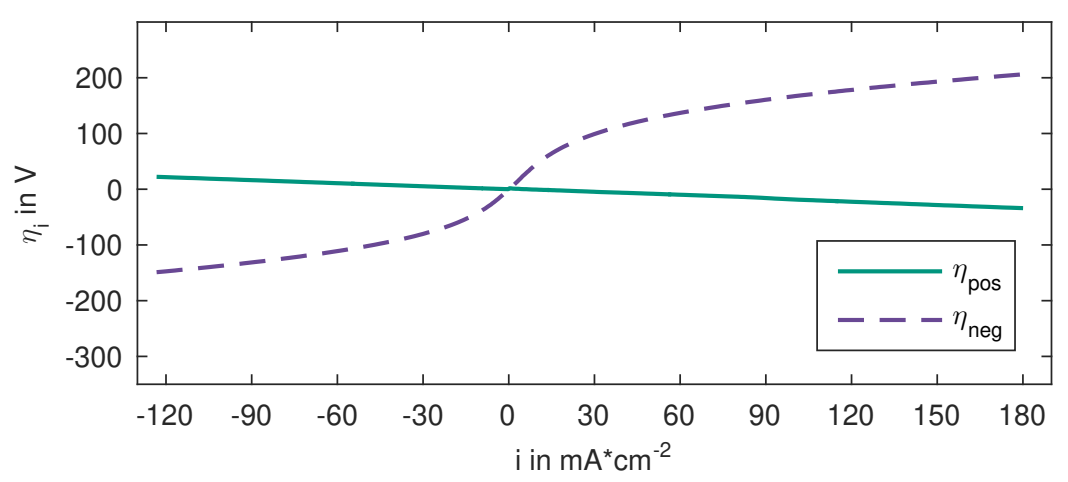

FIGURE 3.18: Negative and positive half cell overpotentials $\left(\eta_{\text {neg }}\right.$ and $\left.\eta_{\text {pos }}\right)$ of planar VRFB cell at a flow rate of $12.8 \mathrm{ml} \mathrm{min}^{-1}$.

TABLE 3.8: Comparison of negative and positive overpotentials with work of J. Langner [72]. The last column displays the contribution of $\eta_{n e g}$ to the residual overpotential $\eta_{\text {res }}=\eta_{\text {pos }}-\eta_{\text {neg. }} .{ }^{1)}$ data include ohmic correction with $R_{\text {corr }}=12 \mathrm{~m} \Omega \pm 0.5$ [72].

\begin{tabular}{|c|c|c|c|c|}
\hline data source & $i\left[\mathrm{mAcm}^{-2}\right]$ & $\eta_{\text {neg }}[\mathrm{mV}]$ & $\eta_{p o s}[\mathrm{mV}]$ & $\mid \frac{\eta_{\text {neg }} \mid}{\left|\eta_{\text {res }}\right|} \cdot 100 \%$ \\
\hline \multirow{2}{*}{ J. Langner1) } & 100 & 109 & -2 & 98.2 \\
\hline & -100 & -114 & 6 & 95.0 \\
\hline \multirow{2}{*}{ this work } & 100 & 167 & -18 & 90.3 \\
\hline & -100 & -137 & 18 & 88.4 \\
\hline
\end{tabular}

The data in the last column in table 3.8 displays the share of the negative overpotential to the residual overpotential and confirms results on studies of the contribution of $\eta_{\text {neg }}$ to the overall cell potential $[3,5,71,72,138,139]$. The limiting nature of the negative electrode on the cell performance was also revealed by studies on a planar $V R F B$ cell with two differentially sized electrodes [5]. Aaron et al. came to a similar conclusion by conducting polarization curve measurements with a DHE and a symmetric cell with either $V^{2+/ 3+}$ or $V^{4+/ 5+}$ electrolyte being fed to both electrodes [3]. By use of Electrochemical Impedance Spectroscopy, Sun et al. were able to further divide the negative overpotential into a kinetic and Nernst diffusion caused share [139] with the reaction kinetic induced overpotential $\left(\eta_{a c t}\right)$ accounting for the major source of 
losses. As the polarization curve at a flow rate of $12.8 \mathrm{ml} \mathrm{min}^{-1}$ shows to be free of concentration overpotentials, negative overpotentials are considered to evolve from the kinetic electrode process $\left(\eta_{\text {act }}\right)$.

It is, thus, concluded that the negative electrode is the limiting electrode of a VRFB cell in terms of the achievable cell performance. Future efforts need to be done to enhance the reaction kinetics of the $V^{2+/ 3+}$-couple at the surface morphology of the porous graphite felt electrode.

\subsubsection{Tubular VRFB Cell Performance}

In this section results on the performance of tubular $V R F B$ cells with flow-by and flow through configuration are presented and evaluated. The influence of the employed methods (Polarization Curve, Current Interrupt CI, Electrochemical Impedance Spectroscopy EIS) on the performance characteristics is analyzed before the performance characteristics of the cell designs are compared.

All tubular VRFB test cells (sec. 3.1.1) are subjected to polarization curve measurements at a $S o C$ of approximately $60 \%$ and cell potential range from $0.8 \mathrm{~V}$ to $1.8 \mathrm{~V}$. This operating point and range is chosen to obtain results on the cell performance, which reflect the actual operating conditions during charge/discharge cycling. However, polarization curves at high and low $\mathrm{SoC}$ are often found in the literature $[2,78,123,172]$, which result in higher discharge and charge current densities, respectively.

\section{Tubular flow-through cell FT-25-VRFB}

In figure 3.19 two polarization curves at a flow rate of $3.2 \mathrm{ml} \mathrm{min}^{-1}$ and $6.4 \mathrm{ml} \mathrm{min}^{-1}$ of a FT-25-VRFB cell with a flow-through electrode configuration are presented. Heat treated GFA6 EA electrode material of SGL Carbon is employed in the inner and outer half cell and an extruded cation exchange membrane is used as a separator.

Measurements are done by a linear potential scan LPS as described in section 3.1.4. Polarization curves are performed at a constant state of charge of $\approx 60 \%$ with a corresponding $\mathrm{OCV}$ of $1.41 \mathrm{~V}$.

Maximum Power and Current Densities: At both flow rates a relatively low maximum current density $\left(i_{\max }\right)$ of $20.5 \mathrm{~mA} \mathrm{~cm}^{-2}$ is achieved at a cell potential of $0.8 \mathrm{~V}$ and results in a maximum volumetric power density of $46 \mathrm{~kW} \mathrm{~m}^{-3}$. Comparison with the planar reference cell (tab. 3.9) clearly shows the significantly lower maximum current and power densities. The area specific power density of the planar 


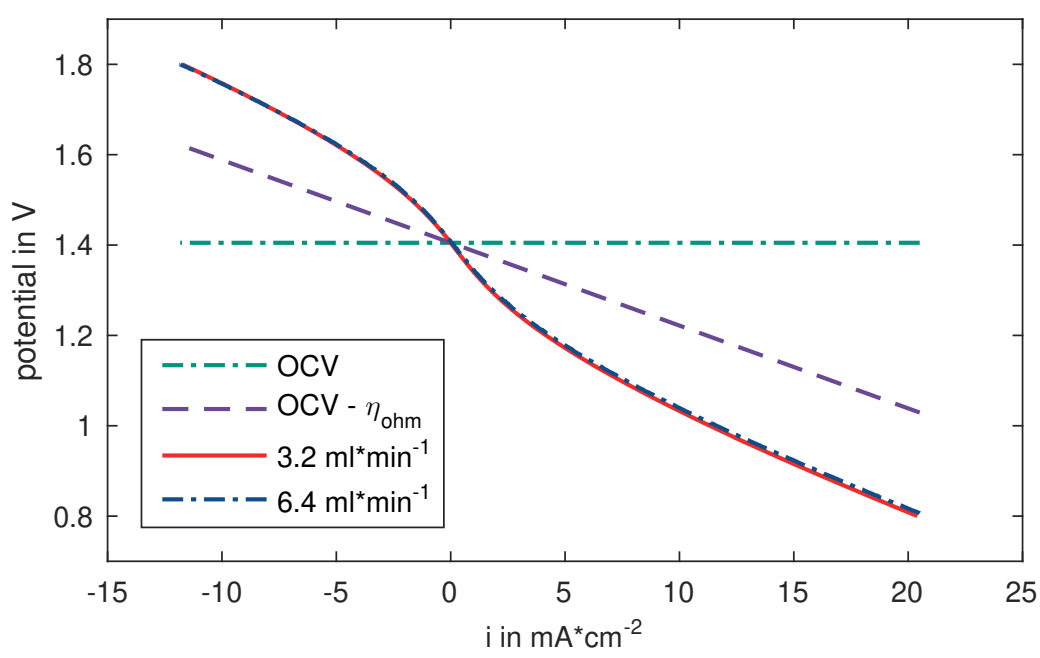

FIGURE 3.19: Polarization curves of tubular FT-25-VRFB Cell with flow-through electrode configuration and extruded membrane at a SoC $\approx 60 \%$ for flow rates of $3.2 \mathrm{ml} \mathrm{min}^{-1}$ and $6.4 \mathrm{ml} \mathrm{min}^{-1}$.

reference cell is roughly $9 \mathrm{x}$ higher than $p_{A, \max }$ of the FT-25-VRFB cell and the volumetric power density outnumbers $p_{v o l, \text { max }}$ of the tubular flow-through cell by a factor of 3.5 .

Performance Limitations: Due to the low current density range no mass transfer related effect on the overpotential can be identified with changing flow rate. Furthermore, no limiting current density $i_{\text {lim }}$ can be determined by fitting of equation 2.68 within the potential range $0.8 \mathrm{~V} \leq E_{\text {cell }} \leq 1.8 \mathrm{~V}$.

The area specific cell resistance $\left(A S R_{C I}\right)$ of $18.3 \Omega \mathrm{cm}^{2}$ is $10 \mathrm{x}$ higher than the $A S R_{C I}$ of the planar reference cell and leads to substantial ohmic overpotentials. Accordingly, the ohmic overpotential is the dominant source of losses and limits the maximum achievable current densities. This high value of the ASR is expected to originate from the contact resistance at the interface of the inner electrode and composite current collector (CCC) surface. Due to the inner CCC diameter of $1.2 \mathrm{~mm}$ a relatively small contact area of $3.2 \mathrm{~cm}^{2}$ is available to contact the inner felt electrode. The actual contact surface area between individual felt fibers and the CCC surface is dependent on the compression of the graphite felt. A non-uniform compression of the electrode felt material across the entire cell cross-section might also occur by membrane 
TABLE 3.9: Maximum power and current densities of FT-25-VRFB and planar reference cell.

\begin{tabular}{lcccccc}
\hline Cell & $\begin{array}{c}E_{\text {cell }}\left(i_{\text {max }}\right) \\
{[\mathrm{V}]}\end{array}$ & $\begin{array}{c}\text { SoC } \\
{[\%]}\end{array}$ & $\begin{array}{c}\dot{Q} \\
{\left[\mathrm{ml} \mathrm{min}^{-1}\right]}\end{array}$ & $\begin{array}{c}i_{\text {max }} \\
{\left[\mathrm{mA} \mathrm{cm}^{-2}\right]}\end{array}$ & $\begin{array}{c}p_{A, \max } \\
{\left[\mathrm{mW} / \mathrm{cm}^{2}\right]}\end{array}$ & $\begin{array}{c}p_{\text {vol,max }} \\
{\left[{\left.\mathrm{kW} / \mathrm{m}^{3}\right]}^{3}\right.}\end{array}$ \\
\hline planar VRFB & 0.80 & 60 & 12.8 & 180.1 & 146.8 & 163.4 \\
FT-25-VRFB & 0.80 & 60 & 3.2 & 20.5 & 16.5 & 46 \\
\hline
\end{tabular}

swelling (increase of tubular membrane diameter), cause a reduced compression in the center and add to the contact resistance.

The residual overpotential $\left(\eta_{\text {res }}\right)$ of $223 \mathrm{mV}$ at $i=20 \mathrm{~mA} \mathrm{~cm}^{-2}$ is more than twice as high as $\eta_{\text {res }}$ of the planar reference cell and is significantly higher than the residual overpotential of the flow-by cell of Aaron et al. (table 3.10). A detailed analysis of the residual overpotentials is given in section 3.2.4.

TABLE 3.10: Comparison of overpotentials of FT-25-VRFB cell with reference cell and published results.

\begin{tabular}{lcccc}
\hline Cell & $\begin{array}{c}i_{\text {cell }} \\
{\left[\mathrm{mA} \mathrm{cm}^{-2}\right]}\end{array}$ & $\begin{array}{c}\eta_{\text {ohm }} \\
{[\mathrm{mV}]}\end{array}$ & $\begin{array}{c}\eta_{\text {res }} \\
{[\mathrm{mV}]}\end{array}$ & $\begin{array}{c}\eta_{i} \\
{[\mathrm{mV}]}\end{array}$ \\
\hline FT-25-VRFB cell & 20 & 366 & 223 & 589 \\
planar VRFB & 20 & 37 & 95 & 132 \\
D. Aaron et al. [2] & 20 & 10 & 60 & 70 \\
\hline
\end{tabular}

\section{Tubular flow-by cell FB-25-VRFB}

Polarization curves of the tubular FB-25-VRFB cell with a welded fumapem F950 membrane, flow-by electrode configuration and felt compression of $25 \%$ are shown in figure. 3.20. Measurements are done at a Coulomb counted state of charge of $60 \%$ and flow rates ranging from $1.6 \mathrm{ml} \mathrm{min}^{-1}$ to $6.4 \mathrm{ml} \mathrm{min}^{-1}$.

Measurement Settings: All curves are obtained by stepwise increasing and decreasing the cell potential by $100 \mathrm{mV}$ as described in section 3.1.4. In order to validate the chosen potential increments, a second measurement run at $\dot{Q}=3.2 \mathrm{ml} \mathrm{min}^{-1}$ with reduced potential step width of $50 \mathrm{mV}$ is done. An identical $E_{\text {cell }} / i$-correlation is obtained, indicating that presented curves are at steady state. Due to the limited 
number of measurement points, polarization curve fitting can not be done.

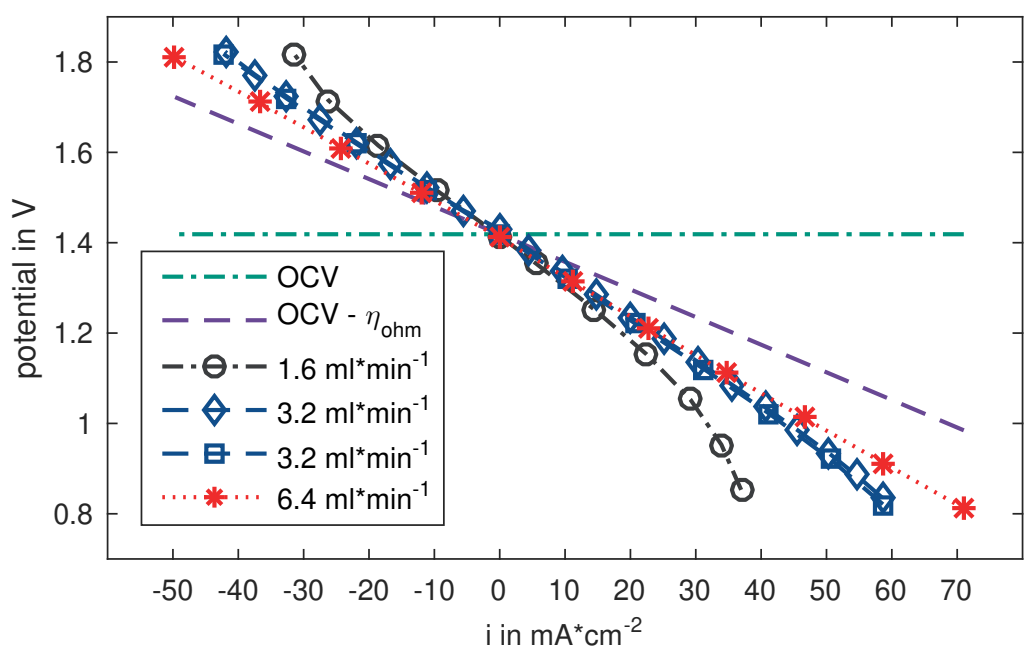

FIGURE 3.20: Polarization curves of tubular FB-25-VRFB cell at a SoC $\approx 60 \%$ and flow rates from $1.6 \mathrm{ml} \mathrm{min}^{-1}$ to $6.4 \mathrm{ml} \mathrm{min}^{-1}$.

Maximum Power and Current Densities: While the smallest flow rate exhibits significant concentration effects and relatively low current densities, a flow rate of $6.4 \mathrm{ml} \mathrm{min}^{-1}$ allows for current densities of $50 \mathrm{~mA} \mathrm{~cm}^{-2}$ (charging) and $71 \mathrm{~mA} \mathrm{~cm}^{-2}$ (discharging). The resulting volumetric power density (per cell volume $V_{\text {cell }}=$ $6.36 \mathrm{ml}$ ) at the maximum $i_{d c h}$ of $142 \mathrm{~kW} / \mathrm{m}^{3}$ is slightly lower than $p_{v o l}$ of the planar reference cell (tab. 3.11) and comparable to the power densities from $140 \mathrm{~kW} / \mathrm{m}^{3}$ to $200 \mathrm{~kW} / \mathrm{m}^{3}$ of a planar cell of PNNL [107]. The membrane area specific power density of $58 \mathrm{~mW} \mathrm{~cm}^{-2}$ at identical maximum $i_{d c h}$ is, however substantially lower than reported values $\left(450 \mathrm{~mW} \mathrm{~cm}^{-2}\right.$ [2], $767 \mathrm{~mW} \mathrm{~cm}^{-2}$ [78]) of planar cells.

Performance Limitations: The polarization curve at a flow rate of $1.6 \mathrm{ml} \mathrm{min}^{-1}$ is strongly governed by mass transfer related overpotentials and allows to read out the limiting current density during discharging $\left(i_{\text {lim }} \approx 38 \mathrm{~mA} \mathrm{~cm}^{-2}\right)$ from figure 3.20.

The total overpotential $\left(\eta_{i}\right)$ of $174 \mathrm{mV}$ of the test cell at $20 \mathrm{~mA} \mathrm{~cm}^{-2}$ is lower than the overpotential derived from Chen et al. [25] $(\approx 290 \mathrm{mV})$ but larger than the value 
TABLE 3.11: Maximum power and current densities of FB-25-VRFB and planar reference cell.

\begin{tabular}{lcccccc}
\hline Cell & $\begin{array}{c}E_{\text {cell }}\left(i_{\text {max }}\right) \\
{[\mathrm{V}]}\end{array}$ & $\begin{array}{c}\text { SoC } \\
{[\%]}\end{array}$ & $\begin{array}{c}\dot{Q} \\
{\left[\mathrm{ml} \mathrm{min}^{-1}\right]}\end{array}$ & $\begin{array}{c}i_{\text {max }} \\
{\left[\mathrm{mA} \mathrm{cm}^{-2}\right]}\end{array}$ & $\begin{array}{c}p_{A, \max } \\
{\left[\mathrm{mW} / \mathrm{cm}^{2}\right]}\end{array}$ & $\begin{array}{c}p_{\text {vol,max }} \\
{\left[{\left.\mathrm{kW} / \mathrm{m}^{3}\right]}^{3}\right.}\end{array}$ \\
\hline planar VRFB & 0.80 & 60 & 12.8 & 180.1 & 146.8 & 163.4 \\
FB-25-VRFB & 0.80 & 60 & 6.4 & 71 & 58 & 142 \\
\hline
\end{tabular}

reported by Aaron et al. [2] $(70 \mathrm{mV})$ (see table 3.12). The main reason for the overpotential difference is the test cell's $A S R_{C I}$ of $6.1 \Omega \mathrm{cm}^{2}$, which was determined by current interrupt measurements. This ASR is comparable e.g. to the ASR of a simple battery by Aaron [4] and imposes strong limitations on available current densities. Aaron et al. [2] reported a very low $A S R_{H F R}$ of $0.50 \Omega \mathrm{cm}^{2}$ and thus a low ohmic overpotential $\eta_{\text {ohm }}$ for their cell design corresponding to higher current densities $i>500 \mathrm{~mA} \mathrm{~cm}^{-2}$. At a flow rate of $6.4 \mathrm{ml} \mathrm{min}^{-1}$ the $i \cdot A S R$-free residual overpotential $\left(\eta_{\text {res }}\right)$ of $52 \mathrm{mV}$ is slightly lower than the value $\left(\eta_{\text {res }}=60 \mathrm{mV}\right)$ derived from Aaron [2] at $20 \mathrm{~mA} \mathrm{~cm}^{-2}$.

TABLE 3.12: Comparison of overpotentials of FB-25-VRFB cell with reference cell and published results.

\begin{tabular}{lcccc}
\hline Cell & $\begin{array}{c}i_{\text {cell }} \\
{\left[\mathrm{mA} \mathrm{cm}^{-2}\right]}\end{array}$ & $\begin{array}{c}\eta_{\text {ohm }} \\
{[\mathrm{mV}]}\end{array}$ & $\begin{array}{c}\eta_{\text {res }} \\
{[\mathrm{mV}]}\end{array}$ & $\begin{array}{c}\eta_{i} \\
{[\mathrm{mV}]}\end{array}$ \\
\hline FB-25-VRFB cell & 20 & 122 & 52 & 174 \\
planar VRFB & 20 & 37 & 95 & 132 \\
D. Aaron et al. [2] & 20 & 10 & 60 & 70 \\
\hline
\end{tabular}

\section{Tubular flow-by cell FB-45-VRFB}

In figure 3.21 polarization curves for flow rates from $3.2 \mathrm{ml} \mathrm{min}^{-1}$ to $9.6 \mathrm{ml} \mathrm{min}^{-1}$ at an $O C V$ of $1.41 \mathrm{~V}$ of a tubular $F B-45-V R F B$ cell with a extruded membrane, $45 \%$ electrode compression ration and flow-by configuration are shown.

Measurement Settings: In order to obtain a higher resolution of measurement points, polarization curve measurements were performed using a linear scan of the cell potential (LPS) instead of a stepwise potential scan (sec. 3.1.4). Polarization curves 
at $\dot{Q}=6.4 \mathrm{ml} \mathrm{min}^{-1}$ are done with both measurement methods to ensure comparability with the $F B-25-V R F B$ cell. For negative polarization (discharging) the $E_{\text {cell }} / i$ correlation is identical while a slightly lower cell potential for current densities below $-10 \mathrm{~mA} \mathrm{~cm}^{-2}$ is observed for the LPS based polarization curve (fig. 3.21). The deviation continuously increases with increasing cell potential until a maximum deviation of the current density of $11.6 \%$ is determined at $E_{\text {cell }}=1.713 \mathrm{~V}$. This difference is assumed to be negligible small and both methods can be applied equally.

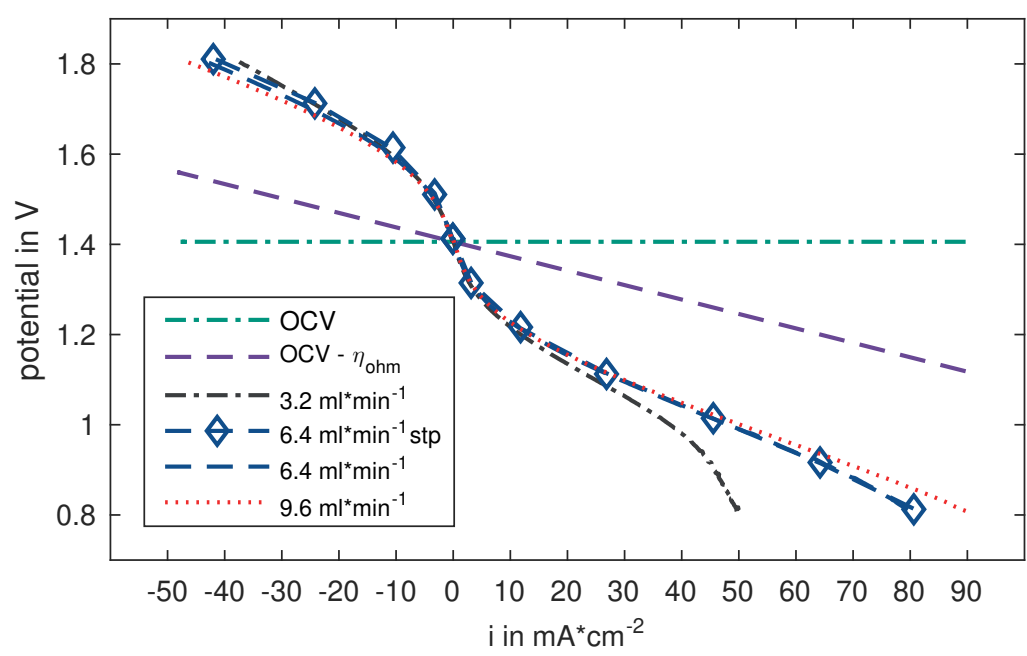

FIGURE 3.21: Polarization curves of tubular FB-45-VRFB cell at a SoC $\approx 60 \%$ for flow rates from $3.2 \mathrm{ml} \mathrm{min}^{-1}$ to $9.6 \mathrm{ml} \mathrm{min}^{-1}$.

Maximum Power and Current Densities: At a flow rate of $3.2 \mathrm{ml} \mathrm{min}^{-1}$ the polarization curve is governed by the mass transfer and a limiting current density $i_{\text {lim }} \approx 52 \mathrm{~mA} \mathrm{~cm}^{-2}$ is obtained during discharging. Although identical electrodes and flow-field geometries are used in the FB-45-VRFB and FB-25-VRFB cell, mass transfer limitations are only observed at a flow rate of $3.2 \mathrm{ml} \mathrm{min}^{-1}$ in the $F B-45-V R F B$ cell but do not appear at an identical flow rate in the $F B-25-V R F B$ cell (fig. 3.20). The mass transfer limitation can be attributed to the blockage of flow channels in the outer half cell. The blockage was caused by an error in the assembly process and was identified after disassembling of the cell. In section 3.2.1 an increase of the pressure drop was identified and also attributed to blocked flow channels.

By increasing the flow rate to $9.2 \mathrm{ml} \mathrm{min}^{-1}$ a maximum current density of $89.7 \mathrm{~mA} \mathrm{~cm}^{-2}$ 
is achieved and a maximum volumetric power density $\left(p_{v o l, m a x}\right)$ of $179.2 \mathrm{~kW} \mathrm{~m}^{-3}$ is estimated. While $p_{v o l, \max }$ exceeds the volumetric power density of the planar reference cell, the area specific power density of $73 \mathrm{~mW} \mathrm{~cm}^{-2}$ is still well below planar reference and literature values (table 3.13).

In figure 3.22 the volumetric power densities of the $F B-45-V R F B$ cell for flow rates

TABLE 3.13: Maximum power and current densities of $F B-45-V R F B$ and planar reference cell.

\begin{tabular}{lcccccc}
\hline Cell & $\begin{array}{c}E_{\text {cell }}\left(i_{\text {max }}\right) \\
{[\mathrm{V}]}\end{array}$ & $\begin{array}{c}\text { SoC } \\
{[\%]}\end{array}$ & $\begin{array}{c}\dot{Q} \\
{\left[\mathrm{ml} \mathrm{min}^{-1}\right]}\end{array}$ & $\begin{array}{c}i_{\text {max }} \\
{\left[\mathrm{mA} \mathrm{cm}^{-2}\right]}\end{array}$ & $\begin{array}{c}p_{A, \max } \\
{\left[\mathrm{mW} / \mathrm{cm}^{2}\right]}\end{array}$ & $\begin{array}{c}p_{\text {vol,max }} \\
{\left[{\left.\mathrm{kW} / \mathrm{m}^{3}\right]}^{3}\right.}\end{array}$ \\
\hline planar VRFB & 0.80 & 60 & 12.8 & 180.1 & 146.8 & 163.4 \\
FB-45-VRFB & 0.80 & 60 & 9.6 & 89.7 & 73 & 179.2 \\
\hline
\end{tabular}

from $3.2 \mathrm{ml} \mathrm{min}^{-1}$ to $9.6 \mathrm{ml} \mathrm{min} \mathrm{m}^{-1}$ are shown. While the absolute maximum of the power density at $3.2 \mathrm{ml} \mathrm{min}^{-1}$ is attained below the maximum current density $\left(i_{\text {max }}=50 \mathrm{~mA} \mathrm{~cm}^{-2}\right)$ at $i=45 \mathrm{~mA} \mathrm{~cm}^{-2}$

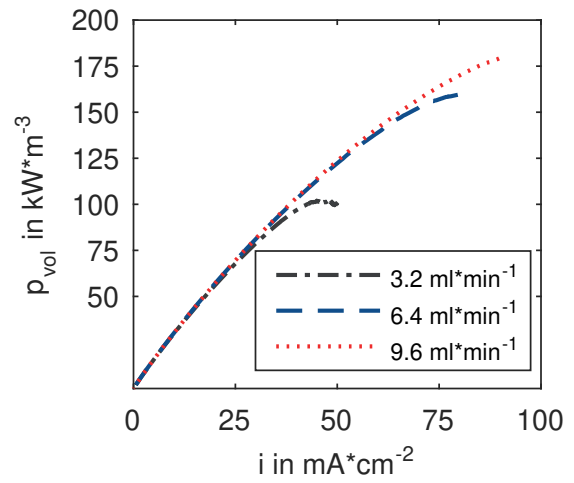

FIGURE 3.22: Volumetric power densities of FB-45-VRFB cell.
$\left(E_{\text {cell }}=0.92 \mathrm{~V}\right)$, the absolute power density at $\dot{Q}=6.4 \mathrm{ml} \mathrm{min}^{-1}$ is achieved at $i_{\text {max }}=80 \mathrm{~mA} \mathrm{~cm}^{-2}\left(E_{\text {cell }}=0.81 \mathrm{~V}\right)$. For a flow rate of $9.6 \mathrm{ml} \mathrm{min}^{-1}$ the maximum determined power density is below the absolute maximum. For storage applications with maximum load (power) requirement cell voltages below $0.8 \mathrm{~V}$ should be considered, accordingly. As the cell performance characterization is done with respect to long term cycling applications, polarization curve measurements below $E_{\text {cell }}=0.8 \mathrm{~V}$ are not considered within this work.

Performance Limitations: The $A S R_{C I}$ of $3.2 \Omega \mathrm{cm}^{2}$ is reduced to almost half of the resistance of the $F B-25-V R F B$ cell but is still almost twice as high as the $A S R_{C I}$ of the reference cell. As graphite felt electrodes of identical thickness are employed in both $F B-V R F B$ cells and the contact resistance reduces exponentially with compression ratios from $0 \%$ to $30 \%$ (see fig. 2.16), the decreased $A S R$ is mainly attributed to a lower contact resistance at the electrode-current collector interface. 
Although the ohmic overpotential is significantly reduced, the total overpotential $\left(\eta_{i}\right)$ of $249 \mathrm{mV}$ (at $i=20 \mathrm{~mA} \mathrm{~cm}^{-2}$ ) exceeds the total overpotential of the FB-25-VRFB cell $(\eta=174 \mathrm{mV})$. Moreover, the residual overpotential is the major source of losses and exceeds the ohmic overpotential throughout the cell potential range from $0.8 \mathrm{~V}$ to $1.8 \mathrm{~V}$.

At $i=20 \mathrm{~mA} \mathrm{~cm}^{-2}$ the residual overpotential is more than 3.5 times higher than the corresponding overpotential of the $F B-25-V R F B$ cell and almost twice as high as $\eta_{\text {res }}$ of the planar cell (table 3.14).

The increased residual overpotential is attributed to a reduced active electrode sur-

TABLE 3.14: Comparison of overpotentials of FB-45-VRFB cell with reference cell and published results.

\begin{tabular}{lcccc}
\hline Cell & $\begin{array}{c}i_{\text {cell }} \\
{\left[\mathrm{mA} \mathrm{cm}^{-2}\right]}\end{array}$ & $\begin{array}{c}\eta_{\text {ohm }} \\
{[\mathrm{mV}]}\end{array}$ & $\begin{array}{c}\eta_{\text {res }} \\
{[\mathrm{mV}]}\end{array}$ & $\begin{array}{c}\eta_{i} \\
{[\mathrm{mV}]}\end{array}$ \\
\hline FB-45-VRFB cell & 20 & 64 & 185 & 249 \\
planar VRFB & 20 & 37 & 95 & 132 \\
D. Aaron et al. [2] & 20 & 10 & 60 & 70 \\
\hline
\end{tabular}

face of the negative electrode (outer half cell). The diminished active electrode surface is caused by a blockage of the outer current collector flow channels.

Polarization Curve Fitting In order to identify the contributions of the ohmic, activation and mass transfer related overpotential, fitting of equation 2.69 and 2.71 to the polarization curve data is performed. Nonlinear regression is done as described in section 3.1.4 to determine the fitting parameters $A S R_{E / i}$, exchange current density $i_{0}$, limiting current density $i_{\text {lim }}$ and tafel slope $b$.

In figure 3.23 the measured polarization curve (Exp.) of the FB-45-VRFB cell at a flow rate of a $9.6 \mathrm{ml} \mathrm{min}^{-1}$ during discharging is plotted against the fitted model (equation 2.69). Fitting parameters are listed in table 3.15. The residuals $(\Delta E=$

TABLE 3.15: Comparison of fitting parameters with reference data ( ${ }^{*}$ measured or literature values).

\begin{tabular}{lccccc}
\hline & & \multicolumn{4}{c}{ Fitting Parameters } \\
& $O C V \mathrm{~V}$ & $b$ & $i_{0} \mathrm{~mA} / \mathrm{cm}^{2}$ & $A S R_{E / i} \Omega \mathrm{cm}^{2}$ & $i_{\text {lim }} \mathrm{mA} / \mathrm{cm}^{2}$ \\
\hline value & 1.4092 & 0.0554 & 0.680 & 3.05 & 100.4 \\
error & \pm 0.0002 & \pm 0.001 & \pm 0.002 & \pm 0.02 & \pm 0.5 \\
reference & $* 1.410$ & $0.0514[5]$ & & $* 3.20(C I)$ & - \\
\hline
\end{tabular}


$\left.E_{\text {cell,Exp }}-E_{\text {cell,Fit }}\right)$ displayed on the right in figure 3.23 show a consistent sub- $m V$ magnitude and reflect the high coefficient of determination $R^{2}=0.99996$.
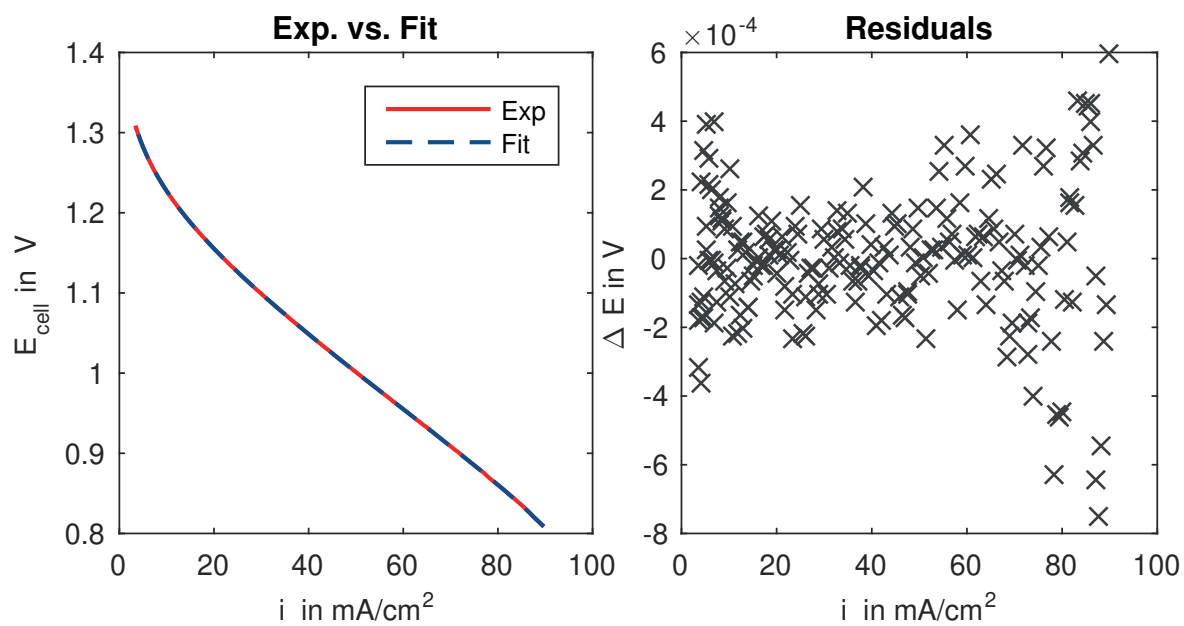

FIGURE 3.23: Left: measured polarization curve of $F B-45-V R F B$ cell at $\dot{Q}=9.6 \mathrm{ml} \mathrm{min}^{-1}$ (Exp.) and fitted model (Fit). Right: Residuals $\left(\Delta E=E_{c e l l, E x p}-E_{c e l l, F i t}\right)$.

The limiting current density of the $F B-45-V R F B$ cell at a flow rate of $9.6 \mathrm{ml} \mathrm{min}^{-1}$ is determined by fitting and yields $i_{l i m}=100.4 \mathrm{~mA} / \mathrm{cm}^{2}$. The fitted $O C V$ value is in accordance with the measured $O C V$ and the Tafel slope (b) compares quite well with the reported values of Agar et al. [5] for heat treated GFA5 EA electrode material (table 3.15).

Polarization curve fitting results in a membrane area specific exchange current density of $0.689 \mathrm{~mA} / \mathrm{cm}^{2}$ (or $j_{0}=0.014 \mathrm{~mA} / \mathrm{cm}^{2}$, relative to $a_{g e o}$ in tab. 3.3). Exchange current densities are defined by the reaction kinetics, electrode surface area, electrode material, electrode treatment and applied methods to measure $j_{0}$ can influence the measured values significantly [43]. A direct comparison of $i_{0}$ with literature values is, thus, not possible as no results of $V R F B$ cells with the electrode material used in the $F B-45-V R F B$ cell have been published. Fitted exchange current density values of the planar reference cell can also not be considered for the comparison as a different electrode material and electrode treatment is used. However, in situ kinetic studies in a planar cell with untreated GDL 10AA electrodes of SGL Carbon $(t=410 \mu \mathrm{m}$, $A=5 \mathrm{~cm}^{2}$ ) and an electrolyte with $0.1 M$ vanadyl sulfate in $5.0 M$ sulfuric acid were done by Aaron et al. [3] and resulted in a membrane specific exchange current densities of $6.799 \mathrm{~mA} / \mathrm{cm}^{2}\left(j_{0}=0.1033 \mathrm{~mA} / \mathrm{cm}^{2}\right.$ estimated with $\left.a_{B E T}\right)$. 
Electrochemical Impedance Spectroscopy is performed to gain knowledge on the processes occuring in the $F B-45-V R F B$ cell. Measurements are conducted at a constant flow rate of $9.6 \mathrm{ml} \mathrm{min}^{-1}$, state of charge of $60 \%$, ac potential perturbation amplitude of $5 \mathrm{mV}$ and frequencies from $60 \mathrm{kHz}$ to $10 \mathrm{mHz}$. At the top of figure 3.24 the measured impedance $Z$ of the $F B-45-V R F B$ cell at an $O C V=1.42 \mathrm{~V}$ is shown in a Nyquist representation, while the impedances at different cell potentials $E_{c e l l}(A-D$ in fig. 3.25) are depicted at the top of figure 3.25.
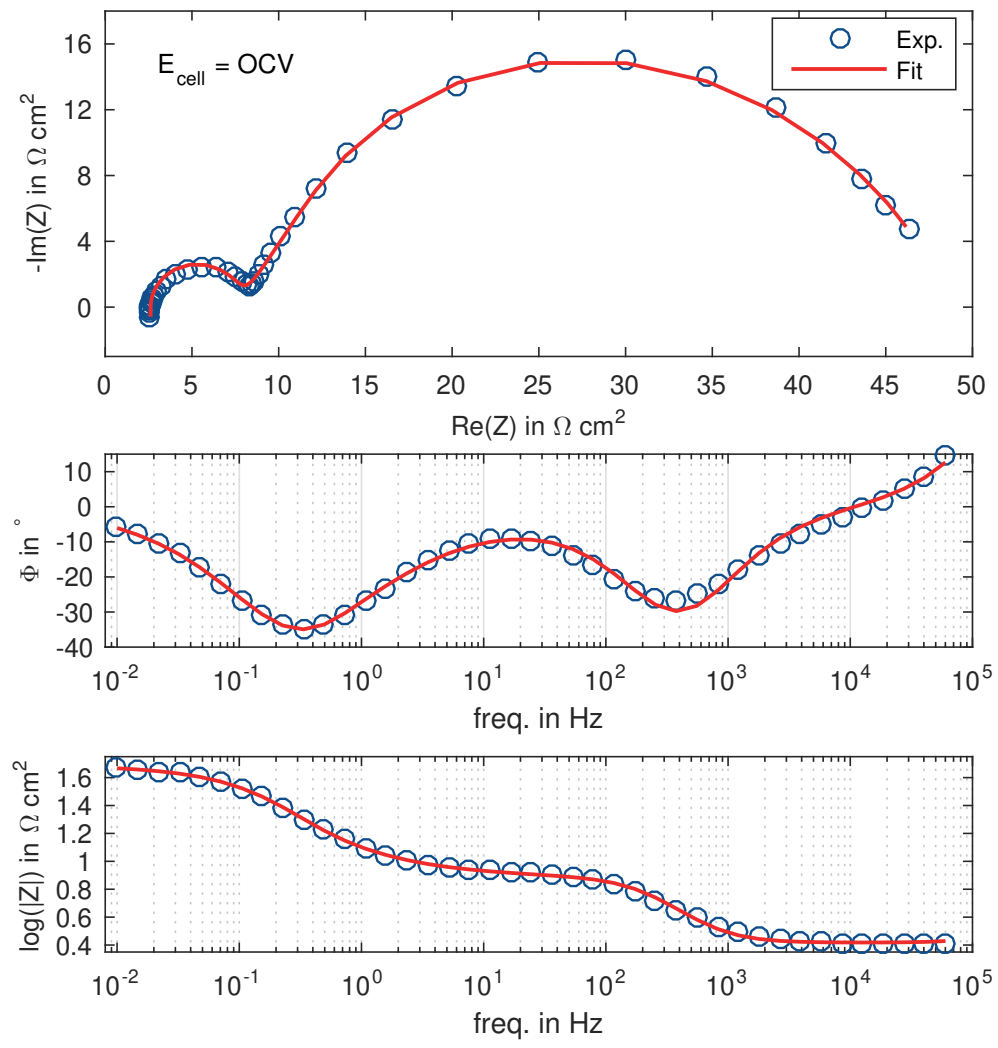

FIGURE 3.24: Measured impedance and fitted model of the FB-45$V R F B$ cell at $O C V$. Top: Nyquist plot; Middle: Bode plot of phase shift $\phi$; Bottom: Bode plot of absolute impedance $|Z|$. 
At frequencies above $12 \mathrm{kHz}$ a positive phase shift $\phi$ and inductive portion appears in the Bode and Nyquist plot (fig. 3.24) of the impedance at OCV, respectively. This inductance is caused by the test cell wiring and can be described by an inductor $(L)$. The ohmic resistance $R_{H F}$ represents the ohmic cell resistance of the cell and is obtained at $\operatorname{Im}(Z)=0$ in the Nyquist representation and $\phi=0$ in the Bode plot.

For $11 \mathrm{~Hz}<$ freq $\leq 6 \mathrm{kHz}$ a semicircle is observed in figure 3.24, which represents the charge transfer process at the electrodes of the cell. While the imaginary part provides information on the capacitive double layer $C$ at the electrode-electrolyte interfaces the real part corresponds to the charge transfer resistance $R_{C T}$.

In the Nyquist plot in figure 3.25 an exponential decrease of $R_{C T}$ with a reduction of the cell potential from $A$ to $C$ is observed and is in agreement with the expected progression (Butler-Volmer Equation), accordingly.
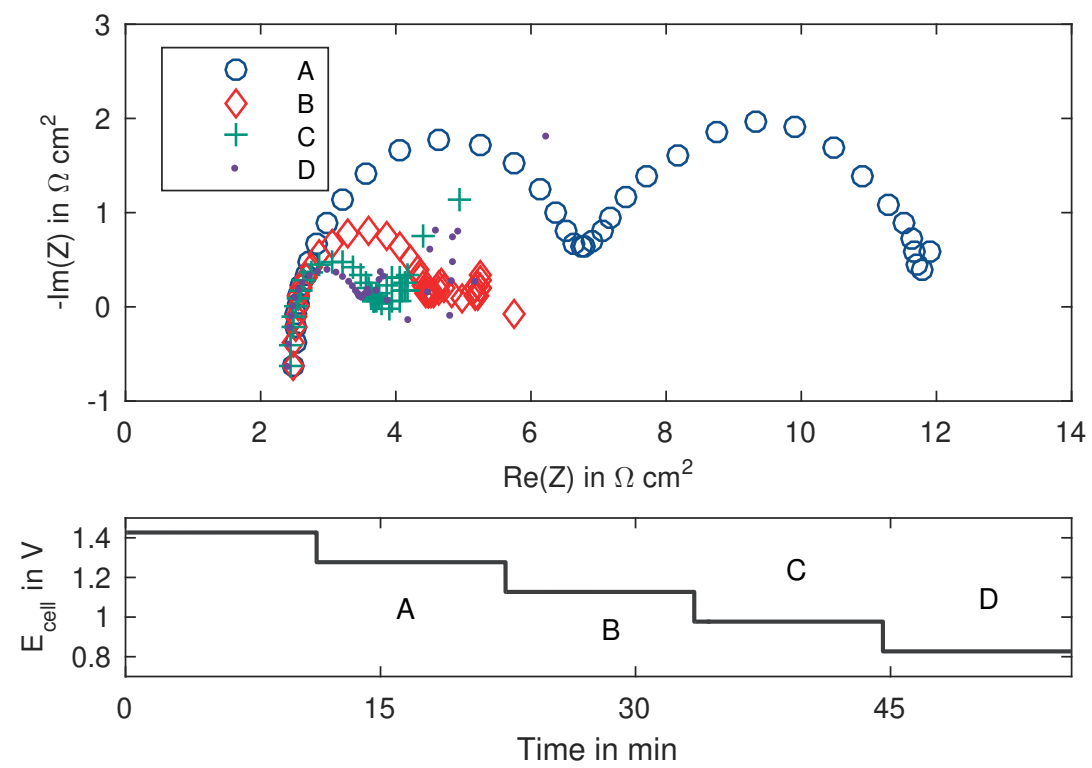

FIGURE 3.25: Top: Nyquist plot of measured impedance of the FB45-VRFB cell at different $E_{\text {cell }}(A, B, C, D)$. Bottom: Applied potentials during EIS measurement.

The second semicircle-like curve shape in figure 3.24 appears at low frequencies between $7.5 \mathrm{~Hz}$ and $10 \mathrm{mHz}$ and is attributed to mass transfer processes. It is considered in the equivalent circuit model with a Warburg element $W_{Z}$ for finite-length diffusion. As the cell is discharged (fig. 3.25) the capacitive and resistive portions 
decrease ( $A$ in fig. 3.25) before the onset of a high noise level $(B-D)$ in the respective portion of the measured signal is observed. This noise is assigned to the pulsation of the electrolyte flow, which is caused by the pumps and is more pronounced at high absolute overpotentials $(B-D)$ as the Nernst diffusion layer thickness is expected to increase.

To quantify the described processes, the equivalent circuit model depicted in figure 3.26 is fitted to the impedance data as described in section 3.1.4. Fitting is only performed for the impedance data at $\mathrm{OCV}$ as the noise signal observed during polarization inhibits a sufficient correlation of the model.

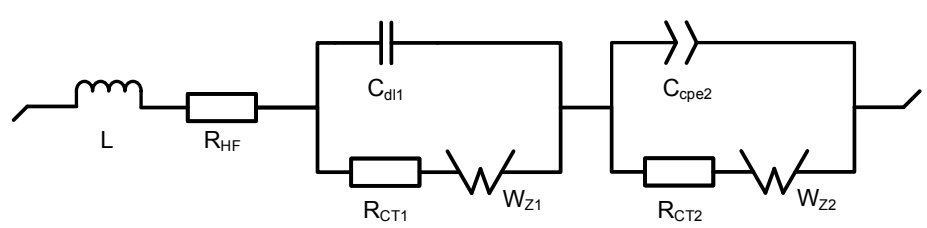

FIGURE 3.26: Equivalent circuit model of a full FB-VRFB cell.

The fitted equivalent circuit model and impedance data of the FB-45-VRFB cell is shown in the Nyquist and Bode plot in figure 3.24 and fitting parameters are listed in table 3.16. The fit results in a $X^{2} /|Z|$ value of 0.041 and shows a good correlation with the measured impedance.

TABLE 3.16: Fitting parameters of equivalent circuit model.

\begin{tabular}{rlrlrl}
\hline & & \multicolumn{3}{c}{ Equivalent Circuit Models } \\
\multicolumn{2}{c}{$L+R$} & Randles with $W_{Z}$ & \multicolumn{3}{c}{ Randles with $C P E$ and $W_{Z}$} \\
\hline \multicolumn{2}{c}{ fit parameter } & \multicolumn{2}{c}{ fit parameter } & \multicolumn{2}{c}{ fit parameter } \\
\hline$L_{1}$ & $0.102 \mu \mathrm{H}$ & $C_{3}$ & $2.122 \mathrm{mF}$ & $Q_{4}$ & $0.909 \mathrm{Fs}^{\mathrm{a}-1}$ \\
$R_{H F}$ & $2.62 \Omega \mathrm{cm}^{2}$ & $R_{3}$ & $4.98 \Omega \mathrm{cm}^{2}$ & $a$ & 0.845 \\
& & $R_{W 3}$ & $0.778 \Omega$ & $R_{4}$ & $26.96 \Omega \mathrm{cm}^{2}$ \\
& & $t_{d 3}$ & $2.02 \mathrm{~s}$ & $R_{W 4}$ & $94.4 \mathrm{~m} \Omega$ \\
\hline
\end{tabular}

By use of equation 2.72 and the charge transfer resistance $R_{C T}$ (determined with fitting parameters $R_{3}$ and $R_{4}$ ) an exchange current density $i_{0}=0.80 \mathrm{~mA} \mathrm{~cm}^{-2}$ is estimated for the FB-45-VRFB cell. The exchange current density determined by EIS 
$\left(i_{0}=0.69 \mathrm{~mA} \mathrm{~cm}^{-2}\right)$ correlates with the estimated $i_{0}$ of the polarization curve fit, accordingly. The $A S R_{E I S}=2.62 \Omega \mathrm{cm}^{2}$ of the $F B-45-V R F B$ cell is deduced from the $R_{H F}$ value and shows to be lower than the $A S R_{C I}=3.20 \Omega \mathrm{cm}^{2}$.

A direct comparison of the frequency domain of the charge transfer portion of the measured full cell impedance with literature values can not be done as solely single electrode impedance measurements are published in [138, 139]. An elaborate investigation of the tubular positive and negative electrodes is, however beyond the scope of this work.

\section{Evaluation of Methods and Fitting Parameters}

As the ohmic overpotential has a large contribution to cell potential Current Interrupt $(C I)$ measurements are integrated in the polarization curve measurement protocols. EIS measurements allow to determine the $A S R$ by fitting or reading out the real part $(R e)$ at a specific frequency $f=12.6 \mathrm{kHz}$ (HFR). A fourth method to determine the $A S R$ is to fit the ohmic portion of a $E_{\text {cell }} / i$-curve. In table 3.17 ASR values of the tubular cells determined by these 4 methods are listed.

TABLE 3.17: Area specific cell resistances ASR (in $\Omega \mathrm{cm}^{2}$ ) of tubular VRFB cells determined by different methods (CI, HFR, EIS with fit and $E / i$-fit).

\begin{tabular}{lccc}
\hline & FB-25-VRFB & FB-45-VRFB & FT-25-VRFB \\
\hline$A S R_{C I}$ & $(6.11 \pm 0.09)$ & $(3.20 \pm 0.06)$ & $(18.33 \pm 0.03)$ \\
$A S R_{H F R}$ & - & $(2.53 \pm 0.06)$ & $(16.3 \pm 0.5)$ \\
$A S R_{E I S}$ & - & 2.62 & 14.75 \\
$A S R_{E / i}$ & $(8.1 \pm 0.2)$ & $(3.05 \pm 0.02)$ & - \\
\hline
\end{tabular}

The standard deviation of the ASR values determined by $C I$ and HFR make up about $2 \%$ of the respective mean values. The ASR values determined by $C I$ are, however $11 \%$ to $21 \%$ higher than the HFR values. In the field of $P E M-F C$ a similar variation of $H F R$ and $C I$ measurement values of $10 \%$ to $30 \%$ is reported [30]. According to Cooper and Smith [30] this increased $A S R_{C I}$ values are due to the response of porous electrodes with non-negligible electrolyte resistance to perturbation effects with a large potential change, as it occurs in CI-measurements. In HFR measurements the amplitude of the voltage stimulation is comparably low $(5 \mathrm{mV}$ in this study). 
Comparison of the $A S R_{C I}$ values with the $A S R$ values obtained by polarization curve fitting of the $F B-45-V R F B$ cell and the planar reference cell reveal a good correlation (systematic error $\leq 5 \%$ ). However, the $A S R_{E / i}$ value of the $F B-25-V R F B$ cell appears to be $33 \%$ higher than the respective $A S R_{C I}$. It is, hence concluded that the polarization curve fitting can be employed to produce valid $A S R$ values when a sufficiently high number of data points is provided (LPS).

The deviation of the $A S R_{H F R}$ from the $A S R_{E / i}$ is rather attributed to the measurement method (high vs. low potential perturbation) than the validity of the fit. This observation is in line with results of Langner [72], who reported $A S R_{E / i}$ values of a planar $V R F B$ cell to be approximately $30 \%$ above $A S R_{H F R}$ values ( freq $=10 \mathrm{kHz}$ and $10 \mathrm{mV} A C$-stimulation).

The ASR values determined by a fit of the impedance spectra correlates quite well with the $A S R_{H F R}$. It has to be noted that the high frequency resistance is dependent on the measurement frequency and shows lower values for higher frequencies. It is, thus, crucial to mention that the frequency of the HFR measurement has to be chosen carefully and no capacitive or inductive portions are present in the measured impedance. The $A S R=0.5 \Omega \mathrm{cm}^{2}$ reported by Aaron et al. [2] was measured at a single frequency within a range from $10 \mathrm{kHz}$ to $100 \mathrm{kHz}$ ( $A C$ perturbation $10 \mathrm{mV}$ ) and can not be compared directly to the $A S R$ values within this thesis, accordingly. However, the area specific resistance of the $F B-45-V R F B$ cell can be assumed to be 4 to 5 times higher than the value reported in [2].

The exchange current density of the $F B-45-V R F B$ cell was determined by polarization curve data fitting and fitting of an equivalent circuit model to the measured impedance. Although obtained $i_{0}$ values showed similar values $\left(i_{0}=0.80 \mathrm{~mA} \mathrm{~cm}^{-2}\right.$ (EIS); $i_{0}=0.69 \mathrm{~mA} \mathrm{~cm}^{-2}$ (Pol. Curve)) it has to be noted that the high number of fitting parameters in the full cell equivalent circuit model tends to produce invalid fits. In order to obtain meaningful quantitative results further investigations on symmetrical electrode cells at various operating conditions should be considered.

\section{Comparison of Cells}

In figure 3.27 the residual overpotentials $\eta_{\text {res }}$ of the tubular flow-by ( $F B-25-V R F B, F B-$ $45-V R F B)$, flow-through (FT-25-VRFB) and planar reference cell are compared. The $F B-25-V R F B$ cell exhibits the lowest $\eta_{\text {res }}$ of all cells. The significantly increased residual overpotentials of $F B-45-V R F B$ can be attributed to the blocked flow channels in the outer current collector.

By comparing the residual overpotentials of the planar VRFB cell and the FB-25$V R F B$ cell it becomes obvious that the combined activation and mass transfer overpotentials $\left(\eta_{\text {res }}\right)$ would permit much higher current densities if the $A S R=6.1 \Omega \mathrm{cm}^{2}$ could be minimized to the level of the planar cell's $A S R=1.8 \Omega \mathrm{cm}^{2}$ (tab. 3.18). 
A reduction of the $A S R$ of the $F B-25-V R F B$ cell by roughly half is achieved by an increased electrode compression and consequential contact resistance reduction ( $F B$ 45 -VRFB $A S R=3.2 \Omega \mathrm{cm}^{2}$ ). It has to be noted that the $F B-45-V R F B$ cell features an extruded tubular membrane with higher thickness than the welded fumapem ${ }^{\circledR}$ F950 membrane of the $F B-25-V R F B$ cell. The conductivity of the extruded $V M$-fumasep ${ }^{\circledR}$ FFT membrane can, thus, be considered as sufficiently high and does not impose limitations on the ASR.

TABLE 3.18: Comparison of overpotentials of tubular VRFB cells with reference cell.

\begin{tabular}{lcccc}
\hline Cell & $\begin{array}{c}i_{\text {cell }} \\
{\left[\mathrm{mA} \mathrm{cm}^{-2}\right]}\end{array}$ & $\begin{array}{c}\eta_{\text {ohm }} \\
{[\mathrm{mV}]}\end{array}$ & $\begin{array}{c}\eta_{\text {res }} \\
{[\mathrm{mV}]}\end{array}$ & $\begin{array}{c}\eta_{i} \\
{[\mathrm{mV}]}\end{array}$ \\
\hline FT-25-VRFB cell & 20 & 366 & 223 & 589 \\
FB-25-VRFB cell & 20 & 122 & 52 & 174 \\
FB-45-VRFB cell & 20 & 64 & 185 & 249 \\
planar VRFB & 20 & 37 & 95 & 132 \\
\hline
\end{tabular}

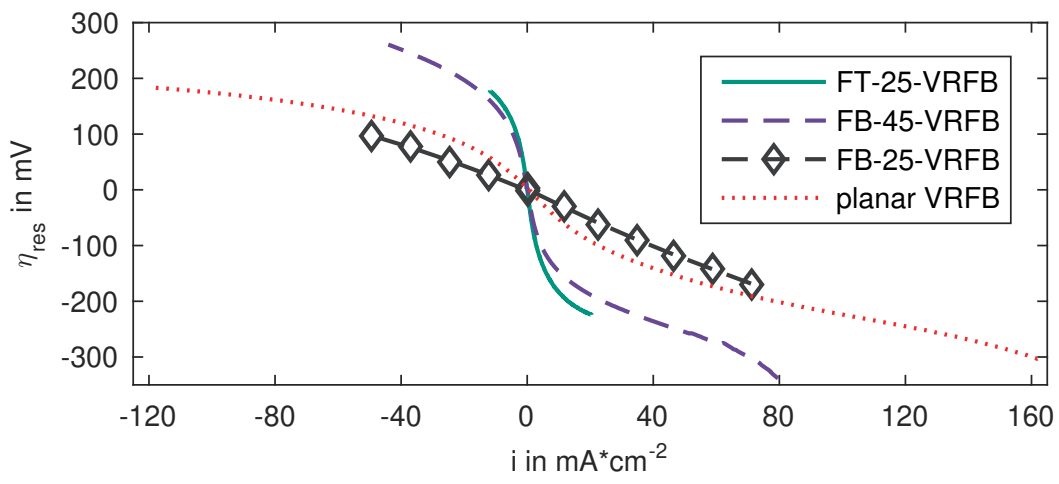

FIGURE 3.27: Residual overpotentials $\eta_{\text {res }}$ of tubular and planar $V R F B$ cells at a flow rate of $6.4 \mathrm{ml} \mathrm{min}^{-1}$.

In previous plots and discussions currents are always related to the active membrane area. This approach is common in the field of fuel cells were a porous thin film layer is often employed as electrode. It is also applied in VRFB literature where a relatively thick layer of 3-D graphite felt electrodes is typically used in cells. As the activation overpotential $\eta_{\text {act }}$ is directly related to the active electrode area, electrode area specific currents densities $j$ should be used to evaluate and compare residual 
overpotentials and quantify the degree of electrode area utilization of different cells. The geometric electrode area $A_{\text {elec }}$ of fibrous media can be estimated as described in section 2.1.1. Specific surface areas can also be calculated by the BET-method $\left(a_{B E T}\right)$ and are 2 to 3 times higher than the estimated specific geometric electrode areas $a_{\text {geo }}$ (see table 3.3). This is due to the fact that a perfectly smooth surface morphology is assumed for $a_{\text {geo }}$, while surface areas calculated by the BET-method include the microscopic surface structure of the electrode. Thermal treatment of the graphite felt material further increases the surface area and effects the active surface area of the electrode [43]. Although the geometric electrode surface related current does not fully reflect the active electrode surface, it enables to compare and evaluate electrodes with rather different geometries and dimensions.

In figure 3.28 the residual overpotentials of the tubular and planar VRFB cells are plotted against the geometric electrode area related current densities $j$.

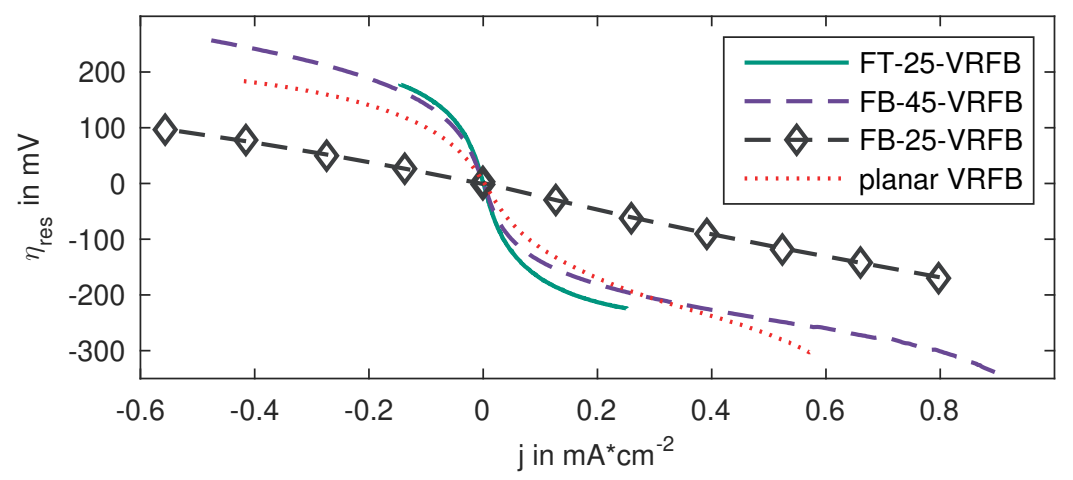

FIGURE 3.28: Residual overpotentials $\eta_{\text {res }}$ over the geometric electrode surface area related current density $j$ of tubular and planar VRFB cells at a flow rate of $6.4 \mathrm{ml} \mathrm{min}^{-1}$.

While the residual overpotentials of the tubular FT-25-VRFB cell are significantly higher than the $\eta_{\text {res }}$ of the planar flow-through cell in figure 3.27, they show a rather similar progression in figure 3.28. This can be attributed to the electrode area, which is 2.6 times bigger in the planar than in the tubular FT-25-VRFB cell.

In flow-by electrode configurations mass transport is mainly based on diffusion of vanadium ions in the porous electrode and convective mass transport of vanadium ions along the interfacial area of the flow channel and electrode [152]. The extent of penetration of convective flow into the pores of the graphite felt is strongly dependent on the felt permeability, electrolyte viscosity, flow rate and flow channel geometry $[33,61,62,89]$. The portion of the electrode area that actively participates in the redox reactions in a flow-by configuration can, thus, not be identified easily. 
However, it can be assumed that only a fraction of the entire electrode area will actively contribute to the current density. Despite this the entire electrode area of the tubular $F B-25 / 45-V R F B$ cells is considered for $j$.

In figure 3.28 the residual overpotential of the planar flow through cell is significantly higher than $\eta_{\text {res }}$ of the $F B-25-V R F B$ cell. As comparable reaction kinetics are assumed to occur on both graphite felt electrode surfaces, flow-through electrodes seem to feature a reduced utilization of electrode surface area, accordingly. This might be due to channeling effects in the flow-through electrode structure. The increase in $\eta_{\text {res }}$ for the $F B-45-V R F B$ cell is attributed to the blocked flow channels ( 7 out of 8 blocked) in the outer half cell.

\subsubsection{Half Cell Overpotentials}

In section 3.2.2 the overpotentials of the positive and negative electrode $\left(\eta_{\text {pos }}, \eta_{\text {neg }}\right)$ of a planar VRFB cell with symmetrical electrodes (size, material) is measured (sec. 3.2.2) and evaluated regarding their contribution to the total residual overpotential $\left(\eta_{\text {res }}\right)$. The dominant share of the negative electrode overpotential is shown and the negative electrode appears to be the limiting electrode in terms of the cell performance. To analyze the overpotential of the tubular FB and FT cells, an analog measurement setup as described in section 2.2.3 is used and test cells are subjected to polarization curve measurements at a $S o C \approx 60 \%$ and flow rate of $6.4 \mathrm{ml} \mathrm{min}^{-1}$.

In figure 3.29 the positive and negative overpotentials of the $F B-45-V R F B$ and $F T$ 25-VRFB cell are compared with $\eta_{\text {neg }}$ and $\eta_{\text {pos }}$ of the planar cell. In contrast to the overpotentials of the $F B-45-V R F B$ and planar cell, overpotential measurements of the FT-25-VRFB cell reveal a rather different ratio of $\eta_{\text {neg }}$ and $\eta_{p o s}$. Although electrodes

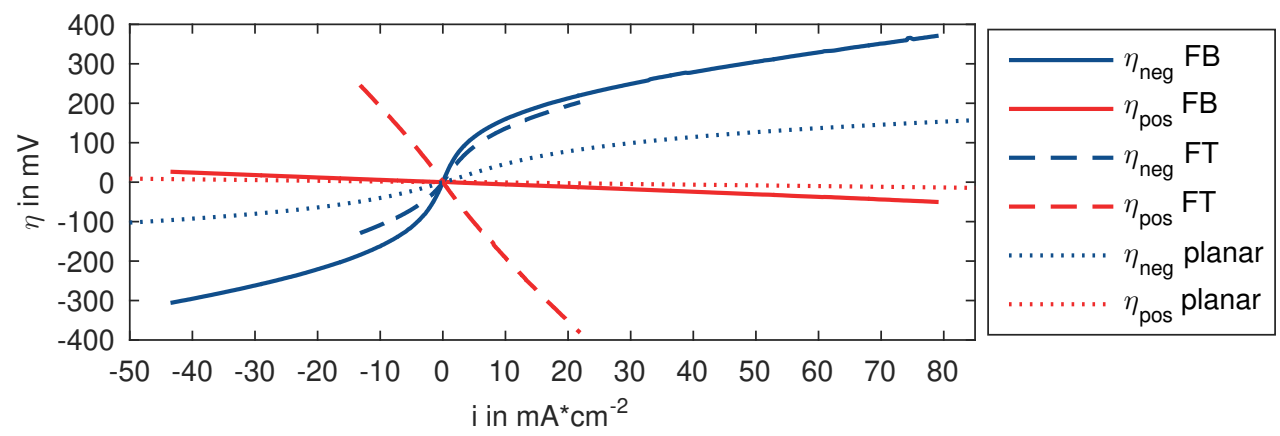

FIGURE 3.29: Positive and negative overpotentials of FB-45-VRFB, FT-25-VRFB and planar cell. 
with identical surface areas are employed in the positive (inner) and negative (outer) half cell of the FT-25-VRFB cell, the absolute values of the positive overpotential predominate the absolute values of $\eta_{\text {neg }}$.

The relatively high share of the positive overpotential agrees with the results of the pressure drop evaluation (see subsection above). Accordingly, the annular clearance between the inner current collector and electrode material is assumed to lead to a partial electrical contacting of the inner electrode and might result in a reduced electrode surface utilization, which would, in turn, cause an increased overpotential.

It should be noted that the elevated negative overpotentials (relative to planar cell) are caused by the smaller electrode thickness $t=1.2 \mathrm{~mm}(t=4.6 \mathrm{~mm}$ in planar cell.). Analog to the planar cell, the negative overpotential of $F B-45-V R F B$ exceeds the overpotential of the positive electrode. However, the negative overpotential of the FB-45$V R F B$ cell outnumbers $\eta_{\text {neg }}$ of the planar cell significantly.

This comparably high $\eta_{\text {neg }}$ is assumed to stem from the reduced active electrode surface area of the negative electrode (outer half cell), which is caused by blocked flow channels. In order to verify this assumption, the half cell configuration of the FB$45-V R F B$ cell is reversed. After switching the negative and positive electrolyte feeds and reversing the electrode connections, the FB-45-VRFB cell is operated with the negative electrode in the inner half cell and positive electrode in the outer half cell. In figure 3.30 negative and positive overpotentials of the $F B-45-V R F B$ cell with the negative electrode in the outer half cell ( $\mathrm{NegOut})$ and the negative electrode in the inner half cell $(\mathrm{Neg} I n)$ are displayed.

The reverse half cell configuration leads to a significant reduction of $\eta_{n e g}$ and a sub-

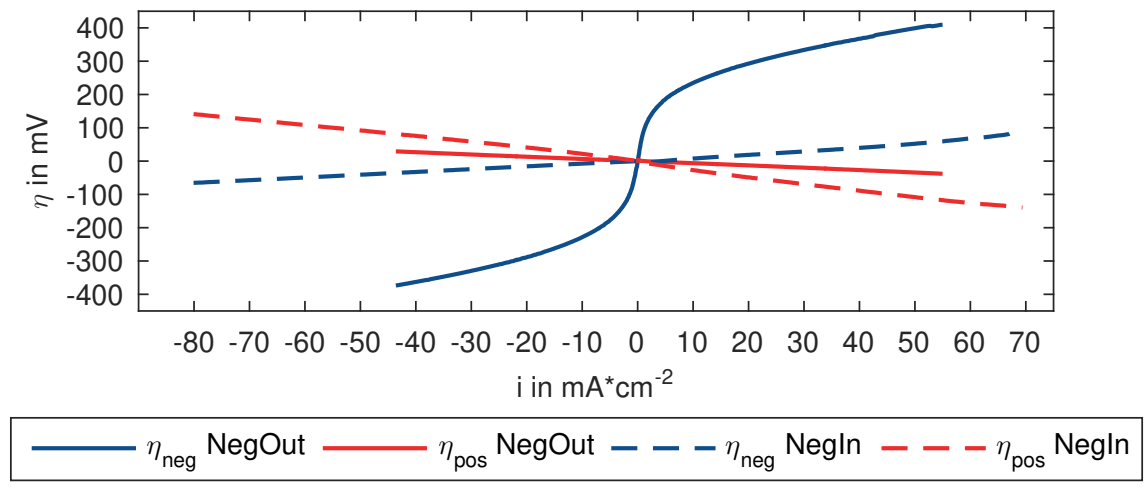

FIGURE 3.30: Positive and negative residual overpotentials $\left(\eta_{\text {pos }}\right.$ $\eta_{n e g}$ ) of tubular FB-45-VRFB cell with changed half cell configuration at a flow rate of $9.6 \mathrm{ml} \mathrm{min} \mathrm{m}^{-1}$.

stantial rise of $\eta_{\text {pos }}$. These results and the increased pressure drop along the negative 
half cell (see figure 3.16) confirm the assumption of a reduced surface area in the negative half cell of $F B-45-V R F B$.

\subsubsection{Charge/Discharge Cycling}

In this section charge/discharge cycling is done to evaluate the cell performance in long term operation and to analyze the battery and system efficiencies. Charge/discharge experiments are conducted based on the measurement routine specified in section 3.1.4. By implementing pressure, density, temperature and potential sensors in the test setup (see figure 3.10) during cycling, additional information on the pumping power $\left(P_{\text {pump }}\right)$, state of charge $(S o C)$ and operational behavior is obtained and evaluated.

Based on the cell performance results (sec. 3.2.3) appropriate constant current densities $(|i|)$ and flow rates $(\dot{Q})$ are chosen for the charge/discharge cycling experiments. As no significant mass transfer related overpotentials are observed in the polarization curves at $\dot{Q}=6.4 \mathrm{ml} \mathrm{min}^{-1}$ for the $F B-25-V R F B$ and $F B-45-V R F B$ cell, a constant flow rate of $6.4 \mathrm{ml} \mathrm{min}^{-1}$ is set for all cycling routines. In order to utilize a substantial portion of the maximum electrolyte capacity $\left(Q_{\max }\right)$ moderate constant current densities are applied during cycling.

As the performance characterization of the tubular flow-through cell (FT-25-VRFB) revealed significant performance limitations (high $\eta_{\text {res }}$ and ASR) it is not considered for further charge/discharge cycling investigations.

In figure 3.31 the current density $|i|=35 \mathrm{~mA} \mathrm{~cm}^{-2}$, cell potential $\left(E_{\text {cell }}\right)$, coulomb counted state of charge $(\operatorname{SoC}(\Delta Q))$, positive and negative electrolyte density $\left(\rho_{\text {pos }}\right.$, $\left.\rho_{\text {neg }}\right)$ and pressure drop across the positive and negative half cell $\left(\Delta p_{\text {pos }}, \Delta p_{\text {neg }}\right)$ of the $F B-25-V R F B$ cell during cycling is plotted over time.

Cycling of the $F B-45-V R F B$ cell is done at a current density $|i|=20 \mathrm{~mA} \mathrm{~cm}^{-2}$ within cell potential limits of $E_{\text {cell }}^{\text {lim }}=0.8 \mathrm{~V}$ and $E_{\text {cell }}^{\text {lim }}=1.7 \mathrm{~V}$. In figure 3.32 the measured positive and negative Nernst potential $\left(E_{\text {pos }}^{0}, E_{\text {neg }}^{0}\right)$, calculated standard cell potential $\left(E_{\text {cell }}^{0}=E_{\text {pos }}^{0}-E_{\text {neg }}^{0}\right)$, coulomb counted $\operatorname{SoC}(\Delta Q)$ as well as the positive and negative overpotentials $\left(\eta_{\text {pos }}, \eta_{\text {neg }}\right)$ during cycling are shown.

In this section efficiencies are evaluated and process as well as operating parameters are analyzed.

\section{Efficiencies}

Electrolyte formation with subsequent charging to a state of charge of $60 \%$ is performed as described in section 3.1.4. A further galvanostatic charge sequence is conducted before 6 charge/discharge cycles are carried out. Out of the 6 charge/discharge 

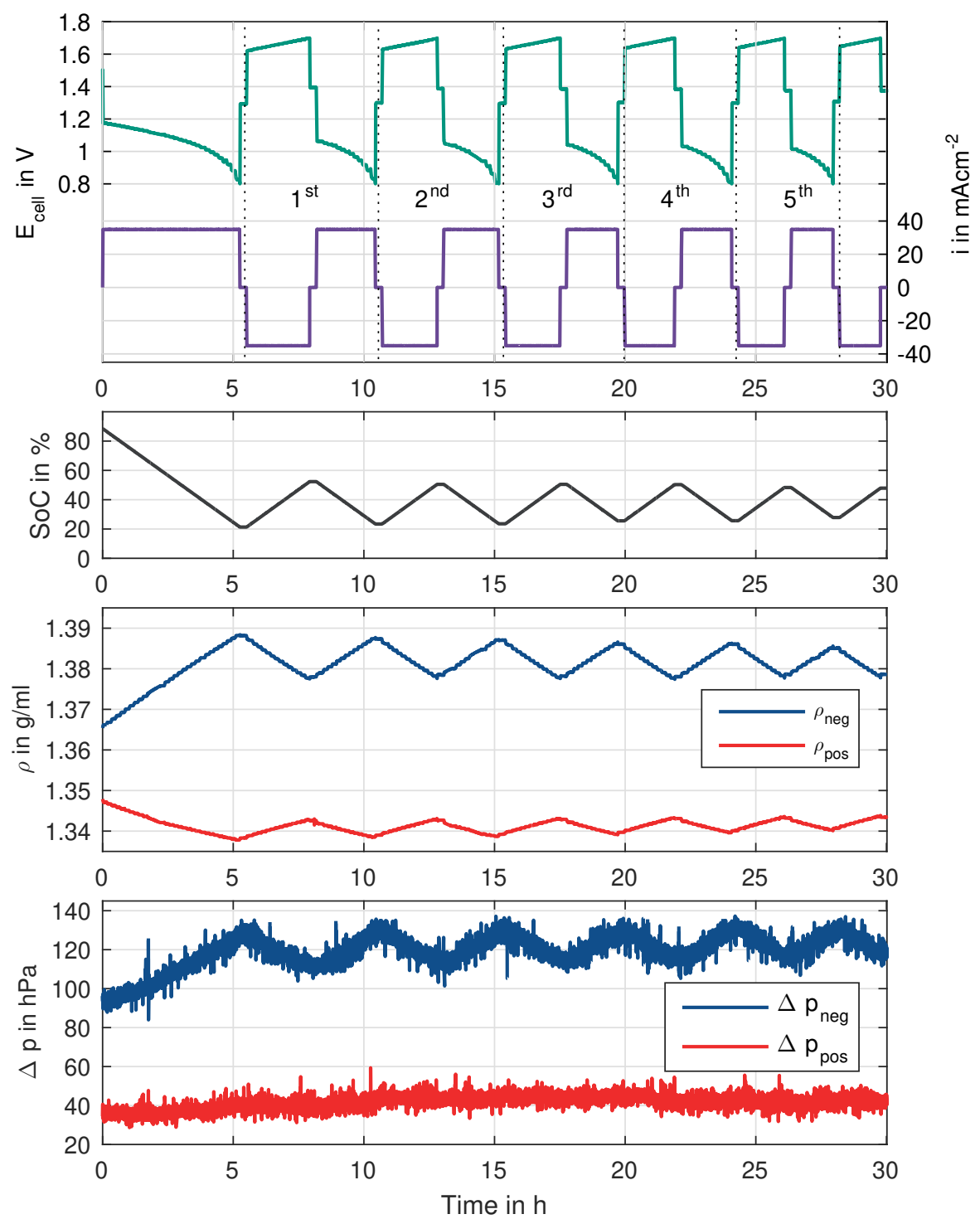

FIGURE 3.31: Cell potential, current density, electrolyte densities,state of charge and pressure drops during charge/discharge cycling of tubular $F B-25-V R F B$ cell at a flow rate of $6.4 \mathrm{ml} \mathrm{min}^{-1}$. 

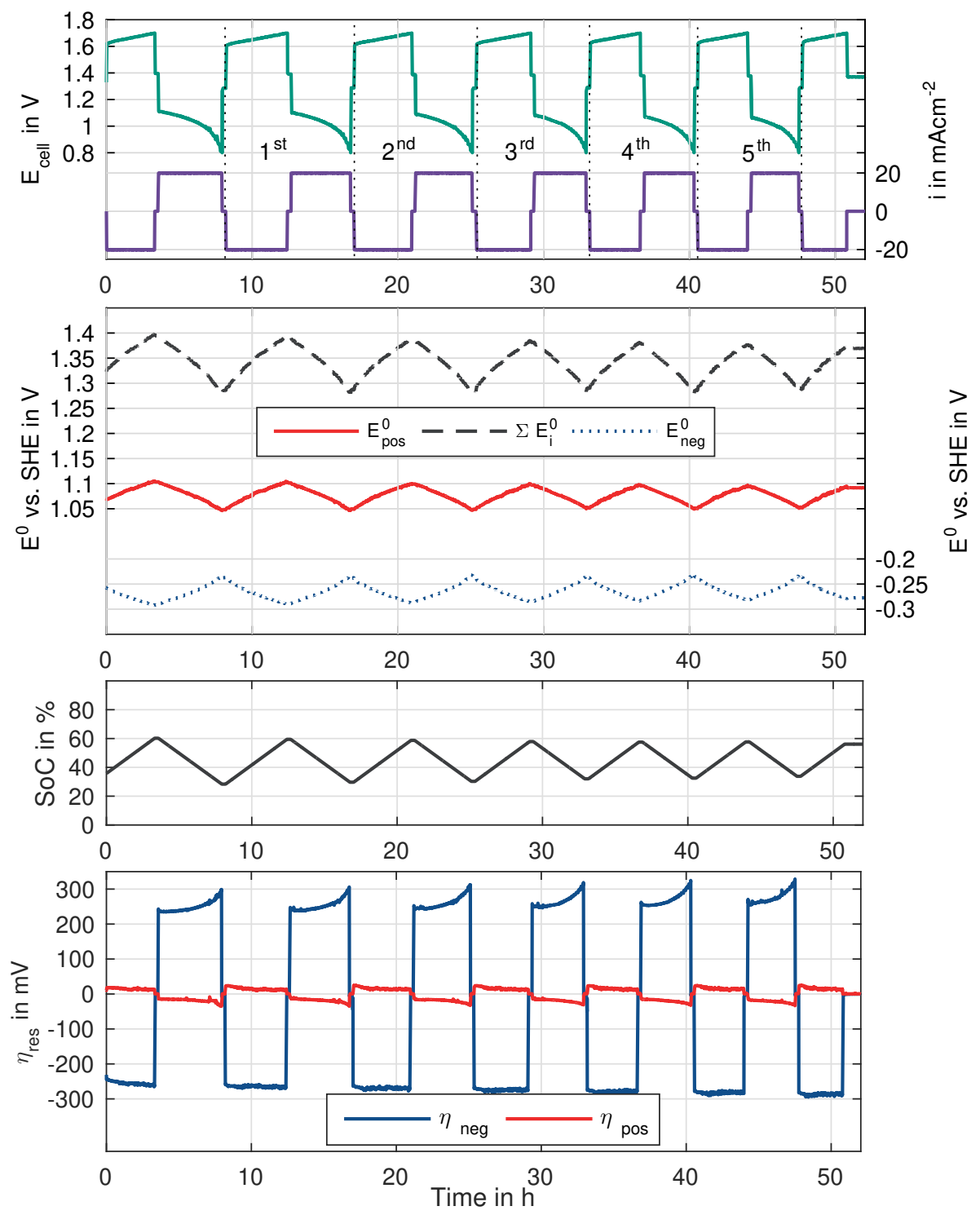

FIGURE 3.32: Cell potential, current density, Nernst potentials, state of charge and residual overpotentials during charge/discharge cycling of tubular $F B-45-V R F B$ cell at a flow rate of $6.4 \mathrm{ml} \mathrm{min}^{-1}$. 
cycles (see figure 3.31 and 3.32), only the last 5 charge (Ch) and discharge (Dch) cycles are considered for the evaluation.

The transferred charge $\left(|\Delta Q|\right.$, eq.: 2.3), transferred energy $\left(\left|\Delta E_{e l}\right|\right.$, eq. 2.47), required energy for electrolyte pumping $\left(\Delta E_{\text {pump }}=\int P_{\text {pump }}(t) d t\right.$, eq. 2.51), coulombic efficiency ( $C E$, eq. 2.58), voltage efficiency ( $V E$, eq. 2.60), energy efficiency ( $E E$, eq. 2.61) and system energy efficiency ( $E E_{s y s}$, eq. 2.63) of the cycling experiments are listed in table 3.19 and 3.20 .

TABLE 3.19: Results of galvanostatic charge (Ch) and discharge (Dch) cycling of $F B-25-V R F B$ cell at $|i|=35 \mathrm{~mA} \mathrm{~cm}^{-2}$. Data is listed in the following units: $|\Delta Q|$ in $\mathrm{mAh},\left|\Delta E_{e l}\right|$ in $\mathrm{Wh},\left|\Delta E_{\text {pump }}\right|$ in mWh.

\begin{tabular}{lcccccccccc}
\hline & \multicolumn{2}{c}{$1^{\text {st }}$ cycle } & \multicolumn{2}{c}{$2^{\text {nd }}$ cycle } & \multicolumn{2}{c}{$3^{\text {rd }}$ cycle } & \multicolumn{2}{c}{$4^{\text {th }}$ cycle } & \multicolumn{2}{c}{$5^{\text {th }}$ cycle } \\
& Ch & Dch & Ch & Dch & Ch & Dch & Ch & Dch & Ch & Dch \\
\hline$|\Delta Q|$ & 1328 & 1238 & 1154 & 1153 & 1153 & 1067 & 1058 & 1051 & 971 & 876 \\
$\left|\Delta E_{\text {el }}\right|$ & 2.207 & 1.220 & 1.928 & 1.117 & 1.922 & 1.033 & 1.768 & 1.008 & 1.620 & 0.835 \\
$\Delta E_{\text {pump }}$ & 7.09 & 6.60 & 6.16 & 6.15 & 6.15 & 5.69 & 5.65 & 5.61 & 5.18 & 4.67 \\
$C E[\%]$ & 93.2 & & 99.8 & \multicolumn{2}{c}{92.5} & \multicolumn{2}{c}{99.3} & 90.2 \\
$V E[\%]$ & 59.3 & 58.0 & 58.1 & 57.4 & 57.1 \\
$E E[\%]$ & 55.3 & 57.9 & 53.8 & 57.0 & 51.5 \\
$E E_{\text {sys }}[\%]$ & 54.8 & 57.4 & 53.3 & & 56.5 & 51.1 \\
\hline
\end{tabular}

TABLE 3.20: Results of galvanostatic charge (Ch) and discharge (Dch) cycling of FB-45-VRFB cell at $|i|=20 \mathrm{~mA} \mathrm{~cm}^{-2}$. Data is listed in the following units: $|\Delta Q|$ in $\mathrm{mAh},\left|\Delta E_{e l}\right|$ in $\mathrm{Wh},\left|\Delta E_{\text {pump }}\right|$ in $\mathrm{mWh}$.

\begin{tabular}{lcccccccccc}
\hline & \multicolumn{2}{c}{$1^{\text {st }}$ cycle } & \multicolumn{2}{c}{$2^{\text {nd }}$ cycle } & \multicolumn{2}{c}{$3^{\text {rd }}$ cycle } & \multicolumn{2}{c}{$4^{\text {th }}$ cycle } & \multicolumn{2}{c}{$5^{\text {th }}$ cycle } \\
& Ch & Dch & Ch & Dch & Ch & Dch & Ch & Dch & Ch & Dch \\
\hline$|\Delta Q|$ & 1333 & 1276 & 1244 & 1219 & 1183 & 1108 & 1092 & 1072 & 1078 & 1023 \\
$\left|\Delta E_{\text {el }}\right|$ & 2.207 & 1.300 & 2.063 & 1.227 & 1.965 & 1.110 & 1.818 & 1.064 & 1.794 & 1.011 \\
$\Delta E_{\text {pump }}$ & 16.6 & 15.9 & 15.5 & 15.2 & 14.7 & 13.8 & 13.6 & 13.4 & 13.4 & 12.7 \\
$C E[\%]$ & \multicolumn{2}{c}{95.7} & \multicolumn{2}{c}{98.0} & \multicolumn{2}{c}{93.7} & \multicolumn{2}{c}{98.1} & 94.9 \\
$V E[\%]$ & 61.5 & & 60.7 & 60.3 & 59.6 & 59.4 \\
$E E[\%]$ & 58.9 & 59.5 & 56.5 & 58.5 & 56.4 \\
$E E_{\text {sys }}[\%]$ & 57.8 & & 58.3 & & 55.4 & & 57.4 & 55.2 \\
\hline
\end{tabular}

Capacity and Electrolyte Utilization: As the cycling experiment is carried out with $100 \mathrm{ml}$ of electrolyte solution in each tank, a maximum capacity ( $Q_{\max }$, eq. 2.6) of 
$4288 \mathrm{~mA} \mathrm{~h}$ is available for charging and discharging, respectively. Within the $1^{\text {st }} \mathrm{cy}$ cle of the $F B-25-V R F B$ cell $30 \%$ of $Q_{\max }$ is utilized, while an electrolyte utilization $\left(U_{\text {elyt }}\right.$, eq. 2.7$)$ of $21.5 \%$ is determined in the $5^{\text {th }}$ cycle. Cycling of the FB-45-VRFB cell reveals a comparable utilization of $30 \%$ in the $1^{\text {st }}$ cycle and $24.5 \%$ in the $5^{\text {th }}$ cycle.

In a RFB storage application a substantially higher utilization $\left(U_{\text {elyt }} \geq 80 \%\right)$ is required in order to reduce electrolyte specific system costs. An increased utilization can be achieved with a reduced current density and/or by subsequent potentiostatic charging and discharging steps. However, solely galvanostatic cycling is performed in this work to alleviate the evaluation and facilitate the comparison with published results.

The fade of the extractable capacity from the $1^{\text {st }}$ to the $5^{\text {th }}$ cycle can be caused by a capacity decrease due to membrane cross-over processes [6], leaks and parasitic side reactions and degradation effects of the cell components (electrode, current collectors, electrical contacts). Degradation is addressed in more detail in section 3.2.6.

Coulomb Efficiency: Cycling of the $F B-25-V R F B$ and $F B-45-V R F B$ cell results in an average coulombic efficiency of $95 \%$ and $96 \%$, respectively and is comparable with published $C E s$ of planar cells and stacks [32, 36, 94, 107]. The cross-over rates and parasitic reactions, such as, oxidation of $V$-ions with ambient air (Oxygen) or gas evolution $\left(\mathrm{H}_{2}, \mathrm{O}_{2}\right)$ at the graphite felt electrodes do not impose a serious performance reduction, accordingly. The welded tubular cation exchange membrane of the FB-25-VRFB has proven to feature similar characteristics as commercially available planar membranes and the welding seam does not curtail the membrane functionality or lead to a membrane failure. The suitability of the developed welding tool and process for the fabrication of tubular membranes is, thus, validated.

Although the extruded membrane of the $F B-45-V R F B$ cell features a thicker membrane than the welded membrane (see table 3.4), no increase of the specific cell resistance is detected and the extruded membrane's conductivity can be considered as sufficiently high. As the coulombic efficiency of the tubular cell with an extruded membrane is of the same magnitude as the FB-25-VRFB cell's $C E$, extrusion of tubular membranes with comparable selectivity, conductivity and stability as commercial planar membranes can be considered as a valid fabrication technique.

Note that the steps in the cell voltage signal and the variation of the coulombic efficiencies from cycle to cycle is caused by the batch like operation with the 4-tank test environment. 
Voltage Efficiency: In the cycling experiment of the $F B-25-V R F B$ and $F B-45-V R F B$ cell an average voltage efficiency of $58 \%$ and $60 \%$ is determined, respectively. Published results of planar $V R F B$ stacks report $V E S$ from $70 \%$ to $85 \%$ for galvanostatic cycling at constant current densities from $20 \mathrm{~mA} \mathrm{~cm}^{-2}$ to $240 \mathrm{~mA} \mathrm{~cm}^{-2}$ [32, 107, 152]. The comparably low voltage efficiency of the $F B-25-V R F B$ cell is mainly caused by the cell's high $A S R$, while the low $V E$ of the $F B-45-V R F B$ cell is strongly driven by the relatively high residual overpotentials. Evaluation of the voltage efficiency progression from the $1^{\text {st }}$ to the $5^{\text {th }}$ cycle (see table 3.19 and 3.20) reveals a consecutive decline, which can be attributed to the degradation of the electrodes (see section 3.2.6).

System Energy Efficiency: To incorporate all cell performance related losses in the evaluation of the tubular VRFB cells, the system energy efficiency $E E_{s y s}$ is determined. $E E_{s y s}$ incorporates the required pumping energy $\Delta E_{\text {pump }}$ during cycling (see table 3.19 and 3.20). Further losses, which will arise from a complete VRFB storage system's balance of plant (e.g. inverter, monitoring systems, control unit,...) are not included in $E E_{\text {sys }}$. By assuming a pumping efficiency $P E$ of $60 \%$ [147] the required pumping energy can be estimated with the flow rate $\left(\dot{Q}=\dot{Q}_{n e g}=\dot{Q}_{\text {pos }}\right)$ and the pressure drops across the positive $\Delta p_{\text {pos }}$ and negative $\Delta p_{n e g}$ half cell (equation 2.51):

$$
\Delta E_{\text {pump }}=\frac{1}{P E} \int \dot{Q}(t) \cdot\left(\Delta p_{\text {pos }}(t)+\Delta p_{\text {neg }}(t)\right) d t
$$

During charge/discharge cycling the pressure drop across the inner (positive) $\Delta p_{\text {pos }}$ and outer (negative) $\Delta p_{\text {neg }}$ half cell of the $F B-25-V R F B$ cell (see figure 3.31) and $F B-45$ $V R F B$ cell (not shown in plot) is measured and utilized to estimate $\Delta E_{\text {pump }}$. In figure 3.33 the system energy efficiency and losses of the $F B-25-V R F B$ and $F B-45-V R F B$ cell are illustrated in Sankey diagrams. While an $E E_{s y s}=55 \%$ is achieved with the $F B$ $25-V R F B$ cell, a slightly higher system energy efficiency of $57 \%$ is determined for the FB-45-VRFB cell.

The losses introduced by the specific cell resistance are the major source of losses (55\%) for the $F B-25-V R F B$ cell. Due to the comparably low residual overpotentials (see figure 3.27 ) associated losses contribute $36 \%$ of the total losses. The required pumping energy results in the lowest share of losses $(1 \%)$.

For the $F B-45-V R F B$ cell $70 \%$ of the losses are introduced by the residual overpotentials, while $18 \%$ of the losses are caused by the specific cell resistance $A S R=3.2 \Omega \mathrm{cm}^{2}$. The comparably high share of the pumping energy related losses of $4 \%$ are caused by the increased pressure drop in the negative half cell (blocked channels) and the extended charge and discharge durations (reduced current density). Comparison of the Sankey diagrams in figure 3.33 adumbrates the potential performance of a error-free fabricated $F B-45-V R F B$ cell without blocked flow channels and residual 

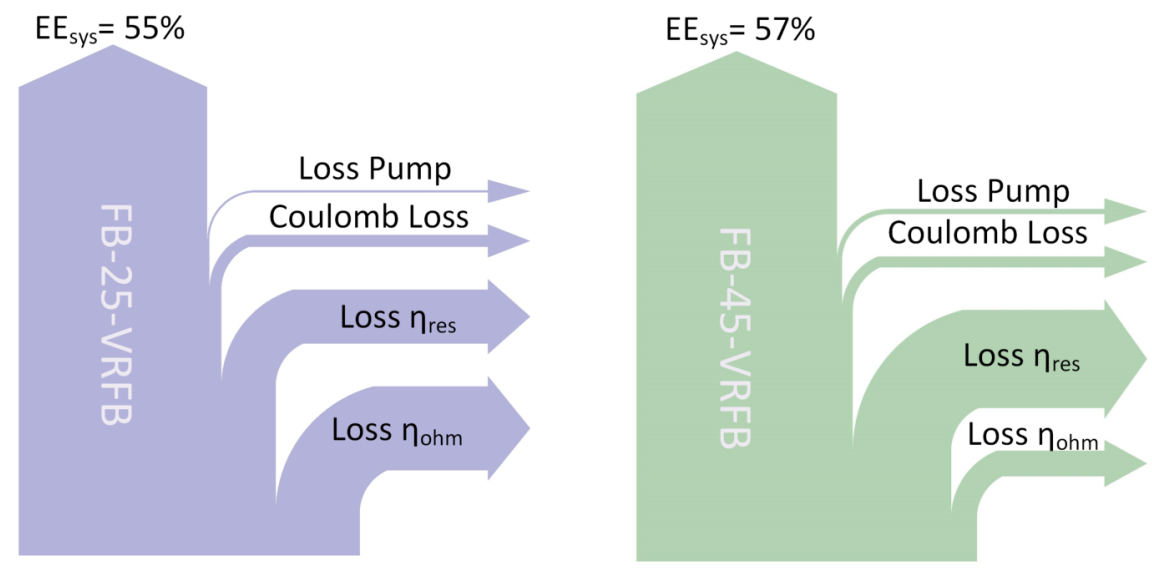

FIGURE 3.33: System energy efficiencies and Sankey diagrams of $F B$-VRFB cells.

overpotential losses analog to the $F B-25-V R F B$ cell.

\section{Operating Parameters}

The electrolyte excess ratio $\lambda_{\text {elyt }}=I_{\text {stoi }} / I_{\text {cell }}$ describes the ratio of the stoichiometric current $I_{\text {stoi }}=\dot{Q} \cdot c_{\text {soc } 50} \cdot F \cdot z$ at $S o C=50 \%\left(c_{s o c 50}=50 \%\right.$ of total vanadium concentration) and the cell current $I_{\text {cell }}$. In order realize high system energy efficiencies of a VRFB storage system, the electrolyte excess ratio has to be optimized regarding the pumping energy and the onset of mass transport related overpotentials $\eta_{c o n c}$. As the optimization of $\lambda_{\text {elyt }}$ is beyond the scope of this work, excess ratios are only determined and the capability of the developed test setup for future works on the evaluation and optimization of $\lambda_{\text {elyt }}$ is demonstrated in this section.

Charge/discharge cycling of the FB-25-VRFB and FB-45-VRFB cell was performed at a constant flow rate of $6.4 \mathrm{ml} \mathrm{min}^{-1}$ and resulted in an electrolyte excess ratio of $\lambda_{\text {elyt }}=15$ and $\lambda_{\text {elyt }}=26$, respectively. Characterization of $\mathrm{kW}$ class VRFB stacks with mixed acid electrolyte at the Pacific Northwest National Laboratory (PNNL) were done with comparable ( $F B-25-V R F B$ ) electrolyte excess ratios from 5.2 to 15.5 [107]. 
Due to the reduced charge/discharge current density of the $F B-45-V R F B$ cell an increased excess ratio is obtained, which is, however, substantially lower than the $\lambda_{\text {elyt }}$ of the planar lab scale cell testing reported in $[170,171]$.

Electrolyte Starvation: In figure 3.34 and 3.32 the positive and negative residual overpotentials of the $F B-45-V R F B$ cell during cycling are displayed. While the overpotentials remain at a constant level during the charge cycles (left in fig 3.34), an increase of the absolute values of the overpotentials at the end of the discharge cycles (right in fig 3.34) is observed. As charging starts from an $\mathrm{SoC}$ between $30 \%$ and $35 \%$ (see Coulomb counted $\operatorname{SoC}(\Delta Q)$ in fig. 3.32) and terminates at an $S o C \approx 60 \%$, a sufficiently high concentration of $V^{4+}$ and $V^{3+}$ is present in the positive and negative electrolyte to prevent a formation of concentration related overpotentials $\eta_{\text {conc }}$. The constant magnitude of the residual overpotentials agrees with results of Langner
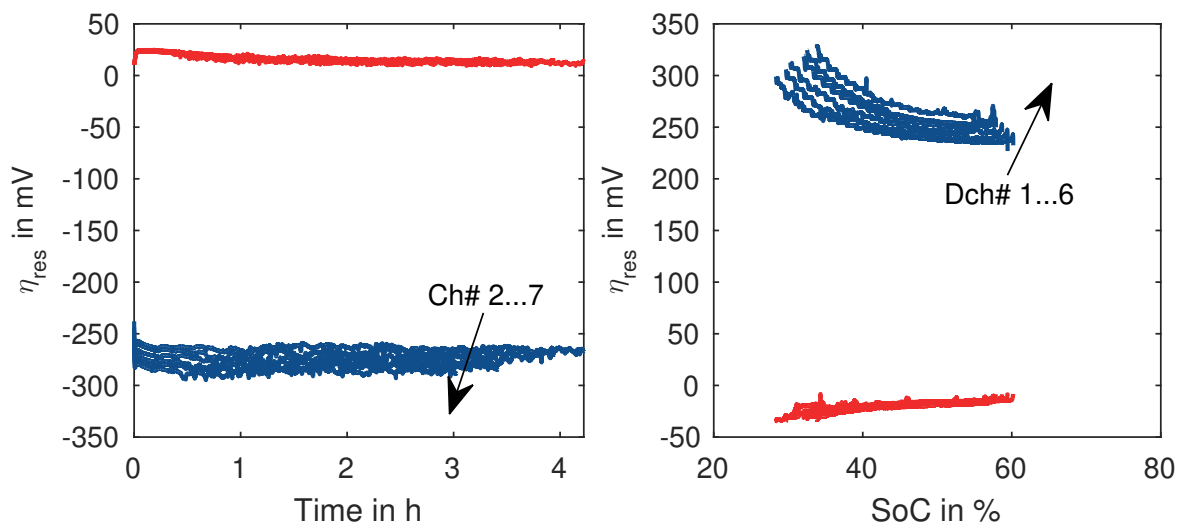

FIGURE 3.34: Left: positive (red) and negative (blue) residual overpotentials during charge cycles \#2...7. Right: positive (red) and negative (blue) residual overpotentials during discharge cycles \#1...6.

et al. [71, 72] on the evaluation of negative and positive overpotentials of a planar VRFB cell at an SoC of $40 \%, 60 \%$ and $80 \%$. The increase of the absolute overpotential values at $\mathrm{SoC}<40 \%$ during the discharge cycles (right in fig 3.34) indicates an onset of concentration and mass transfer related overpotentials $\eta_{\text {conc }}$ and is caused by low $V^{5+}$ and $V^{2+}$ concentrations. Similar electrolyte starvation effects were also determined in the works of Langner et al. [71, 72]. An increased flow rate for low 
SoCs should be considered to reduce $\eta_{c o n c}$ and contribute to an enhanced system energy efficiency, accordingly. Required efforts on the optimization of the electrolyte excess ratio are beyond the scope of this thesis. However, presented results on the in situ measurement of the overpotentials, Nernst potentials and electrolyte density provide a valuable basis for further process parameter optimization and can be used for the on-line monitoring and control of VRFB storage applications in the future.

Note that the rise in the negative residual overpotentials with ongoing charge and discharge cycle numbers (see fig. 3.34) stems from electrode degradation processes and is examined in more detail in the subsequent section.

SoC Dependent Pressure Drop: In figure 3.31 the pressure drops across the positive and negative half cells during charge/discharge cycling are displayed. While the positive pressure drop $\Delta p_{p o s}$ shows a constant magnitude throughout the cycling experiment, the negative pressure drop $\Delta p_{\text {neg }}$ exhibits a variation, which is proportional to the $\mathrm{SoC}$. As the electrolyte flow path geometry can be considered as constant throughout the measurement and the electrolyte temperatures varied insignificantly $\left(T_{\text {elyt }}=23.0^{\circ} \mathrm{C} \pm 0.5^{\circ} \mathrm{C}\right)$ during cycling, pressure drop variations originate from the $\mathrm{SoC}$ dependent variation of the electrolyte viscosity. At a low state of charge $\left(c_{V 3+}>c_{V 2+}\right)$ the negative electrolyte solution exhibits a higher viscosity than at an high $\mathrm{SoC}\left(c_{V 3+}<c_{V 2+}\right)$, accordingly. Furthermore, viscosity variations of the positive electrolyte solution are less sensitive to the variation of the SoC. Measured variations of the viscosity are in accordance with viscosity data published in $[77,159]$. Note that the comparably high viscosity of the $V^{3+}$ electrolyte solution results in an increased pressure drop at low SoCs and will impose supplementary pumping energy losses at the proposed increase of the flow rate at low SoCs (see above). Pressure drop data obtained by in situ measurements might be used for a viscosity estimation and provides additional information for state of charge and state of health models as well as process monitoring systems in future VRFB applications.

\subsubsection{Stability and Degradation}

In previous sections the developed tubular $V R F B$ cells' performance was evaluated (see section 3.2.3) and charge/discharge cycling was conducted to determine the long term operation characteristics. The capacity fade (table 3.19 and 3.20) and overpotential monitoring (fig. 3.34) during cycling indicate a deterioration of the cell performance. In order to investigate the stability and degradation of the cell, long term $O C V$ measurements with subsequent polarization curve measurements were performed according to the routines specified in section 3.1.4. 


\section{Open-Circuit Voltage Stability}

Analog to the cycling experiment, flow rates were held constant at $6.4 \mathrm{ml} \mathrm{min}{ }^{-1}$ while the $O C V$ was measured over a duration of $13 \mathrm{~h}$. The $O C V$ displays a linear decrease for the $F B-25-V R F B$ and $F B-45-V R F B$ cell during the measurement period (not shown in graph). While the drop of the open-circuit voltage $(\triangle O C V)$ proceeds at a rate of $-0.46 \mathrm{mVh}^{-1}$ for the $F B-25-V R F B$ cell a slightly reduced rate of $-0.40 \mathrm{mVh}^{-1}$ is determined for the $F B-45-V R F B$ cell.

The relative contribution of vanadium ion membrane cross-over mechanisms to the total cross-over flux (diffusion, migration and convection) in VRFBs with PFSA based cation exchange membranes (Nafion N117) was investigated in [6]. Diffusion caused vanadium ion cross-over was identified as the dominant transport mechanism and showed to occur in the same direction (negative to positive half cell) during charging and discharging. As similar membrane material (see section 3.1.2) is employed in the tubular VRFB cells and diffusion of vanadium ions through the membrane occurs during the $O C V$ measurement, $O C V$ drops are assumed to originate from diffusion caused cross-over.

As an identical diffusive cross-over rate during $O C V$ measurements and charge/discharge cycling can be assumed, the measured $\triangle O C V$ value can be used to estimate the capacity fade (due to diffusive cross-over) during cycling. Therefore, the $\mathrm{OCV}$ drop ratio of the $F B-45-V R F B$ cell is multiplied with the charge and discharge duration of the $1^{\text {st }}$ cycle $\left(\triangle O C V_{1^{s t} c y c}=-3.32 \mathrm{mV}\right)$ and a corresponding capacity decrease $(\Delta Q)$ of $-50.57 \mathrm{mAh}$ is determined with the equivalent state of charge reduction $\triangle S o C\left(E_{\text {neg }}^{0}\right)$ of $-1.18 \%$. Comparison of the estimated capacity decrease with the charge difference of the $1^{\text {st }}$ cycle $\left(\Delta Q=\left|\Delta Q_{C h}\right|-\Delta Q_{D c h}=57 \mathrm{mAh}\right.$ ) (see tab. 3.20) reveals the dominant contribution of the diffusive cross-over and agrees with the findings of [6]. The open-circuit voltage drop determined in the long term measurement is caused by cross-over and not induced by cell instabilities, accordingly. The increased absolute $\triangle O C V$ ratio of the $F B-25-V R F B$ cell stems from the thinner membrane thickness (see tab. 3.4).

\section{ASR Stability}

During cycling the ASR of the cells is determined by current interrupt measurements before every charge and discharge cycle, respectively (see section 3.1.4). During cycling the $A S R$ of the $F B-25-V R F B$ cell increases by $0.13 \Omega \mathrm{cm}^{2}$ (or $2 \%$ ) while the $A S R$ of the $F B-45-V R F B$ rises by $0.20 \Omega \mathrm{cm}^{2}$ (or $6 \%$ ). Evaluation of the the $A S R$ value progression during cycling reveals a linear rise of the specific cell resistance with increasing cycle number (not shown in graph). In [36] electrode degradation was investigated by long term cycling ( 50 cycles, $11 \mathrm{~d}$ ) of a planar VRFB cell with glassy 
carbon current collectors. A linear increase of the ASR with the cycle number is reported and a deterioration of the $A S R$ by $0.25 \Omega \mathrm{cm}^{2}$ (or $11 \%-14 \%$ ) was determined after 50 cycles. The deterioration of the tubular cell's ASR can be considered as low and is rather attributed to a decline of the porous electrode conductivity and increase of the electrode contact resistance than a degradation of the composite current collectors (CCCs).

Permeation of electrolyte solution into the conductive polymer material of the CCC and consecutive corrosion of the copper components would certainly lead to a substantially higher increase of the ASR. The developed CCCs can be considered as stable within the duration of the experiment, accordingly.

\section{Electrode Degradation}

To evaluate the degradation of the porous electrodes, polarization curve measurements were conducted before and after cycling. As the OCV after cycling $(1.37 \mathrm{~V})$ is below the $O C V$ before cycling $(1.41 \mathrm{~V})$, polarization curves recorded after cycling exhibit increased maximum current densities during charging. The residual overpotentials $\left(\eta_{\text {res }}\right)$ of the FB-45-VRFB cell before and after cycling are shown in figure 3.35.

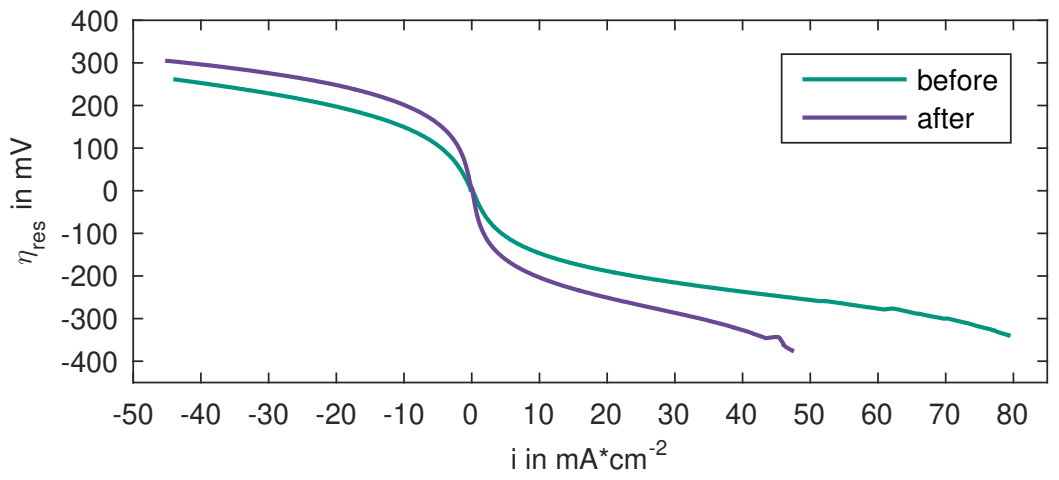

FIGURE 3.35: Residual overpotentials before and after cycling of tubular FB-45-VRFB cell at a flow rate of $6.4 \mathrm{ml} \mathrm{min}^{-1}$.

After cycling the $F B-45-V R F B$ cell displays increased residual overpotentials and a reduced maximum discharge current density $i_{d c h}=48 \mathrm{~mA} \mathrm{~cm}^{-2}$. For the $F B-25-$ $V R F B$ cell an analog increase of the residual overpotentials is determined (not shown in graph). Derr et al. [36] investigated electrode degradation by long term cycling (50 cycles at const. $i=100 \mathrm{~mA} \mathrm{~cm}^{-2}, 11 \mathrm{~d}$ ) of a planar VRFB cell (analog to planar 
reference cell) with GFA 6 EA electrodes. Polarization curve measurements were performed before and after cycling and displayed an increase of the residual overpotentials $\left(100 \mathrm{~mA} \mathrm{~cm}^{-2}\right)$ by $34 \%$.

In [94] the performance and degradation of several $P A N$ based electrode materials (SGL 39 AA, SGL 10 AA, Toray carbon paper TGP-H-120 and SGL SIGRACELL GFD4.6 $E A$ ) was investigated by extended cycling ( 35 cycles at $100 \mathrm{~mA} \mathrm{~cm}^{-2}$ and 38 subsequent cycles at $120 \mathrm{~mA} \mathrm{~cm}^{-2}$ ). Polarization curves with in situ potential measurements (as described in sec. 2.2.3) were conducted to determine the performance and degradation of the electrode materials. Heat treated SGL 39 AA and SGL SIGRACELL GFD4.6 EA exhibited the best performance and were further investigated regarding their stability, accordingly. SGL $10 A A$ electrodes were reported [104] to feature a poor stability. While the SGL SIGRACELL GFD4.6 EA electrodes exhibited almost no degradation after 73 cycles [94], the total overpotential at $i=100 \mathrm{~mA} \mathrm{~cm}^{-2}$ displayed an increase of $175 \%$ for the SGL 39 AA electrodes after 73 cycles.

Residual overpotentials (at $i=-20 \mathrm{~mA} \mathrm{~cm}^{-2}$ ) of the $F B-45-V R F B$ cell display a rise of $20 \%$ after cycling (see fig. 3.35). The electrode material employed in the FB-VRFB cells (see table 3.3) are considered to undergo similar degradation as SGL SIGRACELL GFA6 EA and SGL 39 AA electrodes, accordingly.

By comparing the positive and negative residual overpotentials of the $F B-45-V R F B$ cell after cycling with the respective overpotentials before cycling (see figure 3.36), the dominant influence of the negative electrode on the cell performance degradation becomes apparent. While the negative overpotential exhibits a significant in-

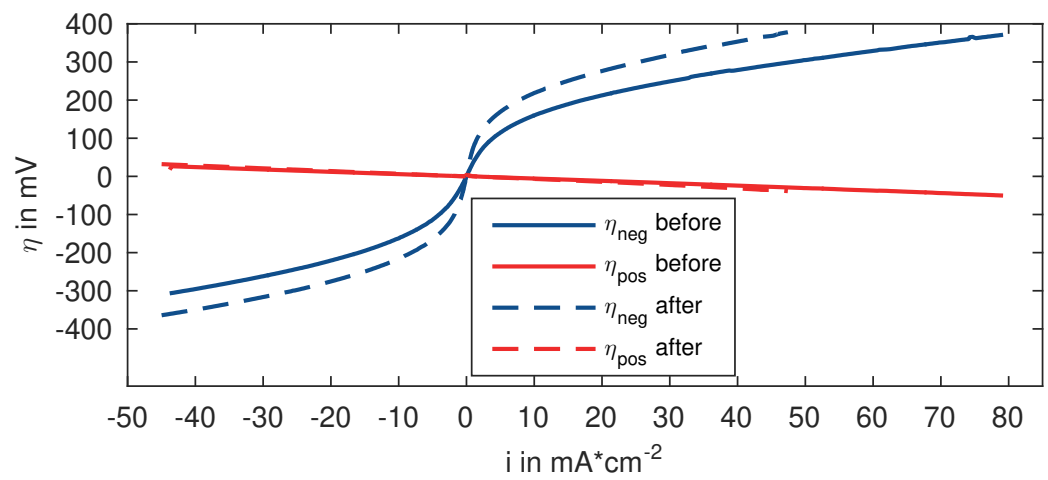

FIGURE 3.36: Positive and negative residual overpotentials before and after cycling of tubular FB-45-VRFB cell.

crease after cycling, only slightly increased positive overpotentials are determined 
after cycling. However, the relative increase of the negative and positive overpotentials are of the same order of magnitude $\left(\left|\Delta \eta_{\text {neg }}\right| \approx\left|\Delta \eta_{\text {pos }}\right| \approx 22 \%\right.$ to $\left.30 \%\right)$. These results agree with the observed increase of the negative overpotentials during the degradation experiments of SGL 39 AA electrode material [94]. Furthermore, the results are in line with findings of Derr et al., who reported a significant increase of the charge transfer resistance $\left(R_{C T}\right)$ of the negative electrode and almost unchanged $R_{C T}$ of the positive electrode after cycling of a planar VRFB with SGL SIGRACELL GFA6 EA electrodes [36]. However, it has to be noted that no dominant influence of the negative electrode on the cell degradation was determined for SGL SIGRACELL GFD4.6 EA electrodes in [94].

In figure 3.37 the average negative and positive residual overpotentials during the charge cycles of the FB-45-VRFB cell (see fig. 3.32) are displayed. As residual overpotentials showed to be constant during charge cycles (see left in fig. 3.34), the average negative $\eta_{\text {neg }}^{-}$and positive $\eta_{\bar{p}}^{-}$s overpotentials are estimated from the arithmetic mean over the first $3 \mathrm{~h}$ of charging. While $\eta_{\text {pos }}$ is stable over the charge cycles, a linear rise of the absolute $\eta_{\text {neg }}$ values with the cycle number can be seen in figure 3.37. In [36] a similar increase of $\eta_{\text {neg }}$ is reported to occur within the first 15 cycles and a significantly reduced degradation rate is determined for the subsequent 35 cycles. While the first 15 cycles of [36] were performed within a period $t \leq 86 \mathrm{~h}$, cycling of the $F B-45-V R F B$ cell took about $50 \mathrm{~h}$ (see fig. 3.32). By assuming similar electrode degradation processes for both experiments, the rise of $\eta_{\text {neg }}^{-}$in figure 3.36

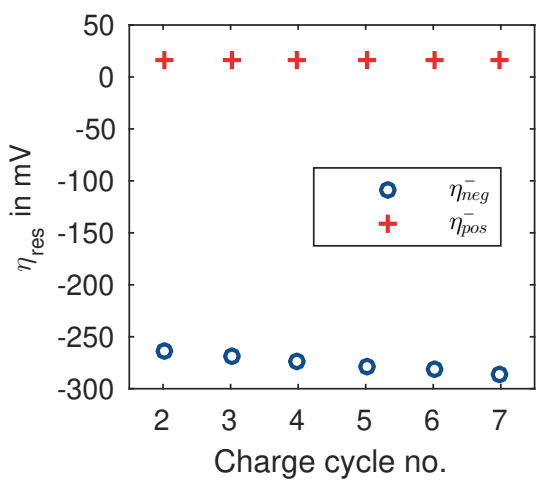

FIGURE 3.37: Mean values of positive and negative residual overpotentials during $C h$ cycles of tubular FB-45-VRFB cell. is expected to proceed at the same rate for several subsequent cycles before a significantly reduced degradation rate will be reached. However, further efforts are required to investigate and verify the degradation of the graphite felt electrode material employed in the tubular flow-by cells in the future.

The detrimental effects on the overpotential at the negative electrode are not fully resolved yet and a review of the literature indicates different mechanisms for graphite felt and carbon paper electrode materials. In published studies on electrode degradation $x$-ray photoelectron spectroscopy (XPS), electrochemical impedance spectroscopy (EIS), 
Raman spectroscopy and scanning electron microscopy (SEM) of electrode materials are performed to investigate the electrode surface chemistry, quantify the electrochemical active surface area, characterize the electrode material (near-to-surface) and analyze the surface morphology, respectively [36, 94, 104]. The influence of chemical aging on the degradation was studied by electrode soaking in electrolyte solutions at different SoCs.

According to [36] negative electrode degradation is rather caused by chemical aging of the Rayon based GFA6 EA graphite felt electrode material than electrochemical aging. Derr et al. proposed oxidation of the carbon felt material by a chemical reaction as the reason for the decline in active sites involved in the $V^{2+} / V^{3+}$ reaction kinetics. Furthermore, a peeling of the graphite felt fibers was detected by SEM and held responsible for a decrease of the electrochemical active surface area.

Pezeshki et al. showed that soaking of PAN based SGL 10 AA carbon paper electrode material had a negligible influence on negative electrode degradation and a loss of oxygen content on the negative electrode surface was ruled out as a reason for the performance degradation [104]. However, charging and discharging at extreme conditions (high/low $\mathrm{SoC}$ ) resulted in a substantial increase of the negative overpotential.

Nibel et al. identified a loss of oxygen content at the PAN based GFD4.6 EA graphite felt electrodes and PAN based SGL 39 AA carbon paper electrodes. However, only the negative SGL 39 AA electrode exhibited increased overpotentials after extended cycling and very negative electrode potentials showed to have a detrimental effect on the negative electrode [94].

In the FB-45-VRFB and FB-25-VRFB cell PAN based GDL \#2614 Pyron graphite felt electrodes are employed. As degradation mechanisms of the negative electrode cannot be related to the fiber precursor type and various effects might be responsible for the performance degradation further research efforts on the degradation mechanisms are required. Detailed investigations of the negative electrode degradation are, however, beyond the scope of this work.

\subsection{Conclusions}

The feasibility of a tubular cell design with a membrane diameter of $5.0 \mathrm{~mm}$ for $V R F B$ applications was demonstrated. The developed cell designs facilitates a fabrication of the cell components (composite current collector and membrane) by an extrusion process and marks an important step towards the cost efficient extrusion of entire half cells and cells in the future.

Tubular cell designs with flow-through and flow-by electrode configurations were designed, fabricated and characterized with the elaborate test rig developed within 
this work. Combination of test methods and utilization of in situ pressure, temperature, density and half cell potential measurements allowed to:

- characterize the cell performance,

- characterize the operating performance,

- reveal major loss mechanisms,

- identify limitations of the studied tubular design and

- detect functional deficiencies induced by the lab scale fabrication and assembly of cells.

In section 3.2.2 the negative half cell of a $V R F B$ was identified as the limiting electrode in terms of the activation and mass transport related overpotentials. The tubular cells studied in this work were configured with a negative outer half cell, as the outer half cell features a slightly higher electrode surface.

\subsubsection{Tubular flow-through VRFB cells (FT-VRFB)}

For the fabrication of tubular $V R F B$ cells with a membrane diameter of $5.0 \mathrm{~mm}$ composite current collectors without flow fields were designed and extruded by Uniwell Rohrsysteme $\mathrm{GmbH} \& \mathrm{CO} K \mathrm{KG}$. As the required cylindrical graphite felt electrode material for the inner half cell of the $F T-V R F B$ cell is not commercially available, a special tool was developed and a routine was established which facilitates the fabrication of cylindrical electrodes from graphite felt sheet material.

The developed outer CCC fulfills the requirement of a stable and leak-tight housing and permits to contact the outer electrodes with sufficiently low electrical contact resistances.

The contact resistance between the inner $C C C$ and the inner electrode has turned out to be the bottle neck of tubular FT-VRFB cell designs. The geometry and setup of the inner tubular half cell features a comparably low contact surface in-between the CCC and the flow-through electrode and limits the down-scaling of the tubular cell diameter.

Manual assembly of the the tubular FT-VRFB cell turned out to be cumbersome and the effective contact resistance in-between the inner CCC and electrode exceeded the theoretical contact resistance significantly. Insufficient electrical contacting of the inner graphite felt electrode might have resulted in a partial utilization of the total electrode surface.

Comparison of residual overpotentials of flow-through electrodes and flow-by electrodes indicated a reduced utilization of the electrode surface of flow-through electrodes relative to flow-by electrodes. Channeling is supposed to cause an inhomogeneous flow distribution across the porous electrode material and a reduced electrochemical active surface. 
Due to the diminished electrical contact of the inner electrode a substantial area specific cell resistance $\left(A S R_{C I}\right)$ of $18.3 \Omega \mathrm{cm}^{2}$ and comparatively high residual overpotential $\left(\eta_{\text {res }}\right)$ of $223 \mathrm{mV}$ (at $i=20 \mathrm{~mA} \mathrm{~cm}^{-2}$ ) was determined and limited the volumetric power density and maximum current density to $46 \mathrm{Wl}^{-1}$ and $20.5 \mathrm{~mA} \mathrm{~cm}^{-2}$, respectively. The maximum current and power densities are, thus, substantially lower than $p_{v o l}$ and $i_{\max }$ of the planar reference cell and the planar cell of J. Langner [72] (table 3.21).

To achieve a reduced $A S R$ and increased current density $\left(i_{\max }\right)$, a up-scaling of the

TABLE 3.21: Maximum power and current densities of FT-25-VRFB and planar flow-through cells.

\begin{tabular}{lcccccc}
\hline Cell & $\begin{array}{c}E_{\text {cell }}\left(i_{\text {max }}\right) \\
{[\mathrm{V}]}\end{array}$ & $\begin{array}{c}\text { SoC } \\
{[\%]}\end{array}$ & $\begin{array}{c}\dot{Q} \\
{\left[\mathrm{ml} \mathrm{min}^{-1}\right]}\end{array}$ & $\begin{array}{c}i_{\text {max }} \\
{\left[\mathrm{mA} \mathrm{cm}^{-2}\right]}\end{array}$ & $\begin{array}{c}p_{A, \max } \\
{\left[\mathrm{mW} / \mathrm{cm}^{2}\right]}\end{array}$ & $\begin{array}{c}p_{\text {vol,max }} \\
{\left[\mathrm{kW}^{3}\right]}\end{array}$ \\
\hline FT-25-VRFB & 0.80 & 60 & 3.2 & 20.5 & 16.5 & 46 \\
planar VRFB & 0.80 & 60 & 12.8 & 180.1 & 146.8 & 163.4 \\
J. Langner [72 $]$ & 0.95 & 60 & - & 150.0 & 141.9 & 124.7 \\
\hline
\end{tabular}

cell diameters or an increased ratio of the inner CCC diameter $D_{C C C i}$ and membrane diameter $D_{\text {mem }}\left(D_{\mathrm{CCC} i} / D_{\mathrm{mem}}\right)$ should be considered for tubular flow-through cell designs. This might, however, conflict with an intended enhancement of the volumetric power density and reduced material costs.

\subsubsection{Tubular flow-by VRFB cells (FB-VRFB)}

For the tubular flow-by cells composite current collectors (CCCs) with integrated flow fields were designed and fabricated by extrusion (Uniwell Rohrsysteme GmbH \& CO KG, Germany). Tubular cation exchange membranes were welded with a specially developed welding device or extruded by Uniwell Rohrsysteme GmbH \& CO $K G$, Germany from VM-fumasep ${ }^{\circledR}$ FFT membrane material of Fumatech BWT GmbH.

A polarization curve analysis of a tubular $F B-V R F B$ cell with an electrode compression ratio of $25 \%$ and a welded membrane $(F B-25-V R F B)$ revealed a maximum discharge current density of $71 \mathrm{~mA} \mathrm{~cm}^{-2}$ at a $S o C$ of $60 \%$. A comparably high specific cell resistance $A S R_{C I}$ of $6.1 \Omega \mathrm{cm}^{2}$ resulted in high ohmic overpotentials and limited the performance of the cell.

Investigations of a tubular flow-by $V R F B$ cell with an extruded membrane and electrode compression ratio of $45 \%(F B-45-V R F B)$ resulted in a reduced $A S R_{C I}$ of $3.2 \Omega \mathrm{cm}^{2}$ and increased maximum current density $\left(i_{\max }\right)$ of $89.7 \mathrm{~mA} \mathrm{~cm}^{-2}$.

For the $F B-25-V R F B$ cell a maximum volume specific power density $\left(p_{v o l, \text { max }}\right)$ of $142 \mathrm{~kW} / \mathrm{m}^{3}$ was estimated at $i_{\max }$. The $p_{v o l, \max }$ of the $F B-45-V R F B$ cell $\left(179.2 \mathrm{~kW} / \mathrm{m}^{3}\right)$ 
marked the highest power density of a tubular VRFB cell within this work.

While the membrane specific maximum current densities of both cells are substantially lower than published results of planar flow-by [2] and flow-through [72] VRFB cells (table 3.22), the cell volume specific power densities are comparable with the $p_{v o l}$ of the "standard electrode" planar VRFB stack of PNNL $\left(140 \mathrm{~kW} / \mathrm{m}^{3}\right.$ to $\left.200 \mathrm{~kW} / \mathrm{m}^{3}\right)$ [107] and the planar flow-through cell of J. Langner [72] (table 3.22).

The feasibility to increase the volumetric power densities with a tubular cell design

TABLE 3.22: Comparison of maximum power and current densities of $F B-V R F B$ cells and published results. ${ }^{1)}$ at $S o C=60 \%$.

\begin{tabular}{lcccccc}
\hline Cell & $\begin{array}{c}E_{\text {cell }}\left(i_{\text {max }}\right) \\
{[\mathrm{V}]}\end{array}$ & $\begin{array}{c}\text { SoC } \\
{[\%]}\end{array}$ & $\begin{array}{c}\dot{Q} \\
{\left[\mathrm{ml} \mathrm{min}^{-1}\right]}\end{array}$ & $\begin{array}{c}i_{\text {max }} \\
{\left[\mathrm{mA} \mathrm{cm}^{-2}\right]}\end{array}$ & $\begin{array}{c}p_{A, \max } \\
{\left[{\left.\mathrm{mW} / \mathrm{cm}^{2}\right]}^{2}\right]}\end{array}$ & $\begin{array}{c}p_{\text {vol,max }} \\
{\left[\mathrm{kW} / \mathrm{m}^{3}\right]}\end{array}$ \\
\hline FB-25-VRFB & 0.80 & 60 & 6.4 & 71 & 58 & 142 \\
FB-45-VRFB & 0.80 & 60 & 9.6 & 89.7 & 73 & 179.2 \\
planar VRFB & 0.80 & 60 & 12.8 & 180.1 & 146.8 & 163.4 \\
J. Langner [72] & 0.95 & 60 & - & 150.0 & 141.9 & 124.7 \\
D. Aaron et al. [2] & 0.20 & 100 & 20 & 920 & $1) 557$ & - \\
\hline
\end{tabular}

was demonstrated, although achieved current densities were comparably low.

It should be noted that commercial $V R F B$ systems are typically operated at current densities below $i_{\text {max }}$ in order to achieve energy efficiencies above $80 \%$ and utilize approximately $80 \%$ of the battery's capacity. A $1 \mathrm{~kW}$-class stack of PNNL and UniEnergy Technologies was operated with a mixed acid vanadium electrolyte at a current density of $80 \mathrm{~mA} \mathrm{~cm}^{-2}$ and resulted in an energy efficiency of $82 \%$ [65]. Volterion reported current densities of $100 \mathrm{~mA} \mathrm{~cm}^{-2}$ for their field-test of a fully welded $2.5 \mathrm{~kW}$ stack [122].

The low $A S R_{H F R}=0.5 \Omega \mathrm{cm}^{2}$ of Aaron et al. [2] is substantially lower than the $A S R_{C I}$ of the $F B-25-V R F B$ cell, but the residual overpotential $\eta_{\text {res }}=52 \mathrm{mV}$ of the tubular cell is in the range of the residual overpotential $(60 \mathrm{mV})$ of [2]. The residual overpotentials of the tubular $F B-25-V R F B$ cell are also lower than those of the planar reference cell studied in section 3.2.2 and reported overpotentials of planar flow-trough cells (table 3.23).

Due to an error in the assembly process of the FB-45-VRFB cell seven out of eight flow channels were blocked and led to a comparably high $\eta_{\text {res }}$ of $185 \mathrm{mV}$ (table 3.23). The residual overpotentials are 3.5 times higher than $\eta_{\text {res }}$ of the flow-by cell without blocked flow channels (table 3.23) and are the major source of losses.

Charge/discharge cycling of the flow-by cells with a welded membrane (FB-25$V R F B)$ and an extruded membrane (FB-45-VRFB) resulted in a Coulomb efficiency $(C E)$ 
TABLE 3.23: Comparison of overpotentials of tubular FB-VRFB cells with planar VRFB cells.

\begin{tabular}{lcccc}
\hline Cell & $\begin{array}{c}i_{\text {cell }} \\
{\left[\mathrm{mA} \mathrm{cm}^{-2}\right]}\end{array}$ & $\begin{array}{c}\eta_{\text {ohm }} \\
{[\mathrm{mV}]}\end{array}$ & $\begin{array}{c}\eta_{\text {res }} \\
{[\mathrm{mV}]}\end{array}$ & $\begin{array}{c}\eta_{i} \\
{[\mathrm{mV}]}\end{array}$ \\
\hline FB-25-VRFB cell & 20 & 122 & 52 & 174 \\
FB-45-VRFB cell & 20 & 64 & 185 & 249 \\
D. Aaron et al. [2] & 20 & 10 & 60 & 70 \\
planar VRFB & 20 & 37 & 95 & 132 \\
J. Langner [72] & 25 & 34 & 82 & 116 \\
\hline
\end{tabular}

of $95 \%$ and $96 \%$, respectively. The CEs of the welded and extruded tubular membrane cells are comparable to the Coulomb efficiencies of planar VRFB cells [32, 36, 94, 107], accordingly.

The system energy efficiencies $E E_{s y s}$ of the tubular $F B-V R F B$ cells with a welded membrane and an extruded membrane are $55 \%$ and $57 \%$ and, thus, well below published energy efficiencies of planar cells. While the major source of losses in $E E_{s y s}$ are caused by the high ASR for the welded membrane cell, the increased residual overpotentials of the cell with an extruded membrane accounts for $70 \%$ of the losses. If an $A S R_{C I}$ of $3.2 \Omega \mathrm{cm}^{2}$ and similar residual overpotential characteristic as determined for the welded membrane cell could be achieved in a tubular flow-by VRFB cell with the developed design, significantly enhanced cell performance and energy efficiencies would be achieved.

Due to the limited scope of this work no further tests of tubular $F B-V R F B$ cells could be realized. However, a reduction of the $A S R_{C I}$ to a value $\leq 1.5 \Omega \mathrm{cm}^{2}$ has to be accomplished by an optimization of the CCC-electrode contact resistance, in order to realize increased $i_{\text {max }}$ and a system energy efficiency $\geq 80 \%$.

Monitoring of the positive and negative residual overpotentials during cycling revealed an onset of mass transport related overpotentials at a low $S o C$ in the negative half cell. The increased $\eta_{\text {conc }}$ portion in the low $S o C$ region in the negative half cell $\left(c_{V 3+}>>c_{V 2+}\right)$ is attributed to the comparably low diffusion coefficient of $V^{3+}$ [159]. To reduce the $\eta_{\text {conc }}$ an increased flow rate of the negative electrolyte during low SoCs should be considered. However, it has to be noted that the pressure drop within this operating range yields the highest values as the viscosity of the negative electrolyte $\left(c_{V 3+}>>c_{V 2+}\right)$ rises with a reduction of the $S o C$ [159]. 


\subsubsection{Degradation}

The degradation of the capacity and cell performance during charge/discharge cycling was investigated and evaluated. The capacity fade observed during cycling is caused by: (i) a cross-over of vanadium ions through the membrane and (ii) a degradation of the electrodes. While cross-over can be adjusted by an implementation of rebalancing methods [105], electrode degradation leads to a permanent loss of performance. Electrode materials employed in the tubular flow-by and flow-through cells exhibited a degradation on a similar scale as the degradation of electrode material (GFA6 EA SGL 39AA and SGL 10AA of SGL Carbon) observed in planar VRFB cells $[36,94,104]$. However, degradation mechanisms are not fully understood yet and require future research efforts.

The composite current collectors developed within this work showed no sign of degradation over the measurement duration and are considered as stable. No changes of the surface morphology and appearance were identified by a visible inspection after disassembly. The deterioration of the ASR is also reported for planar VRFB cells with different bipolar plate materials (glassy carbon, graphite, expanded natural graphite with fluoropolymers) and is rather attributed to a degradation of the electrode material and/or electrode contact than to a corrosion or degradation of the CCCs.

\subsubsection{Measurement Setup and Methods}

\section{VRFB Test Rig and Half Cell Potential Measurements}

A test rig setup with in situ measurement of the electrolyte density, temperature, pressure and half cell potential was developed, integrated and employed for the characterization of $V R F B$ cells. The measurement setup has proven to be a powerful tool for the characterization of the cell performance, as well as the monitoring of operation parameters. Combination of the measurement data shows to be of great value for the identification of loss mechanisms and evaluation of cell design and fabrication induced singularities of the test cells.

The half cell potential measurement setup was employed to measure residual overpotentials of the test cells' positive and negative electrode. By comparing the measured overpotentials of a planar reference cell with a similar setup [72], the half cell potential measurement setup was successfully validated. However, residual overpotential data should only be used for a qualitative evaluation as a highly non-linear potential off-set occurs due to edge effects at the test cell electrodes. Measured half cell overpotentials provided valuable information on the contribution of electrode overpotentials to the cell potential $\left(E_{\text {cell }}(i)\right)$. 
The in situ density and half cell potential measurements can be utilized for the online monitoring of the $S o C[115,136]$ and will be developed for an estimation of the membrane cross-over in the future. Online monitoring of the cross-over and $\mathrm{SoC}$ will be of paramount importance for the battery control and electrolyte rebalancing in VRFB storage systems.

\section{Liquid Permeability of Flow-Through and Flow-By Electrodes}

Implementation of pressure sensors in the VRFB test rig allowed to measure the pressure drop along flow-through and flow-by electrode configurations. Multiple measurement sequences were performed to measure the pressure drop of a fluid as it flows through porous graphite fiber electrodes. An approach to estimate the pressure drop by Darcy's Law with a Kozeny-Carman correlation for the permeability $(K)$ proved to be applicable. However, different Kozeny-Carman constants $\left(c_{K C}\right)$ need to be applied for specific fluids (vanadium electrolyte, water), flow regimes as well as graphite felt surface morphologies (heat treated, pristine). An overview of the determined Kozeny-Carman constants is given in table 3.24.

The pressure drop along tubular flow-by half cells was measured with an analog

TABLE 3.24: Kozeny-Carman constants $c_{K C}$ for porous flow-through graphite felt electrodes.

\begin{tabular}{|c|c|c|c|c|}
\hline \multicolumn{3}{|c|}{ scope of validity } & \multirow[b]{2}{*}{$c_{K C}$} & \multirow[b]{2}{*}{$R^{2}$} \\
\hline fluid & heat treatment & $R e$ & & \\
\hline \multirow{2}{*}{$\mathrm{H}_{2} \mathrm{O}$} & no & $0<\operatorname{Re} \leq 1.5$ & 10.99 & 0.960 \\
\hline & no & $1.5 \leq \operatorname{Re}<10$ & 13.13 & 0.987 \\
\hline \multirow[t]{2}{*}{$V^{3.5+}$} & yes & $0<\operatorname{Re} \leq 1.5$ & 14.54 & 0.992 \\
\hline & no & $0<R e \leq 1.5$ & 15.99 & 0.992 \\
\hline
\end{tabular}

setup and measurement routine. Reference data for the evaluation of the pressure drop in tubular $F B-V R F B$ half cells was recorded and utilized to identify singularities of the tubular test cells. Pressure drop characteristics of flow-by electrode configurations showed to be in accordance with the Law of Hagen-Poiseuielle.

The half cell pressure drop signals during cycling altered proportionally with the $S o C$. The change of the electrolyte viscosity with the $S o C$ represents the proportionality factor and permits to deduce the viscosity from the pressure drop signal. Obtained viscosity data might be integrated in a cross-over model of future online monitoring system of $V R F B$ systems. 


\section{Polarization Curve Analysis}

For the polarization curve analysis two different measurement routines were employed and validated. Polarization curve measurements with a linear scan of the cell potential (LPS) resulted in $E_{c e l l} / i_{\text {cell }}$-characteristics comparable with those recorded with a step wise variation of the cell potential. However, LPS measurements provide a higher resolution of $E_{\text {cell }} / i_{\text {cell }}$-data and are more suitable for the fitting of empirical models. Polarization curve fitting allowed to obtain additional information such as the exchange current density $\left(i_{0}\right)$, Tafel slope $(b)$, limiting current density $\left(i_{\text {lim }}\right)$ and area specific cell resistivity $\left(A S R_{E / i}\right)$. Fitted $A S R_{E / i}$ values yielded comparable results as the $A S R_{C I}$ values determined by current interrupt measurements. CI measurements are, thus, recommended for the performance characterization of full cells.

\section{Electrochemical Impedance Spectroscopy}

The ASR values determined by high frequency resistance (HFR) and EIS measurements $\left(A S R_{H F R}, A S R_{E I S}\right)$ produced $A S R$ values below the $A S R_{E / i}$ and $A S R_{C I}$ values. The deviation is not caused by the measurement accuracy but is attributed to the lower potential perturbation of the impedance measurement and the porous structure of the electrode materials.

Evaluation of impedance measurement data by equivalent circuit model fitting provides additional information on the electrochemical active surface area and contribution of kinetically and mass transport related losses to the residual overpotentials. The exchange current density was estimated from the charge transfer resistance $\left(R_{C T}\right)$ and was of the same order of magnitude as the $i_{0}$ value determined by polarization curve fitting. However, it has to be noted that the high number of fitting parameters in the full cell equivalent circuit model tends to produce invalid fits. For a more detailed evaluation of impedance data additional studies on the positive and negative electrodes and a broad scan of operating parameters is required. 


\section{Chapter 4}

\section{Tubular Vanadium/Air Redox Flow Cells}

In chapter 2 tubular Vanadium/Air Redox Flow Cell design concepts for a cost-effective co-extrusion based production were developed. In this chapter tubular VARFB test cells are fabricated and characterized to evaluate the feasibility of the developed cell designs. While the negative half cells of the tubular VARFB cells feature an analog electrode configuration and identical extruded current collectors as the tubular FB$V R F B$ cells of chapter 3, a bifunctional air electrode needs to be developed for the positive half cell.

At the beginning of this chapter a lab-scale fabrication technique for tubular membrane electrode assemblies ( $M E A s)$ is developed and used to produce tubular $M E A s$ with bifunctional air electrodes. Subsequently, the performance of the developed tubular VARFB cells is characterized and limitations are identified and analyzed.

Part of the results on the fabrication of tubular VARFB cells were published by the author within a poster session at The International Flow Battery Forum 2016 [111]. Oral presentations covering parts of the results were given at the GDCh Scientific Forum Chemistry 2017 [110] and the 10th World Congress of Chemical Engineering [112].

\subsection{Experimental}

Characterization and evaluation of the tubular cells' performance characteristics are done with the methods described in section 2.2. In this section the test cell designs are introduced and the established membrane electrode assembly $(M E A)$ fabrication techniques are specified. The applied measurement routines and parameters used to characterize the test cells are detailed at the end of this section. 


\subsubsection{Tubular Vanadium/Air Redox Flow Cell}

Tubular VARFB cells are designed in consideration of the design principles described in section 2.3. The porous electrode structure of the air half cell is made of a sintered titanium non-woven and features higher specific electric conductivities than the graphite based electrode structures of the vanadium half cell. Accordingly, titanium based air electrode structures are employed in the inner half cell. Furthermore, higher porous electrode volumes with smaller thicknesses and shorter diffusion paths lengths can be realized in the outer half cell and are beneficial for the reduction of $V^{2+/ 3+}$ overpotentials. The intended fabrication process of entire tubular cells by co-extrusion is simplified with a tubular air electrode structure in the inner half cell.

\section{Tubular VARFB Cell Setup}

In figure 4.1 a tubular VARFB cell is displayed. The air electrode is used for the oxygen reduction reaction $(O R R)$ and oxygen evolution reaction $(O E R)$ and is made of a mono-layer gas diffusion electrode (GDE), which is located in the inner half cell. It features an active length of $100 \mathrm{~mm}$ and is surrounded by a tubular membrane with an inner diameter of $5 \mathrm{~mm}$. The negative half cell is composed of a graphite felt electrode and a tubular composite current collector (CCC) with an integrated flow field on the CCC-electrode interface.

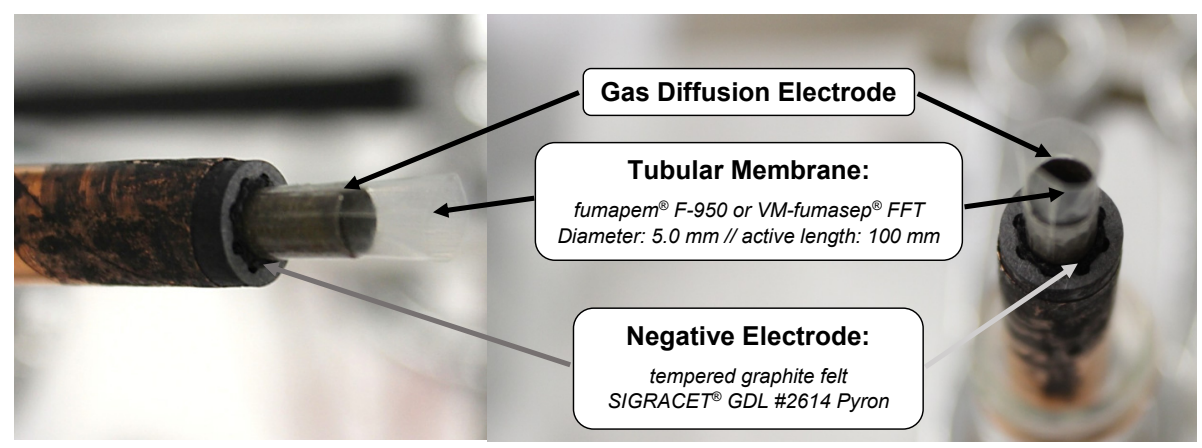

FIGURE 4.1: Pictures of tubular VARFB cells. 


\section{Electrical Contacting of GDE}

To connect the GDE to the power and sense wires two methods are applied. One method employs a current collector to contact the GDE electrically, while the second approach utilizes a contact pin to contact the GDE.

The inner current collector is displayed in figure 4.2 (1). It is made from titanium and features a quadruple helix flow field on the superficies surface. A bore in the center of the current collector is used as the inlet manifold for the gas. The current collector was specially designed and fabricated (Werkzeug- Formen-Maschinenbau-Service (WFM-S), Germany) by electrical discharge machining.

The current collector (1) is threaded into the tubular GDE (2 in fig. 4.2) and the GDE surface is compressed on the 4 quadruple helix crests. Power and sense wires are attached to the current collector with pipe clamps.
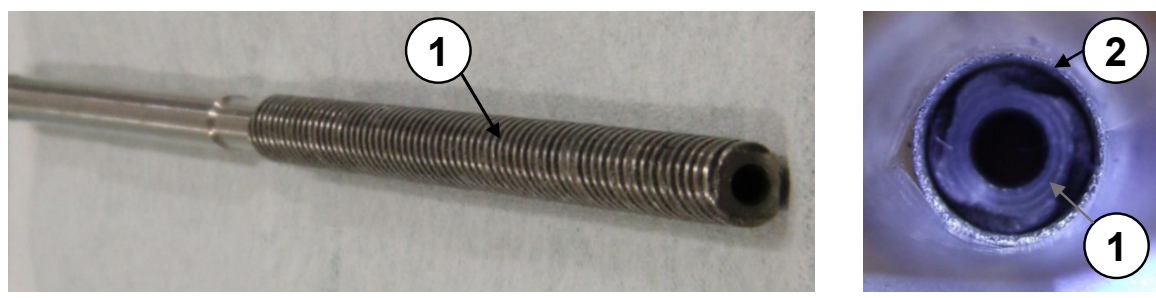

FIGURE 4.2: Left: Picture of tubular Ti current collector with quadruple helix flow field (1). Right: picture of tubular GDE (2) with threaded current collector (1).

For the second contacting method a titanium made pin (fig. 4.3) is inserted into the tubular MEA. The electrical contact is established by a simple compression of the pin's contact surface with the GDE. As the GDE is contacted at one end face, longitudinal electrical conduction is only provided by the GDE structure itself. The contact pin features a bore in the center, which is used to feed the positive half cell with the gas mixture. Power and sense wires are screwed directly on the contact pin.

\section{Cell Housing and Integration}

The test cell is assembled in the test cell housing described in section 3.1.1 and is integrated in the VARFB test rig in an upright position (see fig. 4.7). During operation vanadium electrolyte solution is pumped through the flow field of the outer CCC from the lower end face to the upper end face of the cell. The humidified gas mixture 


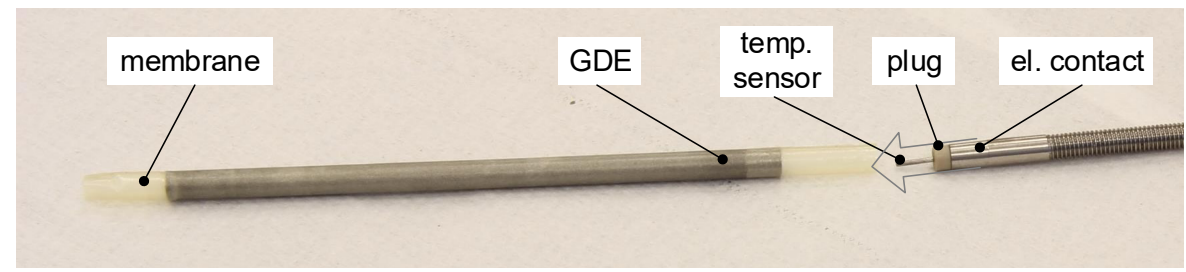

FIGURE 4.3: Picture of tubular GDE with membrane and electrical contact pin.

required for the $O R R$ and $O E R$ in the air half cell flows along the GDE in counter flow mode. Liquid product water does, thus, drain out of the air half cell by gravitational forced advection and pressure difference.

GDE electrodes of all VARFB cells are operated in flow-by configuration. Cells with current collector contacting feature a quadruple helix flow field, while cells with pin contacting are operated with a simple flow-by channel.

\subsubsection{MEA Fabrication and Material Preparation}

In figure 4.4 the components of a tubular VARFB cell are shown. Several preparation and fabrication steps are carried out to adapt the planar precursor materials to the tubular cell geometry.

\section{Negative Half Cell}

The negative half cell is composed of an extruded composite current collector ( $E$ in fig. 4.4) and a graphite felt electrode (D). Negative half cells are fabricated and assembled as already described in section 3.1.2.

The composite current collector (CCC) is extruded from graphite/polyolefin compound material by Uniwell Rohrsysteme $G m b H$ \& Co. KG. A copper foil with a thickness of $50 \mu \mathrm{m}$ is wrapped around the shell to enhance longitudinal electric conductivity. To ensure a low contact resistance at the polymer compound-copper foil interface the electrically conductive adhesive V58 A of SGL Carbon was used to bond both components.

Graphite felt electrodes are made of $700 \mu \mathrm{m}$ thick and $17.4 \mathrm{~mm}$ wide SIGRACET GDL \# 2614 Pyron material of SGL Carbon. To introduce oxygen functional groups to the electrode surface, thermal treatment of the graphite felt sheet material is done at DECHEMA-Forschungsinstitut. Tempering of the felt material is done in a furnace at 


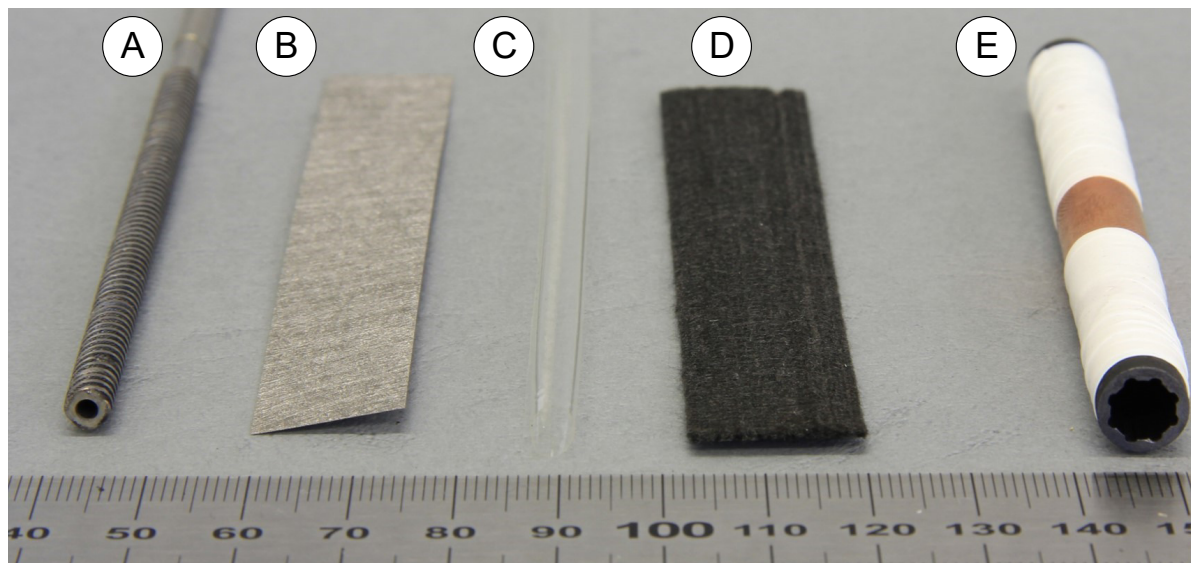

FIGURE 4.4: Picture of tubular VARFB cell components. A:Titanium current collector with quadruple helix flow field; B: gas diffusion electrode $(G D E)$; C: tubular membrane; D: graphite felt electrode; E: outer composite current collector.

$400{ }^{\circ} \mathrm{C}$ for $5 \mathrm{~h}$ in ambient air.

\section{Gas Diffusion Electrode}

Gas diffusion electrodes $(B)$ are made from a sintered Titanium non-woven of Bekaert Fibre Technologies, Belgium. Ti fibers of the non-woven have a fiber thickness of $20 \mu \mathrm{m}$. The non-woven sheet material has a thickness of $160 \mu \mathrm{m}$, area specific mass of $350 \mathrm{~g} / \mathrm{m}^{2}$ and a porosity of $50 \%$.

The porous titanium GDE substrates are coated with a bifunctional $\mathrm{Pt} / \mathrm{IrO} \mathrm{O}_{2}$ catalyst. Coating was done by the DWI Leibniz Institute for Interactive Materials Aachen and the working group of J. Bachmann at the Friedrich-Alexander University Erlangen.

At the DWI Aachen the titanium nonwoven was first pretreated in boiling $6 \mathrm{M} \mathrm{HCl}$. Thermal decomposition was then used to apply $2.0 \mathrm{mg} / \mathrm{cm}^{2}$ of $\mathrm{Pt} / \mathrm{IrO}_{2}\left(70 \%_{w t} / 30 \%_{w t}\right)$ catalyst on the GDE substrate. Chloroplatinic acid $\left(\left(\mathrm{H}_{3} \mathrm{O}\right)_{2} \mathrm{PtCl}_{6} \cdot 6 \mathrm{H}_{2} \mathrm{O}\right)$ and dihydrogen hexachloroiridate $\left(\mathrm{H}_{2} \mathrm{IrCl}_{6} \cdot \mathrm{H}_{2} \mathrm{O}\right)$ where used as precursors.

In the working group of J. Bachmann an anodization method was developed and applied to create a well defined nano-structured surface morphology [116] on the Ti 
GDE substrate [118]. Atomic layer deposition ( $A L D$ ) was then used to form a homogenous $\mathrm{Pt}$ and $\mathrm{IrO}_{2}$ layer $[12,119]$ with a thickness of $1 \mathrm{~nm}$ and $2 \mathrm{~nm}$, respectively. The novel surface treatment and catalyst coating method allows to reduce the catalyst loading by a factor of 200 (relative to thermal decomposition).

Both catalyst coated GDEs where then coated with a PFSA ionomer in order to enhance the ionic conductivity across the porous $G D E$ and enlarge the three phase layer. Therefore, the planar GDE sheets ( $B$ in fig. 4.4) were first bended to obtain the required tubular shape. A hydro-alcoholic fumion ${ }^{\circledR} \mathrm{F}$ dispersion $\left(5 \%_{w t}\right.$ in $E t O H$, $E W=970 \mathrm{~g} \mathrm{eq}^{-1}$ ) was then applied by brushing. After each application step the $G D E$ was dried in an furnace at $80^{\circ} \mathrm{C}$ for $3 \mathrm{~h}$. The application steps were repeated until a fumion loading of $2.6 \mathrm{mg} / \mathrm{cm}^{2}$ was obtained.

\section{MEA Fabrication}

The tubular membrane electrode assembly (MEA) is composed of a GDE and a tubular membrane. A specially designed tool and heat bonding procedure is used to fabricate tubular MEAs.

Tubular membranes with a diameter of $5.0 \mathrm{~mm}$ were obtained by welding or extrusion. Welded tubular membranes were made from fumapem ${ }^{\circledR}$ F950 cation exchange membrane sheet material (FUMATECH BWT GmbH, Germany) as described in section 3.1.2. Extruded tubular membranes were fabricated by Uniwell Rohrsysteme $\mathrm{GmbH} \mathcal{E}$ Co. KG from the perflouronated sulfonic acid /PTFE copolymer granulate material VM-fumasep ${ }^{\circledR}$ FFT of FUMATECH BWT GmbH.

Prior to the heat bonding process tubular membranes were immersed in double distilled water for $1 \mathrm{~h}$. The hydrated membranes were then slipped over the bended $G D E$ and a titanium pin with a length of $170 \mathrm{~mm}$ was inserted in the loose $M E A$. Subsequently, the pin and $M E A$ components were pressed into a specially designed tubular bracket. The annular clearance of the titanium pin and bracket define the compression of the GDE and the membrane. Pins with different diameters are used to adjust the compression to the desired level.

Heat bonding is initiated with fully hydrated membranes. The heat input is done by joule heating of the Ti pin. The developed heat bonding tool and heating method allows to realize a uniform heat input across the entire GDE surface area. The rate of heating can be set within a range from $0.5^{\circ} \mathrm{s}^{-1}$ to $18^{\circ} \mathrm{s}-1$ and heat input durations can be defined with $0.1 \mathrm{~s}$ precision.

Heat bonded MEAs (right in fig. 4.5) were removed from the bracket and pin after the fabrication setup cooled down to $30^{\circ} \mathrm{C}$. Prior to cell assembling, leak tightness testing was performed by applying air (pressure $p_{g} \leq 1000 \mathrm{hPa}$ ) to the interior of the 
tubular $M E A$ and submerging it in double distilled water.
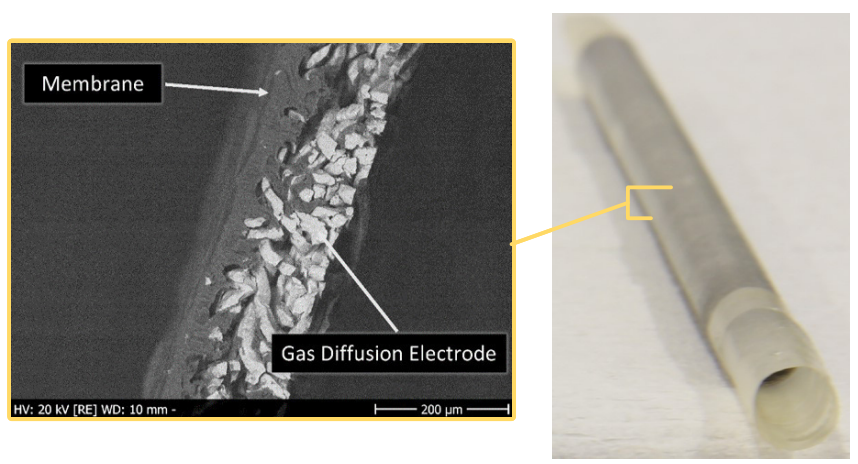

FIGURE 4.5: Right: Tubular membrane electrode assembly $(M E A)$.

Left: $S E M$ picture of the $M E A$ cross-section.

To fabricate tubular $M E A s$ with different bonding strengths, multiple test runs with varied heat input profiles and compression ratios were conducted and evaluated. The described heat bonding process and tool allows to set the penetration depth of the GDE into the membrane accurately. In the scanning electron microscopy (SEM) image in figure 4.5 the cross section of a heat bonded $M E A$ with a welded fumapem ${ }^{\circledR}$ F950 membrane $(t=50 \mu \mathrm{m})$ is displayed. The titanium fibers of the GDE penetrate deep into the membrane material but do not pierce the membrane. The membrane material does also enter into the void volume of the porous non-woven structure. This bonding characteristic is assumed to meet the requirement for an expansion of a 3-phase layer across the GDE structure.

$M E A s$ with two different penetration depth were fabricated and assembled in tubular VARFB cells. In dry state, both MEAs featured a uniform bond across the entire $G D E$ surface. Water uptake of the membrane does, however, lead to a multidimensional swelling of the membrane material and introduces stress to the bond. Both heat bonded $M E A$ types were immersed in double distilled water for several hours to evaluate the bonding strength of the $G D E$ and the membrane. In figure 4.6 the heat bonded MEAs with hydrated membranes and a deep penetration of the GDE $(B)$ and a lower penetration depth $(A)$ are shown. While the $M E A$ with a lower penetration depth suffers from a partial delamination of the membrane (1), no detachment of the membrane is observed when the GDE is penetrated deep into the membrane $(B)$.

In subsequent sections tubular VARFB cells with partially detached ( $t u b$. VARFB PB) 


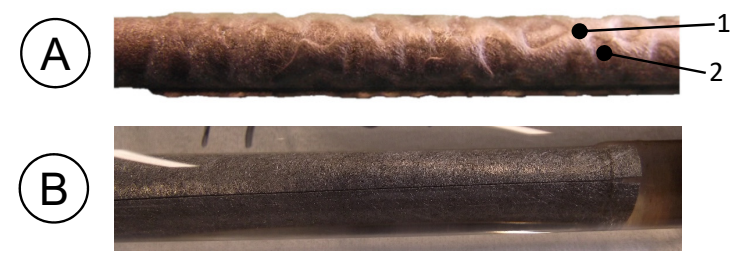

FIGURE 4.6: Heat bonded tubular MEAs with partially bonded GDE $(A)$ and fully bonded GDE (B). 1: detached membrane section. 2: bonded section.

and fully bonded GDE (tub. VARFB FB) are denoted as partially bonded and fully bonded, respectively (see table 4.1).

TABLE 4.1: Overview of tubular VARFB cell setups.

\begin{tabular}{llll}
\hline Component & tub. VARFB $F B$ & tub. VARFB $P B$ & tub. VARFB nano \\
\hline GDE substrate & sintered $T i$ non-woven & sintered $T i$ non-woven & sintered $T i$ non-woven \\
catalyst & $P t / \mathrm{IrO} \mathrm{O}_{2}(70 / 30)$ & $P t / \mathrm{IrO} \mathrm{O}_{2}(70 / 30)$ & $P t / \mathrm{IrO} \mathrm{O}_{2}$ \\
loading & $2.0 \mathrm{mg} / \mathrm{cm}^{2}$ & $2.0 \mathrm{mg} / \mathrm{cm}^{2}$ & $1 \mathrm{~nm} P t, 2 \mathrm{~nm} \mathrm{IrO}_{2}$ \\
coating & thermal decomposition & thermal decomposition & anodization and $A L D$ \\
membrane & fumasep ${ }^{\circledR} F F T$ (extruded) & fumasep ${ }^{\circledR} F F T$ (extruded) & fumasep ${ }^{\circledR} F F T$ (extruded) \\
$M E A$ & fully bonded & partially bonded & partially bonded \\
neg. electrode & $G D L \# 2614 P y r o n$ & GDL $\# 2614$ Pyron & GDL \#2614 Pyron \\
current collector & flow-by CCC (extruded) & flow-by CCC (extruded) & flow-by CCC (extruded) \\
\hline
\end{tabular}

\subsubsection{Vanadium/Air Redox Flow Battery Test Rig}

For the characterization of tubular $V A R F B$ cells a test setup with a liquid electrolyte cycle and a gas feeding unit is required. Hence, a second test rig is developed and forms the basis for the experimental studies of VARFB cells. A schematic diagram of the test rig is illustrated in figure 4.7 .

The liquid electrolyte cycle (left in schematic) is composed of a custom made glass tank, heat tracing and a solenoidal membrane dosing pump (accuracy $\leq \pm 5 \%$, Delta optodrive, ProMinent). A single tank setup is chosen to reduce the cycle's piping volume and permit an operation with small quantities of electrolyte and reduced measurement durations. Electrolyte solution is pumped through the negative VARFB 


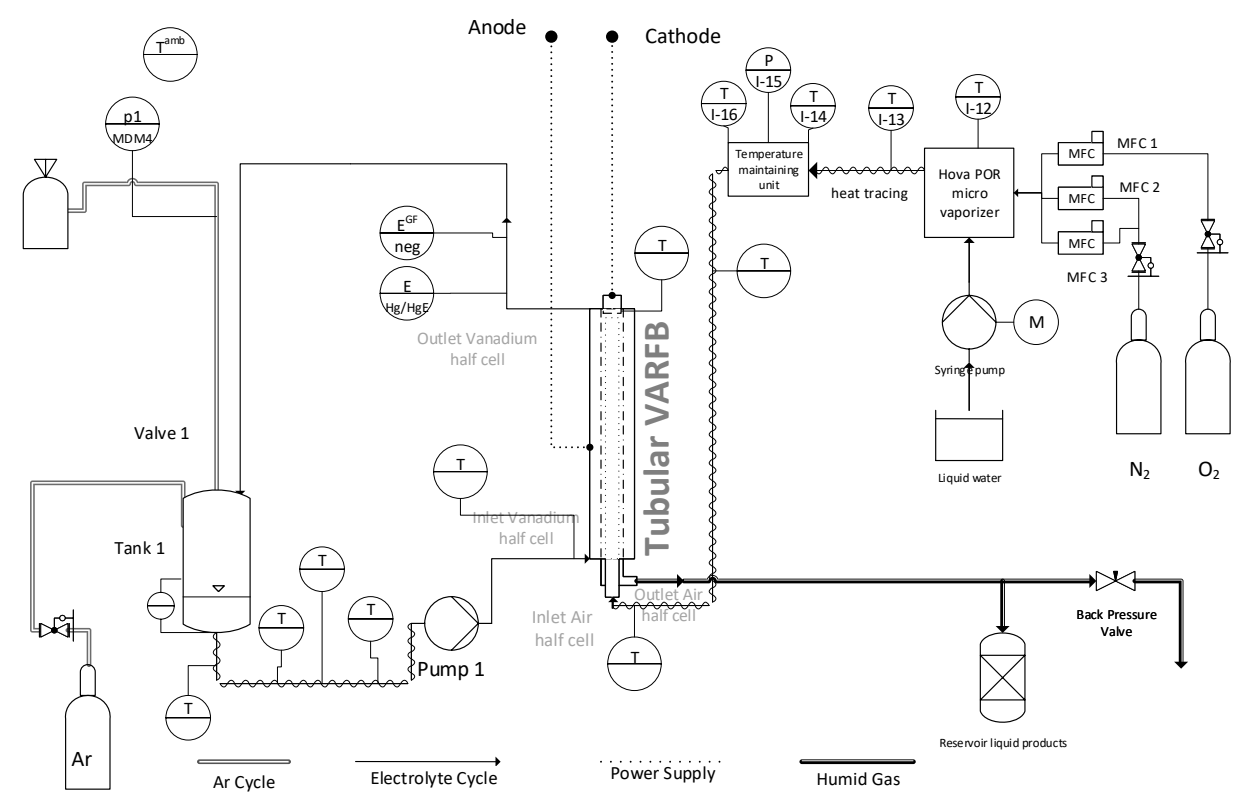

FIGURE 4.7: Schematic of VARFB test rig.

half cell and recirculated to the tank. Installation of an Ar gas bottle with fitted pressure reducer ( $p_{\text {out }}=0.0 \ldots . .500 \mathrm{mbar}$, Doppelregulus of Tescom Europe GmbH) allows to purge the electrolyte cycle prior to measurement runs and enables operation under a static Ar atmosphere with a defined system pressure $p_{\text {sys. }}$. A gas sample collection bag is installed at the outlet of the Ar cycle and allows to withdraw gas samples for ex situ analysis. Monitoring of the electrolyte temperature is done by a $P T-100$ sensor at the inlet of the negative half cell. At the outlet of the half cell a potential measurement armature is installed and enables in situ Nernst potentential and overpotential measurements (see section 2.2.3). The system pressure of the liquid electrolyte cycle is measured by a remote seal pressure sensor $p_{1}$ of EM Technik.

The gas supply of the air half cell is realized by the custom made gas mixture and humidification unit HovaCAL of IAS GmbH Germany. Two mass flow controllers (MFC2 and MFC3) are used to accurately set the volumetric $\mathrm{N}_{2}$ flow rate in a range from $0.4 \mathrm{Nml} / \mathrm{ml}$ to $88.0 \mathrm{Nml} / \mathrm{ml}$. The volumetric oxygen flow rate is controlled by a separate $M F C 1$ and can be varied within a range of $4 \mathrm{Nml} / \mathrm{ml}$ to $80 \mathrm{Nml} / \mathrm{ml}$. The mixture and humidifycation of the gas is done in a micro vaporizer unit. Required 
amounts of water are injected into the vaporizer by syringe pumps and allow to precisely adjust the gas humidity $(R H)$ between $0 \%$ and $100 \%$. To maintain a constant temperature and prevent condensation of water an elaborate heat tracing and insulation is installed from the vaporizer to the inlet of the air half cell. Liquid and gaseous products from the air half cell outlet are conducted through a reservoir and back pressure valve to the exhaust. Temperatures are measured along the entire gas supply piping and the gas system pressure is measured in the temperature maintaining unit. The gas system pressure can be varied from ambient pressure to an absolute pressure of 2.5 bar.

The VARFB test rig is equipped with additional temperature sensors, which are used to measure the temperature inside the tubular GDE, at the test cell housing and in the test setup environment.

Electrochemical experiments are conducted by connecting the SP-240/4A/14V potentiostat of BioLogic to the positive and negative electrode connections of the test cells. System control and data acquisition is realized by a LabVIEW based Virtual Instrument VI (National Instruments) with a connected Programmable Logic Controller PLC of (Phoenix Contact).

\subsubsection{Test Routines}

For the characterization of the tubular VARFB cells a test routine was established, which is composed of several subsequent techniques. The test routine enables to analyze the cell performance at different operating conditions and allows to identify the performance limitations. It comprises the following steps:

1. Electrolyte formation with subsequent charging

2. Start-up process with $O C V, C I$ and $H F R$ measurements

3. Polarization curve measurements

4. EIS measurements

5. Charging

6. Long term $O C V$ measurement

7. Polarization curve measurements

8. EIS measurements

9. Discharging 
10. Long term $O C V$ measurement

11. Polarization curve measurements

12. EIS measurements

Employed methods are introduced in section 2.2. A detailed specification of the deployed measurement settings is given in the subsequent sections.

\section{Electrolyte Formation and start-up process}

Electrolyte Formation: $V^{2+} / V^{3+}$ electrolyte is produced from the commercially available $V^{3.5+}$ electrolyte solution of GfE (Gesellschaft für Elektrometallurgie $\mathrm{mbH}$ ). Formation of the $V^{3.5+}$ electrolyte solution is performed with the planar $V R F B$ cell (see section 3.1.1) in the VRFB test rig (figure 3.11).

To prevent oxidation of the vanadium electrolyte $\left(\mathrm{V}^{2+}\right)$ the entire test rig piping, tank and cell volume is purged with argon gas before formation is done. Pristine $V^{3.5+}$ electrolyte is pumped through the test cell at a constant flow rate for approximately one hour to remove entrapped gas bubbles and hydrate the membrane. Subsequently, the gas cycle of the test rig is purged again with Ar gas and a static overpressure $\Delta p=50 \mathrm{hPa}$ is applied on the system before the actual formation is started. The $V^{3.5+}$ electrolyte is composed of $0.8 \mathrm{MVOSO}_{4}, 0.4 \mathrm{MV}_{2}\left(\mathrm{SO}_{4}\right)_{3}, 0.05 \mathrm{MH}_{3} \mathrm{PO}_{4}$ and $2 \mathrm{MH}_{2} \mathrm{SO}_{4}$. In order to obtain solely $V^{3+}$ in the negative and $\mathrm{VO}^{2+}\left(V^{4+}\right)$ in the positive half cell (corresponding to $S o C=0 \%$ ), $V_{0 S O}$ is reduced to $V^{3+}$ in the negative half cell while $\mathrm{V}_{2}\left(\mathrm{SO}_{4}\right)_{3}$ is oxidized in the positive half cell of the planar VRFB cell. Therefore, two equal volumes $(V=100 \mathrm{ml})$ of $V^{3.5+}$ electrolyte are poured into the tanks of the positive and negative cycles, respectively. Formation is carried out galvanostatically at a constant current density $(i)$ of $35 \mathrm{~mA} \mathrm{~cm}^{-2}$.

For the tubular VARFB experiments $V^{2+} / V^{3+}$ electrolyte with an initial SoC $\leq 0 \%$ and $S o C \approx 95 \%$ are used. To obtain electrolyte solutions with an $S o C \leq 0 \%\left(c_{V 3+}>>\right.$ $\left.c_{V 4+}\right)$ the Nernst potential of the negative electrode $\left(E_{n e g}^{0}\right)$ is monitored with the potential measurement setup (sec. 2.2.3) and formation is terminated as a $E_{\text {neg }}^{0}=365 \mathrm{mV}$ (vs. $S H E$ ) is achieved.

$V^{2+} / V^{3+}$ electrolyte with a $S o C \approx 95 \%$ is produced by galvanostatic charging to a cell potential limit of $1.7 \mathrm{~V}$ with subsequent potentiostatic charging at $E_{\text {cell }}=1.8 \mathrm{~V}$ until a $E_{n e g}^{0}$ of $-375 \mathrm{mV}$ (vs. $\left.S H E\right)$ is measured.

Start-Up Process: For the tubular VARFB experiments $50 \mathrm{ml}$ of $V^{2+} / V^{3+}$ electrolyte is poured into the negative electrolyte tank of the tubular VARFB test rig (section 
4.1.3). In order to remove air from the tubing and void tank volume the electrolyte cycle is first purged with Ar gas.

The start-up process is done to hydrate the tubular membrane and to establish stationary conditions $\left(R H, T_{G D E}, p_{G D E}, T_{\text {elyt }}\right)$ in the gas and electrolyte cycle. Over a duration of $1 \mathrm{~h}$ the electrolyte solution is circulated at a constant flow rate of $6.4 \mathrm{ml} \mathrm{min}^{-1}$ and operating parameters are set in three steps:

1. heat electrolyte up (20 min)

(a) set gas flow rate to $80 \mathrm{Nml} / \mathrm{min} \mathrm{N}_{2}$ and $\mathrm{RH} \approx 100 \%$

(b) step-wise increase of electrolyte temperature

(c) $C I$ and HFR measurements

2. change gas composition ( $20 \mathrm{~min}$ )

(a) set gas flow rate to $80 \mathrm{Nml} / \mathrm{min} \mathrm{N}_{2}$ and $20 \mathrm{Nml} / \mathrm{min} \mathrm{O}_{2}$ maintain $\mathrm{RH} \approx 100 \%$

(b) $C I$ and HFR measurements

3. increase system pressure $(20 \mathrm{~min})$

(a) increase relative pressure in gas and electrolyte cycle to $50 \mathrm{hPa}$ maintain RH $\approx 100 \%$

(b) $C I$ and HFR measurements

In order to monitor the ASR and it's dependence on the membrane hydration, $C I$ and HFR measurements are done at the end of every step. CI measurements consist of a series of 5 excitations of $0.5 \mathrm{~s}$ with $I=-100 \mathrm{~mA}$. The cell potential drop is recorded with $\Delta t=0.4 \mathrm{~ms}$ and the ohmic cell resistance is calculated by use of the software EC-Lab of BioLogic.

HFR measurements include the application of sinusoidal potential signals with an amplitude of $5 \mathrm{mV}$ and frequencies from $100 \mathrm{kHz}$ to $100 \mathrm{~Hz}$. Frequencies are scanned with 6 points per decade (log spacing) from high to low values and 6 measurements are conducted for every frequency value. $A S R_{H F R}$ values are read out from Nyquist plots at $I M(Z)=0$.

\section{Polarization Curves}

Polarization curve measurements are performed at different temperatures, SoCs and gas compositions over the entire test routine. Operating parameters are changed $15 \mathrm{~min}$ ahead of the initiation of the polarization curve routine to ensure stationary conditions. A routine analog to the VRFB routine with a linear potential scan (LPS) 
(right in fig. 3.12) is performed to reveal the $E_{c e l l}(i) / i_{\text {cell }}$-characteristic of the tubular VARFB cells.

Polarization curves of $V A R F B$ cells are done within a cell potential range from $0.4 \mathrm{~V}$ to $2.1 \mathrm{~V}$ (unless otherwise specified) using the test rig described in section 4.1.3. A potential scan is first done from $O C V$ to $E_{\max }=2.1 \mathrm{~V}$ ( $B$ in fig. 4.8). After a relaxation period $t_{d}(C$ in fig. 4.8$)$ a subsequent scan from $O C V$ to $E_{\text {min }}=0.4 \mathrm{~V}$ ( $D$ in fig. 4.8) is performed. Potential scans are done with a linear potential scan (LPS) at $50 \mathrm{mV} \mathrm{min}^{-1}$ or $100 \mathrm{mV} \mathrm{min}^{-1}$.

At the beginning and end of every measurement run Current Interrupt measure-

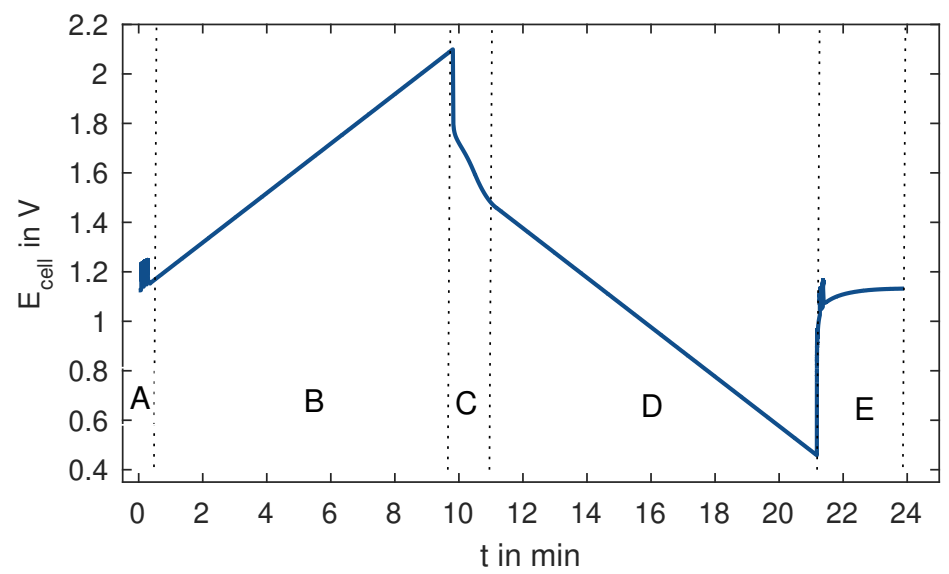

FIGURE 4.8: Polarization curve measurement sequence with a linear potential scan.

ments are conducted ( $A$ and $E$ in fig. 4.8) to determine the $A S R_{C I}$ of the test cell. $C I$ measurements consist of a series of 4 excitations of $0.5 \mathrm{~s}$ with $I=-100 \mathrm{~mA}$. The cell potential drop is recorded with $\Delta t=0.4 \mathrm{~ms}$ and the ohmic cell resistance is calculated by use of the software EC-Lab of BioLogic.

In the final sequence $(E)$ an $O C V$ measurement is done over several minutes to determine the stationary $O C V$ value after discharging.

\section{Electrochemical Impedance Spectroscopy}

The SP-240/4A/14V device of BioLogic is employed to perform EIS measurements of VARFB cells. Solely full cell impedance analysis of VARFB test cells is conducted as cells are connected in two-electrode mode. VARFB cells are characterized by applying sinusoidal potential signals with an amplitude of $5 \mathrm{mV}$ and frequencies from 
$60 \mathrm{kHz}$ to $10 \mathrm{mHz}$. Frequencies are scanned with 6 points per decade (log spacing) from high to low values and three measurements are conducted for every frequency value.

Due to observed $O C V$ instabilities of VARFB cells impedance measurements were also conducted with a sinusoidal current signal with an amplitude of $19.6 \mathrm{~mA}$ and frequencies from $60 \mathrm{kHz}$ to $10 \mathrm{mHz}$. Measurements with a galvanostatic perturbation did result in comparable impedance data. EIS measurement discussed within this work are all performed with a potential stimulus, accordingly.

To determine the fitting parameters $\left(\alpha, R_{c t}, C_{d l}, C_{c p e}, R_{H F}\right)$ of the equivalent circuit model elements that result in a consistent description of the measured impedance data, a non-linear least square fitting algorithm (Simplex) is employed. In this work equivalent circuit model fitting is done by use of the tool $Z$ Fit which is part of the software EC-Lab of BioLogic.

\section{Charging and Discharging with subsequent long-term $O C V$ measurement}

Charging and discharging sequences are done over a period of $1.5 \mathrm{~h}$. Charging is done at a constant voltage of $1.85 \mathrm{~V}$ (unless otherwise specified), while discharging is performed at a constant cell potential of $0.8 \mathrm{~V}$. A moderate charging potential is chosen in order to prevent hydrogen evolution at the negative electrode.

During charge and discharge periods operating parameters (gas flow rate, $\mathrm{N}_{2} / \mathrm{O}_{2}$ composition, $R H, p_{G D E}, T_{G D E}$ ) are varied to study the sensitivity of the cell performance to changes of the operating parameters. To ensure stationary current densities adjusted operating parameters are held constant for $15 \mathrm{~min}$ to $20 \mathrm{~min}$. Measured $E_{\text {cell }} / i_{\text {cell }}$-correlations are used to verify, that $E_{\text {cell }} / i_{\text {cell }}$-characteristics from polarization curve measurements are at steady state.

During charge and discharge sequences the gas composition $\left(\mathrm{N}_{2} / \mathrm{O}_{2}\right)$ is stepwise varied from pure $\mathrm{O}_{2}$ to pure $\mathrm{N}_{2}$ and the relative humidity is set to values from $0 \%$ to $100 \%$. The relative pressure in the positive cycle $\left(p_{G D E}\right)$ and electrolyte cycle $\left(p_{\text {neg }}\right)$ is varied from $0 \mathrm{hPa}$ to $150 \mathrm{hPa}$.

At the end of the charge and discharge steps long term $O C V$ measurements are conducted over durations from $40 \mathrm{~min}$ to $90 \mathrm{~min}$.

\subsection{Results and Discussion}

At the beginning of this section maximum current and power densities of the tubular $V A R F B$ cells are deduced from polarization curve measurements. An evaluation of the $E_{\text {cell }} / i$-characteristic and EIS measurements is then used to identify the performance limitations of the cells. 
Subsequently, observed cross-over processes and parasitic reactions at the GDE and in the negative half cell are analyzed. An evaluation of the electrode overpotentials is done at the end of this section.

The performance of the studied tubular VARFB cells showed to increase slightly after charging ( 5 in routine) and discharging ( 9 in routine). The performance enhancement is assumed to be due to the hydration of the membrane and proliferation of the 3phase layer. Only polarization curves and impedance data measured in sequence 11 and 12 are discussed in this section, accordingly.

Electrical contacting of the tubular VARFB cells' GDE is done by a helix current collector or a contacting pin.

Cells with an inner helix current collector exhibited higher $A S R$ values $\left(11.4 \Omega \mathrm{cm}^{2}\right)$ than VARFB cells, which were contacted with a contacting pin $\left(A S R=3.6 \Omega \mathrm{cm}^{2}\right)$. Increased area specific cell resistances of the cells with an inner helix current collector are attributed to higher contact resistances between the GDE and current collector. Swelling of the membrane increases the $M E A$ diameter during operation and reduces the compression of the GDE and the current collector. Only cells with a contacting of the GDE by contact pins are, hence, considered in this section.

\subsubsection{Cell Performance}

Within this section three different tubular VARFB cells are characterized and evaluated. Two $M E A$ fabrication routines are employed to obtain tubular $M E A s$ with a fully bonded and a partially bonded gas diffusion electrode (GDE). The porous titanium GDE substrates are coated with a bifunctional $\mathrm{Pt} / \mathrm{IrO} \mathrm{O}_{2}$ catalyst by thermal decomposition (DWI Leibniz Institute for Interactive Materials Aachen) or atom layer deposition ALD (Friedrich-Alexander University Erlangen). An overview of the different cell setups is given in table 4.1.

\section{Tubular VARFB with Fully Bonded GDE}

In figure 4.9 the polarization curve of a tubular VARFB with a fully bonded GDE (VARFB FB) and extruded VM-fumasep ${ }^{\circledR}$ FFT membrane (100 $\mu \mathrm{m}$ thickness) is displayed. The GDE is coated with $2.0 \mathrm{mg} / \mathrm{cm}^{2}$ of $P t / \mathrm{IrO}_{2}$ catalyst and $2.7 \mathrm{mg} / \mathrm{cm}^{2}$ fumion F ionomer of Fumatech BWT GmbH.

During the polarization curve measurement vanadium electrolyte solution with a SoC of $30 \%\left(E_{n e g}^{0}=-0.268 \mathrm{mV}\right.$ vs. $\left.S H E\right)$ and temperature of $34.0^{\circ} \mathrm{C}$ is pumped through the negative half cell with a flow rate of $6.4 \mathrm{ml} \mathrm{min}^{-1}$. Oxygen is fed to the GDE with a flow rate of $80.0 \mathrm{Nml}$ and $100 \%$ relative humidity at $33.0^{\circ} \mathrm{C}$ and $1103.5 \mathrm{hPa}$. 
The polarization curve is recorded at a scan rate of $100 \mathrm{mV} \mathrm{min}^{-1}$ within a cell potential $\left(E_{\text {cell }}\right)$ range from $0.46 \mathrm{~V}$ to $2.10 \mathrm{~V}$.

In figure 4.9 two open-circuit voltage $(\mathrm{OCV})$ values are shown. Within the $\triangle O C V$

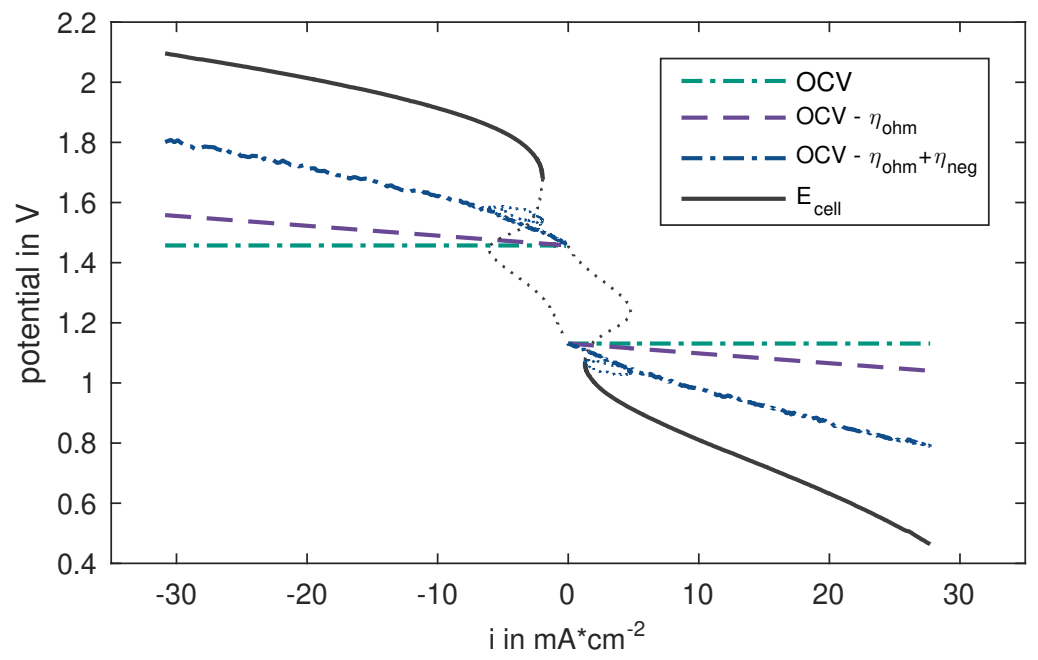

FIGURE 4.9: Polarization curve of tubular VARFB FB cell at SoC $\approx 30 \%\left(E_{\text {neg }}^{0}=-0.268 \mathrm{~V}\right) . \quad \mathrm{O}_{2}$ flow rate: $80 \mathrm{Nml} / \mathrm{min}$, $R H=100 \%$; electrolyte flow rate: $6.4 \mathrm{ml} \mathrm{min}^{-1}$.

range a peak of the cell potential occurs during the charge and discharge sequence of the polarization curve, respectively (dotted in fig. 4.9). The peaks are caused by an oxidation and reduction of vanadium cross-over ions in the GDE. An elaborate study of the $O C V$ drop and the $E_{\text {cell }} / i$ peaks is done in section 4.2.2.

Maximum Power and Current Densities: The polarization curve in figure 4.9 exhibits a linear increase of $E_{\text {cell }}$ for current densities $\left(i_{c h}\right)$ between $-10 \mathrm{~mA} \mathrm{~cm}^{-2}$ and $-32 \mathrm{~mA} \mathrm{~cm}^{-2}$. No mass transfer limitation or onset of mass transfer related overpotentials is limiting the current density during charging within the applied cell potential range. During discharging an onset of mass transfer related overpotentials is observed for current densities above $22 \mathrm{~mA} \mathrm{~cm}^{-2}\left(E_{\text {cell }} \leq 0.6 \mathrm{~V}\right)$. As the residual overpotentials of the negative electrode ( $\left|\eta_{\text {neg }}\right|$ in fig. 4.9) display a linear increase with $i_{d c h}$ in the mentioned section, mass transfer related overpotentials are assumed to arise in the GDE for the oxygen reduction reaction (ORR).

During charging a maximum current density $\left(i_{c h, \max }\right)$ of $-32 \mathrm{~mA} \mathrm{~cm}^{-2}$ is achieved at 
$E_{c e l l}=2.1 \mathrm{~V}$. Hosseiny et al. [51] reported a substantially lower $i_{c h, \text { max }}$ of $-2.4 \mathrm{~mA} \mathrm{~cm}^{-2}$ for their planar VARFB cell with a mono-layered titanium mesh GDE with Pt / Ir catalyst (see table 4.2).

Noack et al. developed a planar Vanadium-PEM water electrolysis (V-PEMWE) cell with a catalyst coated membrane (CCM) [99]. The polarization curve was measured with an electrolyte solution with equal $V^{4+}$ and $V^{3+}$ concentrations $\left(V^{3.5+}\right.$ electrolyte) and resulted in an $i_{c h, \text { max }}$ of $-75 \mathrm{~mA} \mathrm{~cm}^{-2}\left(E_{\text {cell }}>2.5 \mathrm{~V}\right)$ [99]. For a state of charge of $50 \%$ the $E_{\text {cell }} / i$ characteristic of the cell of Noack et al. [99] is, however, comparable with the tubular VARFB (tab. 4.2).

grosse Austing et al. performed charge cycles of a planar VARFB cell with a membrane surface area of $4 \mathrm{~cm}^{2}$ and a double-layer air/water electrode at a constant current density of $-40 \mathrm{~mA} \mathrm{~cm}^{-2}$ within a cell potential range from $1.8 \mathrm{~V}$ to $2.0 \mathrm{~V} \mathrm{[16].}$ During charging $2 \mathrm{MH}_{2} \mathrm{SO}_{4}$ was circulated through the positive half cell. Although no polarization curves were published in [16] maximum charge current densities are expected to outreach $i_{c h \text {,max }}$ of the tubular VARFB FB and $V$-PEMWE cell (table 4.2).

The $V A R F B F B$ allows for a maximum discharge current density of $28 \mathrm{~mA} \mathrm{~cm}^{-2}$

TABLE 4.2: Comparison of $i_{c h, \max }$ of tubular VARFB cell with results of planar VARFBs $[16,51]$ and Vanadium-PEM Water Electolysis ( $V$ PEMWE) cell [99]. 1) Data from charge cycle.

\begin{tabular}{llcccc}
\hline Cell & $\begin{array}{l}\text { Anode } \\
\text { catalyst }\end{array}$ & water supply & $\begin{array}{c}S o C \\
{[\%]}\end{array}$ & $\begin{array}{c}E_{\text {cell }}\left(i_{\text {max }}\right) \\
{[\mathrm{V}]}\end{array}$ & $\begin{array}{c}i_{\text {max }} \\
{\left[\mathrm{mA} \mathrm{cm}^{-2}\right]}\end{array}$ \\
\hline tub. VARFB & mono layer $\mathrm{Pt} / \mathrm{IrO} \mathrm{O}_{2}$ & $\mathrm{H}_{2} \mathrm{O}_{g}$ & 30 & 2.1 & -32 \\
1) planar VARFB [51] & mono layer $\mathrm{Pt} / \mathrm{Ir}$ & $\mathrm{H}_{2} \mathrm{O}_{l}$ & - & $2.1-2.3$ & -2.4 \\
1) planar VARFB [16] & double-layer $\mathrm{Pt}, \mathrm{IrO}_{2}$ & $2 \mathrm{M} \mathrm{H}_{2} \mathrm{SO}_{4}$ & $0-93$ & $1.8-2.0$ & -40 \\
1) V-PEMWE [99] & CCM Ir & none & 50 & 2.4 & -43 \\
\hline
\end{tabular}

at a cell potential of $0.46 \mathrm{~V}$ (fig. 4.9). The maximum power density $\left(p_{A, \max }\right)$ of $13.23 \mathrm{~mW} / \mathrm{cm}^{2}$ is achieved at a somewhat higher $E_{\text {cell }}$ of $0.54 \mathrm{~V}$.

For the discharge cycles of the planar VARFB of Hosseiny et al. [51] a mono-layered sintered titanium GDE was assembled in the positive half cell (cathode). However, a significantly lower discharge current density of $2.4 \mathrm{~mA} \mathrm{~cm}^{-2}$ was applied for the discharge cycles (see table 4.3).

Discharge cycles of the planar VARFB of grosse Austing et al. [16] where done at a current density of $40 \mathrm{~mA} \mathrm{~cm}^{-2}$ with an average power density $\left(p_{A, a v}\right)$ of $33.8 \mathrm{~mW} / \mathrm{cm}^{2}$. The discharge performance of the planar VARFB cell with a double-layer cathode [16] exceeds the performance characteristic of the tubular VARFB cell and $p_{A, a v}$ is more than 2.5 times higher than the $p_{A, \max }$ of the tubular VARFB FB (tab. 4.3). 
TABLE 4.3: Comparison of $i_{d c h, \max }$ and $p_{A, \max }$ of tubular VARFB cell with results of planar VARFBs [16, 51] and Vanadium-Oxygen Fuel Cells (VOFC) $[85,95] .{ }^{1)}$ Data from discharge cycle. ${ }^{2)}$ average power density of $d c h$-cycle.

\begin{tabular}{llcccl}
\hline Cell & $\begin{array}{l}\text { Cathode } \\
\text { catalyst }\end{array}$ & $\begin{array}{c}\text { SoC } \\
{[\%]}\end{array}$ & $\begin{array}{c}E_{\text {cell }}\left(i_{\max }\right) \\
{[\mathrm{V}]}\end{array}$ & $\begin{array}{c}i_{\text {dch,max }} \\
{\left[\mathrm{mAcm}^{-2}\right]}\end{array}$ & $\begin{array}{l}p_{A, \max }\left(E_{\text {cell }}\right) \\
{\left[\mathrm{mW} / \mathrm{cm}^{2}\right]([\mathrm{V}])}\end{array}$ \\
\hline tub. VARFB & mono layer $P t / \mathrm{IrO} \mathrm{C}_{2}$ & 30 & 0.46 & 28 & $13.2(0.54)$ \\
1) planar VARFB [51] & mono layer $P t / \mathrm{Ir}$ & - & $0.8-0.4$ & 2.4 & $2.6(1.1)$ \\
1) planar VARFB [16] & double-layer $P t, \mathrm{IrO}_{2}$ & $93-0$ & $0.9-0.5$ & 40 & $2)_{33.8(0.9-0.5)}$ \\
VOFC [95] & CCM Pt & 100 & 0.22 & 59 & $23.0(0.56)$ \\
VOFC [85] & ELAT GDL Pt & 100 & 0.45 & 41 & $18.3(0.45)$ \\
\hline
\end{tabular}

Noack et al. [95] reported a maximum power density of $23 \mathrm{~mW} / \mathrm{cm}^{2}$ for a planar Vanadium/Oxygen Fuel Cell (VOFC) with an $A_{m e m}=280 \mathrm{~cm}^{2}$. The $p_{A, \text { max }}$ and maximum discharge current density of the planar VOFC is approximately twice as high as for the tubular VARFB (table 4.3). Menictas and Skyllas-Kazacos bonded a commercial Pt coated ELAT GDL to Nafion N112 and Nafion N117 membranes with an active surface area of $20 \times 20 \mathrm{~cm}^{2}$. The $M E A$ was employed in a VOFC and a maximum discharge current density of $40.5 \mathrm{~mA} \mathrm{~cm}^{-2}$ and $p_{A, \max }$ of $18.3 \mathrm{~mW} / \mathrm{cm}^{2}$ was achieved at $E_{\text {cell }}=0.45 \mathrm{~V}$.

Performance Limitations: In the polarization curve of the tubular VARFB FB (fig. $4.9)$ two open-circuit voltage (OCV) values are shown. While the $O C V$ during charging $(1.46 \mathrm{~V})$ is comparable with the theoretical standard cell potential $\left(E_{c e l l}^{00}\right)$ of $1.49 \mathrm{~V}$ (equation 2.13 with fig. 2.3), a reduced $O C V$ of $1.13 \mathrm{~V}$ is measured after the discharge sequence ( $E$ in figure 4.8). The $O C V$ during charging is derived from the measured at the end of the $O C V$ measurement sequence ( $C$ in figure 4.8). By use of the in situ half cell potential measurement setup (see section 2.2.3) the Nernst potential of the negative electrode $\left(E_{\text {neg }}^{0}\right)$ is measured throughout the entire polarization curve measurement and yields a constant value of $-268 \mathrm{mV}( \pm 1 \mathrm{mV})$ vs. SHE. The opencircuit voltage drop between charging and discharging $(\triangle O C V=-330 \mathrm{mV})$ is, thus, caused by a drop of the air electrode potential $\left(E_{\text {pos }}^{0}\right)$. Note, that the GDE is fed with $80.0 \mathrm{Nml}$ oxygen at a constant temperature, pressure and humidity during all $\mathrm{OCV}$ measurement steps.

In the field of PEM fuel cells the phenomenon of a reduced $O C V$ is well known and $O C V$ values of cells are typically below $1.0 \mathrm{~V}\left(O C V_{\text {theo }}=1.23 \mathrm{~V}\right)[164,167]$. The decreased open-circuit voltage is due to mixed potentials in the GDE, which are 
caused by $P t$ oxide film formation, $P t$ dissolution and/or the carbon-support material, permeated hydrogen or an oxidation of organic impurities [164, 167]. In the tubular VARFB a cross-over of vanadium ions into the GDE is expected to occur [13]. Vanadium ions might contribute to the mixed potentials and result in an $\triangle O C V$ of $-330 \mathrm{mV}$.

A similar OCV drop was reported by Hosseiny et al. [51] and OCV values of VOFCs $[85,95,97]$ and the VPEMWE [99] cell also showed to be significantly lower than the standard cell potentials.

The diminished $O C V$ leads to reduced power densities and adds to the voltage losses of the tubular VARFB cell.

In the charge sequence of figure $4.9 \mathrm{a}$ formation of gas bubbles is detected in the negative half cell for cell potentials above $2.0 \mathrm{~V}$. The onset of the gas evolution occurs at a negative electrode potential $\left(E_{\text {neg }}(i)=E_{\text {neg }}^{0}-\eta_{\text {neg }}\right)$ of $-0.456 \mathrm{~V}$ (vs. SHE) and is attributed to hydrogen evolution at the graphite felt electrodes. Parasitic hydrogen evolution is known to occur for low electrode potentials at the negative electrode of $V R F B$ cells $[43,72,121,153]$ and a significant evolution of hydrogen was reported by Wei et al. [153] for $E_{\text {neg }}(i) \leq-0.7 \mathrm{~V}$ (vs. SCE).

Accordingly, the maximum current density and cell potential during charging is limited by the hydrogen evolution at the negative electrode. For the the tubular VARFB with a fully bonded GDE at a SoC of $30 \%$ current densities have to be limited to $\left|i_{\text {cell,ch }}\right| \leq 19.25 \mathrm{~mA} \mathrm{~cm}^{-2}$ to avoid parasitic hydrogen evolution.

CI-measurements of the tubular VARFB FB resulted in an $A S R_{C I}$ of $3.27 \Omega \mathrm{cm}^{2}$ and ohmic overpotentials have the smallest contribution to the total overpotential $\left(\eta_{i}\right)$. $A S R$ values of planar VOFCs where estimated by a fit of the ohmic section and are three to four times higher $\left(11.1 \Omega \mathrm{cm}^{2}\right.$ to $18.3 \Omega \mathrm{cm}^{2}$ [85], $14.0 \Omega \mathrm{cm}^{2}$ to $15.6 \Omega \mathrm{cm}^{2}$ [95]) than the $A S R_{C I}$ of the tubular cell. In contrast to the tubular VRFB cells, the area specific cell resistance of the tubular VARFB is below planar reference cells. A direct comparison of the ASR of planar VARFB cells can not be done as no resistance values were reported in [16] and [51].

The total overpotentials of the tubular VARFB FB cell during discharging are slightly above $\eta_{i}$ of the planar VOFC cell of Noack et al. [95] but significantly lower than the values reported by Menictas and Skyllas-Kazacos [85]. The $i * A S R$-free overpotentials during discharging at $i_{\text {cell }}=20 \mathrm{~mA} \mathrm{~cm}^{-2}$ are below the values of a planar $V O F C$ with $0.4 \mathrm{mg} \mathrm{cm}^{-2} \mathrm{Pt}$ loading [85] but are more than twice as high as the values of a VOFC with $1.0 \mathrm{mg} \mathrm{cm}^{-2} P t$ loading and residual overpotentials of the VOFC $\left(A_{\text {mem }}=280 \mathrm{~cm}^{2}\right)$ of Noack et al. [95].

In general residual overpotentials of both, VOFC cells and the tubular VARFB FB cell during discharging are comparably high. The slow reaction kinetics of the $O R R$ 
TABLE 4.4: Comparison of overpotentials of tubular VARFB cell with fully bonded GDE with published results. $\left.{ }^{1}\right) E L A T$ GDL with Nafion N112 membrane and $0.4 \mathrm{mg} \mathrm{cm}^{-2}$ Pt loading. ${ }^{2}$ )ELAT GDL with Nafion $N 117$ membrane and $1.0 \mathrm{mg} \mathrm{cm}^{-2}$ Pt loading.

\begin{tabular}{|c|c|c|c|c|}
\hline Cell & $\begin{array}{c}i_{\text {cell }} \\
{\left[\mathrm{mA} \mathrm{cm}^{-2}\right]}\end{array}$ & $\begin{array}{c}\left|\eta_{\text {ohm }}\right| \\
{[\mathrm{mV}]}\end{array}$ & $\begin{array}{l}\left|\eta_{\text {res }}\right| \\
{[\mathrm{mV}]}\end{array}$ & $\begin{array}{r}\left|\eta_{i}\right| \\
{[\mathrm{mV}]}\end{array}$ \\
\hline \multirow{2}{*}{ tub. VARFB } & 20 & 65 & 434 & 499 \\
\hline & -20 & 65 & 492 & 557 \\
\hline planar $\left.V O F C^{1}\right)$ [85] & 21 & 231 & 486 & 717 \\
\hline planar $V O F C^{2}$ ) [85] & 20 & 396 & 204 & 600 \\
\hline planar VOFC [95] & 20 & 280 & 180 & 460 \\
\hline
\end{tabular}

at room temperature leads to substantial activation overpotentials and might be reduced by elevated operating temperatures.

During charging an even higher residual overpotential than during discharging is estimated (table 4.4) for the tubular VARFB cell. Comparison with the overpotentials of the VPEM WE cell and planar VARFB cell can not be done as the polarization curve published by Noack et al. [99] is strongly effected by a cross-over induced $O C V$ drop and no polarization curves, as well as $O C V$ and $A S R$ values were published by grosse Austing et al. [16].

The residual overpotential of the negative electrode is shown in the polarization plot in figure 4.9. It features a high noise level and $\eta_{\text {neg }}$ values outnumber the overpotentials at the negative electrodes of tubular flow-by VARFB cells significantly. The noise level and comparably high values of $\eta_{n e g}$ are assumed to be caused by gas bubbles in the negative half cell. After initialization of the measurement routine an onset of a gas formation was detected. The gas formation is independent from applied potentials and currents, did not vary with changing system pressure in the positive half cell (no membrane leak) and intensified over the period of the experiment $(14 \mathrm{~h})$.

Gas evolution in the negative half cell was also reported for the VOFC of Noack et al. [97]. Solid Vanadium oxide particles in the electrolyte solution were assumed to act catalytically and lead to a reduction of protons by $V^{2+}$ ions. A similar noise level of the negative electrode overpotential occurred during long-term tests of a VOFC and were attributed to a gas formation at the graphite electrodes [97]. Furthermore, a decomposition of the vanadium electrolyte solution was reported by Noack et al.. Filtering of the electrolyte solution prior to discharge experiments was reported to prevent gas formation. In the publications on VOFCs [85, 95], a VPEM WE cell [99] and planar VARFB cells $[16,51]$ no such gas evaluation is mentioned.

During the tubular VARFB cell tests no decomposition of the vanadium electrolyte 
was detected and no gas evolution was ever observed during formation, characterization and/or charge/discharge cycling of VRFB cells with identical electrolyte solution. Furthermore, gas formation did not occur at the beginning of the measurements, but started after approximately 2 hours of operation and showed to increase in intensity with time. It is, thus, assumed that the gas formation in the negative half cell is linked to cross-over processes (e.g. oxygen cross-over, $V$ ion cross-over). Gas bubbles at the graphite felt electrode surface are held responsible for the high noise level of the potential signal and a reduced active surface area of the electrodes with increased activation overpotentials. The gas evolution in the negative half cell is analyzed in detail in section 4.2.2.

By assuming stationary conditions during the polarization curve measurement (low scan rate), voltage efficiency $(V E)$ values can be deduced $\left(V E=E_{\text {cell, dch }} / E_{\text {cell,ch }}\right)$ from the $E_{\text {cell }} / i$-characteristic. For a constant $S o C$ of $30 \%$ and current density of $20 \mathrm{~mA} / \mathrm{cm}^{2}$ a voltage efficiency of $31.4 \%$ is estimated for the tubular VARFB with a fully bonded GDE. The VE of the planar VARFB of grosse Austing et al. [16] was estimated (equation 2.60) from charge/discharge cycling data and can, thus, not be compared directly with the $V E$ of the tubular VARFB. However, the $V E$ of $49.5 \%$ at $i_{\text {cell }}=20 \mathrm{~mA} / \mathrm{cm}^{2}[16]$ is significantly higher than the voltage efficiency achieved in this work.

\section{Tubular VARFB with Partially Bonded GDE}

A tubular VARFB cell with a partially bonded GDE (VARFB PB) was fabricated as described in section 4.1.2. The GDE was only partially bonded to the membrane in order to reduce the penetration depth of the GDE into the membrane and yield a thicker membrane layer. As gas evolution in the negative half cell is assumed to be linked to cross-over processes, an increased membrane thickness should lead to a reduced gas evolution.

Indeed, the onset of the gas evolution showed to start at a later point of time in the experiment and the intensity of the gas evolution was lower than in the previous experiment.

Polarization curves are performed at a $\mathrm{SoC}$ of $70 \%$ with a constant electrolyte flow rate of $6.4 \mathrm{ml} \mathrm{min}^{-1}$ and a potential scan rate of $100 \mathrm{mV} \mathrm{min}^{-1}$. The potential limit during charging is set to $1.9 \mathrm{~V}$ to prevent hydrogen evolution. In figure 4.10 several polarization curves at different gas compositions are displayed. $E_{\text {cell }} / i$ peaks at the beginning of the charge and discharge steps occurred at comparable magnitudes and peak potentials as the peaks in figure 4.9 but are not shown in figure 4.10 for a better readability. 


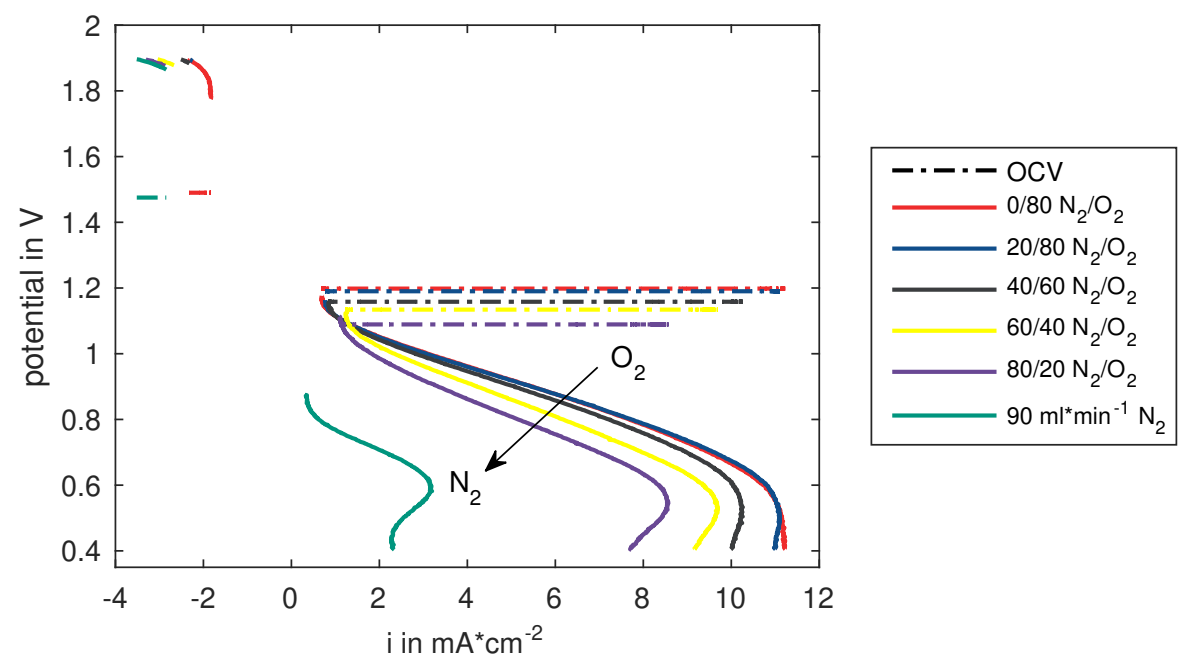

FIGURE 4.10: Polarization curves of tubular VARFB $P B$ for different gas compositions.

Maximum Current Densities: Due to the high $S_{0} C$, a high residual overpotential of the $O E R$ and a comparably low potential limit during charging, maximum current densities $\left(\left|i_{c h, \max }\right|\right)$ do not exceed $4 \mathrm{~mA} \mathrm{~cm}^{-2}$.

All polarization curves exhibit a strong mass transfer limitation during discharging and the maximum discharge current density of $11.1 \mathrm{~mA} \mathrm{~cm}^{-2}$ is three times lower than $i_{\text {max }, \text { dch }}$ of the cell with a fully bonded GDE.

Performance Limitations: The mass transfer limitation and comparably low $i_{\text {max }}$,dch is assumed to be caused by a low contact area of the membrane and GDE with a diminished 3-phase layer. As the limiting discharge current density decreases with reducing $\mathrm{O}_{2}$ concentration (constant total gas flow rate), mass transfer limitations are rather caused by a limited transport rate of $\mathrm{O}_{2}$ to the reactive side than a mass transport limitation due to a GDE blockage with product water ("GDE flooding"). $O C V$ values measured after the discharge step decrease from $1.19 \mathrm{~V}$ for pure $\mathrm{O}_{2}$ gas supply to $1.09 \mathrm{~V}$ for a $\mathrm{N}_{2} / \mathrm{O}_{2}$ gas composition of $80 / 20$ ( $E_{\text {neg }}^{0}=$ const.). The variation of the OCV with the gas composition is in accordance with the expected behavior (Nernst Equation). The OCV drop between charging and discharging is in the same range as for the tubular VARFB cell with a fully bonded GDE and is attributed to 
mixed potentials in the GDE and vanadium ion cross over.

\section{Tubular VARFB with Partially Bonded and Flooded GDE}

In order to verify the assumption of a reduced contact area of the GDE and the membrane, the tubular $V A R F B P B$ cell is operated with a fully flooded GDE during the charge sequence. $2 \mathrm{M} \mathrm{H}_{2} \mathrm{SO}_{4}$ is injected into the positive half cell prior to the charge sequence ( $B$ in fig. 4.8 ) of the polarization curve measurement. Flooding of the GDE is expected to increase the electrochemically active electrode area and permit a sufficient supply of water for the OER.

After charging, the $2 \mathrm{M} \mathrm{H}_{2} \mathrm{SO}_{4}$ is withdrawn from the positive half cell (during $\mathrm{OCV}$ measurement $C$ in fig. 4.8) and the GDE is fed with $80.0 \mathrm{Nml}$ of $\mathrm{O}_{2}$ while discharging.

In figure 4.11 two polarization curves of the tubular VARFB cell with a partially bonded GDE are shown. One $E_{\text {cell }} / i$-characteristic is measured with the routine specified above (flooded in fig. 4.11) and a second polarization curve is recorded at a constant $\mathrm{O}_{2}$ flow rate.

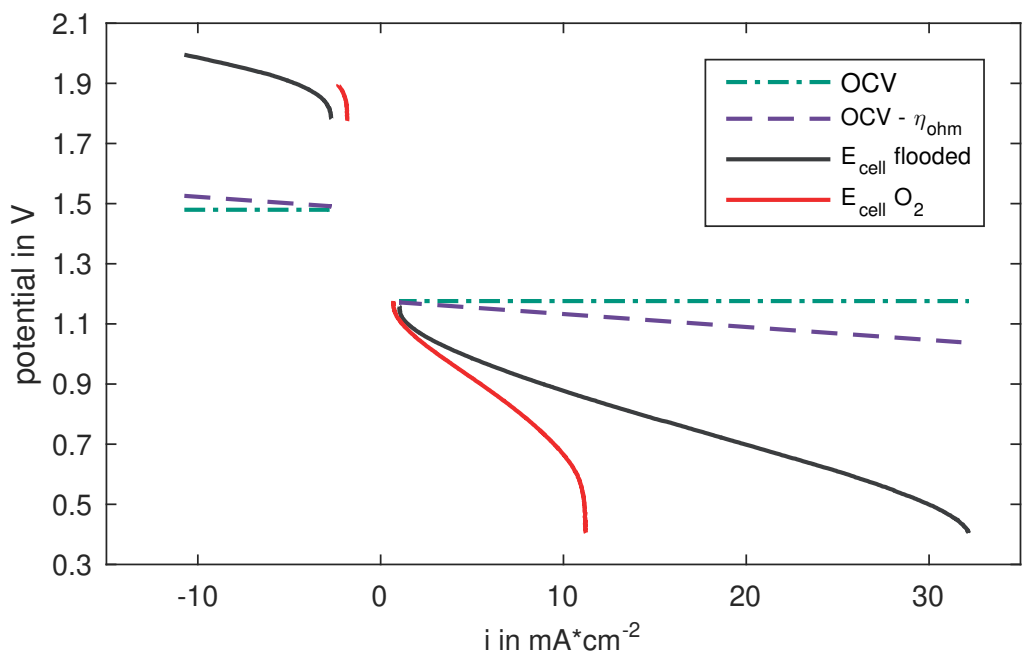

FIGURE 4.11: Polarization curves of tubular VARFB $P B$ cell at SoC $\approx 70 \%$. E Eell $\mathrm{O}_{2}$ is measured at a $\mathrm{O}_{2}$ flow rate: $80 \mathrm{Nml} / \mathrm{min}$, $\mathrm{RH}=100 \%$; $E_{\text {cell }}$ flooded is recorded with a $2 \mathrm{MH}_{2} \mathrm{SO}_{4}$-flooded GDE during $c h$ and $\mathrm{O}_{2}$ during discharging. 
Maximum Power and Current Densities: During charging a maximum current density of $-10.8 \mathrm{~mA} / \mathrm{cm}^{2}$ is achieved at $2.0 \mathrm{~V}$ with the tubular VARFB with a flooded $G D E$. The set cell potential limit of $1.9 \mathrm{~V}$ restricts the current density of the $\mathrm{O}_{2}$-fed cell during charging. However, the overpotentials of the tubular cell with $\mathrm{O}_{2}$ supply are higher than those of the tubular VARFB with a flooded GDE at identical current densities.

After flooding the GDE with sulfuric acid, the discharge $E_{\text {cell }} / i$-characteristic of the tubular VARFB cell shows a profoundly different shape. Although both polarization curves are performed at an identical $\mathrm{O}_{2}$ flow rate, lower overpotentials and a substantially higher maximum current density are achieved after flooding. The enhanced performance is believed to originate from a larger 3-phase layer in the GDE. Residual $\mathrm{H}_{2} \mathrm{SO}_{4}$ might be entrapped between the GDE and the membrane and result in a larger active electrode surface area and facilitate a better ionic conductivity in the porous GDE structure.

The maximum discharge current density of $32 \mathrm{~mA} \mathrm{~cm}^{-2}$ exceeds $i_{\text {max }, \mathrm{dch}}$ of the tubular VARFB with a fully bonded GDE and the maximum power density of $15.4 \mathrm{~mW} / \mathrm{cm}^{2}$ marks the highest value for tubular VARFB cells within this work. The maximum current density during discharging is substantially higher than $i_{\text {max }}$ dch of Hosseiny et al. [51] but falls below the values of Vanadium/Oxygen Fuel Cells [85, 95] and the planar VARFB of grosse Austing et al. [16] (table 4.5).

TABLE 4.5: Comparison of $i_{d c h, \max }$ and $p_{A, \max }$ of tubular VARFB cell with results of planar VARFBs $[16,51]$ and Vanadium-Oxygen Fuel Cells (VOFC) $[85,95] .{ }^{1)}$ Data from discharge cycle. ${ }^{2)}$ average power density of $d c h$-cycle.

\begin{tabular}{llcccl}
\hline Cell & $\begin{array}{l}\text { Cathode } \\
\text { catalyst }\end{array}$ & $\begin{array}{c}S o C \\
{[\%]}\end{array}$ & $\begin{array}{c}E_{\text {cell }}\left(i_{\max }\right) \\
{[\mathrm{V}]}\end{array}$ & $\begin{array}{c}i_{\text {dch,max }} \\
{\left[\mathrm{mAcm}^{-2}\right]}\end{array}$ & $\begin{array}{c}p_{A, \max }\left(E_{\text {cell }}\right) \\
{\left[\mathrm{mW} / \mathrm{cm}^{2}\right]([\mathrm{V}])}\end{array}$ \\
\hline tub. VARFB & mono layer $P t / I r \mathrm{Ir}_{2}$ & 70 & 0.40 & 32 & $15.4(0.56)$ \\
1) planar VARFB [51] & mono layer Pt/Ir & - & $0.8-0.4$ & 2.4 & $2.6(1.1)$ \\
1) planar VARFB [16] & double-layer Pt, $\mathrm{IrO}_{2}$ & $93-0$ & $0.9-0.5$ & 40 & $2) 33.8(0.9-0.5)$ \\
VOFC [95] & CCM Pt & 100 & 0.22 & 59 & $23.0(0.56)$ \\
VOFC [85] & ELAT GDL Pt & 100 & 0.45 & 41 & $18.3(0.45)$ \\
\hline
\end{tabular}

Performance Limitations: At current densities above $27 \mathrm{~mA} \mathrm{~cm}^{-2}$ the polarization curve of the VARFB PB (after flooding) shows an increased decline of the cell potential. The additional overpotential is caused by mass transfer related losses $\left(\eta_{\text {conc }}\right)$ and was also observed in the polarization curve of the tubular VARFB with a fully bonded GDE (fig. 4.9) at comparable current densities. 
At a current density of $20 \mathrm{~mA} \mathrm{~cm}^{-2}$ the cell exhibits total overpotential of $478 \mathrm{mV}$. The residual overpotentials of $392 \mathrm{mV}$ are more than 4.5 times higher than the ohmic overpotential $\left(\eta_{\text {ohm }}=86 \mathrm{mV}\right)$ and represent the biggest source of losses. The residual overpotentials are, however, smaller than $\eta_{\text {res }}$ of the tubular VARFB with a fully bonded GDE $(434 \mathrm{mV})$ and the residual overpotentials of the planar VOFC with a Nafion N112 membrane and $0.4 \mathrm{mg} \mathrm{cm}^{-2}$ Pt loading of Menictas and Skyllas-Kazacos [85] (table 4.6).

TABLE 4.6: Comparison of overpotentials of tubular VARFB PB with published results. ${ }^{1}$ )ELAT GDL with Nafion N112 membrane and $0.4 \mathrm{mg} \mathrm{cm}^{-2}$ Pt loading. ${ }^{2}$ )ELAT GDL with Nafion N117 membrane and $1.0 \mathrm{mg} \mathrm{cm}^{-2} \mathrm{Pt}$ loading.

\begin{tabular}{lcccc}
\hline Cell & $\begin{array}{c}i_{\text {cell }} \\
{\left[\mathrm{mA} \mathrm{cm}^{-2}\right]}\end{array}$ & $\begin{array}{c}\left|\eta_{\text {ohm }}\right| \\
{[\mathrm{mV}]}\end{array}$ & $\begin{array}{c}\left|\eta_{\text {res }}\right| \\
{[\mathrm{mV}]}\end{array}$ & $\begin{array}{c}\left|\eta_{i}\right| \\
{[\mathrm{mV}]}\end{array}$ \\
\hline tub. VARFB & 20 & 86 & 392 & 478 \\
planar VOFC ${ }^{1}$ ) [85] & -10 & 43 & 464 & 507 \\
planar VOFC [85] $_{\text {planar VOFC [95] }}$ & 21 & 231 & 486 & 717 \\
\hline
\end{tabular}

Electrochemical Impedance Spectroscopy measurements are conducted to gain knowledge of the processes in the cell and quantify their contribution to the overall performance. Impedance measurements of the tubular VARFB with a partially bonded GDE are done after flooding at $O C V$. The positive half cell is fed with $80.0 \mathrm{Nml}$ of $\mathrm{O}_{2}$ and a constant electrolyte flow rate of $6.4 \mathrm{ml} \mathrm{min}^{-1}(\mathrm{SoC}=70 \%)$ is maintained during the measurement. Sinusoidal potential perturbation is done with an amplitude of $5 \mathrm{mV}$ with frequencies from $60 \mathrm{kHz}$ to $10 \mathrm{mHz}$. In figure 4.12 the measured impedance is displayed in Nyquist and Bode representation.

In the Nyquist plot two semicircle like sections appear, which can be assigned to two frequency domains in the Bode plots. While the first semicircle appears within a frequency domain from $11.2 \mathrm{~Hz}$ to $27.5 \mathrm{kHz}$, the second semicircle like section appears at frequencies below $11.2 \mathrm{~Hz}$.

The semicircle in the higher frequency domain is assigned to the charge transfer at the negative electrode as the time constant is characteristic for $V^{2+} / V^{3+}$ redox reactions [139]. The characteristic frequency domain of the charge transfer and mass transfer processes of the $\operatorname{ORR}[103,130,149]$ is within the frequency range of the second semicircle and allows to relate the lower frequency region to the air electrode. 

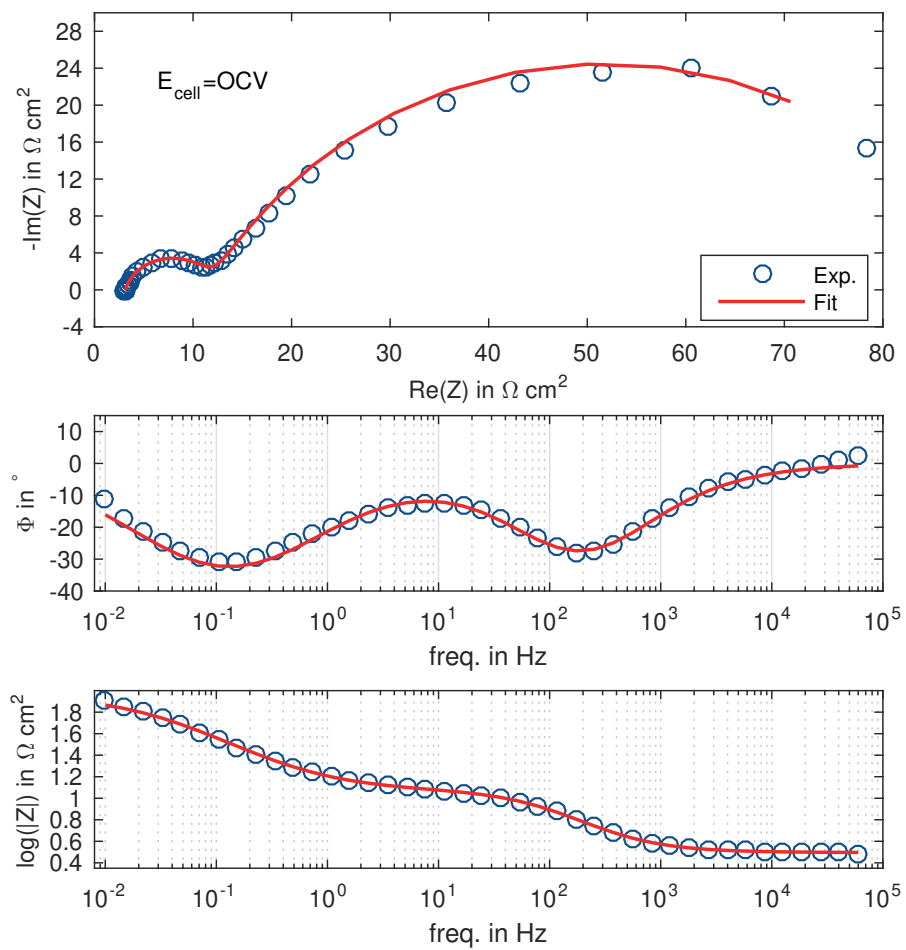

FIGURE 4.12: Measured impedance and fitted model of the tubular VARFB PB cell after GDE flooding at OCV $\left(\dot{Q}_{G D E}=80 \mathrm{Nml} / \mathrm{min}\right.$ $\mathrm{O}_{2}$ ). Top: Nyquist plot; Middle: Bode plot of phase shift $\phi$; Bottom: Bode plot of absolute impedance $|Z|$.

Fitting of an equivalent circuit model to the measured impedance data is done with the Z-fit tool of EC-Lab. A Simplex algorithm is employed to fit the equivalent circuit model depicted in figure $2.12 \mathrm{C}$. Constant phase elements are used for both electrodes to account for non-ideal electrode material properties. The fit yields a $X^{2} /|Z|$-value of 0.043 and is shown in figure 4.12. Determined fitting parameters are listed in table 4.7 .

The area specific cell resistance $\left(A S R_{E I S}\right)$ is considered in the model by the fitting parameter $R_{H F}$ (table 4.7). The $A S R_{E I S}$ is lower than the $A S R$ value, which was measured by $C I\left(A S R_{C I}=4.31 \Omega \mathrm{cm}^{2}\right)$. The deviation of the $A S R$ values is caused by the applied measurement method as already described in section 3.2.3. 
The charge transfer resistance $\left(R_{C T, 1}\right)$ and double layer capacity $\left(C_{1}\right)$ describe the charge transfer at the negative electrode, while $R_{C T, 2}$ and $C_{2}$ quantify the positive electrode reaction.

Noack et al. performed EIS measurements of a VOFC at OCV in charged and discharged state [95]. The measured impedance also features two time constants at comparable frequency domains as the impedance of the tubular VARFB. In [95] an analog equivalent circuit model ( $C$ in fig. 2.12) was used and permits to compare the normalized fitting parameters of the tubular VARFB with the VOFC in charged state (table 4.7).

The $A S R_{E I S}$ of the VOFC is more than 3 times higher than the $A S R_{E I S}$ of the tubular VARFB. The comparably high area specific cell resistance of the Vanadium/Oxygen Fuel Cell is caused by the cell design, which features two membranes with a $\mathrm{H}_{2} \mathrm{SO}_{4}$ filled cavity. The cavity was employed to minimize vanadium ion cross-over into the positive half cell [95]. In the positive half cell of the VOFC of Noack et al. a catalyst coated membrane is used, which needs to be contacted with a gas diffusion layer $(G D L)$. The additional contact resistances in-between the porous electrode layer and the GDL is expected to further increase the ASR. The mono-layer design of the tubular air electrode permits significantly lower $A S R$ values as the GDE structure can be contacted electrically with a simple contacting pin.

The double layer capacity of the negative electrode $\left(C_{1}\right)$ of the tubular VARFB is more than 8.5 times smaller than $C_{1}$ of the VOFC. The electrode thickness of the tubular electrode is $700 \mu \mathrm{m}$, while "several layers" [95] of graphite felt electrodes with a thickness of $5.0 \mathrm{~mm}$ (per layer) where used in the VOFC. The comparably high double layer capacity of the VOFC can, thus, be attributed to the higher surface area of the electrode.

The charge transfer resistance of the $V^{2+} / V^{3+}$ reaction $\left(R_{C T, 1}\right)$ is 2.7 times higher for the tubular VARFB than the VOFC. By use of equation 2.72 an exchange current density of $i_{0}=3.03 \mathrm{~mA} / \mathrm{cm}^{2}$ and $i_{0}=8.29 \mathrm{~mA} / \mathrm{cm}^{2}$ is estimated with the $R_{C T, 1}$ of the tubular VARFB and VOFC, respectively. In view of the high surface area of the $V O F C$ a greater difference of the exchange current densities would be expected. However, the different electrode materials and electrolyte compositions used in both cells might also have a substantial influence on the exchange current density.

In contrast to the negative electrode capacity, the double layer capacity of the tubular $G D E\left(C_{2}\right)$ is almost twice as high as the respective value of the VOFC. This deviation of the double layer capacities can be attributed to the higher catalyst loading of the tubular VARFB $\left(2.0 \mathrm{mg} / \mathrm{cm}^{2} \mathrm{Pt} / \mathrm{IrO}_{2}(70 / 30)\right.$ vs. $0.6 \mathrm{mg} / \mathrm{cm}^{2}$ to $\left.0.8 \mathrm{mg} / \mathrm{cm}^{2} \mathrm{Pt}\right)$, the different catalyst material and coating method, the unequal 3-phase layer properties, as well as the different electrode structures (Ti GDL vs. CCM).

The charge transfer resistance of the tubular air electrode is 3 times lower than $R_{C T, 2}$ 
TABLE 4.7: Comparison of tubular VAFRB fitting parameters with fitting parameters of planar VOFC $\left(280 \mathrm{~cm}^{2}\right)$ of Noack et al. [95].

\begin{tabular}{lccccccc}
\hline cell & \multicolumn{5}{c}{ fit parameter } \\
& $R_{H F}$ & $C_{1}$ & $R_{C T 1}$ & $a_{1}$ & $C_{2}$ & $R_{C T 2}$ & $a_{2}$ \\
\hline tub. VARFB & $3.12 \Omega \mathrm{cm}^{2}$ & $0.22 \mathrm{mF} \mathrm{cm}^{-2}$ & $8.48 \Omega \mathrm{cm}^{2}$ & 0.81 & $67.48 \mathrm{mF} \mathrm{cm}^{-2}$ & $80.44 \Omega \mathrm{cm}^{2}$ & 0.70 \\
VOFC [95] & $10.4 \Omega \mathrm{cm}^{2}$ & $1.9 \mathrm{mF} \mathrm{cm}^{-2}$ & $3.1 \Omega \mathrm{cm}^{2}$ & 0.76 & $35.0 \mathrm{mF} \mathrm{cm}^{-2}$ & $246.4 \Omega \mathrm{cm}^{2}$ & 0.87 \\
\hline
\end{tabular}

of the VOFC. Solving equation 2.72 with the charge transfer resistance of the tubular VARFB results in an exchange current density of $i_{0}=1.597 \times 10^{-4} \mathrm{~A} / \mathrm{cm}^{2}$. The exchange current density is in accordance with the measured $i_{0}=1.22 \times 10^{-4} \mathrm{~A} / \mathrm{cm}^{2}$ of a PEMFC cathode with a $P t$ catalyst coated $\left(1.0 \mathrm{mg} / \mathrm{cm}^{2}\right.$ loading $) E-T E K$ gas diffusion layer at a temperature of $23^{\circ} \mathrm{C}$ [167].

The exchange current density of $5.214 \times 10^{-5} \mathrm{~A} / \mathrm{cm}^{2}$ of the VOFC cathode [95] is, however, substantially lower.

\section{Tubular VARFB with Nano-Structured GDE}

The tubular VARFB cells investigated in the previous sections employed a GDE with a catalyst loading of $2.0 \mathrm{mg} / \mathrm{cm}^{2} \mathrm{Pt} / \mathrm{IrO}_{2}(70 / 30)$. In order to lower the power specific costs of a VARFB cell, a reduction of the catalyst material costs is required.

Nano-structured GDE electrodes where coated at the Friedrich-Alexander University Erlangen by $A L D$ with a reduced catalyst loading $\left(1 \mathrm{~nm}\right.$ thick $P t$ layer and a $\operatorname{IrO}_{2}$ layer with a thickness of $2 \mathrm{~nm}$ ). The tubular $M E A$ was fabricated with a partially bonded GDE as described in section 4.1.2.

In order to prevent hydrogen evolution in the negative half cell $50 \mathrm{ml}$ vanadium electrolyte solution with an initial $S o C$ below $0 \%\left(c_{V 3+}>>c_{V 4+}, E_{\text {neg }}^{0}=350.1 \mathrm{mV}\right.$ vs. $S H E$ ) is used for the experiment. As the low $S o C$ only permits to charge the tubular $V A R F B$, the polarization curve is performed from OCV to a cell potential of $3.0 \mathrm{~V}$. The high $E_{\text {neg }}^{0}$ permits to set a comparably high cell potential limit as the negative electrode potential $\left(E_{\text {neg }}\left(i_{\text {cell }}\right)\right)$ is expected to remain above the potential of the hydrogen evolution $(-0.456 \mathrm{~V}$ vs. $S H E)$.

In the left plot of figure 4.13 the $E_{\text {cell }} / i$-characteristic of the tubular VARFB with a nano-structured GDE is displayed. The polarization curve is recorded with a scan rate of $50 \mathrm{mV} \mathrm{min}^{-1}$ at a gas flow rate of $100 \mathrm{Nml} / \mathrm{min}\left(\mathrm{N}_{2} / \mathrm{O}_{2}=80 / 20\right)$ and a constant electrolyte flow rate of $6.4 \mathrm{ml} \mathrm{min}^{-1}$. The relative humidity of the gas mixture was set close to $100 \%$ and a temperature of $31.95^{\circ} \mathrm{C}$ and pressure of $1026.1 \mathrm{hPa}$ was measured in the GDE. 
The $O C V$ of $0.883 \mathrm{~V}$ is composed of the negative and positive Nernst potential of $0.350 \mathrm{~V}$ and $1.233 \mathrm{~V}$, respectively. Note that $E_{\text {pos }}^{0}$ and $E_{\text {neg }}^{0}$ yield values close to the respective standard potentials (fig. 2.3).

Current interrupt measurements of the tubular VARFB with a nano-structured GDE result in an $A S R_{C I}$ of $(7.67 \pm 0.02) \Omega \mathrm{cm}^{2}$ and are almost twice as high as the $A S R_{C I}$ of the tubular VARFB with a partially bonded GDE. The increased ASR might be caused by a reduced bonding area of the GDE and the membrane.

The residual overpotentials of the negative and positive electrode show comparably high values and restrict $i_{c h, \max }$ to $-9.5 \mathrm{~mA} / \mathrm{cm}^{2}$.

The substantial residual overpotentials of the negative electrode are due to a two electron reduction of $\mathrm{VO}^{2+}$ to $\mathrm{V}^{2+}$ with a subsequent oxidation to $\mathrm{V}^{3+}$ [99]. An ana$\log$ behavior of the negative electrode overpotentials was observed by Noack et al. during charging of a VPEM WE cell [99] with $V^{3.5+}$ electrolyte and can also be detected during electrolyte formation at the negative electrode of VRFB cells. Note that the $\eta_{\text {neg }}$ signal does not exhibit a high noise level and no gas formation was observed during the polarization curve measurement.

The severe residual overpotential of the $O E R$ might be caused by a poor bond of the GDE and membrane (diminished three phase layer), as well as the low catalyst loading.
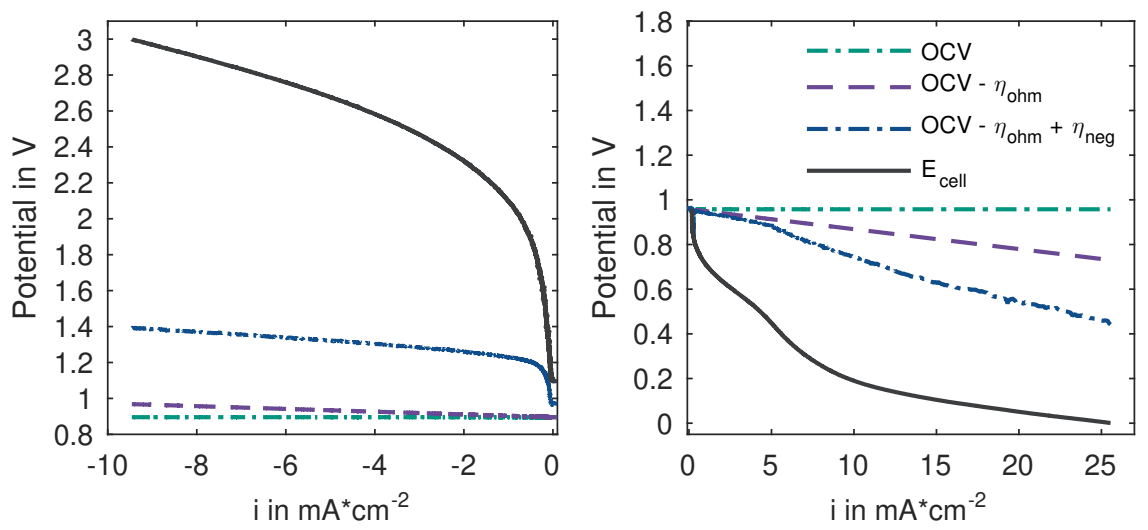

FIGURE 4.13: Polarization curves of tubular VARFB cell with partially bonded GDE and nano-structured GDE. Left: Charge sequence at $\mathrm{SoC}<0 \%\left(c_{V 4+}>>c_{V 3+}\right)$. Right: Discharge sequence at $\mathrm{SoC} \approx 20 \%$. $\mathrm{O}_{2}$ flow rate: $80 \mathrm{Nml} / \mathrm{min}, \mathrm{RH}=100 \%$.

In order to conduct discharge polarization curve measurements the tubular VARFB 
was charged at a constant current density of $-7.5 \mathrm{~mA} / \mathrm{cm}^{2}$ over a period of $4 \mathrm{~h}$ until a $S o C$ of $20 \%\left(E_{n e g}^{0}=-243.8 \mathrm{mV}\right.$ vs. $\left.S H E\right)$ was achieved.

The discharge polarization curve of the tubular $V A R F B$ is shown in the right plot of figure 4.13. The measurement was performed at a $\mathrm{O}_{2}$ flow rate of $80 \mathrm{Nml} / \mathrm{min}, G D E$ temperature of $29.5^{\circ} \mathrm{C}$, relative humidity close to $100 \%$ and a pressure of $1023.6 \mathrm{hPa}$. The vanadium electrolyte flow rate was held constant at $6.4 \mathrm{ml} \mathrm{min}{ }^{-1}$ and a scan rate

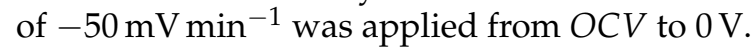

Current interrupt measurements of the tubular VARFB cell revealed an increased $A S R_{C I}$ of $(8.8 \pm 0.3) \Omega \mathrm{cm}^{2}$ relative to the $A S R_{C I}$ at charging. The rise of the cell resistance is assumed to originate from a delamination of the partially bonded GDE during the charge sequence.

Due to the low $O C V$ of $0.958 \mathrm{~V}$ and the severe overpotentials of the $O R R$ the maximum discharge current density of $25 \mathrm{~mA} / \mathrm{cm}^{2}$ is achieved at a cell potential close to $0 \mathrm{~V}$. The maximum power density is, hence very low and lies well below the power densities of the tubular VARFB cells with a catalyst loading of $2 \mathrm{mg} / \mathrm{cm}^{2}$ and published values of VARFB and Vanadium/Oxygen Fuel Cells (table 4.8).

TABLE 4.8: Comparison of $i_{d c h, \max }$ and $p_{A, \max }$ of tubular VARFB cell with nano-structured GDE surface with results of planar VARFBs [16, 51] and Vanadium-Oxygen Fuel Cells (VOFC) [95]. 1) Data from discharge cycle. ${ }^{2)}$ average power density of $d c h$-cycle.

\begin{tabular}{llcccc}
\hline Cell & $\begin{array}{l}\text { Cathode } \\
\text { catalyst }\end{array}$ & $\begin{array}{c}S o C \\
{[\%]}\end{array}$ & $\begin{array}{c}E_{\text {cell }}\left(i_{\max }\right) \\
{[\mathrm{V}]}\end{array}$ & $\begin{array}{c}i_{\text {dch,max }} \\
{\left[\mathrm{mA} \mathrm{cm}^{-2}\right]}\end{array}$ & $\begin{array}{c}p_{A, \max }\left(E_{\text {cell }}\right) \\
{\left[\mathrm{mW} / \mathrm{cm}^{2}\right]}\end{array}$ \\
\hline tub. VARFB & mono layer $P t / \mathrm{IrO} \mathrm{C}_{2}$ & 20 & 0.01 & 25 & $2.3(0.41 \mathrm{~V})$ \\
1) planar VARFB [51] & mono layer $P t / \mathrm{Ir}$ & - & $0.8-0.4$ & 2.4 & $2.6(1.1 \mathrm{~V})$ \\
1) planar VARFB [16] & double-layer $\mathrm{Pt}, \mathrm{IrO}_{2}$ & $93-0$ & $0.9-0.5$ & 40 & $2) 33.8$ \\
VOFC [95] & CCM Pt & 100 & 0.22 & 59 & $23.0(0.56 \mathrm{~V})$ \\
\hline
\end{tabular}

\subsubsection{Cross-Over and OCV drop}

Evaluation of the performance characteristics of tubular VARFB cells revealed an unstable OCV. After charging and discharging sequences a difference of the opencircuit voltage $\left(\triangle O C V=O C V_{c h}-O C V_{d c h}\right)$ of approximately $330 \mathrm{mV}$ is observed for every tubular $V A R F B$ cell examined within this work. This $\triangle O C V$ accounts for $23.8 \%$ of the entire voltage losses $\left(\right.$ at $\left.\left|i_{\text {cell }}\right|=20 \mathrm{~mA} / \mathrm{cm}^{2}\right)$ of the tubular VARFB with 
a fully bonded GDE (figure 4.9).

OCV Drop: In figure 4.14 the $O C V, E_{\text {pos }}^{0}$ and $E_{\text {neg }}^{0}$ is shown over a period of $85 \mathrm{~min}$. The long-term $O C V$ measurement was done after charging of the tubular VARFB with a fully bonded GDE at a electrolyte flow rate of $6.4 \mathrm{ml} \mathrm{min}^{-1}$ and steady $\mathrm{O}_{2}$ flow of $80 \mathrm{Nml} / \mathrm{min}$.

The initial OCV of $1.43 \mathrm{~V}(t=3 \mathrm{~min})$ decreases at a constant rate of $-187.7 \mathrm{mV} \mathrm{h}^{-1}$

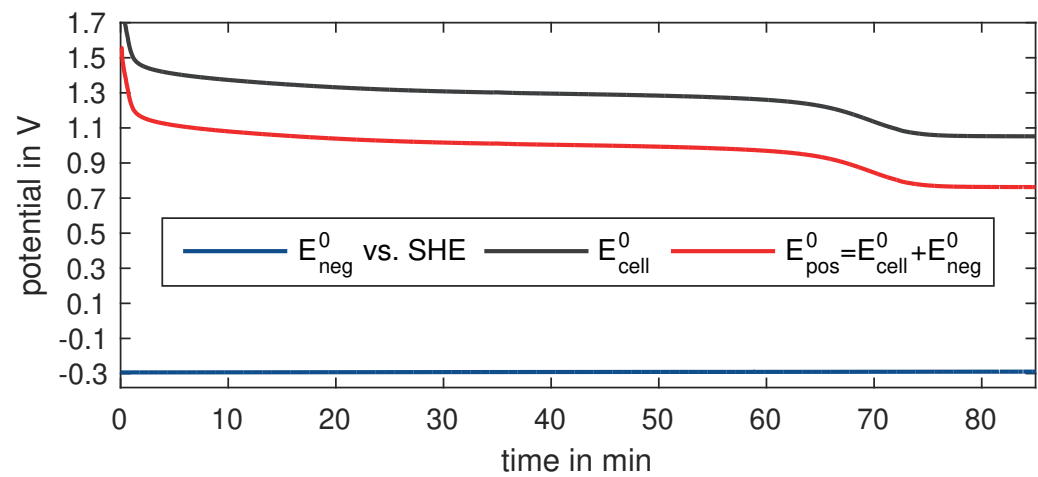

FIGURE 4.14: $O C V\left(E_{\text {cell }}^{0}\right), E_{\text {neg }}^{0}$ and $E_{\text {cell }}^{0}$ during long term OCV measurement of tubular VARFB FB.

over a period of $58 \mathrm{~min}$ to $1.25 \mathrm{~V}$. Over the subsequent $10 \mathrm{~min}$ the $O C V$ undergoes another drop of $-190 \mathrm{mV}$ until it stabilizes at $1.06 \mathrm{~V}$.

In contrast to the $O C V$, the Nernst potential of the negative electrode $\left(E_{\text {neg }}^{0}\right)$ remains at a comparably stable level over the entire measurement period and increases linearly by $3.18 \mathrm{mVh}^{-1}$ from it's initial value of $-293.7 \mathrm{mV}$ vs. SHE. This rise of $E_{\text {neg }}^{0}$ can be explained by oxygen permeation from the GDE into the negative half cell and/or a cross-over of $V^{2+}$ into the GDE, which will both result in a reduction of the $S o C$ and increase of $E_{\text {neg }}^{0}[13]$.

As the $E_{n e g}^{0}$ increase accounts only for a small portion of the open-circuit voltage drop, the $O C V$ instability is mainly caused by the positive electrode potential. Over the measurement period $E_{\text {pos }}^{0}$ undergoes a decrease, which is similar to the $O C V$ drop (figure 4.14). $E_{\text {pos }}^{0}$ declines from $1.135 \mathrm{~V}(t=3 \mathrm{~min}$ ) to $0.959 \mathrm{~V}$ ( $t=62 \mathrm{~min}$ ), before a drop to $0.764 \mathrm{~V}(t=70 \mathrm{~min})$ is observed. 
An $O C V$ drop of a VARFB cell with a comparable shape and similar values was first reported by Hosseiny et al. [51] and instable and reduced $O C V$ values were observed in Vanadium/Oxygen Fuel cells $[85,95,97]$, the planar VARFB of grosse Austing et al. [13, 16], as well as the Vanadium PEM Water Electrolysis cell of Noack et al. [99].

Mixed Potentials: In the field of PEM Fuel Cells reduced OCV values are a well known phenomenon and the measured values of the cathode at $O C V\left(E_{\mathrm{O}_{2} / \mathrm{H}_{2} \mathrm{O}}^{0^{\prime}}\right)$ are typically below the standard potential $\left(E_{\mathrm{O}_{2} / \mathrm{H}_{2} \mathrm{O}}\right)[164,167]$. The reduced potential at the cathode is caused by mixed potentials, which arise as several reactions occur simultaneously at the $P t$ surface:

The potential of the $\mathrm{O}_{2} / \mathrm{H}_{2} \mathrm{O}$ reaction $\left(E_{\mathrm{O}_{2} / \mathrm{H}_{2} \mathrm{O}}^{00}=1.229 \mathrm{~V}\right)$ :

$$
\mathrm{O}_{2}+4 \mathrm{H}^{+}+4 e^{-} \rightleftharpoons 2 \mathrm{H}_{2} \mathrm{O}
$$

and the potential of the $P t$ surface with $\mathrm{O}_{2}\left(E_{P t / P t O}^{00}=0.88 \mathrm{~V}\right.$ [167]):

$$
\mathrm{Pt}+\mathrm{H}_{2} \mathrm{O} \rightleftharpoons \mathrm{PtO}+2 \mathrm{H}^{+}+2 e^{-}
$$

combine to a standard mixed electrode potential $\left(E_{\text {mixed }}^{00}\right)$ of $1.06 \mathrm{~V}$ vs. SHE [167]. This mixed potential is further reduced to values from $0.9 \mathrm{~V}$ to $1.0 \mathrm{~V}$ vs. SHE by impurities, which are introduced by the Nafion (or fumion) layer [167].

Analog reactions and impurities are held responsible for the reduced potential in the positive electrode of the VARFB. However, these mixed potentials do not explain the entire $\triangle O C V$ and cross-over processes, which are specific to the VARFB, need to be considered.

In figure 4.15 the cross-over processes, electrode redox reactions and parasitic reactions in a tubular VARFB are illustrated. $V^{2+}$ and $V^{3+}$ ions permeate through the membrane from the negative half cell to the $G D E[13,66,95]$. Due to the negative potential of $V^{2+}$ solutions, $V^{2+}$ is instantaneously oxidized at the $P t$ surface of the $G D E$, while hydrogen simultaneously evolves by a reduction of protons ( $C$ in fig. 4.15) [95]:

$$
\begin{gathered}
2 V^{2+} \rightarrow V^{3+}+2 e^{-} \quad E_{V 2+/ 3+}^{00}=-0.26 V \text { vs.SHE } \\
2 H^{+}+2 e^{-} \rightarrow H_{2} \quad E_{H^{+} / H}^{00}=0.00 V \text { vs.SHE } \\
2 V^{2+}+2 H^{+} \rightarrow V^{3+}+H_{2} \quad E^{00}=0.26 V \text { vs.SHE }
\end{gathered}
$$

The $V^{3+}$ ions, which are then present in the GDE are further oxidized to $V O^{2+}(B)$ by $\mathrm{O}_{2}$ or/and at the GDE (depending on actual GDE potential) [13]. The appearance of $V^{3+}$ and $V O^{2+}$ ions in the GDE introduces another potential $\left(E_{V 3+}^{00} / V^{2+}=0.34 \mathrm{~V}\right.$ 
vs. $S H E)$, which adds to the mixed potentials and further reduces $E_{\text {pos }}^{0}$.

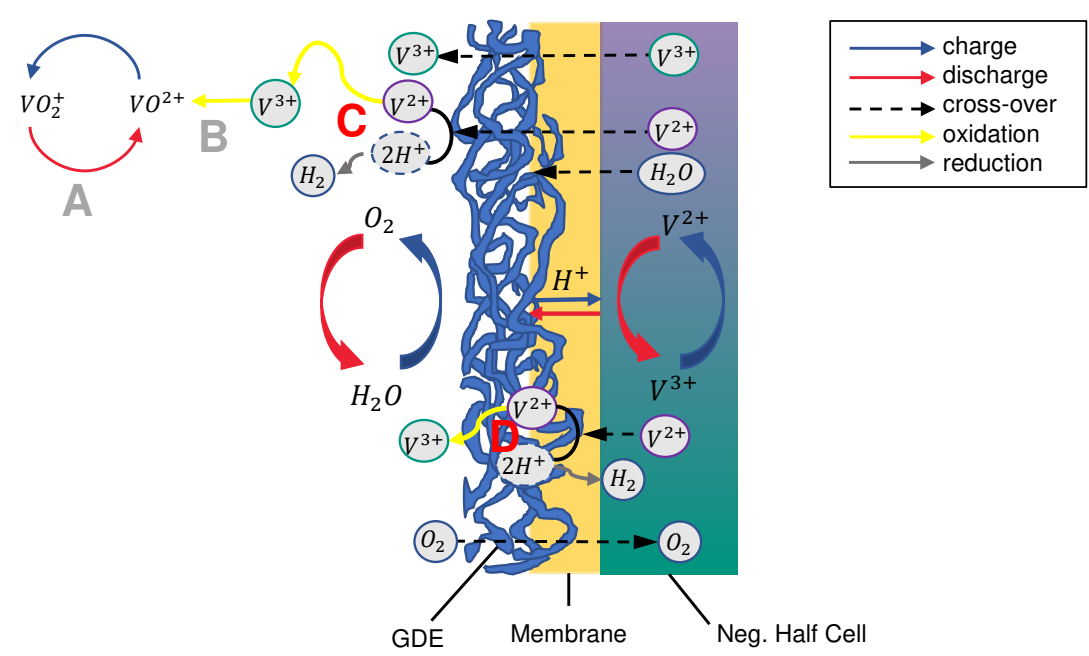

FIGURE 4.15: Schematic of redox reactions and cross-over in tubular VARFB cell.

Current Peaks: In the $\triangle O C V$ section of the polarization curves a peak occurs during charging and discharging, respectively (dotted in fig. 4.9). These peaks were observed during all polarization curve measurements of tubular VARFB cells. At the left of figure 4.16 the current density $\left(i_{\text {cell }}\right)$ of a polarization curve measurement is plotted over the cell potential. The potential of the positive electrode $\left(E_{\text {pos }}\left(i_{\text {cell }}\right)\right)$ is estimated from the measured $E_{n e g}\left(i_{\text {cell }}\right)$ (vs. SHE) and the $i_{\text {cell }} * A S R$-free cell potential (right in fig. 4.16). The peaks exhibit an anodic and a cathodic potential peak $\left(E_{p, i}\right)$ of $1.066 \mathrm{~V}$ and $0.924 \mathrm{~V}$, respectively. Due to the polarization curve measurement routine an anodic potential scan $\left(i_{\text {cell }} \leq 0 \mathrm{Ch}\right)$ is done before a negative potential scan $\left(i_{\text {cell }} \geq 0 \mathrm{Dch}\right)$ is performed. The applied scan rate of $100 \mathrm{mV} \mathrm{min}^{-1}$ is substantially lower than scan rates, which are typically employed in Cyclic Voltammetry (CV) measurements. However, the $i_{c e l l} / E_{\text {pos }}$-correlation exhibits a similar progression at comparable potentials as $C V$ data of the $V \mathrm{O}^{2+} / V \mathrm{O}_{2}^{+}$redox couple [21, 100, 106]. As the cell is charged $\mathrm{VO}^{2+}\left(\mathrm{V}^{4+}\right)$ might be oxidized to $\mathrm{VO}_{2}^{+}\left(\mathrm{V}^{5+}\right)$. After charging solely $V \mathrm{O}_{2}^{+}$would then be present in the GDE. Subsequent discharging might lead to a reduction to $\mathrm{VO}^{2+}(A)$. 
For the characterization of tubular VARFB cells multiple polarization curves were recorded over a period of $10 \mathrm{~h}$ to $14 \mathrm{~h}$. The amount of charge, which was transferred during the peak showed to increase with the duration of the experiments. This increase of the charge corresponds to an increase of the amount of vanadium ions, which diffused into the GDE over time.

grosse Austing et al. [16] did not perform polarization curve measurements of their $V A R F B$ cell but observed a similar effect during charge/discharge cycling. After the first charge/discharge cycle a reduced cell potential was detected at the beginning of the $2^{\text {nd }}$ and $3^{\text {rd }}$ charge sequence. Prior to the $4^{\text {th }} \mathrm{ch} / \mathrm{dch}$ cycle the electrolyte in the positive half cell $\left(2 \mathrm{M} \mathrm{H}_{2} \mathrm{SO}_{4}\right)$ and the vanadium electrolyte were replaced. The cell potential at the beginning of the $4^{\text {th }}$ charge sequence did not exhibit reduced values. It was assumed [16] that the reduced cell potentials were due to an oxidation of $\mathrm{VO}^{2+}$ in the positive half cell and replacement of the electrolyte led to a removal of $\mathrm{VO}^{2+}$ ions.

The current peaks observed during polarization curve measurements of the tubular $V A R F B$ cells are, thus, in accordance with the observations of grosse Austing et al. and can be attributed to an oxidation and reduction of $\mathrm{VO}^{2+}$ and $\mathrm{VO}_{2}^{+}$, respectively.
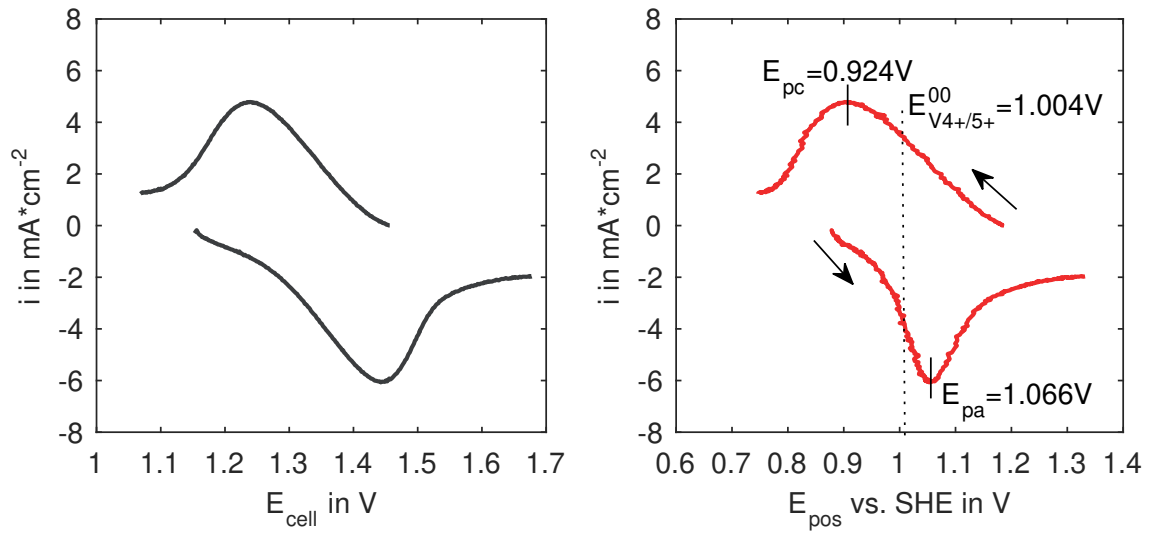

FIGURE 4.16: Left: Current over cell potential of doted polarization curve section (fig. 4.9). Right: Current over Air electrode potential.

Gas Evolution: Characterization of the VARFB cells revealed a gas evolution in the negative half cell (section 4.2.1), which is assumed to lead to a high noise level of the $E_{n e g}$ signal and an increased overpotential at the negative electrode. 
The gas evolution was independent from the applied cell potential and intensified with the measurement time. Furthermore, an increased gas evolution was detected for tubular VARFB cells with a fully bonded GDE. During the charge sequence of a tubular VARFB cell with a nano-structured GDE and a vanadium electrolyte at a SoC $<0 \%\left(c_{V 3+}>>c_{V 4+}\right)$ no gas evolution was observed in the negative half cell (left in fig. 4.13). As the SoC increased an onset of the gas evolution was observed, which intensified with a rising SoC.

The fabrication of tubular $M E A s$ by heat bonding results in a penetration of the $G D E$ substrate into the membrane (see $S E M$ image in fig. 4.5). In the schematic of the VARFB cross-over processes (fig. 4.15) the penetration of the GDE into the membrane is illustrated.

As $V^{2+}$ ions permeate through the membrane, they get in contact with the Pt catalyst on the GDE. At the $P t$ surface $V^{2+}$ is instantaneously oxidized and protons are reduced to $\mathrm{H}_{2}$ (see above). If the $V^{2+}$ ions get in contact with GDE in the positive half cell $(C)$, product $\mathrm{H}_{2}$ gas escapes through the positive half cell. If the GDE is, however, penetrated deep into the membrane and is only separated from the negative half cell by a comparably thin membrane layer $(D), \mathrm{H}_{2}$ gas is expected to enter the negative half cell and ascend in bubbles.

The gas evolution in the negative half cell is, thus, assumed to be caused by a crossover of $V^{2+}$ ions and penetration of the GDE into the membrane. The observed increase of the gas evolution intensity for fully bonded GDEs is a result of the high penetration depth of the GDE, accordingly. The delayed onset of the gas evolution after the initialization of the experiments can be assigned to the time dependent $V^{2+}$ cross-over process.

The absence of the gas evolution during charging of the tubular VARFB at a SoC $<0 \%$ is due to the fact, that no $V^{2+}$ ions were present in the electrolyte solution.

Skyllas-Kazacos and Noack proposed [95], that $\mathrm{H}_{2}$ evolution at the GDE surface might be responsible for a delamination of the GDE from the membrane.

Permeation of gaseous $\mathrm{O}_{2}$ from the positive half cell into the negative half cell [13, 51] might also contribute to the formation of gas bubbles in the negative half cell and lead to increased overpotentenials and self-discharge of the battery (oxidation of $V^{2+}$ ).

Gas evolution in the negative half cell might be reduced by a minimization of the $V^{2+}$ cross-over rate and/or an increase of the effective membrane thickness. However, $\mathrm{H}_{2}$ gas evolution is considered as a major drawback for the development of VARFB cells with a mono-layered GDE with $\mathrm{Pt} / \mathrm{IrO}_{2}$ catalysts and requires further research efforts on the minimization of the vanadium cross-over through the membrane and the optimization of the $M E A$ fabrication. 


\subsubsection{Electrode Overpotentials}

For all tubular $V A R F B$ cell characterized within this work the residual overpotentials accounted for the major source of voltage losses. At a current density of $20 \mathrm{~mA} / \mathrm{cm}^{2}$ $38.4 \%$ of the total voltage losses of the tubular VARFB with a fully bonded GDE were caused by the residual overpotentials of the positive electrode $\left(\eta_{p o s}\right)$. The residual overpotentials of the negative electrode $\left(\eta_{\text {neg }}\right)$ made up $28.4 \%$ of the losses.

In figure $4.17 \eta_{\text {pos }}$ and $\eta_{\text {neg }}$ of a tubular VARFB cell with a fully bonded and partially bonded GDE are displayed. Overpotential data are obtained from the polarization curve measurements, which are shown in figure 4.9 and 4.11 .

Negative Electrode Overpotentials are measured with the potential measurement setup introduced in section 2.2.3. In contrast to the overpotential measurements of tubular VRFB cells, negative electrode potentials $\left(E_{n e g}\left(i_{\text {cell }}\right)\right)$ are measured between the $H g E$ and negative electrode of the tubular VARFB cells. $\eta_{n e g}$ is then estimated from the Nernst Potential of the negative electrode $\left(E_{\text {neg }}^{0}\right)$ and $E_{\text {neg }}\left(i_{\text {cell }}\right)$ $\left(\eta_{\text {neg }}=E_{\text {neg }}\left(i_{\text {cell }}\right)-E_{\text {neg }}^{0}\right.$.

The negative overpotentials $\left(\eta_{n e g}\right)$ in figure 4.17 do all exhibit a high noise level, which is caused by the ascension of gas bubbles in the negative half cell. Gas bubbles are assumed to originate from $\mathrm{H}_{2}$ gas, which evolves at the Pt surface of the $G D E$ in the membrane and permeates into the negative half cell (see section above). Although an identical electrode material, comparable electrode geometry and analog electrolyte composition is employed in tubular VRFB and VARFB cells, the magnitude of $\eta_{\text {neg }}$ is substantially higher than $\eta_{\text {neg }}$ values of tubular VRFB cells. At $20 \mathrm{~mA} / \mathrm{cm}^{2}$ a $\eta_{\text {neg }}$ of the $F B-45-V R F B$ of $18.6 \mathrm{mV}$ is measured (NegIn in fig. 3.30), while the negative electrode overpotential of the tubular VARFB with a partially bonded GDE reaches a value of $141 \mathrm{mV}$ at an identical $i_{\text {cell }}$.

The increased negative overpotentials are assumed to be due to the gas bubbles in the negative electrode, which will reduce the active electrode surface area. The extensive negative overpotentials also limit the maximum current density during charging as the negative electrode overpotential $\left(E_{n e g}\left(i_{\text {cell }}\right)\right)$ easily reaches a potential of $-0.456 \mathrm{~V}$ vs. SHE, which is critical in terms of the onset of the hydrogen evolution at graphite electrodes [153].

The difference of the negative overpotentials of the tubular VARFB with a partially bonded GDE and a fully bonded GDE stem from the different $S o C$ of $70 \%$ and $30 \%$, respectively. 


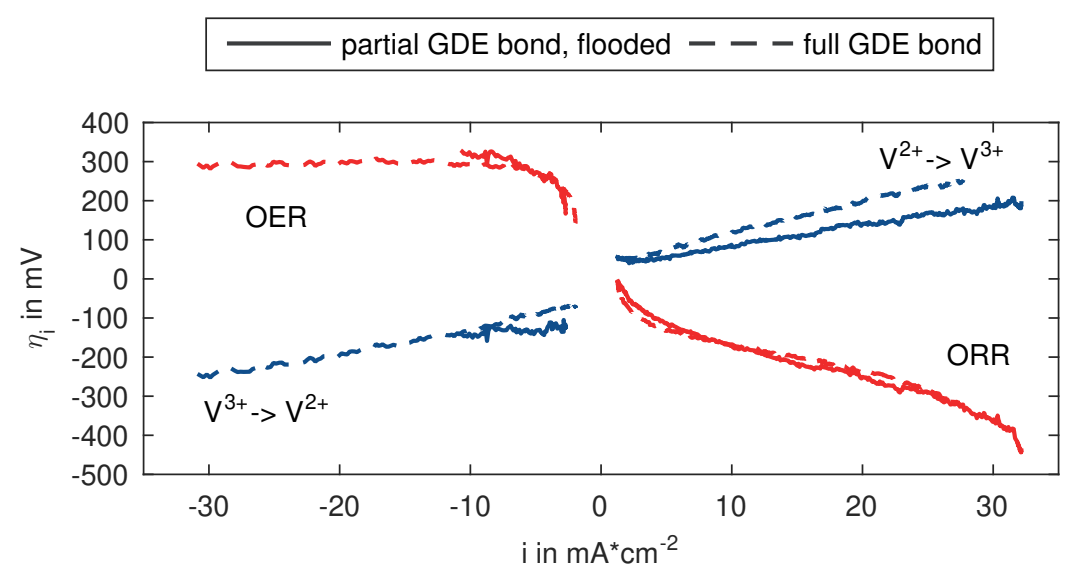

FIGURE 4.17: Negative (blue) and positive (red) electrode overpotentials of tubular VARFB with a fully bonded GDE (dashed) and a partially bonded GDE (line). Gas supply GDE: $80 \mathrm{Nml} / \mathrm{min}$ $\mathrm{O}_{2}, \mathrm{RH}=100 \%$. VARFB with partially bonded GDE flooded with $2 \mathrm{MH}_{2} \mathrm{SO}_{4}$ during OER.

Positive Electrode Overpotentials: Due to the small dimensions of the tubular cells reference electrodes could not be integrated in the positive half cell or the tubular membrane. The residual overpotentials of the positive electrode $\left(\eta_{\text {pos }}\right)$ are thus constructed from the $i_{\text {cell }} * A S R$-free cell potential and the negative electrode potential $\left(E_{n e g}(i)\right)$.

During charing the positive half cell of the tubular VARFB with a partially bonded GDE was flooded with $2 \mathrm{M} \mathrm{H}_{2} \mathrm{SO}_{4}$, while humidified ( $\mathrm{RH} \approx 100 \%$ ) oxygen was fed to the positive half cell of the VARFB with a fully bonded GDE. Flooding is expected to reduce $\eta_{\text {pos }}$ as the entire GDE surface is immersed in $\mathrm{H}_{2} \mathrm{SO}_{4}$. However, the positive overpotentials for the $O E R$ of both cells show similar values (fig. 4.17). It is, hence, concluded that the fully bonded $M E A$ features a good ionic connection of the active electrode surface and the membrane (3-phase layer). Furthermore, no mass transport limitation is observed during charging of the tubular VARFB with a fully bonded GDE. The water supply of the GDE is, however, ambiguous and is assumed to stem from both, water which permeates through the membrane (fig. 4.15) and water from the humidified gas supply.

The $\eta_{\text {pos }}$ of $296 \mathrm{mV}$ (at $i_{\text {cell }}=-20 \mathrm{~mA} / \mathrm{cm}^{2}$ ) represent the highest share of the entire overpotentials of the cell and account for $21.4 \%$ of the voltage losses.

A direct comparison of the OER overpotentials with the planar VARFB of grosse Austing et al. [16] can not be done, as solely the positive electrode potentials are 
reported and no $E_{\text {pos }}^{0}$ is mentioned. The polarization curve of the VPEM WE cell of Noack et al. can't also be employed as a reference as the cell suffered from a reduce $O C V$ due to vanadium cross-over and features reduced potentials $\left(E_{\text {pos }}(i), E_{\text {cell }}(i)\right)$ for current densities from $0 \mathrm{~mA} / \mathrm{cm}^{2}$ to $20 \mathrm{~mA} / \mathrm{cm}^{2}$, which are assumed to be due to the oxidation of vanadium cross-over ions in the positive half cell (see section 4.2.2). High OER overpotentials are also observed in the field of unitized regenerative PEM fuel cells and can be reduced by increased operation temperatures [51, 163].

During discharging the positive half cell of both cells was supplied with $\mathrm{O}_{2}$ and the overpotentials for the $O R R$ are comparable. For current densities from $0 \mathrm{~mA} / \mathrm{cm}^{2}$ to $26 \mathrm{~mA} / \mathrm{cm}^{2}$ ORR overpotentials lie below the values of the OER. At a current density of $20 \mathrm{~mA} / \mathrm{cm}^{2} \eta_{\text {pos }}(235 \mathrm{mV})$ contributes $17 \%$ to the total voltage losses of the tubular VARFB with a fully bonded GDE.

The residual overpotentials for the ORR (at $\left.i_{\text {cell }}=20 \mathrm{~mA} / \mathrm{cm}^{2}\right)$ of the tubular VARFB cells are less than half of the $\eta_{\text {pos }}=500 \mathrm{mV}$ of a $51 \mathrm{~cm}^{2}$ VOFC of Noack et al. [97].

\subsection{Conclusions}

Within this work tubular Vanadium/Air Redox Flow Cells with a mono-layered bifunctional GDE were successfully fabricated and characterized for the first time. The developed tubular cell design enables to fabricate entire half cells and cells with a co-extrusion process in the future.

The lab-scale fabrication of tubular Membrane Electrode Assemblies (MEAs) with a diameter of $5.0 \mathrm{~mm}$ and active electrode length of $100.0 \mathrm{~mm}$ was done with specially designed tools and an elaborate heat bonding routine.

Tubular MEAs with partially bonded and fully bonded GDEs with two different $\mathrm{Pt} / \mathrm{IrO}_{2}$ catalyst loadings and coating methods where fabricated, integrated into tubular VARFB cells and characterized in a specially developed test rig by polarization curve, EIS and long-term OCV measurements.

\subsubsection{Performance Characteristics and Limitations}

Polarization curve measurements of tubular VARFB cells with partially bonded ( $P B)$ and fully bonded $(F B) G D E s$ were conducted to characterize the cell performance. GDEs were coated with bifunctional $\mathrm{Pt} / \mathrm{IrO} \mathrm{O}_{2}$ catalysts by the DWI Leibniz Institute for Interactive Materials Aachen and the working group of J. Bachmann at the FriedrichAlexander University Erlangen (FAU). At the DWI $2.0 \mathrm{mg} / \mathrm{cm}^{2}$ of $\mathrm{Pt} / \mathrm{IrO}_{2}(70 / 30)$ was applied by thermal decomposition, while at the FAU the GDE surface was first treated with an anodic oxidation process to create a nano-structured surface and then 
coated by $A L D$ with $P t(1 \mathrm{~nm})$ and $\mathrm{IrO}_{2}(2 \mathrm{~nm})$ layers.

\section{Maximum Current and Power Densities}

Polarization curve measurements of the tubular VARFB with a partially and a fully bonded GDE $\left(2.0 \mathrm{mg} / \mathrm{cm}^{2}\right.$ catalyst loading $)$ resulted in maximum discharge current densities of $32 \mathrm{~mA} \mathrm{~cm}^{-2}$ and $28 \mathrm{~mA} \mathrm{~cm}^{-2}$, respectively. For the cell with a partially bonded GDE a maximum membrane surface specific power density $\left(p_{A, \max }\right)$ of $15.4 \mathrm{~mW} / \mathrm{cm}^{2}$ was achieved at a cell potential of $0.56 \mathrm{~V}$. The tubular VARFB cell with a fully bonded GDE allowed for a slightly lower $p_{A, \max }$ of $13.2 \mathrm{~mW} / \mathrm{cm}^{2}$.

The tubular VARFB cell with a partially bonded GDE and nano-structured electrode surface exhibited a $i_{d c h, \max }$ of $25 \mathrm{mAcm}^{-2}$, but suffered from low cell potentials, which resulted in a poor power density (see table 4.9).

The achieved $i_{d c h, \max }$ and $p_{A, \max }$ of the tubular VARFB cells with a catalyst loading of $2.0 \mathrm{mg} / \mathrm{cm}^{2}$ outreached the reported current and power densities of a planar VARFB cell of Hosseiny et al. [51] by a factor of 10. In contrast to the VARFB cells of this work, different mono-layered GDE electrodes were employed in the cell of Hosseiny et al. for charging and discharging.

The planar VARFB cell with a unitized double-layered electrode of grosse Austing et al. marks today's benchmark in terms of the performance characteristic and the average discharge power density of $33.8 \mathrm{~mW} / \mathrm{cm}^{2}$ is twice as high as $p_{A, \max }$ of the tubular VARFB cells.

TABLE 4.9: $i_{d c h, \max }$ and $p_{A, \max }$ of tubular VARFB cells with partially bonded $P B$ and fully bonded $F B G D E s$, as well as nano-structured GDE surface (nano). Reference data of planar VARFBs $[16,51]$ and Vanadium-Oxygen Fuel Cells (VOFC) [95]. 1) Data from discharge cycle. ${ }^{2)}$ average power density of $d c h$-cycle.

\begin{tabular}{|c|c|c|c|c|c|}
\hline Cell & $\begin{array}{l}\text { Cathode } \\
\text { catalyst }\end{array}$ & $\begin{array}{l}\text { SoC } \\
{[\%]}\end{array}$ & $\begin{array}{c}E_{\text {cell }}\left(i_{\text {max }}\right) \\
{[\mathrm{V}]}\end{array}$ & $\begin{array}{c}i_{d c h, \max } \\
{\left[\mathrm{mA} \mathrm{cm}^{-2}\right]}\end{array}$ & $\begin{array}{l}p_{A, \max }\left(E_{\text {cell }}\right) \\
{\left[\mathrm{mW} / \mathrm{cm}^{2}\right]}\end{array}$ \\
\hline tub. VARFB $(F B)$ & mono layer $\mathrm{Pt} / \mathrm{IrO}_{2}$ & 30 & 0.46 & 28 & $13.2(0.54 \mathrm{~V})$ \\
\hline tub. VARFB (PB) & mono layer $\mathrm{Pt} / \mathrm{IrO}_{2}$ & 70 & 0.40 & 32 & $15.4(0.56 \mathrm{~V})$ \\
\hline tub. VARFB (nano) & mono layer $\mathrm{Pt} / \mathrm{IrO}_{2}$ & 20 & 0.01 & 25 & $2.3(0.41 \mathrm{~V})$ \\
\hline 1) planar VARFB [51] & mono layer $P t / I r$ & - & $0.8-0.4$ & 2.4 & $2.6(1.1 \mathrm{~V})$ \\
\hline 1) planar VARFB [16] & double-layer $\mathrm{Pt}, \mathrm{IrO}_{2}$ & $93-0$ & $0.9-0.5$ & 40 & 2) 33.8 \\
\hline $280 \mathrm{~cm}^{2}$ VOFC [95] & CCM Pt & 100 & 0.22 & 59 & $23.0(0.56 \mathrm{~V})$ \\
\hline VOFC [85] & ELAT GDE Pt & 100 & 0.45 & 41 & $18.3(0.45 \mathrm{~V})$ \\
\hline
\end{tabular}


Planar Vanadium/Oxygen Fuel Cells (VOFCs) were developed and investigated by C. Menictas and M. Skyllas-Kazacos [85] and at the Fraunhofer Institute for Chemical Technology, Germany [95, 97, 150]. The VOFC of Noack et al. [95] employed a double membrane cell design and allowed for a $p_{A, \max }$ of $23.0 \mathrm{~mW} / \mathrm{cm}^{2}$ and a two times higher $i_{d c h, \text { max }}=59 \mathrm{~mA} \mathrm{~cm}^{-2}$ than the tubular VARFBs (table 4.9).

The reported current density of $41 \mathrm{~mA} \mathrm{~cm}^{-2}$ of the planar VOFC of Menictas and Skyllas-Kazacos [85] also exceeds $i_{d c h, \text { max }}$ of this work, but the maximum power density of the VOFC with a Pt coated $\left(0.4 \mathrm{mg} / \mathrm{cm}^{2}\right) E L A T$ GDE is only slightly higher than $p_{A, \max }$ of the tubular VARFB with a catalyst loading of $2.0 \mathrm{mg} / \mathrm{cm}^{2}$.

With the tubular VARFB FB a maximum charge current density of $-32 \mathrm{~mA} \mathrm{~cm}^{-2}$ was achieved at a cell potential of $2.1 \mathrm{~V}$. The current density during charging is significantly higher than the $i_{c h, \max }$ of the planar VARFB of Hosseiny et al. [51] but falls below the cycling current density of the planar VARFB of grosse Austing et al. [16] and $i_{c h, \max }$ of the Vanadium PEM Water Electrolysis cell of Noack et al. [99] (see table 4.10).

TABLE 4.10: Comparison of $i_{c h \text {, max }}$ of tubular VARFB cells with results of planar VARFBs $[16,51]$ and Vanadium-PEM Water Electolysis (V-PEMWE) cell [99]. ${ }^{1)}$ Data from charge cycle.

\begin{tabular}{llcccc}
\hline Cell & $\begin{array}{l}\text { Anode } \\
\text { catalyst }\end{array}$ & water supply & $\begin{array}{c}S o \mathrm{C} \\
{[\%]}\end{array}$ & $\begin{array}{c}E_{\text {cell }}\left(i_{\text {max }}\right) \\
{[\mathrm{V}]}\end{array}$ & $\begin{array}{c}i_{\text {max }} \\
{\left[\mathrm{mA} \mathrm{cm}^{-2}\right]}\end{array}$ \\
\hline tub. VARFB $(F B)$ & mono layer $\mathrm{Pt} / \mathrm{IrO}_{2}$ & $\mathrm{H}_{2} \mathrm{O}_{g}$ & 30 & 2.1 & -32 \\
tub. VARFB $(\mathrm{PB})$ & mono layer $\mathrm{Pt} / \mathrm{IrO}_{2}$ & $\mathrm{H}_{2} \mathrm{SO}_{4}$ & 70 & 2.0 & -11 \\
1) planar VARFB [51] & mono layer $\mathrm{Pt} / \mathrm{Ir}$ & $\mathrm{H}_{2} \mathrm{O}_{l}$ & - & $2.1-2.3$ & -2.4 \\
1) planar VARFB [16] & double-layer $\mathrm{Pt}, \mathrm{IrO}_{2}$ & $2 \mathrm{M} \mathrm{H}_{2} \mathrm{SO}_{4}$ & $0-93$ & $1.8-2.0$ & -40 \\
1) V-PEMWE [99] & CCM Ir & none & 50 & 2.4 & -43 \\
\hline
\end{tabular}

\section{Performance Limitations}

The performance of the tubular VARFB cells was strongly limited by substantial total overpotentials $\left(\eta_{i}\right.$ in table 4.11). The residual overpotentials at the positive electrode $(O R R, O E R)$ represent the major contribution to $\eta_{i}$.

The bond between the GDE and the membrane is essential for the formation of a 3-phase layer across the entire GDE surface. A durable and large-scale bond could only be realized by a deep penetration of the GDE into the membrane material. Partial bonding led to strong mass transfer limitations in the GDE with comparably low current densities and high residual overpotentials. Penetration of the GDE into the 
membrane is, however, assumed to lead to the formation of hydrogen (reduction of $\mathrm{H}^{+}$) at the $\mathrm{Pt}$ surface of the penetrated GDE as $V^{2+}$ ions are transferred through the membrane (cross-over) and might then be oxidized to $V^{3+}$ at the Pt surface of the $G D E$. Evolved hydrogen is assumed to permeate into the negative half cell where it reduces the electrochemically active surface of the negative electrode. As a result low negative electrode potentials $\left(E_{n e g}(i)\right)$ are obtained and the critical potential for the hydrogen evolution at graphite electrodes $(-0.456 \mathrm{~V}$ vs. SHE) appears at comparably low current densities $\left(i_{\text {cell }}=-19.25 \mathrm{~mA} \mathrm{~cm}^{-2}\right)$ and cell potentials $(2.0 \mathrm{~V})$ during charging.

In addition to the high residual overpotentials, the measured open-circuit voltage $(O C V)$ of the tubular VARFB cells showed to fall below the theoretical $E_{\text {cell }}^{00}$ of $1.49 \mathrm{~V}$ by more than $-0.330 \mathrm{~V}$. Reduced $O C V$ values could be attributed to unstable and reduced potentials in the positive half cell, which are mainly caused by mixed potentials of $E_{\mathrm{H} 2 \mathrm{O} / \mathrm{O} 2}^{00}, E_{\mathrm{Pt} / \mathrm{PtO}}^{00}$ (reaction of Pt surface with oxygen) and potentials of vanadium ions $E_{V 3+, V 4+, V 5+}^{00}$ which are present in the GDE (see cross-over).

The combination of the reduced $O C V$ and the high residual overpotentials results in low power densities and an actual energy density, which is well below the theoretical energy density of VARFBs.

TABLE 4.11: Comparison of overpotentials of tubular VARFB cells published results. ${ }^{1}$ )ELAT GDL with Nafion N112 membrane and $0.4 \mathrm{mg} \mathrm{cm}^{-2}$ Pt loading. ${ }^{2}$ )ELAT GDL with Nafion N117 membrane and $1.0 \mathrm{mg} \mathrm{cm}^{-2} \mathrm{Pt}$ loading.

\begin{tabular}{lcccc}
\hline Cell & $\begin{array}{c}i_{\text {cell }} \\
{\left[\mathrm{mA} \mathrm{cm}^{-2}\right]}\end{array}$ & $\begin{array}{c}\left|\eta_{\text {ohm }}\right| \\
{[\mathrm{mV}]}\end{array}$ & $\begin{array}{c}\left|\eta_{\text {res }}\right| \\
{[\mathrm{mV}]}\end{array}$ & $\begin{array}{c}\left|\eta_{i}\right| \\
{[\mathrm{mV}]}\end{array}$ \\
\hline tub. VARFB (FB) & 20 & 65 & 434 & 499 \\
& -20 & 65 & 492 & 557 \\
tub. VARFB (PB) & 20 & 86 & 392 & 478 \\
planar VOFC $\left.{ }^{1}\right)[85]$ & -10 & 43 & 464 & 507 \\
planar VOFC ${ }^{2}$ [85] & 21 & 231 & 486 & 717 \\
planar VOFC [95] & 20 & 396 & 204 & 600 \\
\hline
\end{tabular}

\subsubsection{Cross-Over}

Apart from the the high residual overpotentials for the $O R R$ and $O E R$, cross-over processes through the membrane are considered as the major drawback for the development of tubular VARFB cells with a mono layered GDE. Cross-over processes 
lead to a:

- self discharge of the VARFB,

- permanent loss of capacity,

- reduced open-circuit voltage,

- increased overpotential at the negative electrode and

- delamination of the GDE from the membrane.

Throughout all experiments a cross-over of $V^{2+}$ and $V^{3+}$ ions from the negative half cell through the cation exchange membrane was assumed to occur. Due to the potential at the GDE and the utilization of $P t$ catalysts $V^{2+}$ cross-over ions are instantaneously oxidized to $V^{3+}$ at the $P t$ surface and are further oxidized by $\mathrm{O}_{2}$ or at the GDE. The presence of $V^{3+} / V^{4+}$ in the GDE adds to the mixed potentials of the $G D E$ and results in volatile and reduced $E_{p o s}^{0}$ values.

Polarization curve measurements led to the assumption, that charging and discharging of the cell leads to an oxidation of $V^{4+}$ (to $V^{5+}$ ) and reduction to $V^{4+}$, respectively.

The cross-over of vanadium ions leads to a permanent loss of the battery's capacity, which is intolerable for long-term storage applications with long cycle lifes.

The required penetration of the GDE into the membrane is assumed to lead to an oxidation of $V^{2+}$ in the membrane and simultaneous reduction of $\mathrm{H}^{+}$to $\mathrm{H}_{2}$. The evolution of $\mathrm{H}_{2}$ in the membrane might lead to a permeation of $\mathrm{H}_{2}$ into the negative half cell and could cause a delamination of the GDE from the membrane. Ascension of the $\mathrm{H}_{2}$ gas bubbles through the porous graphite felt electrode causes increased negative electrode overpotentials and limit the maximum charge current density (see above).

Oxygen cross-over from the positive half cell into the negative half cell is known to occur in VARFBs $[13,51]$ and leads to a self discharge of the battery $\left(V^{2+} \rightarrow V^{3+}\right)$. The cross-over of water into the GDE [13] might, however, have a beneficial effect on the formation of the 3-phase layer and contribute to the $\mathrm{H}_{2} \mathrm{O}$ supply during charging.

\subsubsection{Voltage Losses}

The voltage losses (at $\left|i_{\text {cell }}\right|=20 \mathrm{~mA} \mathrm{~cm}^{-2}$ ) of a tubular VARFB with a fully bonded GDE and a catalyst loading of $2.0 \mathrm{mg} / \mathrm{cm}^{2}$ are illustrated in the Sankey Diagram in figure 4.18.

A voltage efficiency $(V E)$ of $31.4 \%$ was estimated from the the $E_{c e l l} / i$-characteristic at a current density of $20 \mathrm{~mA} \mathrm{~cm}^{-2}$. The $V E$ is significantly lower than the voltage 
efficiency (49.5\%) of the planar VARFB of grosse Austing et al. [16], which was estimated from charge/discharge cycling data at $\left|i_{\text {cell }}\right|=20 \mathrm{~mA} \mathrm{~cm}^{-2}$.

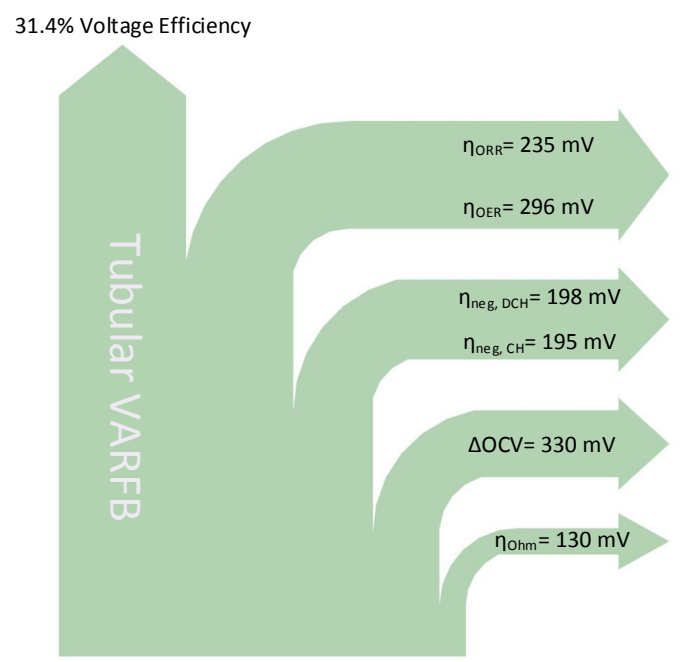

FIGURE 4.18: Voltage losses of the tub. VARFB with a fully bonded $G D E$ at $20 \mathrm{~mA} \mathrm{~cm}^{-2}$

The residual overpotentials at the positive electrode (ORR and $O E R)$ accounted for $38.4 \%$ of the voltage losses and represent the highest source of losses. Overpotentials of the OER ( $21.4 \%$ of losses) exceeded the overpotentials of the ORR $(17.0 \%)$. An exchange current density of $i_{0}=1.597 \times 10^{-4} \mathrm{~A} / \mathrm{cm}^{2}$ was estimated for the positive electrode by impedance data fitting. The $i_{0}$ of the tubular VARFB is comparable to exchange current densities $\left(i_{0}=1.22 \times 10^{-4} \mathrm{~A} / \mathrm{cm}^{2}\right)$ of the ORR of PEM FC cathodes [167]. OER and ORR reactions are known to be sluggish and can be enhanced by higher operating temperatures [16, 51, 163].

The observed overpotentials at the negative electrode ( $28.4 \%$ of losses) were $10 \times$ higher than $\eta_{\text {neg }}$ of tubular VRFB cells. Increased $\eta_{\text {neg }}$ of tubular VARFB cells are caused by ascending $\mathrm{H}_{2}$ bubbles in the negative half cell ( $\mathrm{H}_{2}$ evolution at GDE) and might only be reduced by a minimization or prevention of $V^{2+}$ cross-over.

The OCV drop accounted for $23.8 \%$ of the voltage losses and was caused by mixed potentials in the GDE. The decrease of $E_{\mathrm{H}_{2} \mathrm{O} / \mathrm{O}_{2}}^{00}$ by reactions of the Pt surface with $\mathrm{O}_{2}$ $\left(E_{P t / P t O}^{00}=0.88 \mathrm{~V}\right.$ vs. $\left.S H E[167]\right)$ can hardly be avoided but the potential reduction due to the presence of vanadium ions in the GDE could be precluded by a prevention of $V^{2+} / V^{3+}$ cross-over. 
The smallest source of voltage losses was introduced by the $A S R_{C I}=3.27 \Omega \mathrm{cm}^{2}$ of the tubular VARFB.

In all experiments a vanadium electrolyte solution with $1.6 \mathrm{M} \mathrm{V}^{2+} / \mathrm{V}^{3+}$ was employed and resulted in a theoretical energy density $\left(E_{\mathrm{H}_{2} \mathrm{O} / \mathrm{O}_{2}}^{00}\right)$ of $63.9 \mathrm{Whl}^{-1}$ (or $47.0 \mathrm{Wh} \mathrm{kg}^{-1}$ ). The reduced OCV of the tubular VARFB cell lowers the theoretical energy density to $48.5 \mathrm{Whl}^{-1}$ (or $35.6 \mathrm{~W} \mathrm{~h} \mathrm{~kg}^{-1}$ ), while the actual energy density at maximum discharge power density (see table 4.10 ) is further reduced by the voltage losses to $23.2 \mathrm{Wh} \mathrm{h}^{-1}$ (or $17.0 \mathrm{~W} \mathrm{~h} \mathrm{~kg}^{-1}$ ). Note, that the capacity losses due to crossover processes and parasitic side reactions have not been included in the estimation of the actual energy density.

Accordingly, the actual energy density of the tubular VARFB is only slightly higher than the actual energy density (at $p_{A, \max }$ ) of the tubular FB-45-VRFB $\left(12.9 \mathrm{~W} \mathrm{~h} \mathrm{~kg}^{-1}\right)$.

\subsubsection{Tubular MEA Design}

The developed tubular membrane electrode assembly (MEA) design is composed of a mono layer GDE with a bifunctional $\mathrm{Pt} / \mathrm{IrO}_{2}$ catalyst in the inner half cell.

A $M E A$ design with an inner GDE was chosen to achieve lower area specific cell resistances and facilitate a cost efficient $M E A$ fabrication by a co-extrusion process. Mono layered GDEs reduce the number of cell components and do thereby minimize the fabrication process complexity and costs for an extrusion based MEA production.

The lab scale fabrication of tubular MEAs from Ti based GDE structures and extruded membranes with a diameter of $5.0 \mathrm{~mm}$ was successfully achieved by a specially developed heat bonding tool and routine. However, the fabrication of a tubular MEA with a durable bond between the GDE and the membrane has turned out to be delicate and is essential for the realization of a broad expanse of the 3-phase layer. The hydration of the membrane during operation leads to a multi dimensional swelling of the membrane material and introduces tensions to the bond. Deep penetration depths of the GDE into the membrane material have shown to provide bonds with a sufficient strength and durability and are assumed to support the formation of a three phase layer as membrane material penetrates deep into the GDE structure.

The deep penetration of the GDE into the membrane does, however, lead to severe problems when $V^{2+}$ ions are transferred into or through the membrane (cross-over). The oxidation of $V^{2+}$ at the $P t$ surface of the GDE and simultaneous reduction of $\mathrm{H}^{+}$is assumed to result in an $\mathrm{H}_{2}$ gas evolution at the contact surface of the GDE and the membrane. For deep penetration depth the effective membrane thickness is 
comparably thin and $\mathrm{H}_{2}$ is likely permeating into the negative half cell. The crossover of $V^{2+}$ and presence of $P t$ in the membrane is, hence, considered as a decisive factor for the development of tubular VARFB cells with a mono layered GDE.

Noack et al. employed two membranes with a cavity between both half cells. The cavity was purged with $\mathrm{H}_{2} \mathrm{SO}_{4}$ [95] or $1.6 \mathrm{M} \mathrm{V}{ }^{3+}$ [97]. The double membrane design prevented $\mathrm{H}_{2}$ formation at the $\mathrm{Pt}$ surface but is considered as too complex for an integration in tubular VARFB cells and would result in high production, material and operation costs.

The planar VARFB of grosse Austing et al. did not suffer from a gas evolution in the negative half cell due to a double layered cathode design. As the layer adjacent to the membrane is only coated with $\mathrm{IrO}_{2}$ and is flooded with $\mathrm{H}_{2} \mathrm{SO}_{4}$ during operation, it does not need to be heat bonded to the membrane and the formation of $\mathrm{H}_{2}$ at the Pt surface will only (if at all) occur at the second layer.

The mono layered GDE was directly contacted with a contact pin at the end face of the tubular MEA and allowed for an $A S R_{C I}$ of $3.27 \Omega \mathrm{cm}^{2}$. The $A S R$ values of the tubular VARFB cells is substantially lower than $A S R$ values of planar VOFC cells, which are in a range from $9.8 \Omega \mathrm{cm}^{2}$ to $19.8 \Omega \mathrm{cm}^{2}[85,95,97]$.

The successful development of VARFB cells with mono layered GDEs is considered to depend on the development of ultra low cross-over membranes. 



\section{Chapter 5}

\section{Conclusions and Outlook}

\subsection{Conclusions}

\section{Tubular VRFB Cells}

The feasibility of a tubular cell design with a membrane diameter of $5.0 \mathrm{~mm}$ for $V R F B$ applications was demonstrated. The developed cell design facilitates a fabrication of the cell components (composite current collector and membrane) by an extrusion process and marks an important step towards the cost efficient extrusion of entire half cells and cells in the future.

Tubular cell designs with flow-through and flow-by electrode configurations were designed, fabricated and characterized with the elaborate test rig developed within this work.
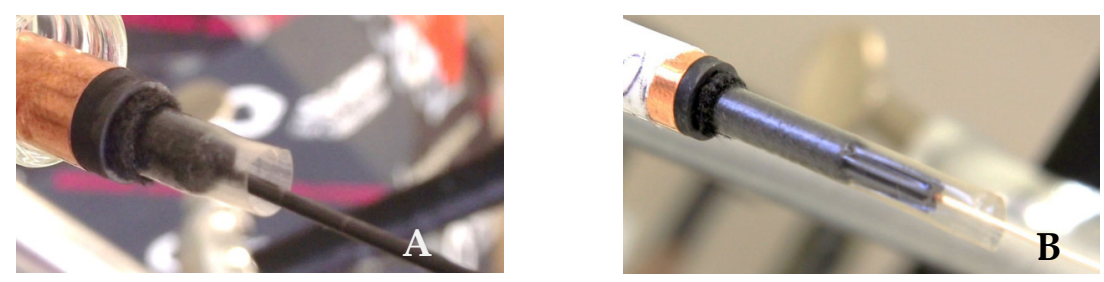

FIGURE 5.1: Picture of tubular flow-through $(A)$ and flow-by $(B)$ $V R F B$ test cell.

\section{Tubular Flow-Through VRFB cells (FT-VRFB)}

For the fabrication of tubular $V R F B$ cells with a membrane diameter of $5.0 \mathrm{~mm}$ composite current collectors (CCC) without flow fields were designed and extruded by 
Uniwell Rohrsysteme GmbH \& CO KG.

The contact resistance between the inner $C C C$ and the inner electrode has turned out to be the bottle neck of tubular FT-VRFB cell designs. The geometry and setup of the inner tubular half cell features a comparably low contact surface in-between the CCC and the flow-through electrode and limits the down-scaling of the tubular cell diameter.

Manual assembly of the the tubular FT-VRFB cell turned out to be cumbersome and the effective contact resistance in-between the inner CCC and electrode exceeded the estimated contact resistance significantly. Insufficient electrical contacting of the inner graphite felt electrode might have resulted in a partial utilization of the total electrode surface.

Comparison of residual overpotentials of flow-through electrodes and flow-by electrodes revealed a reduced utilization of the electrode surface of flow-through electrodes relative to flow-by electrodes. Channeling is supposed to cause an inhomogeneous flow distribution across the porous electrode material and a reduced electrochemical active surface.

Cell Performance: Due to the diminished electrical contact of the inner electrode a substantial area specific cell resistance $\left(A S R_{C I}\right)$ of $18.3 \Omega \mathrm{cm}^{2}$ and comparatively high residual overpotential ( $\left.\eta_{\text {res }}\right)$ of $223 \mathrm{mV}$ (at $i=20 \mathrm{~mA} \mathrm{~cm}^{-2}$ ) was determined and limited the volumetric power density and maximum current density to $46 \mathrm{Wl}^{-1}$ and $20.5 \mathrm{~mA} \mathrm{~cm}^{-2}$, respectively. The maximum current and power densities are, thus, substantially lower than $p_{v o l}$ and $i_{\max }$ of planar reference cells.

To achieve a reduced $A S R$ and increased current density $\left(i_{\max }\right)$, a up-scaling of the cell diameters or an increased ratio of the inner CCC diameter $\left(D_{C C C}\right)$ and membrane diameter $\left(D_{\mathrm{mem}}\right)\left(D_{\mathrm{CCC} i} / D_{\mathrm{mem}}\right)$ should be considered for tubular flow-through cell designs. This might, however, conflict with an intended enhancement of the volumetric power density and reduced material costs.

\section{Tubular Flow-By VRFB cells ( $F B-V R F B)$}

For the tubular flow-by cells composite current collectors (CCCs) with integrated flow fields were designed and fabricated by extrusion (Uniwell Rohrsysteme GmbH \& CO KG, Germany). Tubular cation exchange membranes were welded with a specially developed welding device or extruded by Uniwell Rohrsysteme GmbH \& CO $K G$, Germany from VM-fumasep ${ }^{\circledR}$ FFT membrane material of Fumatech BWT GmbH. 
Cell Performance: A polarization curve analysis of a tubular $F B-V R F B$ cell with an electrode compression ratio of $25 \%$ and a welded membrane (FB-25-VRFB) revealed a maximum discharge current density of $71 \mathrm{~mA} \mathrm{~cm}^{-2}$ at a $S o C$ of $60 \%$. A comparably high specific cell resistance $A S R_{C I}$ of $6.1 \Omega \mathrm{cm}^{2}$ resulted in high ohmic overpotentials and limited the performance of the cell.

Investigations of a tubular flow-by VRFB cell with an extruded membrane and electrode compression ratio of $45 \%(F B-45-V R F B)$ resulted in a reduced $A S R_{C I}$ of $3.2 \Omega \mathrm{cm}^{2}$ and increased maximum current density $\left(i_{\max }\right)$ of $89.7 \mathrm{~mA} \mathrm{~cm}^{-2}$.

The maximum volume specific power density $\left(p_{v o l, \max }=179.2 \mathrm{~kW} / \mathrm{m}^{3}\right)$ of the $F B$ $45-V R F B$ cell marked the highest power density of a tubular VRFB cell within this work.

While the membrane specific maximum current densities of both cells are substantially lower than published results of planar VRFB cells, the cell volume specific power densities are comparable with the $p_{v o l}$ of the "standard electrode" planar VRFB stack of $P N N L\left(140 \mathrm{~kW} / \mathrm{m}^{3}\right.$ to $\left.200 \mathrm{~kW} / \mathrm{m}^{3}\right)$ [107].

The feasibility to increase the volumetric power densities with a tubular cell design was demonstrated, although achieved current densities were comparably low.

The $A S R_{H F R}=0.5 \Omega \mathrm{cm}^{2}$ of Aaron et al. [2] is substantially lower than the $A S R_{C I}$ of the $F B-25-V R F B$ cell, but the residual overpotential $\eta_{\text {res }}=52 \mathrm{mV}$ of the tubular cell is in the range of the residual overpotential $(60 \mathrm{mV})$ of [2]. The residual overpotentials of the tubular $F B-25-V R F B$ cell are also lower than those of planar reference cells.

Due to an error in the assembly process of the FB-45-VRFB cell seven out of eight flow channels were blocked and led to a comparably high $\eta_{\text {res }}$ of $185 \mathrm{mV}$. The residual overpotentials are 3.5 times higher than $\eta_{\text {res }}$ of the flow-by cell without blocked flow channels and are the major source of losses.

Efficiencies: Charge/discharge cycling of the flow-by cells with a welded membrane ( $F B-25-V R F B)$ and an extruded membrane $(F B-45-V R F B)$ resulted in a Coulomb efficiency $(C E)$ of $95 \%$ and $96 \%$, respectively. The CEs of the welded and extruded tubular membrane cells are comparable to the Coulomb efficiencies of planar VRFB cells $[32,36,94,107]$, accordingly.

The system energy efficiencies $E E_{s y s}$ of the tubular $F B-V R F B$ cells with a welded membrane and an extruded membrane are with $55 \%$ and $57 \%$ well below published energy efficiencies of planar cells. While the major source of losses in $E E_{s y s}$ are caused by the high ASR for the welded membrane cell, the increased residual overpotentials of the cell with an extruded membrane accounts for $70 \%$ of the losses. If an $A S R_{C I}$ of $3.2 \Omega \mathrm{cm}^{2}$ and similar residual overpotential characteristic as determined for the welded membrane cell could be achieved in a tubular flow-by VRFB cell with the developed design, significantly enhanced cell performance and energy 

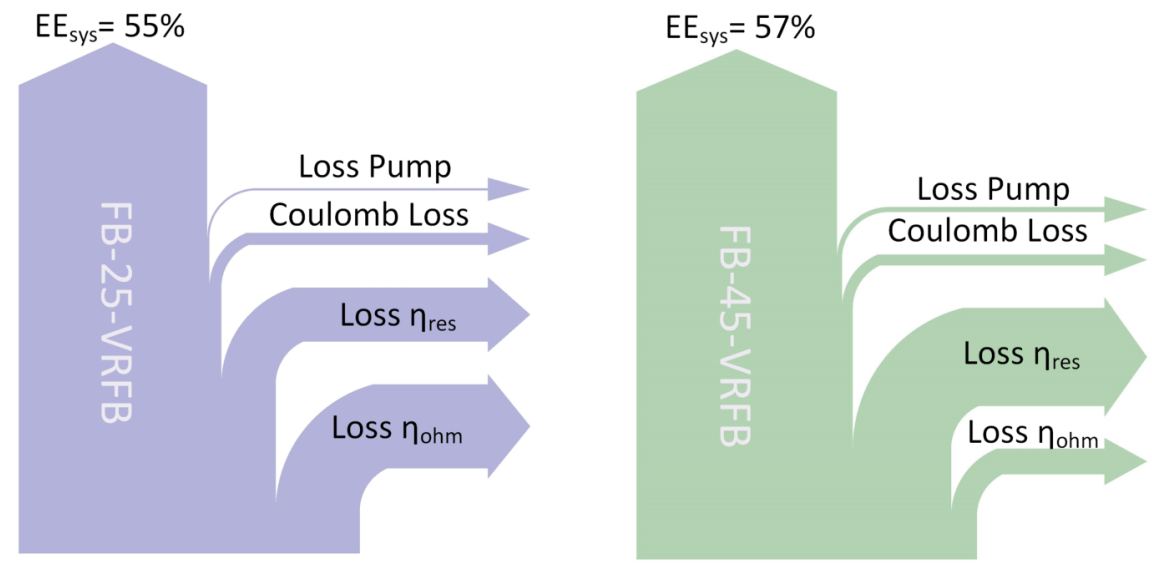

FIGURE 5.2: System energy efficiencies and Sankey diagrams of $F B$ VRFB cells.

efficiencies would be achieved.

Degradation of the capacity and cell performance during charge/discharge cycling was investigated and evaluated. The capacity fade observed during cycling is caused by: (i) a cross-over of vanadium ions through the membrane and (ii) a degradation of the electrodes. While cross-over can be adjusted by an implementation of rebalancing methods [105], electrode degradation leads to a permanent loss of performance. Electrode materials employed in the tubular flow-by and flow-through cells exhibited a degradation on a similar scale as the degradation of electrode material (GFA6 EA SGL 39AA and SGL 10AA of SGL Carbon) observed in planar VRFB cells [36, 94, 104]. 


\section{Tubular VARFB Cells}

Within this work tubular Vanadium/Air Redox Flow Cells with a mono-layered bifunctional GDE were successfully fabricated and characterized for the first time. The developed tubular cell design enables to fabricate entire half cells and cells with a co-extrusion process in the future.

The lab-scale fabrication of tubular membrane electrode assemblies (MEAs) with a diameter of $5.0 \mathrm{~mm}$ and active electrode length of $100.0 \mathrm{~mm}$ was done with specially designed tools and an elaborate heat bonding routine.
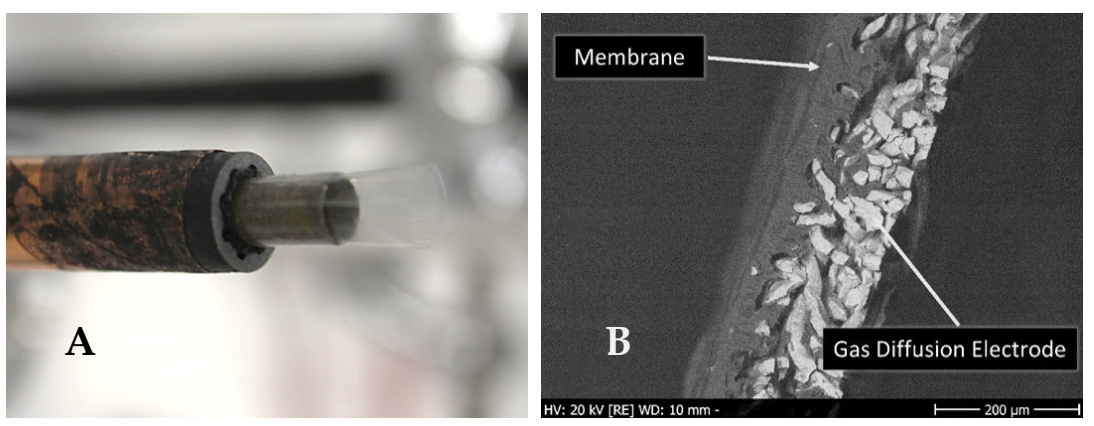

FIGURE 5.3: Picture of tubular VARFB cell $(A)$ and image of tubular $M E A(B)$.

Cell Performance: Polarization curve measurements of the tubular VARFB with a $\mathrm{Pt} / \mathrm{IrO}_{2}$ catalyst loading of $2.0 \mathrm{mg} / \mathrm{cm}^{2}$ resulted in a maximum discharge current density of $32 \mathrm{~mA} \mathrm{~cm}^{-2}$ and a maximum membrane surface specific power density $\left(p_{A, \text { max }}\right)$ of $15.4 \mathrm{~mW} / \mathrm{cm}^{2}$ was achieved at a cell potential of $0.56 \mathrm{~V}$.

The achieved $i_{d c h, \text { max }}$ and $p_{A, \text { max }}$ of the tubular VARFB cells with a catalyst loading of $2.0 \mathrm{mg} / \mathrm{cm}^{2}$ outreached the reported current and power densities of a planar VARFB cell of Hosseiny et al. [51] by a factor of 10. However, the reported discharge power density of the planar $V A R F B$ cell of grosse Austing et al. allows for an average discharge power density of $33.8 \mathrm{~mW} / \mathrm{cm}^{2}$ [16].

The developed tubular VARFB cell features a maximum charge current density of $-32 \mathrm{~mA} \mathrm{~cm}^{-2}$ at a cell potential of $2.1 \mathrm{~V}$. The current density during charging is significantly higher than the $i_{c h, \max }$ of the planar VARFB of Hosseiny et al. [51] but falls below the cycling current density of the planar VARFB of grosse Austing et al. [16]. The performance of the tubular VARFB cells was strongly limited by substantial total overpotentials $\left(\eta_{i}\right)$. The residual overpotentials at the positive electrode $(O R R$, 
$O E R$ ) represent the major contribution to $\eta_{i}$.

A durable and large-scale bond of the GDE and the membrane could only be realized by a deep penetration of the GDE into the membrane material. Partial bonding led to strong mass transfer limitations in the GDE with comparably low current densities and high residual overpotentials. Penetration of the GDE into the membrane is, however, assumed to lead to the formation of hydrogen (reduction of $\mathrm{H}^{+}$) at the $P t$ surface of the penetrated GDE as $V^{2+}$ ions are transferred through the membrane (cross-over) and might then oxidized to $V^{3+}$ at the Pt surface of the GDE. Evolved hydrogen is assumed to permeate into the negative half cell where it reduces the electrochemically active surface of the negative electrode. As a result low negative electrode potentials $\left(E_{\text {neg }}(i)\right)$ are obtained and the critical potential for the hydrogen evolution at graphite electrodes $(-0.456 \mathrm{~V}$ vs. SHE) appears at comparably low current densities $\left(i_{\text {cell }}=-19.25 \mathrm{~mA} \mathrm{~cm}^{-2}\right)$ and cell potentials $(2.0 \mathrm{~V})$ during charging. In addition to the high residual overpotentials, the measured open-circuit voltage $(\mathrm{OCV})$ of the tubular VARFB cells showed to fall below the theoretical $E_{c e l l}^{00}$ of $1.49 \mathrm{~V}$ by more than $-0.330 \mathrm{~V}$. Reduced $O C V$ values could be attributed to unstable and reduced potentials in the positive half cell, which are mainly caused by mixed potentials of $E_{\mathrm{H} 2 \mathrm{O} / \mathrm{O} 2}^{00} E_{\mathrm{Pt} / \mathrm{PtO}}^{00}$ (reaction of $P t$ surface with oxygen) and potentials of cross-over vanadium ions $E_{V 3+, V 4+, V 5+}^{00}$, which are present in the GDE.

Cross-Over processes through the membrane are considered as the major drawback for the development of tubular VARFB cells with a mono layered GDE. Crossover processes lead to a:

- self discharge of the VARFB,

- permanent loss of capacity,

- reduced open-circuit voltage,

- increased overpotential at the negative electrode and

- delamination of the GDE from the membrane.

Throughout all experiments a cross-over of $V^{2+}$ and $V^{3+}$ ions from the negative half cell through the cation exchange membrane was assumed to occur. Due to the potential at the GDE and the utilization of $P t$ catalysts $V^{2+}$ cross-over ions are instantaneously oxidized to $V^{3+}$ at the $P t$ surface and are further oxidized by $\mathrm{O}_{2}$ or at the GDE. The presence of $V^{3+} / V^{4+}$ in the GDE adds to the mixed potentials of the $G D E$ and results in volatile and reduced $E_{\text {pos }}^{0}$ values.

Polarization curve measurements led to the assumption, that charging and discharging of the cell leads to an oxidation of $V^{4+}$ (to $V^{5+}$ ) and reduction to $V^{4+}$, respectively. 
The cross-over of vanadium ions leads to a permanent loss of the battery's capacity, which is intolerable for long-term storage applications with long cycle lifes.

The required penetration of the GDE into the membrane is assumed to lead to an oxidation of $V^{2+}$ in the membrane and simultaneous reduction of $\mathrm{H}^{+}$to $\mathrm{H}_{2}$. The evolution of $\mathrm{H}_{2}$ in the membrane is assumed to lead to a permeation of $\mathrm{H}_{2}$ into the negative half cell and might cause a delamination of the GDE from the membrane. Ascension of the $\mathrm{H}_{2}$ gas bubbles through the porous graphite felt electrode causes increased negative electrode overpotentials and limits the maximum charge current density (see above).

Voltage Losses: The combination of the reduced $O C V$ and the high residual overpotentials results in low power densities and an actual energy density, which is well below the theoretical energy density of VARFBs.

A voltage efficiency $(V E)$ of $31.4 \%$ was estimated from the the $E_{c e l l} / i$-characteristic at a current density of $20 \mathrm{~mA} \mathrm{~cm}^{-2}$. The $V E$ is significantly lower than the voltage efficiency (49.5\%) of the planar VARFB of grosse Austing et al. [16], which was estimated from charge/discharge cycling data at $\left|i_{\text {cell }}\right|=20 \mathrm{~mA} \mathrm{~cm}^{-2}$.

The residual overpotentials at the positive electrode (ORR and $O E R)$ accounted for

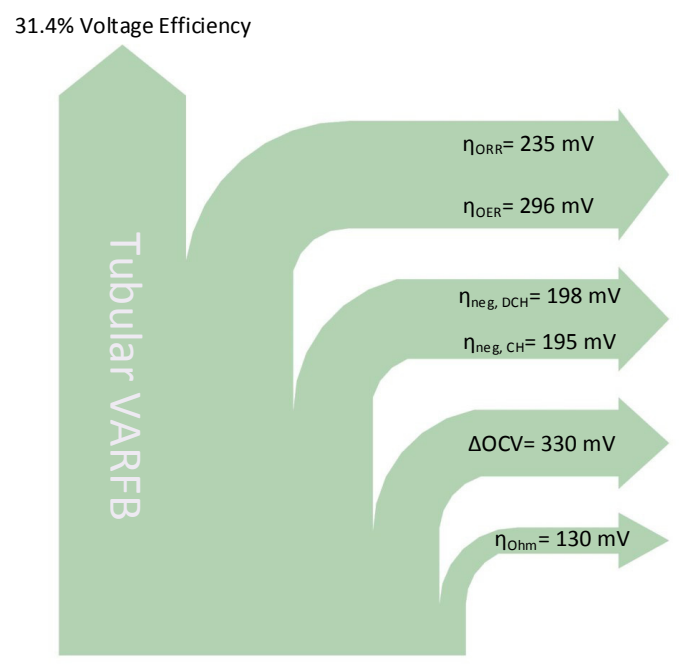

FIGURE 5.4: Voltage losses of the tub. VARFB at $20 \mathrm{~mA} \mathrm{~cm}^{-2}$

$38.4 \%$ of the voltage losses and represent the highest source of losses. Overpotentials of the OER ( $21.4 \%$ of losses) exceeded the overpotentials of the ORR $(17.0 \%)$. 
The observed overpotentials at the negative electrode ( $28.4 \%$ of losses) were 10 times higher than $\eta_{n e g}$ of tubular VRFB cells. Increased $\eta_{\text {neg }}$ of tubular VARFB cells are caused by ascending $\mathrm{H}_{2}$ bubbles in the negative half cell $\left(\mathrm{H}_{2}\right.$ evolution at GDE) and might only be reduced by a minimization or prevention of $V^{2+}$ cross-over.

The OCV drop accounted for $23.8 \%$ of the voltage losses and was caused by mixed potentials in the GDE. The decrease of $E_{\mathrm{H}_{2} \mathrm{O} / \mathrm{O}_{2}}^{00}$ by reactions of the Pt surface with $\mathrm{O}_{2}$ $\left(E_{P t / P t O}^{00}=0.88 \mathrm{~V}\right.$ vs. SHE [167]) can hardly be avoided but the potential reduction due to the presence of vanadium ions in the GDE could be precluded by a prevention of $V^{2+} / V^{3+}$ cross-over.

The smallest source of voltage losses was introduced by the $A S R_{C I}=3.27 \Omega \mathrm{cm}^{2}$ of the tubular VARFB.

Energy Density: In all experiments a vanadium electrolyte solution with $1.6 \mathrm{M}$ $V^{2+} / V^{3+}$ was employed and resulted in a theoretical energy density $\left(E_{\mathrm{H}_{2} \mathrm{O} / \mathrm{O}_{2}}^{00}\right)$ of $63.9 \mathrm{~W} \mathrm{hl}^{-1}$ (or $47.0 \mathrm{~W} \mathrm{~h} \mathrm{~kg}^{-1}$ ). The reduced OCV of the tubular VARFB cell lowers the theoretical energy density to $48.5 \mathrm{~W} \mathrm{hl}^{-1}$ (or $35.6 \mathrm{~W} \mathrm{~h} \mathrm{~kg}^{-1}$ ), while the actual energy density at maximum discharge power density is further reduced by the voltage losses to $23.2 \mathrm{Whl}^{-1}$ (or $17.0 \mathrm{~W} \mathrm{~h} \mathrm{~kg}^{-1}$ ). Note, that the capacity losses due to crossover processes and parasitic side reactions have not been included in the estimation of the actual energy density.

Accordingly, the actual energy density of the tubular VARFB is only slightly higher than the actual energy density (at $p_{A, \max }$ ) of the tubular $F B-45-V R F B\left(12.9 \mathrm{~W} \mathrm{~h} \mathrm{~kg}^{-1}\right)$.

\subsection{Outlook}

\section{Tubular VRFB Cells}

For a cost efficient production of tubular $V R F B$ cells entire cells need to be fabricated by an in-line extrusion process. Financial and development efforts into fabrication tools and processes have to be done to establish a reproducible cell manufacturing line. Stable production processes might then enable to maintain tight tolerances and permit to increase the cell length.

Within this work the area specific cell resistance (ASR) of tubular VRFB cells could be reduced to $3.2 \Omega \mathrm{cm}^{2}$. In order to obtain higher current densities and a system energy efficiency $\geq 80 \%$, a further reduction of the $A S R$ to values below $1.5 \Omega \mathrm{cm}^{2}$ has to be achieved. Measured ASRs outnumber the calculated cell resistivity and deviations are considered to stem from insufficient contacting. Development efforts 
should, therefore, focus on the reduction of the contact resistance.

The tubular VRFB cells ability for an utilization in a cost efficient electrical energy storage system should be demonstrated. To demonstrate the up-scaling from single cell level to stacks with $\approx 100$ cells, a prototype of a tubular VRFB stack will be developed and evaluated in the future.

Degradation of the graphite felt electrodes was detected after charge/discharge cycling of the cells. Degradation mechanisms are yet not very well understood and require further investigations.

Achieved current densities and comparably low residual overpotentials are in contradiction to the expected mass transfer characteristics in flow-by electrodes. An exclusive mass transfer by diffusion is doubtful but models of the flow velocity in flow-by electrode setups predict no mass transfer by forced convection in the porous electrode. Research efforts on the mass transfer in porous graphite felt electrodes is needed.

Redox Flow Batteries with other aqueous electrolytes than the vanadium electrolyte used in this work utilize similar half cell configurations, electrode materials and membranes. The developed tubular cell design could therefore also be used in RFBs with novel electrolytes in the future.

\section{Tubular VARFB Cells}

Cross-over of vanadium ions through the membrane is considered as a major drawback for the development of tubular VARFB cells with a mono-layered gas diffusion electrode.

Cross-over might be minimized by thicker membrane layers or research and development efforts on membranes with an ultra high selectivity for vanadium ions.

Measures to prevent cross-over of $V^{2+}$ by an additional membrane layer and cavity [95] are considered as too complex for tubular VARFB cells and might lead to a cost intensive fabrication and operation.

The developed tubular membrane electrode assembly could, however, be used in tubular PEM Electrolysis cells or Reversible PEM Fuel Cells with a tubular cell design. 



\section{Bibliography}

[1] BioLogic Application Note No. 27. Ohmic Drop. I - Effect on measurements. http:/ /www.bio-logic.net/en/application-notes-2/. Accessed on 20. Aug. 2018, 13:20 (UTC+1).

[2] D. Aaron et al. "Dramatic performance gains in vanadium redox flow batteries through modified cell architecture". In: J. Power Sources 206 (2012), pp. 450453. DOI: $10.1016 / j$. jpowsour. 2011.12.026.

[3] D. Aaron et al. "In Situ Kinetics Studies in All-Vanadium Redox Flow Batteries". In: ECS Electrochemistry Letters 2.3 (2013), A29-A31. DOI: 10 . 1149/2 . 001303 eel.

[4] D. Aaron et al. "Polarization curve analysis of all-vanadium redox flow batteries". In: J. Appl. Electrochem. 41 (2011), pp. 1175-1182. DOI: 10 . 1007/s10800011-0335-7.

[5] Ertan Agar et al. "Identification of performance limiting electrode using asymmetric cell configuration in vanadium redox flow batteries". In: Journal of Power Sources 225 (2013), pp. 89-94. DOI: 10.1016/j . jpowsour . 2012 .10 . 016.

[6] Ertan Agar et al. "Species transport mechanisms governing capacity loss in vanadium flow batteries: Comparing Nafion $(\mathbb{R}$ and sulfonated Radel membranes". In: Electrochimica Acta 98 (2013), pp. 66-74. DOI: 10.1016/j . electacta . 2013.03 .030 .

[7] International Energy Agency. Key world energy statistics 2018. Paris, France, Sept. 2018.

[8] Agora Energiewende. translated by author, last visited 10. December 2018, 2:10 pm (UTC +1:00). URL: www . agora-energiewende. de/service/agorameter/ chart/power_generation/.

[9] T. Alston et al. "A 1000-cell SOFC reactor for domestic cogeneration". In: J. Power Sources 71 (1998), pp. 271 -274. ISSN: 0378-7753. DOI: /10.1016/S03787753(97) 02756-0. 
[10] Søren Juhl Andreasen, Jakob Rabjerg Vang, and Søren Knudsen Kær. "High temperature PEM fuel cell performance characterisation with $\mathrm{CO}$ and $\mathrm{CO} 2$ using electrochemical impedance spectroscopy". In: International Journal of Hydrogen Energy 36.16 (2011), pp. 9815-9830. DOI: 10 . 1016 / j . ijhydene . 2011.04 .076$.

[11] L. F. Arenas, F. C. Walsh, and C. Ponce de León. "3D-Printing of Redox Flow Batteries for Energy Storage: A Rapid Prototype Laboratory Cell". In: ECS J. Solid State Sci. Technol. 4 (2015), P3080-P3085. DOI: 10.1149/2.0141504jss.

[12] Loïc Assaud et al. "Systematic increase of electrocatalytic turnover at nanoporous platinum surfaces prepared by atomic layer deposition". In: Journal of Materials Chemistry A 3.16 (2015), pp. 8450-8458. DOI: 10.1039/c5ta00205b.

[13] Jan grosse Austing et al. "Investigation of crossover processes in a unitized bidirectional vanadium/air redox flow battery". In: Journal of Power Sources 306 (2016), pp. 692-701. DOI: 10 .1016/j . jpowsour. 2015.12.052.

[14] Jan grosse Austing et al. "Layer-by-layer modification of Nafion membranes for increased life-time and efficiency of vanadium/air redox flow batteries". In: Journal of Membrane Science 510 (2016), pp. 259-269. DOI: 10 . 1016/ j . memsci.2016.03.005.

[15] Jan grosse Austing et al. "Performance of a Vanadium/Air Redox Flow Battery (VARFB) Comprising a Two-Layered Cathode". In: The International Flow Battery Forum. Swanbarton Limited, July 2014, pp. 10-11.

[16] Jan grosse Austing et al. "Study of an unitised bidirectional vanadium/air redox flow battery comprising a two-layered cathode". In: Journal of Power Sources 273 (2015), pp. 1163-1170. DOI: 10.1016/j . jpowsour.2014.09.177.

[17] Evgenij Barsoukov and J. Ross Macdonald, eds. Impedance Spectroscopy. John Wiley \& Sons, Inc., 2005. DOI: 10.1002/0471716243.

[18] R. Byron Bird, Warren E. Stewart, and Edwin N. Lightfoot. Transport Phenomena, Revised 2nd Edition. John Wiley \& Sons, Inc., 2006. ISBN: 9780470115398.

[19] Christian Blanc. "Modeling of a Vanadium Redox Flow Battery Electricity Storage System". PhD thesis. École Polytechnique Fédérale de Lausanne, Apr. 2009.

[20] O. Bohlen. Impedance-based Battery Monitoring. Aachener Beiträge des ISEA. Shaker, 2008. ISBN: 9783832276065.

[21] A. Bourke et al. "Electrode Kinetics of Vanadium Flow Batteries: Contrasting Responses of V(II)-V(III) and V(IV)-V(V) to Electrochemical Pretreatment of Carbon". In: Journal of The Electrochemical Society 163.1 (2015), A5097-A5105. DOI: $10.1149 / 2.0131601 \mathrm{jes}$. 
[22] P.C. Carman. "Fluid Flow Through Granular Beds". In: Trans. Instn Chem. Engrs 15 (1937), pp. 32-48.

[23] R. Carta et al. "Behaviour of a carbon felt flow by electrodes Part I: Mass transfer characteristics". In: Journal of Applied Electrochemistry 21.9 (1991), pp. 793798. DOI: $10.1007 /$ bf 01402816 .

[24] CellCube. last visited 28. January 2019, 07:35 pm (UTC+ 1:00). URL: www . cellcube.com/.

[25] Dongyang Chen et al. "Preparation and properties of sulfonated poly(fluorenyl ether ketone) membrane for vanadium redox flow battery application". In: $J$. Power Sources 195 (2010), pp. 2089 -2095. ISSN: 0378-7753. DOI: 10 . 1016 / j . jpowsour.2009.11.010.

[26] Hongning Chen, Guangtao Cong, and Yi-Chun Lu. "Recent progress in organic redox flow batteries: Active materials, electrolytes and membranes". In: Journal of Energy Chemistry 27.5 (2018), pp. 1304-1325. DOI: 10 . 1016 / j . jechem.2018.02.009.

[27] Qing Chen, Louise Eisenach, and Michael J. Aziz. "Cycling Analysis of a Quinone-Bromide Redox Flow Battery". In: Journal of The Electrochemical Society 163.1 (2016), A5057-A5063. DOI: 10.1149/2.0081601jes.

[28] Qing Chen et al. "A Quinone-Bromide Flow Battery with $1 \mathrm{~W} / \mathrm{cm} 2$ Power Density". In: Journal of The Electrochemical Society 163.1 (2016), A5010-A5013. DOI: $10.1149 / 2.0021601$ jes.

[29] Chanyong Choi et al. "A review of vanadium electrolytes for vanadium redox flow batteries". In: Renewable and Sustainable Energy Reviews 69 (2017), pp. 263-274. DOI: 10.1016/j.rser.2016.11.188.

[30] K.R. Cooper and M. Smith. "Electrical test methods for on-line fuel cell ohmic resistance measurement". In: Journal of Power Sources 160.2 (2006), pp. 10881095. DOI: $10.1016 / \mathrm{j}$. jpowsour .2006.02.086.

[31] S. Corcuera and Maria Skyllas-Kazacos. "State-of-charge monitoring and electrolyte balancing methods for the vanadium redox flow". In: European Chemical Bulletin 1(12) (2012), pp. 511-519. DOI: 10.17628/ecb.2012.1.511-519.

[32] Álvaro Cunha et al. "Vanadium redox flow batteries: a technology review". In: Int. J. Energy Res. 39 (2015), pp. 889-918. ISSN: 1099-114X. DOI: 10 . 1002 / er. 3260 .

[33] R. M. Darling and M. L. Perry. "The Influence of Electrode and Channel Configurations on Flow Battery Performance". In: Journal of the Electrochemical Society 161.9 (2014), A1381-A1387. DOI: 10.1149/2.0941409jes. 
[34] Oana David, Youri Gendel, and Matthias Wessling. “Tubular macro-porous titanium membranes". In: Journal of Membrane Science 461 (2014), pp. 139-145. DOI: $10.1016 / j$.memsci.2014.03.010.

[35] Deeya Energy. last visited 16. January 2019, 5:30 pm (UTC +1:00). URL: www . deeyaenergy.com/about/.

[36] Igor Derr et al. "Degradation of all-vanadium redox flow batteries (VRFB) investigated by electrochemical impedance and X-ray photoelectron spectroscopy: Part 2 electrochemical degradation". In: Journal of Power Sources 325 (2016), pp. 351-359. DOI: 10.1016/j . jpowsour. 2016.06.040.

[37] W.J. Dollard. "Solid oxide fuel cell developments at Westinghouse". In: J. Power Sources 37 (1992), pp. 133 -139. ISSN: 0378-7753. DOI: 10 . 1016/03787753 (92) 80070-R.

[38] EISENHUTH GMBH \& CO KG and TECH UNIVERSITAET CLAUSTHAL. "Rahmen mit integrierter Bipolarplatte fuer elektrochemischen Reaktor". German pat. DE102012024753 (A1). June 2014.

[39] EnerVault. last visited 16. January 2019, 06:05 pm (UTC+ 1:00). URL: www . enervault.com/about-us/.

[40] Ray R. Eshraghi et al. Microfibrous fuel cell assemblies comprising fiber-supported electrocatalyst layers, and methods of making same. US Patent US 2005/0181269 A1. U.S. pat. Research Triangle Park, NC 27709, US, 2005.

[41] Holger Fink, Jochen Friedl, and Ulrich Stimming. "Composition of the Electrode Determines Which Half-Cell's Rate Constant is Higher in a Vanadium Flow Battery". In: The Journal of Physical Chemistry C 120.29 (2016), pp. $15893-$ 15901. DOI: $10.1021 /$ acs.jpcc.5b12098.

[42] S. D. Fraser and V. Hacker. "An empirical fuel cell polarization curve fitting equation for small current densities and no-load operation". In: Journal of Applied Electrochemistry 38.4 (2007), pp. 451-456. DOI: 10 . 1007 / s10800 - 007 9458-2.

[43] Jochen Friedl and Ulrich Stimming. "Determining Electron Transfer Kinetics at Porous Electrodes". In: Electrochimica Acta 227 (2017), pp. 235-245. DOI: 10. 1016/j.electacta.2017.01.010.

[44] Tino Hagemann et al. "An aqueous all-organic redox-flow battery employing a (2,2,6,6-tetramethylpiperidin-1-yl)oxyl-containing polymer as catholyte and dimethyl viologen dichloride as anolyte". In: Journal of Power Sources 378 (2018), pp. 546-554. DOI: 10.1016/j . j powsour. 2017.09.007.

[45] Shaker Haji. "Analytical modeling of PEM fuel cell i-V curve". In: Renewable Energy 36.2 (2011), pp. 451-458. DOI: 10.1016/j . renene.2010.07.007. 
[46] Carl H. Hamann and Wolf Vielstich. Elektrochemie (German Edition). WileyVCH, 1997. ISBN: 978-3527278947.

[47] Wensheng He and Trung Van Nguyen. "Edge Effects on Reference Electrode Measurements in PEM Fuel Cells". In: Journal of The Electrochemical Society 151.2 (2004), A185. DOI: 10.1149/1.1634272.

[48] Thomas Höfler and Norbert Stroh. Production of tubular fuel cells, fuel cell modules, base elements and ion exchanger membranes. WIPO Patent WO 2000054358 A1. 2000.

[49] Ulrich Felix Hermann Höhberger. Hollow Conductor-fuel cell element having a conductor arrangement, and method for the production thereof. WIPO Patent WO 2003/103079 A3. German pat. 86316 Friedberg, Germany, 2003.

[50] Seyed Schwan Hosseiny. "Vanadium / Air Redox Flow Battery". PhD thesis. University of Twente, July 2011. DOI: 10.3990/1.9789036532259.

[51] S.S. Hosseiny, M. Saakes, and M. Wessling. "A polyelectrolyte membranebased vanadium/air redox flow battery". In: Electrochemistry Communications 13.8 (2011), pp. 751-754. DOI: 10.1016/j . elecom.2010.11.025.

[52] Mianyan Huang et al. "The current and future prospects for vanadium flow batteries in China". In: The International Flow Battery Forum. Swanbarton Limited, June 2017, pp. 36-37.

[53] Nicholas S. Hudak. "Practical thermodynamic quantities for aqueous vanadiumand iron-based flow batteries". In: Journal of Power Sources 269 (2014), pp. 962 974. DOI: $10.1016 / j$. jpowsour. 2013.12.089.

[54] Brian Huskinson et al. "A metal-free organic-inorganic aqueous flow battery". In: Nature 505.7482 (Jan. 2014), pp. 195-198. ISSN: 0028-0836. DOI: 10. $1038 /$ nature12909.

[55] Tobias Janoschka et al. "An aqueous, polymer-based redox-flow battery using non-corrosive, safe, and low-cost materials". In: Nature 527.7576 (Nov. 2015), pp. 78-81. ISSN: 0028-0836. DOI: 10.1038/nature15746.

[56] Ludwig Jörissen. "Bifunctional oxygen/air electrodes". In: Journal of Power Sources 155.1 (2006), pp. 23-32. DOI: 10.1016/j . jpowsour.2005.07.038.

[57] John K. Kaldellis, ed. Stand-Alone and Hybrid Wind Energy Systems: Technology, Energy Storage and Applications (Woodhead Publishing Series in Energy). Woodhead Publishing, 2010. ISBN: 9781845695279.

[58] Hiroko Kaneko, Akira Negishi, and Ken Nozaki. "Redox Battery". U.S. pat. 5318865. June 1994.

[59] W. Kangro and H. Pieper. "Zur Frage der Speicherung von elektrischer Energie in Flüssigkeiten". In: Electrochimica Acta 7.4 (1962), pp. 435-448. DOI: 10.1016/0013-4686(62) 80032-2. 
[60] Walther Kangro. "Verfahren zur Speicherung von elektrischer Energie". German pat. 914264. June 1954.

[61] Xinyou Ke et al. "Flow distribution and maximum current density studies in redox flow batteries with a single passage of the serpentine flow channel". In: Journal of Power Sources 270 (2014), pp. 646-657. DOI: 10. 1016/j . jpowsour . 2014.07 .155$.

[62] Xinyou Ke et al. "Mathematical Modeling of Electrolyte Flow in a Segment of Flow Channel over Porous Electrode Layered System in Vanadium Flow Battery with Flow Field Design". In: Electrochimica Acta 223 (2017), pp. 124134. DOI: $10.1016 / \mathrm{j}$.electacta. 2016.12.017.

[63] Kevin Kendall, Nguyen Q. Minh, and Subhash C. Singhal. "Chapter 8 - Cell and Stack Designs". In: High Temperature and Solid Oxide Fuel Cells. Ed. by Subhash C Singhal and Kevin Kendall. Amsterdam: Elsevier Science, 2003, pp. 197 -228. ISBN: 978-1-85617-387-2. DOI: 10 . 1016 / B978 - 185617387 - 2 / 50025-8.

[64] Junbom Kim. "Modeling of Proton Exchange Membrane Fuel Cell Performance with an Empirical Equation". In: Journal of The Electrochemical Society 142.8 (1995), p. 2670. DOI: 10.1149/1. 2050072.

[65] Soowhan Kim et al. " $1 \mathrm{~kW} / 1 \mathrm{kWh}$ advanced vanadium redox flow battery utilizing mixed acid electrolytes". In: J. Power Sources 237 (2013), pp. 300 -309. ISSN: 0378-7753. DOI: $10.1016 / j$. jpowsour . 2013.02.045.

[66] K. W. Knehr et al. "A Transient Vanadium Flow Battery Model Incorporating Vanadium Crossover and Water Transport through the Membrane". In: Journal of the Electrochemical Society 159.9 (2012), A1446-A1459. DOI: 10.1149/2. 017209jes.

[67] K.W. Knehr and E. C. Kumbur. "Open circuit voltage of vanadium redox flow batteries: Discrepancy between models and experiments". In: Electrochem. Commun. 13 (2011), pp. 342-345. DOI: 10.1016/j .elecom. 2011.01.020.

[68] S. König, M.R. Suriyah, and T. Leibfried. "Model based examination on influence of stack series connection and pipe diameters on efficiency of vanadium redox flow batteries under consideration of shunt currents". In: J. Power Sources 281 (2015), pp. 272 -284. ISSN: 0378-7753. DOI: $10.1016 / \mathrm{j}$. jpowsour . 2015.01 .119$.

[69] Timo Kurz et al. "An impedance-based predictive control strategy for the state-of-health of PEM fuel cell stacks". In: Journal of Power Sources 180.2 (2008), pp. 742-747. DOI: 10.1016/j . jpowsour. 2008.02.062.

[70] Peter Kurzweil. Brennstoffzellentechnik. Vol. 2. Springer Fachmedien Wiesbaden, 2013. ISBN: 978-3-658-00084-4. DOI: 10.1007/978-3-658-00085-1. 
[71] J. Langner et al. "Determination of Overpotentials in All Vanadium Redox Flow Batteries". In: ECS Transactions 58.37 (2014), pp. 1-7. DOI: 10 . 1149 / 05837.0001 ecst.

[72] Joachim Langner. "Koflenstoffbasierte Faser-Elektroden für Vanadium Redoxflow Batterien". PhD thesis. Karlsruher Institut für Technologie (KIT), Oct. 2016.

[73] Armin Laube. "Development of a tubular all vanadium redox flow battery stack concept". MA thesis. Berliner Tor 5, 20099 Hamburg: HAW Hamburg, 2016.

[74] V. Lawlor et al. "Review of the micro-tubular solid oxide fuel cell: Part I. Stack design issues and research activities". In: J. Power Sources 193 (2009), pp. 387 -399. ISSN: 0378-7753. DOI: 10.1016/j . jpowsour . 2009.02.085.

[75] P. Leung et al. "Recent developments in organic redox flow batteries: A critical review". In: Journal of Power Sources 360 (2017), pp. 243-283. DOI: 10 . 1016/ j.jpowsour.2017.05.057.

[76] Liyu Li. "Competitive value propositions of VRFB versus Li-ion batteries". In: The International Flow Battery Forum. Swanbarton Limited, June 2017.

[77] Xiangrong Li et al. "Investigation of the use of electrolyte viscosity for online state-of-charge monitoring design in vanadium redox flow battery". In: Applied Energy 211 (2018), pp. 1050-1059. DOI: 10 .1016/j . apenergy . 2017.12. 009.

[78] Q. H. Liu et al. "High Performance Vanadium Redox Flow Batteries with Optimized Electrode Configuration and Membrane Selection". In: Journal of the Electrochemical Society 159.8 (2012), A1246-A1252. DOI: 10.1149/2.051208 jes.

[79] Xiangkun Ma, Huamin Zhang, and Xianfeng Li. "New Product Development of RongKe Power". In: The International Flow Battery Forum. Swanbarton Limited, June 2017, pp. 50-51.

[80] Xiangkun Ma, Huamin Zhang, and Feng Xing. "A three-dimensional model for negative half cell of the vanadium redox flow battery". In: Electrochimica Acta 58 (2011), pp. 238-246. DOI: 10.1016/j . electacta.2011.09. 042.

[81] Digby D. Macdonald. "Review of mechanistic analysis by electrochemical impedance spectroscopy". In: Electrochimica Acta 35.10 (1990), pp. 1509-1525. DOI: $10.1016 / 0013-4686$ (90) 80005-9.

[82] Klaus-Michael Mangold. "Electrochemical Impedance Spectroscopy Course". In: DECHEMA Forschungsinstitut, 2015. Chap. Introduction to Electrochemical Impedance Spectroscopy, pp. 4-39. 
[83] Klaus-Michael Mangold. “Elektrochemie für Naturwissenschaftler, Ingenieure und Techniker". In: DECHEMA Forschungsinstitut, 2013. Chap. Fundamentals of Electrochemistry, p11-p11.

[84] Scott McGregor. "RedT - Maximise Your Energy". In: The International Flow Battery Forum. Swanbarton Limited, June 2017.

[85] Chris Menictas and Maria Skyllas-Kazacos. "Performance of vanadium-oxygen redox fuel cell". In: Journal of Applied Electrochemistry 41.10 (2011), pp. 12231232. DOI: $10.1007 / \mathrm{s} 10800-011-0342-8$.

[86] Chris Menictas et al. "New flow battery design concepts for increasing power density and market penetration". In: The International Flow Battery Forum. Swanbarton Limited, June 2016, pp. 56-57.

[87] Chris Menictas et al. "Vanadium-oxygen hybrid fuel cell: Design and performance". In: The International Flow Battery Forum. Swanbarton Limited, July 2018.

[88] Jan van der Merwe et al. "Characterisation tools development for PEM electrolysers". In: International Journal of Hydrogen Energy 39.26 (2014), pp. 14212 14221. DOI: $10.1016 / j$. ijhydene.2014.02.096.

[89] Jarrod D. Milshtein et al. "Quantifying Mass Transfer Rates in Redox Flow Batteries". In: Journal of The Electrochemical Society 164.11 (2017), E3265-E3275. DOI: $10.1149 / 2.0201711$ jes.

[90] Lars Mollenhoff. "A partnership of microgrids and Flow Batteries". In: The International Flow Battery Forum. Swanbarton Limited, June 2017.

[91] Haruyuki Nakanishi et al. "Brennstoffzelle". German pat. DE112006000323.2 (Aichi, JP). Aug. 2006.

[92] Haruyuki Nakanishi et al. "Verfahren zur Herstellung einer röhrenförmigen Brennstoffzelle". German pat. DE112006002128.1 (Aichi, JP). Mar. 2007.

[93] National Aeronautics and Space Administration. (NASA-TM-79067) Redox Flow Cell Development and Demonstration Project - Calender Year 1977. Research rep. NASA Lewis Research Center, 1979.

[94] Olga Nibel et al. "Performance of Different Carbon Electrode Materials: Insights into Stability and Degradation under Real Vanadium Redox Flow Battery Operating Conditions". In: Journal of The Electrochemical Society 164.7 (2017), A1608-A1615. DOI: $10.1149 / 2.1081707$ jes.

[95] Jens Noack et al. "Development and characterization of a $280 \mathrm{~cm}^{2}$ vanadium/oxygen fuel cell". In: Journal of Power Sources 253 (2014), pp. 397-403. DOI: 10 . 1016/j . j powsour. 2013.12.070. 
[96] Jens Noack et al. "Luftatmende Brennstoffzelle und Zellstapel für die Oxidation von Ionen mit Sauerstoff". German pat. DE102011107185B3 (80686 München). Aug. 2012.

[97] Jens Noack et al. "Study of the long-term operation of a vanadium/oxygen fuel cell". In: Journal of Power Sources 326 (2016), pp. 137-145. DOI: 10.1016/ j.jpowsour.2016.06.121.

[98] Jens Noack et al. "The Chemistry of Redox-Flow Batteries". In: Angew. Chem. Int. Ed. 54 (2015), pp. 9776-9809. ISSN: 1521-3773. DOI: 10. 1002/anie. 201410823.

[99] Jens Noack et al. "Vanadium proton exchange membrane water electrolyser". In: Journal of Power Sources 349 (2017), pp. 144-151. DOI: 10.1016/j . jpowsour . 2017.03 .039 .

[100] Gaku Oriji, Yasushi Katayama, and Takashi Miura. "Investigation on V(IV)/V(V) species in a vanadium redox flow battery". In: Electrochimica Acta 49.19 (2004), pp. 3091-3095. DOI: 10.1016/j . electacta.2004.02.020.

[101] Aishwarya Parasuraman et al. "Review of material research and development for vanadium redox flow battery applications". In: Electrochim. Acta 101 (2013), pp. 27 -40. ISSN: 0013-4686. DOI: 10.1016/j . electacta.2012.09.067.

[102] Michal Pavelka, Frank Wandschneider, and Petr Mazur. "Thermodynamic derivation of open circuit voltage in vanadium redox flow batteries". In: Journal of Power Sources 293 (Oct. 2015), pp. 400-408. DOI: 10. 1016/j . jpowsour. 2015.05 .049$.

[103] PEM Fuel Cell Durability Handbook, Two-Volume Set: PEM Fuel Cell Diagnostic Tools (Pem Fuel Durability Handbook) (Volume 1). CRC Press, 2011. IsBN: 978-14398-3919-5.

[104] Alan M. Pezeshki et al. "The Cell-in-Series Method: A Technique for Accelerated Electrode Degradation in Redox Flow Batteries". In: Journal of The Electrochemical Society 163.1 (2015), A5202-A5210. DOI: 10.1149/2.0251601jes.

[105] Ai Quoc Pham and On Kok Chang. "Systems and methods for rebalancing redox flow battery electrolytes". U.S. pat. 8980454 B2 (Sunnyvale, CA, US). Mar. 2015.

[106] Faizur Rahman and Maria Skyllas-Kazacos. "Vanadium redox battery: Positive half-cell electrolyte studies". In: Journal of Power Sources 189.2 (2009), pp. 1212-1219. DOI: 10.1016/j . jpowsour . 2008.12.113.

[107] David Reed et al. "Stack Developments in a kW Class All Vanadium Mixed Acid Redox Flow Battery at the Pacific Northwest National Laboratory". In: J. Electrochem. Soc. 163 (2016), A5211-A5219. DOI: 10.1149/2 .0281601jes. 
[108] Klaus Rennebeck and Bernd Hildenbrand. Tubular apparatus for use in energy conversion. WIPO Patent WO 2010121581 A1. Blumenstr. 16, 73240 Wendlingen, Germany, 2010.

[109] Simon Ressel. "Theoretical and Experimental Analysis of Tubular Vanadium Redox Flow Batteries". MA thesis. Berliner Tor 21, 20099 Hamburg, Germany: Hamburg University of Applied Sciences, Mar. 2011.

[110] Simon Ressel et al. "A Tubular Cell Design for Redox Flow Batteries". In: GDCh Scientific Forum Chemistry 2017, Berlin. Sept. 2017.

[111] Simon Ressel et al. "A tubular vanadium/air redox flow cell - Fabrication and first experimental results". In: The International Flow Battery Forum 2016, Karlsruhe, Germany - Conference Poster Papers. IFBF, June 2016, pp. 134-135.

[112] Simon Ressel et al. "Development of Tubular All Vanadium and Vanadium/Air Redox Flow Batteries". In: 10th World Congress of Chemical Engineering. 2017.

[113] Simon Ressel et al. "Influence of electrode configurations of tubular redox flow cells on performance characteristics". In: The International Flow Battery Forum 2017. The International Flow Battery Forum, Manchester, United Kingdom, June 2017, pp. 118-119. ISBN: 978-0-9571055-7-7.

[114] Simon Ressel et al. "Performance of a vanadium redox flow battery with tubular cell design". In: Journal of Power Sources 355 (2017), pp. 199-205. DOI: $10.1016 / j$. jpowsour. 2017.04.066.

[115] Simon Ressel et al. "State of charge monitoring of vanadium redox flow batteries using half cell potentials and electrolyte density". In: Journal of Power Sources 378 (2018), pp. 776-783. DOI: 10.1016/j . j powsour.2018.01.006.

[116] Valentin Roscher et al. "Accurate tuning of ordered nanotubular platinum electrodes by galvanic plating". In: Dalton Trans. 43.11 (2014), pp. 4345-4350. DOI: 10.1039/c3dt52608a.

[117] C. Rozain and P. Millet. "Electrochemical characterization of Polymer Electrolyte Membrane Water Electrolysis Cells". In: Electrochimica Acta 131 (2014), pp. 160-167. DOI: 10.1016/j . electacta.2014.01.099.

[118] Stefanie Schlicht et al. "Highly Reversible Water Oxidation at Ordered Nanoporous Iridium Electrodes Based on an Original Atomic Layer Deposition". In: ChemElectroChem 5.9 (2018), pp. 1259-1264. DOI: 10.1002/celc. 201800152.

[119] Stefanie Schlicht et al. "Minimization of Catalyst Loading on Regenerative Fuel Cell Positive Electrodes Based on Titanium Felts using Atomic Layer Deposition". In: ChemElectroChem (2018). DOI: 10.1002/celc. 201801220.

[120] Volkmar M. Schmidt. Elektrochemische Verfahrenstechnik. Wiley-VCH Verlag GmbH \& Co. KGaA, 2003. DOI: 10.1002/3527602143. 
[121] Ruediger Schweiss, Alexander Pritzl, and Christian Meiser. "Parasitic Hydrogen Evolution at Different Carbon Fiber Electrodes in Vanadium Redox Flow Batteries". In: Journal of The Electrochemical Society 163.9 (2016), A2089-A2094. DOI: $10.1149 / 2.1281609$ jes.

[122] Thorsten Seipp. "Field test experience with $2.5 \mathrm{~kW}$ fully welded stacks". In: The International Flow Battery Forum 2018. The International Flow Battery Forum, Lausanne, Switzerland. July 2018. ISBN: 978-0-9571055-8-4.

[123] Thorsten Seipp et al. "Recent Progress in fully welded stack technology". In: The International Flow Battery Forum 2017. The International Flow Battery Forum, Manchester, United Kingdom, June 2017.

[124] Thorsten Seipp et al. "Zelle und Zellstack einer Redox-Flow-Batterie". German pat. DE102013107516 (A1). Jan. 2015.

[125] SGL Carbon. Datasheet: Sigrafine HLM. SGL Carbon GmbH. May 2015.

[126] SGL Carbon. Technical data sheet SIGRACELL battery felt. SGL Carbon GmbH. May 2017.

[127] A.A. Shah, M.J. Watt-Smith, and F.C. Walsh. "A dynamic performance model for redox-flow batteries involving soluble species". In: Electrochimica Acta 53.27 (2008), pp. 8087-8100. DOI: 10.1016/j. electacta.2008.05.067.

[128] Zhi-Gang Shao et al. "A tubular direct methanol fuel cell with Ti mesh anode". In: J. Power Sources 160 (2006), pp. 1003 -1008. ISSN: 0378-7753. DOI: $10.1016 / j$. jpowsour. 2006.02.047.

[129] Toshikazu Shibata et al. "Demonstration of $60 \mathrm{MW}$ h Vanadium Flow Battery System for Grid Control". In: The International Flow Battery Forum. Limited Swanbarton, June 2017, pp. 68-69.

[130] Ramesh Kumar Singh et al. “Electrochemical Impedance Spectroscopy of Oxygen Reduction Reaction (ORR) in a Rotating Disk Electrode Configuration: Effect of Ionomer Content and Carbon-Support". In: Journal of The Electrochemical Society 162.6 (2015), F489-F498. DOI: 10.1149/2.0141506jes.

[131] Stefania Siracusano et al. "Enhanced performance and durability of low catalyst loading PEM water electrolyser based on a short-side chain perfluorosulfonic ionomer". In: Applied Energy 192 (2017), pp. 477-489. DOI: 10 . 1016/ $j$. apenergy . 2016.09.011.

[132] M. Skyllas-Kazacos and M. Kazacos. "State of charge monitoring methods for vanadium redox flow battery control". In: J. Power Sources 196 (2011), pp. 8822-8827. DOI: 10.1016/j . jpowsour. 2011.06.080.

[133] M. Skyllas-Kazacos et al. "Progress in Flow Battery Research and Development". In: J. Electrochem. Soc. 158 (2011), R55-R79. DOI: 10.1149/1.3599565. 
[134] C. Stolze et al. "Micro-Tubular Flow Cell Design Utilizing Commercial Hollow Fiber Dialysis Membranes for Size-Exclusion Based Flow Batteries". In: Energy Technology 6.11 (2018), pp. 2296-2310. DOI: 10.1002/ente. 201800183.

[135] Christian Stolze et al. "A Tubular Polymer Redox Flow Battery with a Ceramic Membrane". In: Energy Technology 5.2 (2016), pp. 225-227. DOI: 10 . 1002/ente. 201600304.

[136] Thorsten Struckmann et al. "In situ state of charge and crossover estimation of vanadium redox flow batteries from electrolyte potentials and densities". In: The International Flow Battery Forum 2018. The International Flow Battery Forum, Lausanne, Switzerland. July 2018, pp. 118-119. ISBN: 978-0-95710558-4.

[137] Theresa Sukkar and Maria Skyllas-Kazacos. "Water transfer behaviour across cation exchange membranes in the vanadium redox battery". In: Journal of Membrane Science 222.1-2 (2003), pp. 235-247. DOI: 10.1016/s0376-7388 (03) 00309-0.

[138] C.-N. Sun et al. "Probing Electrode Losses in All-Vanadium Redox Flow Batteries with Impedance Spectroscopy". In: ECS Electrochemistry Letters 2.5 (2013), A43-A45. DOI: 10.1149/2.001305eel.

[139] C.-N. Sun et al. "Resolving Losses at the Negative Electrode in All-Vanadium Redox Flow Batteries Using Electrochemical Impedance Spectroscopy". In: Journal of the Electrochemical Society 161.6 (2014), A981-A988. DOI: 10.1149/2. 045406jes.

[140] Ao Tang, Jie Bao, and Maria Skyllas-Kazacos. "Studies on pressure losses and flow rate optimization in vanadium redox flow battery". In: J. Power Sources 248 (2014), pp. 154 -162. ISSN: 0378-7753. DOI: 10 . 1016/j . j powsour. 2013. 09.071.

[141] Ao Tang et al. "Investigation of the effect of shunt current on battery efficiency and stack temperature in vanadium redox flow battery". In: J. Power Sources 242 (2013), pp. 349 -356. ISSN: 0378-7753. DOI: 10 . 1016/j . j powsour. 2013. 05.079 .

[142] Z. Tang et al. "Monitoring the State of Charge of Operating Vanadium Redox Flow Batteries". In: ECS Transactions 41(23) (2012), pp. 1-9. DOI: 10.1149/1. 3697449 .

[143] K. Thanapalan et al. "Advanced EIS Techniques for Performance Evaluation of Li-ion Cells". In: IFAC Proceedings Volumes 47.3 (2014), pp. 8610-8615. DOI: 10.3182/20140824-6-za-1003.02463. 
[144] VDI 2221 Systematic approach to the development and design of technical systems and products. German. Beuth Verlag $\mathrm{GmbH}$, Berlin. Verband Deutscher Ingenieure (VDI), May 1993.

[145] VDI-Wärmeatlas (VDI-Buch) (German Edition). Springer Vieweg, 2013. ISBN: 978-3-642-19980-6.

[146] M. Vijayakumar et al. "Elucidating the higher stability of vanadium(V) cations in mixed acid based redox flow battery electrolytes". In: Journal of Power Sources 241 (2013), pp. 173 -177. ISSN: 0378-7753. DOI: 10 . 1016/j . jpowsour . 2013. 04.072.

[147] Vilayanur Viswanathan et al. "Cost and performance model for redox flow batteries". In: J. Power Sources 247 (2014), pp. 1040 -1051. ISSN: 0378-7753. DOI: $10.1016 / j$. jpowsour. 2012.12.023.

[148] Norbert Wagner. "Einsatz der Impedanzspektroskopie in der Brennstoffzellenforschung". In: tm - Technisches Messen 78.1 (2011). DOI: 10 . 1524/teme. 2011.0073.

[149] Norbert Wagner. "Electrochemical Impedance Spectroscopy Course". In: DECHEMA Forschungsinstitut, 2015. Chap. EIS in Fuel Cell Science, pp. 4-39.

[150] F.T. Wandschneider et al. "A coupled-physics model for the vanadium oxygen fuel cell". In: Journal of Power Sources 259 (2014), pp. 125-137. DOI: 10 . 1016/j . jpowsour. 2014.02.087.

[151] Travis Ward, Xianglin Li, and Amir Faghri. "Performance characteristics of a novel tubular-shaped passive direct methanol fuel cell". In: J. Power Sources 196 (2011), pp. 6264 -6273. ISSN: 0378-7753. DOI: 10.1016/j . j powsour . 2011. 04.012.

[152] Adam Z. Weber et al. "Redox flow batteries: a review". In: J. Appl. Electrochem. 41 (2011), p. 1137. ISSN: 1572-8838. DOI: 10.1007/s10800-011-0348-2.

[153] L. Wei et al. "In-situ investigation of hydrogen evolution behavior in vanadium redox flow batteries". In: Applied Energy 190 (2017), pp. 1112-1118. DOI: $10.1016 / j$. apenergy . 2017.01.039.

[154] Xiaoliang Wei et al. "Materials and Systems for Organic Redox Flow Batteries: Status and Challenges". In: ACS Energy Letters 2.9 (2017), pp. 2187-2204. DOI: 10.1021/acsenergylett.7b00650.

[155] Zhongbao Wei et al. "Dynamic thermal-hydraulic modeling and stack flow pattern analysis for all-vanadium redox flow battery". In: Journal of Power Sources 260 (2014), pp. 89-99. DOI: 10.1016/j . jpowsour. 2014.02.108.

[156] Claudia Weidlich et al. "tubulair \pm - Tubular Redox Flow Battery". In: The International Flow Battery Forum 2014. The International Flow Battery Forum, Hamburg. July 2014. 
[157] Jan Winsberg et al. "Redox-Flow-Batterien: von metallbasierten zu organischen Aktivmaterialien". In: Angewandte Chemie 129.3 (2016), pp. 702-729. DOI: 10.1002/ange. 201604925.

[158] Rick Winter. "Flow Batteries for duck curves". In: The International Flow Battery Forum. July 2014, pp. 56-58.

[159] Shuibo Xiao et al. "Broad temperature adaptability of vanadium redox flow battery-Part 1: Electrolyte research". In: Electrochimica Acta 187 (2016), pp. 525534. DOI: 10.1016/j. electacta. 2015.11.062.

[160] Bo Yang et al. "An Inexpensive Aqueous Flow Battery for Large-Scale Electrical Energy Storage Based on Water-Soluble Organic Redox Couples". In: Journal of The Electrochemical Society 161.9 (2014), A1371-A1380. DOI: 10.1149/2 . 1001409 jes.

[161] Zhenguo Yang et al. "Electrochemical Energy Storage for Green Grid". In: Chem. Rev. 111 (2011), pp. 3577-3613. DOI: 10.1021/cr100290v.

[162] M.S. Yazici. "Passive air management for cylindrical cartridge fuel cells". In: J. Power Sources 166 (2007), pp. 137 -142. ISSN: 0378-7753. DOI: 10 .1016/ j . jpowsour.2006.12.085.

[163] Sung-Dae Yim et al. "Optimization of bifunctional electrocatalyst for PEM unitized regenerative fuel cell". In: Electrochimica Acta 50.2-3 (2004), pp. 713 718. DOI: 10.1016/j.electacta.2004.02.068.

[164] N. Yousfi-Steiner et al. "A review on polymer electrolyte membrane fuel cell catalyst degradation and starvation issues: Causes, consequences and diagnostic for mitigation". In: Journal of Power Sources 194.1 (2009), pp. 130-145. DOI: $10.1016 / j$. jpowsour. 2009.03.060.

[165] X YUAN et al. "AC impedance technique in PEM fuel cell diagnosis-A review". In: International Journal of Hydrogen Energy 32.17 (2007), pp. 4365-4380. DOI: $10.1016 / j$.ijhydene.2007.05.036.

[166] Xiao-Zi Yuan et al. Electrochemical Impedance Spectroscopy in PEM Fuel Cells. Springer London, 2010. DOI: 10.1007/978-1-84882-846-9.

[167] Jianlu Zhang et al. "PEM fuel cell open circuit voltage (OCV) in the temperature range of $23^{\circ} \mathrm{C}$ to $120^{\circ} \mathrm{C}$ ". In: Journal of Power Sources 163.1 (2006), pp. 532 537. DOI: $10.1016 / j$.jpowsour.2006.09.026.

[168] Wenhong Zhang, Le Liu, and Lin Liu. "An on-line spectroscopic monitoring system for the electrolytes in vanadium redox flow batteries". In: RSC Adv. 5.121 (2015), pp. 100235-100243. DOI: 10.1039/c5ra21844f.

[169] Shihuang Zhong et al. "Flexible, conducting plastic electrode and process for its preperation". U.S. pat. 5665212 (Kensington, Australia). Sept. 1997. 
[170] X.L. Zhou et al. "A high-performance dual-scale porous electrode for vanadium redox flow batteries". In: Journal of Power Sources 325 (2016), pp. 329 336. ISSN: 0378-7753. DOI: $10.1016 / j$. jpowsour. 2016.06.048.

[171] X.L. Zhou et al. "A highly permeable and enhanced surface area carbon-cloth electrode for vanadium redox flow batteries". In: Journal of Power Sources 329 (2016), pp. 247 -254. ISSN: 0378-7753. DOI: 10 . 1016/ j . jpowsour . 2016 . 08. 085.

[172] X.L. Zhou et al. "Critical transport issues for improving the performance of aqueous redox flow batteries". In: Journal of Power Sources 339 (2017), pp. 1 -12. ISSN: 0378-7753. DOI: 10.1016/j . jpowsour. 2016.11.040. 



\section{List of Figures}

1.1 Net power demand and power generation (by source) in Germany over the course of one week in October 2018 [8]. . . . . . . . . . . 2

1.2 Illustration of a Redox Flow Battery. . . . . . . . . . . . . . . . . . 3

1.3 Schematic illustration of an All Vanadium Redox Flow Battery. . . . . . . 7

1.4 Schematic of a Vanadium/Air Redox Flow Battery. . . . . . . . . . . . . 10

1.5 Planar Redox Flow Cell setup. . . . . . . . . . . . . . . . . . . . . . . . 14

1.6 Electrode configurations; left: flow-by, right: flow-through. . . . . . . . 15

1.7 Tubular cell setup with sealings. . . . . . . . . . . . . . . 17

2.1 Schematic of electrochemical cell with connected $d c$ power source (E) and ampere meter $(\mathrm{A}) . \ldots \ldots \ldots \ldots . \ldots 24$

2.2 Schematic of porous electrode and SEM images of fibrous electrode material. . . . . . . . . . . . . . . . . . . 27

2.3 List of selected standard electrode potentials vs. the standard hydrogen electrode $S H E . \ldots \ldots \ldots \ldots$. . . . . . . . . . . 28

2.4 Estimated (equation 2.18) open-circuit voltage (OCV) of a VRFB cell with a total vanadium concentration of $c_{V}=1.6 \mathrm{moll}^{-1}$ and electrolyte composition as used in this work. . . . . . . . . . . . . 30

2.5 Plot of transfer-current-potential relationship $j\left(\eta_{a c t}\right)$ (equation 2.36 with $\alpha=0.55)$ and reduction and oxidation current densities $\left(j_{\text {red }}\right.$ and $\left.j_{o x}\right) . \quad .33$

2.6 Potential drop and current perturbation signal of a current interrupt measurement. . . . . . . . . . . . . . . . 4 42

2.7 Polarization curve with the three characteristic sections: activation polarization, ohmic (operating range) and mass transfer controlled. . . . 43

2.8 Left: Schematic of half cell potential measurement setup. Right corner: Picture of potential flow armature. . . . . . . . . . . . . . 48

2.9 Polarization curves of planar VRFB cell at a flow rate of $12.8 \mathrm{ml} \mathrm{min}^{-1}$ with measured $\eta_{\text {pos }}, \eta_{\text {neg }}, \eta_{\text {ohm }}, \mathrm{OCV}$ and constructed cell potential (dot-

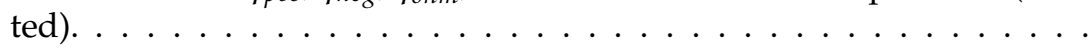


2.10 Potential mismatch $\left(\Delta \eta_{i}\right)$ of the constructed and measured cell potential (dashed) and potential mismatch $\left(\Delta \eta_{i}\right)$ of the verification potential with subtracted $O C V$ and $\eta_{o h m}$ portions $\left(\Delta \eta_{i}=E_{v f y}-O C V-\eta_{o h m}\right) . \quad . \quad 50$

2.11 Schematic of EIS measurement setup and method. . . . . . . . . . . . . 51

2.12 A: Simplified Randles equivalent circuit B: Randles equivalent circuit with diffusive mass transfer C: simplified full cell equivalent circuit. . 53

2.13 Left: Nyquist plot of simplified Randles circuit (A in fig 2.12). Right: Bode Plots of simplified Randles circuit. . . . . . . . . . . . . . . . . 54

2.14 Nyquist plot of Randles circuit (B in fig 2.12) with infinite Warburg element (left) and finite Warburg element (right) . . . . . . . . . . . . . 55

2.15 Illustration of membrane electrode assembly. Detail right: 3-phaselayer with charge and mass transfer. . . . . . . . . . . . . . .

2.16 Left: Compression ratio dependent specific contact resistance of GFA EA electrode; right: specific resistivity of GFA EA electrode. . . . . . . . 63

2.17 Illustration of tubular flow-through half cells with graphite current collectors. . . . . . . . . . . . . . . . . . . . 64

2.18 Estimated ASR of flow-through half cells with graphite current collector. Left: inner half cell, right: outer half cell. . . . . . . . . . . . . . 65

2.19 Illustration of tubular flow-through half cells with composite current collectors. . . . . . . . . . . . . . . . . 66

2.20 Estimated ASR of flow-through half cells with composite current collector (CCC). Left: inner half cell, right: outer half cell. . . . . . . . . . . 67

2.21 Estimated share of required pumping power $\left(P_{\text {pump }} / P_{\text {cell }}\right)$ for tubular VRFB cell with flow-by electrodes. . . . . . . . . . . . . . . . . . 70

2.22 Tubular VARFB cell concepts. . . . . . . . . . . . . . . . 72

3.1 A: Cross-sectional view of permeability test cell for inner electrode samples. B: Top view of permeability test cell for outer electrode samples (not true to scale). . . . . . . . . . . . . . . . . . . . . . . . . . . 76

3.2 Outer flow-by permeability cell. . . . . . . . . . . . . . . . . 77

3.3 Exploded view of the planar VRFB reference cell (Micro Flow Cell of ElectroCell, Denmark). . . . . . . . . . . . . . . . . . . . 78

3.4 A: Picture of tubular VRFB test cell with flow-through electrode configuration (FT-VRFB); B: Schematic of cell cross section; 1 outer composite current collector; 2 outer electrode; 3 membrane; 4 inner electrode; 5 inner composite current collector. . . . . . . . . . . . . . . .

3.5 A: Picture of tubular VRFB test cell with flow-by electrode configuration (FB-VRFB); B: Schematic of cell cross section; 1 outer composite current collector; 2 outer electrode; 3 membrane; 4 inner electrode; 5 inner composite current collector. . . . . . . . . . . . . . 
3.6 Test cell housing (B) with assembled VRFB cell (C) and electrode terminals $(\mathrm{A}, \mathrm{D}) . \ldots \ldots \ldots$. . . . . . . . . . . . . . 81

3.7 Left: frozen graphite sheet material. Middle: developed drilling tool with cylindrical electrode in the center. Right: cylindrical graphite felt electrode after fabrication. . . . . . . . . . . . . . . . . 83

3.8 A: Welding tool B: Welding setup C: Welded fumapem ${ }^{\circledR}$ F950 membrane. 85

3.9 Picture of extruded VM-fumasep ${ }^{\circledR}$ FFT membranes. . . . . . . . . . . . 86

3.10 Schematic of VRFB test rig. . . . . . . . . . . . . . . . . 87

3.11 Picture of VRFB test rig with integrated VRFB cell. . . . . . . . . . . . 88

3.12 Polarization curve measurement sequence with a stepwise potential scan (left) and linear potential scan (right). . . . . . . . . . . . . . . . . 91

3.13 Measured pressure drop along flow-through electrodes with different lengths and a compression ratio of $25 \%$ (fluid: $\mathrm{H}_{2} \mathrm{O}$ ). Calculated pressure drops $\Delta p_{K C}$ with determined $c_{K C}$ constants. . . . . . . . . . . . 95

3.14 Pressure drop across inner and outer flow-by electrode with $\mathrm{H}_{2} \mathrm{O}$ and $V^{3.5+}$ Vanadium electrolyte. . . . . . . . . . . . . . . 96

3.15 Pressure drop across positive and negative half cell of $F T-25-V R F B$ cell at different flow rates and $\mathrm{SoC} \approx 50 \%$. . . . . . . . . . . . . . 98

3.16 Pressure drop across positive and negative half cell of $F B-25 / 45-V R F B$ cells at different flow rates and $S o C \approx 50 \%$. . . . . . . . . . . . . . . 99

3.17 Polarization curves of planar $V R F B$ cell at a $S o C \approx 50 \%$ and flow rates of $6.4 \mathrm{ml} \mathrm{min}^{-1}, 9.6 \mathrm{ml} \mathrm{min}^{-1}$ and $12.8 \mathrm{ml} \mathrm{min}^{-1}$. . . . . . . . . . . 100

3.18 Negative and positive half cell overpotentials $\left(\eta_{n e g}\right.$ and $\left.\eta_{p o s}\right)$ of planar VRFB cell at a flow rate of $12.8 \mathrm{ml} \mathrm{min}^{-1}$. . . . . . . . . . . . . . 103

3.19 Polarization curves of tubular FT-25-VRFB Cell with flow-through electrode configuration and extruded membrane at a $S o C \approx 60 \%$ for flow rates of $3.2 \mathrm{ml} \mathrm{min}^{-1}$ and $6.4 \mathrm{ml} \mathrm{min}^{-1} \ldots \ldots$. . . . . . . . . . 105

3.20 Polarization curves of tubular $F B-25-V R F B$ cell at a $S o C \approx 60 \%$ and flow rates from $1.6 \mathrm{ml} \mathrm{min}^{-1}$ to $6.4 \mathrm{ml} \mathrm{min}^{-1}$. . . . . . . . . . . . . 107

3.21 Polarization curves of tubular $F B-45-V R F B$ cell at a $S o C \approx 60 \%$ for flow rates from $3.2 \mathrm{ml} \mathrm{min}^{-1}$ to $9.6 \mathrm{ml} \mathrm{min}^{-1}$. . . . . . . . . . . . . . . 109

3.22 Volumetric power densities of $F B-45-V R F B$ cell. . . . . . . . . . . . . . 110

3.23 Left: measured polarization curve of $F B-45-V R F B$ cell at $\dot{Q}=9.6 \mathrm{ml} \mathrm{min}^{-1}$

(Exp.) and fitted model (Fit). Right: Residuals $\left(\Delta E=E_{c e l l, E x p}-E_{c e l l, F i t}\right) .112$

3.24 Measured impedance and fitted model of the $F B-45-V R F B$ cell at $O C V$. Top: Nyquist plot; Middle: Bode plot of phase shift $\phi$; Bottom: Bode plot of absolute impedance $|Z|$. . . . . . . . . . . . . . . . . . . . 113

3.25 Top: Nyquist plot of measured impedance of the $F B-45-V R F B$ cell at different $E_{\text {cell }}(A, B, C, D)$. Bottom: Applied potentials during EIS measurement. . . . . . . . . . . . . . . . . . 114

3.26 Equivalent circuit model of a full $F B-V R F B$ cell. . . . . . . . . . . . . . 115 
3.27 Residual overpotentials $\eta_{\text {res }}$ of tubular and planar VRFB cells at a flow rate of $6.4 \mathrm{ml} \mathrm{min}^{-1} \ldots \ldots \ldots$. . . . . . . . . . . . . . . 118

3.28 Residual overpotentials $\eta_{\text {res }}$ over the geometric electrode surface area related current density $j$ of tubular and planar VRFB cells at a flow rate of $6.4 \mathrm{ml} \mathrm{min}^{-1}$

3.29 Positive and negative overpotentials of FB-45-VRFB, FT-25-VRFB and planar cell. . . . . . . . . . . . . . . . . . . . 120

3.30 Positive and negative residual overpotentials $\left(\eta_{\text {pos }} \eta_{n e g}\right)$ of tubular FB$45-V R F B$ cell with changed half cell configuration at a flow rate of $9.6 \mathrm{ml} \mathrm{min}^{-1}$

3.31 Cell potential, current density, electrolyte densities, state of charge and pressure drops during charge/discharge cycling of tubular FB-25-VRFB cell at a flow rate of $6.4 \mathrm{ml} \mathrm{min}^{-1}$.

3.32 Cell potential, current density, Nernst potentials, state of charge and residual overpotentials during charge/discharge cycling of tubular $F B-45-V R F B$ cell at a flow rate of $6.4 \mathrm{ml} \mathrm{min}^{-1}$.

3.33 System energy efficiencies and Sankey diagrams of $F B-V R F B$ cells. . . . 128

3.34 Left: positive (red) and negative (blue) residual overpotentials during charge cycles \#2...7. Right: positive (red) and negative (blue) residual overpotentials during discharge cycles \#1...6.

3.35 Residual overpotentials before and after cycling of tubular $F B-45-V R F B$ cell at a flow rate of $6.4 \mathrm{ml} \mathrm{min}^{-1}$.

3.36 Positive and negative residual overpotentials before and after cycling of tubular FB-45-VRFB cell.

3.37 Mean values of positive and negative residual overpotentials during Ch cycles of tubular FB-45-VRFB cell. . . . . . . . . . . . . . . . . . . . . 134

4.1 Pictures of tubular VARFB cells. . . . . . . . . . . . . . . . . . . . . . . . 144

4.2 Left: Picture of tubular Ti current collector with quadruple helix flow field (1). Right: picture of tubular GDE (2) with threaded current collector (1). . . . . . . . . . . . . . . . . . . . 145

4.3 Picture of tubular GDE with membrane and electrical contact pin. . . . 146

4.4 Picture of tubular VARFB cell components. A:Titanium current collector with quadruple helix flow field; B: gas diffusion electrode (GDE); C: tubular membrane; D: graphite felt electrode; E: outer composite current collector. . . . . . . . . . . . . . . . . . . . . . . . . . . . . . . 147

4.5 Right: Tubular membrane electrode assembly $(M E A)$. Left: SEM picture of the $M E A$ cross-section. . . . . . . . . . . . . . . . . . . . . . . . . 149

4.6 Heat bonded tubular MEAs with partially bonded GDE $(A)$ and fully bonded GDE $(B)$. 1: detached membrane section. 2: bonded section. . 150

4.7 Schematic of VARFB test rig. . . . . . . . . . . . . . . . 151 
4.8 Polarization curve measurement sequence with a linear potential scan. 155

4.9 Polarization curve of tubular VARFB FB cell at $S o C \approx 30 \%\left(E_{\text {neg }}^{0}=-0.268 \mathrm{~V}\right)$.

$\mathrm{O}_{2}$ flow rate: $80 \mathrm{Nml} / \mathrm{min}, \mathrm{RH}=100 \%$; electrolyte flow rate: $6.4 \mathrm{ml} \mathrm{min}^{-1} .158$

4.10 Polarization curves of tubular VARFB PB for different gas compositions.164

4.11 Polarization curves of tubular VARFB PB cell at $S o C \approx 70 \%$. E $E_{\text {cell }} \mathrm{O}_{2}$ is measured at a $\mathrm{O}_{2}$ flow rate: $80 \mathrm{Nml} / \mathrm{min}, \mathrm{RH}=100 \% ; E_{\text {cell }}$ flooded is recorded with a $2 \mathrm{MH}_{2} \mathrm{SO}_{4}$-flooded $\mathrm{GDE}$ during ch and $\mathrm{O}_{2}$ during discharging. . . . . . . . . . . . . . . . 165

4.12 Measured impedance and fitted model of the tubular VARFB PB cell after $G D E$ flooding at $O C V\left(\dot{Q}_{G D E}=80 \mathrm{Nml} / \mathrm{min} \mathrm{O}_{2}\right)$. Top: Nyquist plot; Middle: Bode plot of phase shift $\phi$; Bottom: Bode plot of absolute impedance $|Z| . \ldots \ldots \ldots$. . . . . . . . . . . . . . . 168

4.13 Polarization curves of tubular $V A R F B$ cell with partially bonded GDE and nano-structured GDE. Left: Charge sequence at $\mathrm{SoC}<0 \%\left(c_{V 4+}>>\right.$ $\left.c_{V 3+}\right)$. Right: Discharge sequence at $S o C \approx 20 \%$. $\mathrm{O}_{2}$ flow rate: $80 \mathrm{Nml} / \mathrm{min}$, RH $=100 \%$. . . . . . . . . . . . . . . . . . 171

$4.14 \mathrm{OCV}\left(E_{\text {cell }}^{0}\right), E_{\text {neg }}^{0}$ and $E_{\text {cell }}^{0}$ during long term $O C V$ measurement of tubular VARFB FB. . . . . . . . . . . . . . . . . . . . . . . . . 173

4.15 Schematic of redox reactions and cross-over in tubular VARFB cell. . . . 175

4.16 Left: Current over cell potential of doted polarization curve section (fig. 4.9). Right: Current over Air electrode potential. . . . . . . . . . 176

4.17 Negative (blue) and positive (red) electrode overpotentials of tubular VARFB with a fully bonded GDE (dashed) and a partially bonded GDE (line). Gas supply GDE: $80 \mathrm{Nml} / \mathrm{min} \mathrm{O}_{2}, \mathrm{RH}=100 \%$. VARFB with partially bonded GDE flooded with $2 \mathrm{MH}_{2} \mathrm{SO}_{4}$ during OER. . . . 179

4.18 Voltage losses of the tub. VARFB with a fully bonded GDE at $20 \mathrm{~mA} \mathrm{~cm}^{-2} 185$

5.1 Picture of tubular flow-through $(A)$ and flow-by $(B)$ VRFB test cell. . . 189

5.2 System energy efficiencies and Sankey diagrams of $F B-V R F B$ cells. . . . 192

5.3 Picture of tubular VARFB cell $(A)$ and image of tubular $M E A(B)$. . . . 193

5.4 Voltage losses of the tub. VARFB at $20 \mathrm{~mA} \mathrm{~cm}^{-2} \ldots \ldots$. . . . . . 195 



\section{List of Tables}

2.1 Specific electric restivities of potential electrode and current collector materials. . . . . . . . . . . . . . . . . . . . . 64

3.1 Liquid permeability measurement samples (flow-through (FT): Sigracell GFA6 EA, flow-by (FB): GDL \#2614 Pyron of SGL Carbon, Germany) with properties and settings. . . . . . . . . . . . . . 77

3.2 Overview of cell components and fabrication techniques of tubular $F B$-VRFB and FT-VRFB test cells. . . . . . . . . . . . . . . 82

3.3 Specification of used Sigracell graphite felt materials (SGL Carbon) [126]. ${ }^{1 \text { ) }}$ $B E T$ surface area before heat treatment. ${ }^{2)}$ determined by scanning electron microscopy (SEM). ${ }^{3)}$ calculated with equation $2.11 .{ }^{4)}$ calculated with equation $2.10 \ldots \ldots \ldots$. . . . . . . . . . 83

3.4 List of tubular VRFB cells with membrane properties. . . . . . . . . . . 86

3.5 Kozeny-Carman constants $c_{K C}$ for porous flow-through graphite felt electrodes. . . . . . . . . . . . . . . . . . 96

3.6 Comparison of maximum power and current densities of planar VRFB and published results. ${ }^{1)}$ at $S o C=60 \% . \ldots \ldots \ldots \ldots 1$

3.7 Comparison of overpotentials of planar VRFB cell and published results.102

3.8 Comparison of negative and positive overpotentials with work of J. Langner [72]. The last column displays the contribution of $\eta_{n e g}$ to the residual overpotential $\eta_{\text {res }}=\eta_{\text {pos }}-\eta_{\text {neg }} .{ }^{1)}$ data include ohmic correction with $R_{\text {corr }}=12 \mathrm{~m} \Omega \pm 0.5[72] \ldots \ldots \ldots$. . . . . . . . . . 103

3.9 Maximum power and current densities of $F T-25-V R F B$ and planar reference cell. . . . . . . . . . . . . . . . . . . . . 106

3.10 Comparison of overpotentials of FT-25-VRFB cell with reference cell and published results. . . . . . . . . . . . . . . . 106

3.11 Maximum power and current densities of $F B-25-V R F B$ and planar reference cell. . . . . . . . . . . . . . . . . . . . . . . . . . 108

3.12 Comparison of overpotentials of $F B-25-V R F B$ cell with reference cell and published results. 
3.13 Maximum power and current densities of $F B-45-V R F B$ and planar reference cell. . . . . . . . . . . . . . . . . . . . . . 110

3.14 Comparison of overpotentials of $F B-45-V R F B$ cell with reference cell and published results.

3.15 Comparison of fitting parameters with reference data $\left({ }^{*}\right.$ measured or literature values). . . . . . . . . . . . . . . . . . . 111

3.16 Fitting parameters of equivalent circuit model. . . . . . . . . . . . . . . 115

3.17 Area specific cell resistances $A S R$ (in $\Omega \mathrm{cm}^{2}$ ) of tubular VRFB cells determined by different methods (CI,HFR, EIS with fit and $E / i$-fit). . 116

3.18 Comparison of overpotentials of tubular VRFB cells with reference cell. 118

3.19 Results of galvanostatic charge (Ch) and discharge (Dch) cycling of $F B-25-V R F B$ cell at $|i|=35 \mathrm{~mA} \mathrm{~cm}^{-2}$. Data is listed in the following units: $|\Delta Q|$ in $\mathrm{mAh},\left|\Delta E_{e l}\right|$ in $\mathrm{Wh},\left|\Delta E_{\text {pump }}\right|$ in $\mathrm{mWh}$. . . . . . . . . 125

3.20 Results of galvanostatic charge (Ch) and discharge (Dch) cycling of $F B-45-V R F B$ cell at $|i|=20 \mathrm{~mA} \mathrm{~cm}^{-2}$. Data is listed in the following units: $|\Delta Q|$ in $\mathrm{mAh},\left|\Delta E_{e l}\right|$ in $\mathrm{Wh},\left|\Delta E_{\text {pump }}\right|$ in $\mathrm{mWh}$. . . . . . . . . 125

3.21 Maximum power and current densities of FT-25-VRFB and planar flowthrough cells. . . . . . . . . . . . . . . . . . . 137

3.22 Comparison of maximum power and current densities of $F B$-VRFB cells and published results. ${ }^{1)}$ at $S o C=60 \%$. . . . . . . . . . . . . . 138

3.23 Comparison of overpotentials of tubular FB-VRFB cells with planar VRFB cells. . . . . . . . . . . . . . . . . . . . . . . . . . 139

3.24 Kozeny-Carman constants $c_{K C}$ for porous flow-through graphite felt electrodes. . . . . . . . . . . . . . . . . 141

4.1 Overview of tubular VARFB cell setups. . . . . . . . . . . . . . . . . 150

4.2 Comparison of $i_{c h, \text { max }}$ of tubular VARFB cell with results of planar VARFBs $[16,51]$ and Vanadium-PEM Water Electolysis (V-PEMWE) cell [99]. 1) Data from charge cycle. . . . . . . . . . . . . . . . . . . . . . . 159

4.3 Comparison of $i_{d c h, \max }$ and $p_{A, \max }$ of tubular VARFB cell with results of planar VARFBs $[16,51]$ and Vanadium-Oxygen Fuel Cells (VOFC) [85, 95]. ${ }^{1)}$ Data from discharge cycle. ${ }^{2)}$ average power density of $d c h$-cycle. 160

4.4 Comparison of overpotentials of tubular VARFB cell with fully bonded GDE with published results. ${ }^{1}$ )ELAT GDL with Nafion N112 membrane and $0.4 \mathrm{mg} \mathrm{cm}^{-2}$ Pt loading. $\left.{ }^{2}\right)$ ELAT GDL with Nafion N117 membrane and $1.0 \mathrm{mg} \mathrm{cm}^{-2} \mathrm{Pt}$ loading. . . . . . . . . . . . . . . . . 162

4.5 Comparison of $i_{d c h, \max }$ and $p_{A, \max }$ of tubular VARFB cell with results of planar VARFBs [16, 51] and Vanadium-Oxygen Fuel Cells (VOFC) [85, 95]. ${ }^{1)}$ Data from discharge cycle. ${ }^{2)}$ average power density of $d c h$-cycle.166 
4.6 Comparison of overpotentials of tubular VARFB PB with published results. ${ }^{1}$ )ELAT GDL with Nafion $N 112$ membrane and $0.4 \mathrm{mg} \mathrm{cm}^{-2} \mathrm{Pt}$ loading. ${ }^{2}$ )ELAT GDL with Nafion N117 membrane and $1.0 \mathrm{mg} \mathrm{cm}^{-2}$ Pt loading. . . . . . . . . . . . . . . . . 167

4.7 Comparison of tubular VAFRB fitting parameters with fitting parameters of planar VOFC $\left(280 \mathrm{~cm}^{2}\right)$ of Noack et al. [95]. . . . . . . . . . . . 170

4.8 Comparison of $i_{d c h, \text { max }}$ and $p_{A, \text { max }}$ of tubular VARFB cell with nanostructured GDE surface with results of planar VARFBs [16, 51] and Vanadium-Oxygen Fuel Cells (VOFC) [95]. 1) Data from discharge cycle.

2) average power density of $d c h$-cycle. . . . . . . . . . . . . . 172

$4.9 i_{d c h, \text { max }}$ and $p_{A, \max }$ of tubular VARFB cells with partially bonded $P B$ and fully bonded $F B$ GDEs, as well as nano-structured GDE surface (nano). Reference data of planar VARFBs $[16,51]$ and Vanadium-Oxygen Fuel Cells (VOFC) [95]. 1) Data from discharge cycle. ${ }^{2)}$ average power density of $d c h$-cycle. . . . . . . . . . . . . . . . . . . . . . . 181

4.10 Comparison of $i_{c h \text {,max }}$ of tubular VARFB cells with results of planar VARFBs $[16,51]$ and Vanadium-PEM Water Electolysis (V-PEMWE) cell [99]. 1) Data from charge cycle. . . . . . . . . . . . . . . . . . . 182

4.11 Comparison of overpotentials of tubular VARFB cells published results. ${ }^{1}$ )ELAT GDL with Nafion N112 membrane and $0.4 \mathrm{mg} \mathrm{cm}^{-2} \mathrm{Pt}$ loading. ${ }^{2}$ )ELAT GDL with Nafion $N 117$ membrane and $1.0 \mathrm{mg} \mathrm{cm}^{-2}$ Pt loading. . . . . . . . . . . . . . . 183 